\title{
PG\&E WaveConnect Program finalReport
}

Pacific Gas and Electric Company

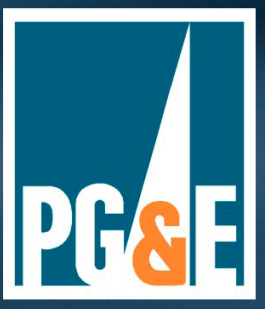

Submitted to the United States Department of Energy Report DOE/GO/18170-1

December 2011 



\title{
PG\&E WaveConnect Program
}

Final Report

Submitted to

\section{United States Department of Energy}

Report DOE/GO/18170-1

Submitted by

\section{Pacific Gas and Electric Company}

\begin{abstract}
Authors
Brendan P. Dooher, Edward Cheslak, Robert Booth, Doug Davy, Annette Faraglia, Ian Caliendo, Gina Morimoto, Douglas Herman
\end{abstract}




\section{Principal Investigators}

Brendan P. Dooher, Ph.D.

Senior Engineer

PG\&E

bxd6 at pge dot com
Edward Cheslak, Ph.D.

Senior Consulting Scientist

PG\&E

efc 3 at pge dot com

\section{Acknowledgements}

We would like to acknowledge the many organizations and individual who contributed their time and unique expertise to the overall WaveConnect effort and in creating the basis for this final report. These included PG\&E contractors CH2M Hill, Kearns and West, Science Applications International Corp. (SAIC), and Humboldt State University (HSU), as well as the members of the Humboldt Working Group and public agencies that contributed greatly to the project as it developed. Reviewing and editing by Brian Fies of BBF Consult are also gratefully acknowledged.

\section{Citation}

Dooher, B.P., Cheslak, E, Booth, R., Davy, D., Faraglia, A., Caliendo, I. Morimoto, G. and Herman, D. 2011. PG\&E WaveConnect Program Final Report. DOE/GO/18170-1. Pacific Gas and Electric Company, San Francisco, CA, December 2011. 265 pp.

\section{Legal Notice}

This report was prepared by Pacific Gas and Electric Company. Neither Pacific Gas and Electric Company nor any of its employees and agents:

1. makes any written or oral warranty, expressed or implied, including, but not limited to those concerning merchantability or fitness for a particular purpose;

2. assumes any legal liability or responsibility for the accuracy, completeness, or usefulness of any information, apparatus process, method, or policy contained herein; or

3. represents that its use would not infringe any privately owned rights, including, but not limited to, patents, trademarks, or copyrights. 


\section{Abstract}

The PG\&E WaveConnect project was intended to demonstrate the technical and economic viability of wave power in the open ocean adjacent to PG\&E's service territory. WaveConnect was conceived as a multi-stage development process leading to long-term megawatt-scale wave power production. The first-stage tasks consisted of site selection, permitting, pilot plant design, and assessment of technology and commercial readiness. The second stage would have included development of infrastructure, undersea cabling, and deployment of wave energy conversion devices (WECs). In the third stage, the most promising WEC devices would have been deployed in larger quantities and connected to the grid. The program was halted near the end of the first stage for reasons described below. This report documents the findings of Stage One, which was funded by the California Public Utilities Commission (CPUC) for $\$ 4.8$ million and by the U.S. Department of Energy (DOE) for $\$ 1.2$ million, for a total of $\$ 6$ million.

\section{Site Selection}

After studying the wave energy potential, grid interconnection and other project infrastructure along the California coast, PG\&E selected two sites: one near Eureka, called the Humboldt WaveConnect (HWC) project, and another near Vandenberg Air Force Base, called the Central Coast WaveConnect (CCWC) project.

\section{Permitting}

FERC issued PG\&E preliminary permits for HWC in 2008 and for CCWC in 2010. PG\&E chose to use FERC's recently promulgated Pilot Project Licensing Process (PPLP), which was intended to streamline licensing to allow relatively quick and easy installation, operation, and environmental testing for pilot projects. Permitting, however, proved to be complicated, timeconsuming and expensive, mainly because of the uncertain impacts of WEC devices. As WaveConnect efforts proceeded, PG\&E learned that even under the PPLP the project would still require a full analysis under the California Environmental Quality Act (CEQA), including an Environmental Impact Report, as well as Monitoring and Adaptive Management Plans (MAMPs) and other requirements that had significant cost and scheduling implications. A majority of Stage One efforts were expended on permitting activities.

\section{Pilot Plant Design}

PG\&E prepared a conceptual design for a 5-MW pilot test facility at the Humboldt site, which consisted of an off-shore deployment area where WECs of different designs and from different device manufacturers could be tested. PG\&E was to provide permitting, subsea cables, and onshore facilities necessary to connect WaveConnect to an existing PG\&E substation, while the WEC manufacturers would provide, operate and maintain their devices during the test period.

\section{Technology and Commercial Readiness}

PG\&E issued a Request for Information to the wave power industry to assess the technical and commercial capabilities of WEC manufacturers. Sixteen manufacturers responded, representing the four best-known and most mature WEC designs: the attenuator, point absorber, floating oscillating water column (OWC), and oscillating wave surge converter (OWSC). PG\&E found that WECs are early-stage devices with evolving designs and little real-world operating experience. These characteristics made environmental impacts difficult to assess, which complicated permitting efforts. It also made a megawatt-scale demonstration project difficult to 
support because early stage WECs are costly and have limited track records for performance and reliability.

\section{Results}

PG\&E withdrew its Draft Pilot License Application (DPLA) for HWC in November 2010 and surrendered its preliminary permit for CCWC in May 2011, effectively discontinuing the WaveConnect project for the following combination of reasons:

- Permitting issues were much more challenging than originally anticipated. Stage One project funding of \$6 million proved insufficient to complete the necessary development and permitting work. During Stage One development, PG\&E determined that permitting costs would be $\$ 2$ million to $\$ 5$ million greater than originally budgeted.

- The cost of developing a five-year, 5-MW WaveConnect pilot project at Humboldt Bay is much greater than the $\$ 15$ million to $\$ 20$ million originally estimated. Even assuming that vendors provide WEC devices at no cost to the utility, which was the proposed strategy with WaveConnect, PG\&E concluded that a pilot project comparable to HWC would cost approximately $\$ 47$ million. If WEC devices were purchased for such a project, its total cost would be on the order of $\$ 90$ million.

- It is unclear when or if wave power will become competitive with renewable energy alternatives. Significant additional investment in design, testing and demonstration will be needed to improve designs and reduce costs. Using a vendor-provided installed cost goal of $\$ 2500 / \mathrm{kW}$ for mature WECs in five to 10 years, PG\&E concluded that their LCOE would be in the range of \$175-\$250/MWh, which is not competitive with current or near-term renewable alternatives such as wind or solar photovoltaics.

Although PG\&E discontinued the WaveConnect project and no WEC devices were deployed, WaveConnect advanced PG\&E's understanding of the technological, engineering, permitting, environmental, economic, stakeholder, and related issues involved in undertaking any wave power project now or in the future. As WEC technologies mature, and regulatory and permitting agencies grow more familiar with their environmental impacts, PG\&E believes that wave power will merit further evaluation, demonstration and deployment. 


\section{Executive Summary}

\section{Key Takeaways}

- PG\&E initiated the WaveConnect program in 2007 to investigate the potential of converting ocean wave energy along the California coast into electrical power. As described in this report, PG\&E gathered information on wave energy conversion (WEC) devices, modeled wave power economics, and began the process of licensing and permitting to evaluate wave power in an off-shore demonstration array. In the end, no WECs were deployed and PG\&E suspended the WaveConnect program due to challenges related to project permitting, licensing, economics, and stakeholder concerns.

- Wave energy is a predictable baseload resource with a net capacity factor (NCF) comparable to wind energy.

- Site selection is complex and involves many variables; optimal sites for wave power projects are rare. Projects sited on the Outer Continental Shelf may offer permitting, environmental, technical and economic advantages.

- Assuming marine biological impacts are found to be negligible or readily manageable, wave power may be a very environmentally benign form of power generation.

- As environmental impacts are better understood and verified, cost impacts for the permitting processes will likely drop considerably.

- Commercial-scale economics improve significantly with project scale.

- Improvements in renewable incentives would improve wave energy economics.

- The high costs of licensing, permitting and other processes do not currently justify pursuing the limited licenses available through FERC's expedited Pilot Project Licensing Process (PPLP). Until more experience is gained with wave power technologies, FERC's Integrated Licensing Process (ILP) may be a more efficient way to pursue hydrokinetic projects.

- Even using the most favorable assumptions, the LCOE for a large wave power project is approximately $\$ 175 / \mathrm{MW}$, which is not competitive in today's RPS market.

- The WaveConnect program provided an opportunity to test the regulatory process and work with local, state and federal agencies on a first-of-its-kind, real-world wave power project. Gaining greater understanding of the difficulties and successes that emerged is a key outcome of WaveConnect that will inform future policy making and wave power projects.

\section{Overview}

With a service territory that includes approximately 500 miles $(800 \mathrm{~km})$ of the California coastline, PG\&E is well positioned to evaluate the potential for clean, renewable electricity from the energy contained in ocean waves. Previous studies, including one by PG\&E (PG\&E 1991), 
suggest that the equivalent of tens of thousands of megawatts are theoretically untapped along the Pacific coast, although for practical purposes only a small fraction could likely be exploited. Given the very early state of wave energy research and development, PG\&E began the WaveConnect program to investigate its uncertain but possibly significant potential.

WaveConnect was intended to evaluate, and possibly test, full-scale market-ready and nearmarket-ready wave energy converters (WECs), which transform the kinetic energy of wave motion into electric power. The most successful of these devices could, in subsequent project phases, graduate to long-term power production. The program plan was to moor WECs of different designs provided by different suppliers within an off-shore deployment area, with PG\&E providing permitting, subsea cables, and on-shore facilities necessary to connect WaveConnect to the electric grid. WaveConnect was deliberately technology agnostic, and the original permit applications, Requests for Information (RFIs), Scopes of Work (SOWs) and other specifications did not designate any particular WEC devices. Rather, PG\&E hoped to create a process through which WEC manufacturers (WECoMs) could apply to test and demonstrate fullscale devices at WaveConnect facilities, with all parties gaining invaluable real-world performance data and experience. Ultimately, four different types of WECs were available for WaveConnect participation: attenuators, point absorbers, floating oscillating water columns, and oscillating wave surge converters (OWSC).

Three California sites were investigated to host possible WaveConnect projects:

- Near the city of Fort Bragg in Mendocino County (Mendocino WaveConnect)

- Near the city of Eureka in Humboldt County (Humboldt WaveConnect)

- Near Vandenberg Air Force Base in Santa Barbara County (Central Coast WaveConnect).

Through a selection process discussed below and documented in the full report, the Mendocino site was rejected in favor of the Humboldt site, which was where the vast majority of WaveConnect permitting, regulatory, technology evaluation, modeling, environmental assessment, and stakeholder engagement activities subsequently focused. Concurrent with work on the Humboldt WaveConnect (HWC) project, PG\&E also explored the possibility of developing the Central Coast WaveConnect (CCWC) site, for which FERC issued a preliminary permit and PG\&E began initial information gathering and stakeholder contact.

After a considerable investment of time and effort pursuing licensing, permitting, data collection, planning, and communication with WEC manufacturers, local stakeholders, and the several public agencies involved, PG\&E suspended work on the HWC project in November 2010 and the CCWC project in May 2011. As described below and in the full report, the WaveConnect program was designed to take advantage of the Federal Energy Regulatory Commission (FERC) expedited Pilot Project Licensing Process (PPLP). However, other permitting, regulatory, environmental, and stakeholder engagement processes involved in siting a wave power project largely negated any potential advantages offered by the PPLP. PG\&E ultimately decided that WaveConnect was untenable at both sites given the state of the technologies and the available funding and resources. 
Even though final permitting efforts were abandoned and no WEC devices were deployed at any of the WaveConnect sites, the WaveConnect program accomplished a great deal in advancing PG\&E's understanding of the technological, engineering, regulatory, permitting, environmental, economic, stakeholder, and related issues involved in undertaking any wave power project now or in the future. This report summarizes the process PG\&E developed and followed, the extensive stakeholder communication and cooperation involved, the accomplishments, and the resulting lessons learned, which will benefit future developers of wave power.

\section{WaveConnect Timeline}

- February 2007: PG\&E filed two FERC Preliminary Permit Applications to potentially develop marine hydrokinetic facilities at the Humboldt and Mendocino sites. PG\&E also filed with the California Public Utilities Commission (CPUC) for \$6 million in ratepayer funds to undertake the feasibility studies under a proposed Emerging Renewable Resource Program (ERRP). Initial informal outreach to stakeholders was initiated.

- March 2008: FERC issued preliminary permits for the Humboldt and Mendocino sites to investigate the feasibility of the projects, including securing the necessary data to determine the viability of the proposed project and prepare a license application.

- June 2008: PG\&E applied for \$1.2 million in federal grants from the U.S. Department of Energy (DOE) to fund initial environmental and engineering efforts, conditional on matching funds. The DOE grant was awarded in September 2008 contingent upon securing additional funding.

- Early 2009: The CPUC authorized PG\&E to examine the possibility of a wave energy system off the coast of California, allowing for $\$ 4.8$ million to be used for the first permitting and initial engineering phase. Matched with the $\$ 1.2$ million award from the DOE, total WaveConnect funding was $\$ 6$ million. With initial funding secured, PG\&E formally began the full WaveConnect project development effort.

- June 2009: PG\&E surrendered its permit for the Mendocino site due to inadequate harbor facilities. It also reduced its Humboldt WaveConnect project site to inside the Outer Continental Shelf (OCS) boundary, due to agency conflict between FERC and BOEMRE.

- December 2009: PG\&E submitted a FERC Preliminary Permit Application for CCWC.

- March 2010: PG\&E filed a FERC Draft Pilot License Application (DPLA) for HWC, the first in the nation for a wave energy facility.

- May 2010: FERC granted a preliminary permit for CCWC.

- November 2010: PG\&E formally withdrew its DPLA for the HWC site, effectively ending the Humboldt WaveConnect project.

- May 2011: PG\&E surrendered its preliminary permit for the CCWC site, effectively ending the Central Coast WaveConnect project. 


\section{General Physical Description}

As originally conceived, the project site was envisioned to have a fully built-out total installed capacity of up to $40 \mathrm{MW}$, with the WaveConnect deployment to consist of eight to $200 \mathrm{WEC}$ devices. It also would include one or more submarine transmission cables, integrated generators, anchoring devices, an on-shore transmission line, and appurtenant facilities. It was expected to generate up to 100 gigawatt-hours $(\mathrm{GWh})$ annually. As the location for the initial pilot phase of such a project, the Humboldt Wave Connect WEC deployment area consisted of a rectangle approximately $3.7 \mathrm{~km}$ long and $0.9 \mathrm{~km}$ wide oriented parallel to the coastline that could contain several types of WECs with a total generating capacity of $5 \mathrm{MW}$ (Figure ES-1). The on-shore generator tie-line would have connected to an existing PG\&E substation.

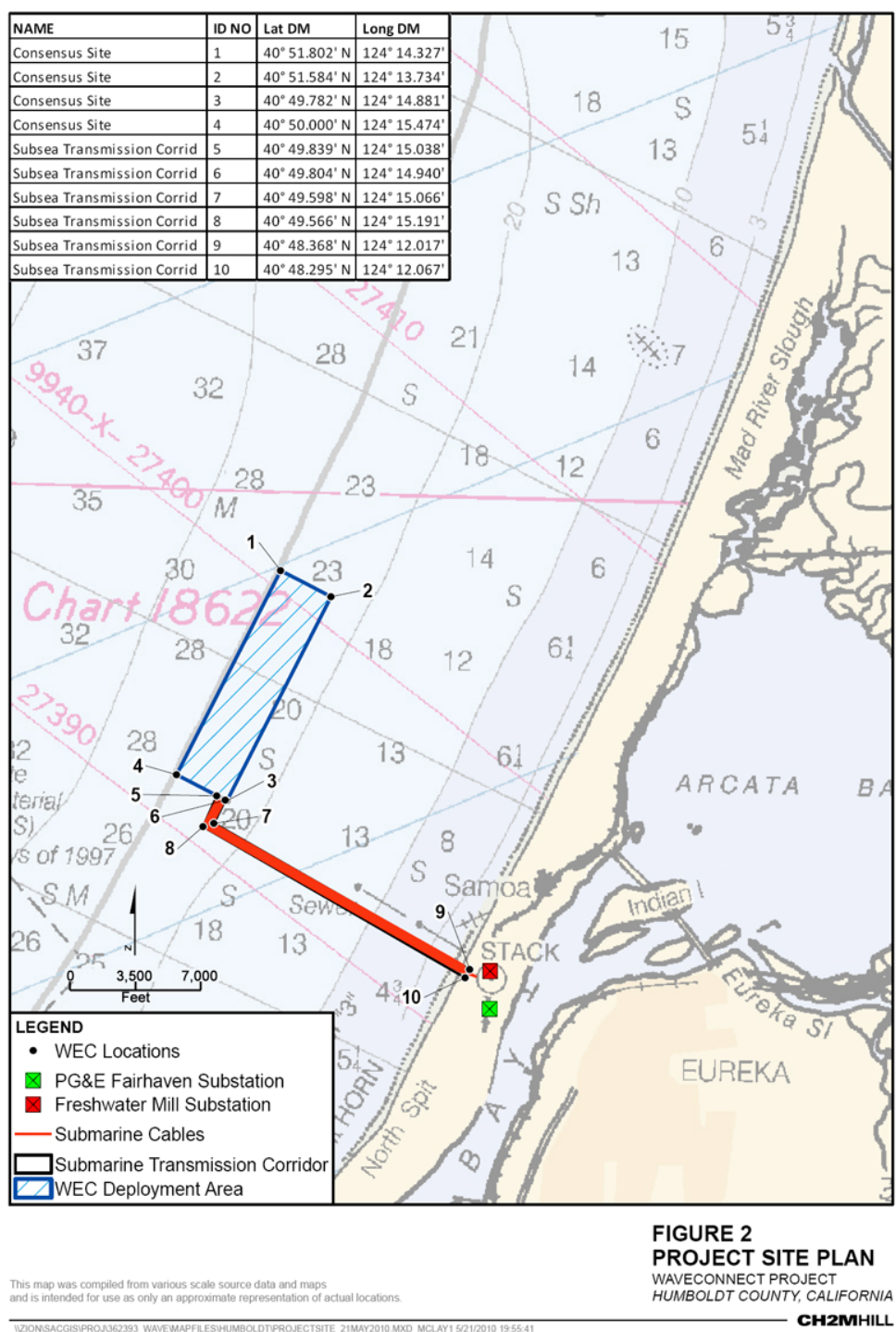

Figure ES-1: Project Site Plan for 5-MW pilot-phase Humboldt WaveConnect project off the coast of Eureka, California 
Within the WaveConnect deployment area, each WEC unit—which, depending on technology type, might range in size from 50 to 150 feet in diameter and 100 feet or more in depth-would be equipped with mooring cables securing it to the ocean floor plus a submarine transmission cable to carry electricity to shore.

Figure ES-2 shows how two types of WECs, oscillating wave surge converters and point absorbers, might be deployed. The watch circles of the floating WEC devices are indicated by the green dashed outlines, while the Y-shaped lines indicate the arrangement of their mooring cables. The figure also shows the umbilical cables (dashed lines) and network of submarine transmission cables (red lines) used to carry electricity to the on-shore substation.

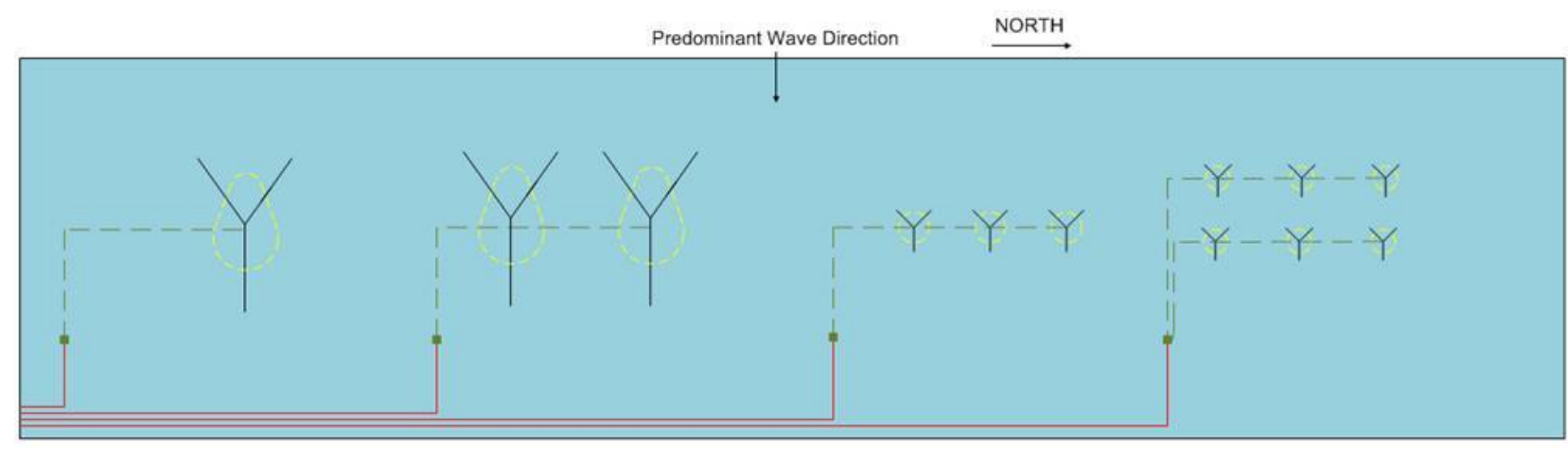

Figure ES-2: Hypothetical arrangement of Oscillating Wave Surge Converter and Point Absorber WECs

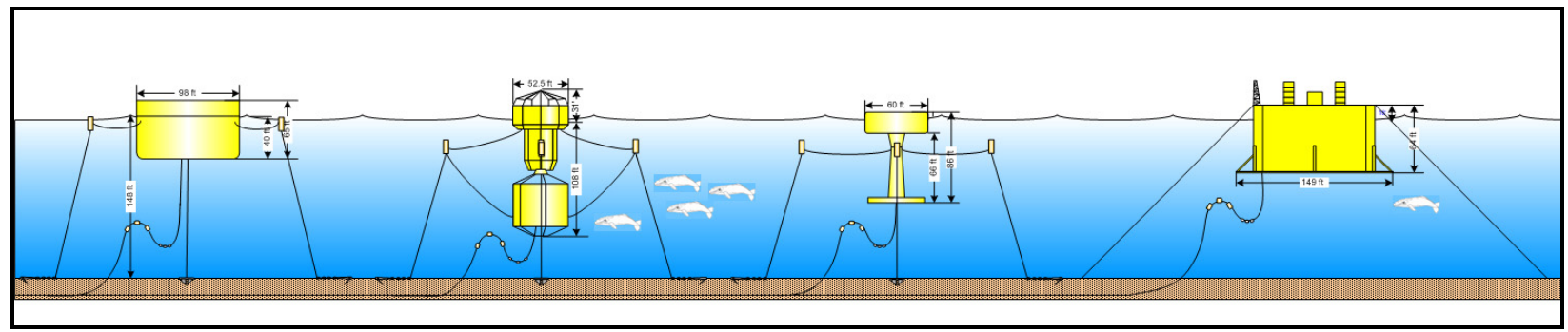

Figure ES-3: Conceptual illustration of representative WEC dimensions and mooring schemes

Figure ES-3 illustrates four schematic WEC devices, along with their mooring schemes and electrical cables, deployed in 150 feet of water. From left to right, they are an oscillating water column device, two different point absorber designs, and another oscillating water column device. To provide a size comparison, illustrations of gray whales are provided at the same scale.

\section{Permitting and Regulatory Process}

Because a wave power project had never been licensed by federal or state agencies in the United States, WaveConnect was poised to pioneer the permitting and regulatory process. This proved to be a significant challenge. In order to construct and operate HWC, PG\&E was required to 
obtain licenses, permits and other regulatory authorizations from a number of federal, state, and local entities, including a license from FERC and a lease from the California State Lands Commission (CSLC) to use state submerged lands.

In February 2007, PG\&E applied to FERC for a Preliminary Permit for the project site, which would provide PG\&E three years of exclusive rights to conduct studies, without affecting any other existing uses during this period. In March 2008, FERC issued PG\&E a three-year Preliminary Permit for the HWC. The project area under the Preliminary Permit originally included both state submerged lands and lands on the OCS under the jurisdiction of the U.S. Department of the Interior's Minerals Management Service (MMS), later known as the Bureau of Ocean Energy Management, Regulation, and Enforcement (BOEMRE). In January 2008, PG\&E submitted a nomination for a limited-term lease on the OCS to MMS. However, for reasons that included the high cost of obtaining a MMS lease as well as uncertainty regarding FERC versus MMS jurisdiction over projects on the OCS, PG\&E withdrew from the MMS leasing process. At PG\&E's request, FERC issued an order reducing the Preliminary Permit boundary to only state submerged lands in July 2009.

In an effort to promote the expeditious testing and development of new hydrokinetic technologies, FERC issued a white paper on Hydrokinetic Pilot Project Licensing Process (PPLP) in 2007. The intent of the PPLP, which was premised on the assumption that hydrokinetic projects would have less-than-significant environmental impacts, was to streamline the FERC licensing process to allow relatively quick and easy project installation, operation, and environmental testing, in contrast to the five years or more typically involved in licensing through FERC's default Integrated Licensing Process (ILP). Under the PPLP, a pilot license application would only have to contain a description of the project and the existing environmental setting, and require only the gathering of already-existing environmental data and basic pre-application surveys without the need for extensive environmental studies and data collection that normally would be required. However, FERC also put significant limitations on projects eligible to use the PPLP: they were to be small (generally less than $5 \mathrm{MW}$ ), able to be shut down or removed on short notice if environmental effects were found to be significant, and were to avoid sensitive locations. Further, FERC specified that the resulting license would be short term (generally five years covering construction, operation, and project removal and site restoration), and would require project removal unless an application for a full license were subsequently filed.

In March 2010, PG\&E filed a Draft Pilot License Application (DPLA) with FERC. The DPLA included a general description of the project and the types of WECs that might be installed, a description of the environmental setting, existing environmental data, and three Monitoring and Adaptive Management Plans (MAMPs). Others involved in the licensing of hydrokinetic projects in California include the U.S. Fish and Wildlife Service (USFWS), National Marine Fisheries Service (NOAA-NMFS), U.S. Army Corps of Engineers, U.S. Coast Guard, California Department of Fish and Game (CDFG), California State Lands Commission, California Coastal Commission, California State Water Resources Control Board, California Office of Historic Preservation, as well as local agencies to a lesser degree. 
Soon after PG\&E filed its draft DPLA, these and other resource agencies and interested parties submitted written responses that yielded more than 300 individual comments on specific issues, a majority of which requested more detailed information on the WECs or the project description, or requested pre-project data on potential effects on environmental resources including species listed under the Federal Endangered Species Act (ESA). FERC requested additional information and asked PG\&E to submit revised MAMPs by August 30, 2010.

Based on discussions regarding a lease of state submerged land, CSLC advised PG\&E that the commission would be required to perform a California Environmental Quality Act (CEQA) full analysis of the project, which would likely involve preparing an Environmental Impact Report (EIR). The CSLC estimated that analysis would take about 12 months, with significant up-front costs to be paid by PG\&E. Further, the CEQA analysis had the potential to require mitigation for potential impacts on state submerged land. CSLC leases usually have a 30-year term and require a construction bond, a performance bond, and a Mitigation Monitoring Plan bond. PG\&E was advised by CSLC that the lease for Humboldt would likely include WEC maintenance reports and possible WEC performance reports. Lease valuation is based on "across the fence" values, but CSLC indicated it would work with PG\&E to determine a fair value for the lease for HWC.

PG\&E hoped to use the PPLP process to quickly and cost-effectively license Humboldt to serve as a test platform for new hydrokinetic technologies. However, the relevant resource agencies often had their own mandatory processes, pre-project data requirements, and permitting concerns that conflicted with or exceeded the demands of the PPLP. While PG\&E could have addressed the DPLA comments and revised its MAMPs as requested by FERC, this effort would have required a level of continued consultation with resource agencies and other interested parties that exceeded the expectations of using the PPLP and had significant cost and scheduling implications.

The high cost of completing the PPLP process at FERC and the CEQA process at the CSLC, combined with the limitations and requirements of any pilot license that might be issued by FERC (including its short term, implementation of mitigation measures, and requirement to remove a project at any time if there were any adverse environmental effect), plus the likely requirements of a CSLC lease, led PG\&E to conclude that it should cease to pursue the HWC project. Accordingly, on November 30, 2010, PG\&E filed with FERC to formally withdraw its DPLA for Humboldt.

\section{Permitting and Regulatory Lessons Learned}

PG\&E gained valuable experience regarding FERC's PPLP, the process that CSLC follows to grant leases to hydrokinetic projects seeking to use state submerged lands, and the process that MMS/BOEMRE uses for granting leases for such projects on the OCS. PG\&E also developed a network of key contacts from the relevant agencies and other stakeholders with respect to hydrokinetic matters.

Many of the comments and concerns submitted in response to PG\&E's DPLA were driven by PG\&E's inability to precisely describe technical features of the WECs it proposed to use due 
ongoing WEC design changes as their development continued. Until the hydrokinetic industry matures and applicants can more specifically identify the characteristics of the WECs they plan to deploy, agencies and other stakeholders will continue to have concerns about such projects.

Agencies other than FERC have not developed procedures to expedite hydrokinetic applications comparable to FERC's PPLP, and in some cases (e.g., USFWS and NMFS in carrying out their ESA and MMPA responsibilities) may not be able to do so. Use of FERC's ILP, under which larger projects can be licensed with longer license terms (up to 50 years), may prove to be a more efficient way to pursue projects using hydrokinetic technologies.

Because hydrokinetic technology is new and largely untested, and the potential environmental impacts of WECs are largely unknown, agencies and other stakeholders tend to be conservative in their assessments of potential environmental impacts and demand higher levels of information on environmental resources and impacts. Until experience is gained with specific WEC devices, it is unlikely that use of FERC's expedited PPLP to obtain licenses for hydrokinetic projects will be successful.

The WaveConnect program and Humboldt WaveConnect project provided an opportunity to test the regulatory process and work with local, state and federal agencies on a first-of-its-kind, realworld wave power project. Gaining greater understanding of the difficulties and successes that emerged is a key outcome of WaveConnect that will inform policy making and wave power projects in the future.

\section{Engineering Technology Evaluation}

PG\&E evaluated a number of different WEC technologies for the WaveConnect project. Although many interesting and promising concepts exist, only a limited number of wave power technologies are ready or nearly ready for commercial application. Most have insufficient longterm operational experience to assess how effectively and reliably they would produce power.

Part of the challenge of developing and demonstrating wave power technologies is that, unlike with wind or solar power, there is limited nearby grid infrastructure for taking power from the offshore generators. Infrastructure to interconnect with the grid may cost many millions of dollars, along with additional costs associated with regulations and permitting. An additional challenge is the limited amount of reliable data on technologies, performance and risks of the devices.

To learn more about the available WEC technologies, PG\&E issued an industry-wide Request for Information (RFI) to which $16 \mathrm{WECoMs}$ responded. PG\&E entered into discussions with those offering technologies that best matched the HWC project scope and site characteristics, and met the DOE Technology Readiness Level (TRL) of 6 or higher. RFI respondents included manufacturers whose devices are based on the four best-known and most technologically advanced types of WEC designs: the attenuator, point absorber, floating oscillating water column (OWC), and oscillating wave surge converter (OWSC). 
Regardless of design, each WEC device requires a cable to transmit medium-voltage alternating current (HVAC) from the WEC down to the sea floor, where it connects with similar cables from the other units in a WEC array and conveys the power to the grid interconnection point, where the transmission cables terminate (a few WEC designs involve pumping water to shore, which PG\&E did not consider appropriate for the permit area or project). Based on experience from the off-shore wind and petroleum industries as well as internal discussions among PG\&E engineers and WECoMs, consensus emerged that the optimal future build-out at the HWC site would use $34.5-\mathrm{kV}$ cable rated at no more than $30 \mathrm{MW}$.

Other critical concerns that affect cost and risk assessment include mooring schemes and materials, operation and maintenance (O\&M) costs, the probability of extreme weather events, and expected lifetime in harsh marine environments.

\section{Modeling Output and Cost}

Figure ES-4 illustrates hypothetical wave power production along the California coast based on the performance of a representative WEC unit. In general, northern California offers greater power-production potential than southern California due to the sheltering effect of the Channel Islands and shallow depth of the OCS off the southern coast, which dissipate the energy of ocean waves as they approach the mainland.

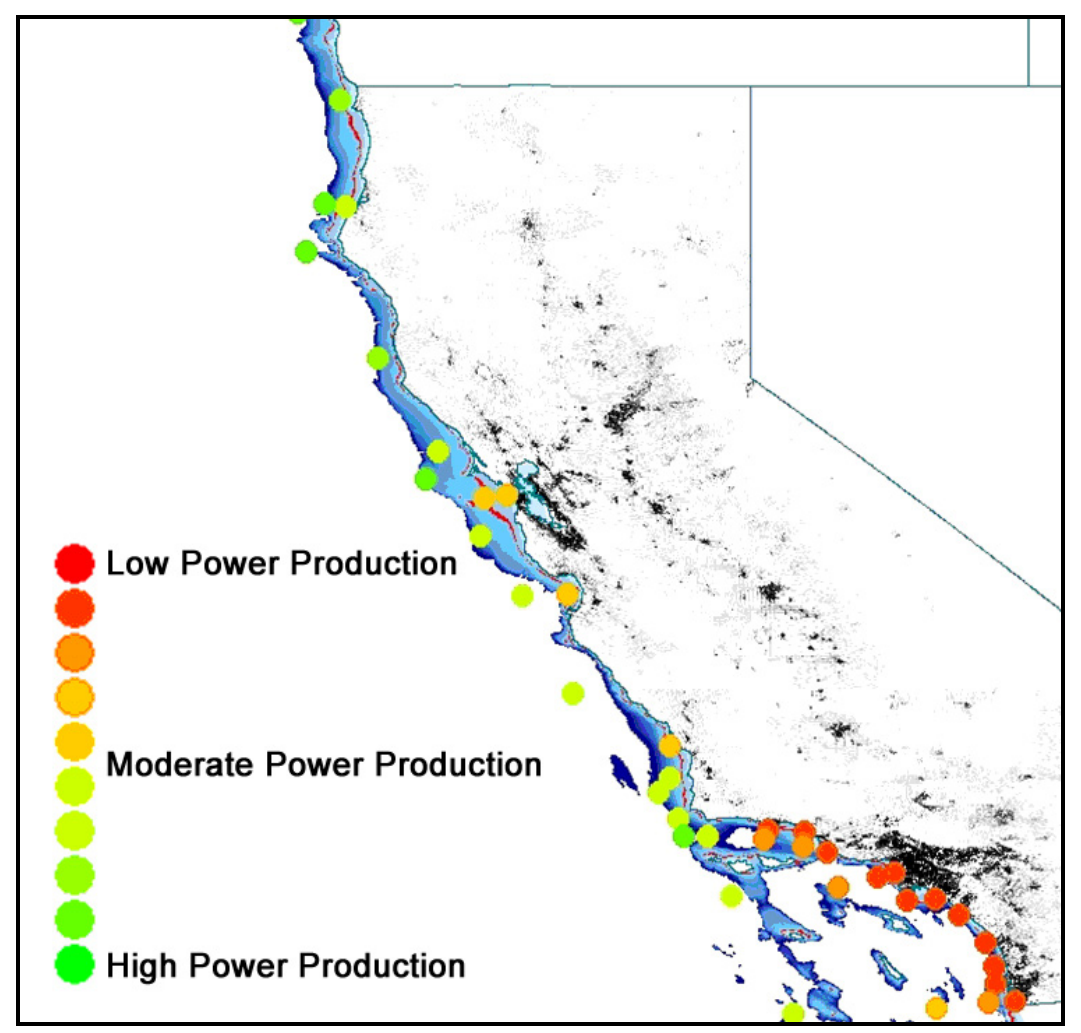

Figure ES-4: Hypothetical power production at the NDBC buoys along the California coast 
PG\&E modeled a hypothetical 30-MW array consisting of three different WEC technologies, with a maximum of $10 \mathrm{MW}$ per technology. Figure ES-5 shows the expected power production in winter (January) for the individual devices and the total array. Figure ES-6 shows an example of hourly production for the same month. As can be seen in these figures, the $30 \mathrm{MW}$ of installed generation is rarely achieved. However, this WEC array would produce at least $12 \mathrm{MW}$ for half of January and at least 17.5 MW for one-fourth of the month.

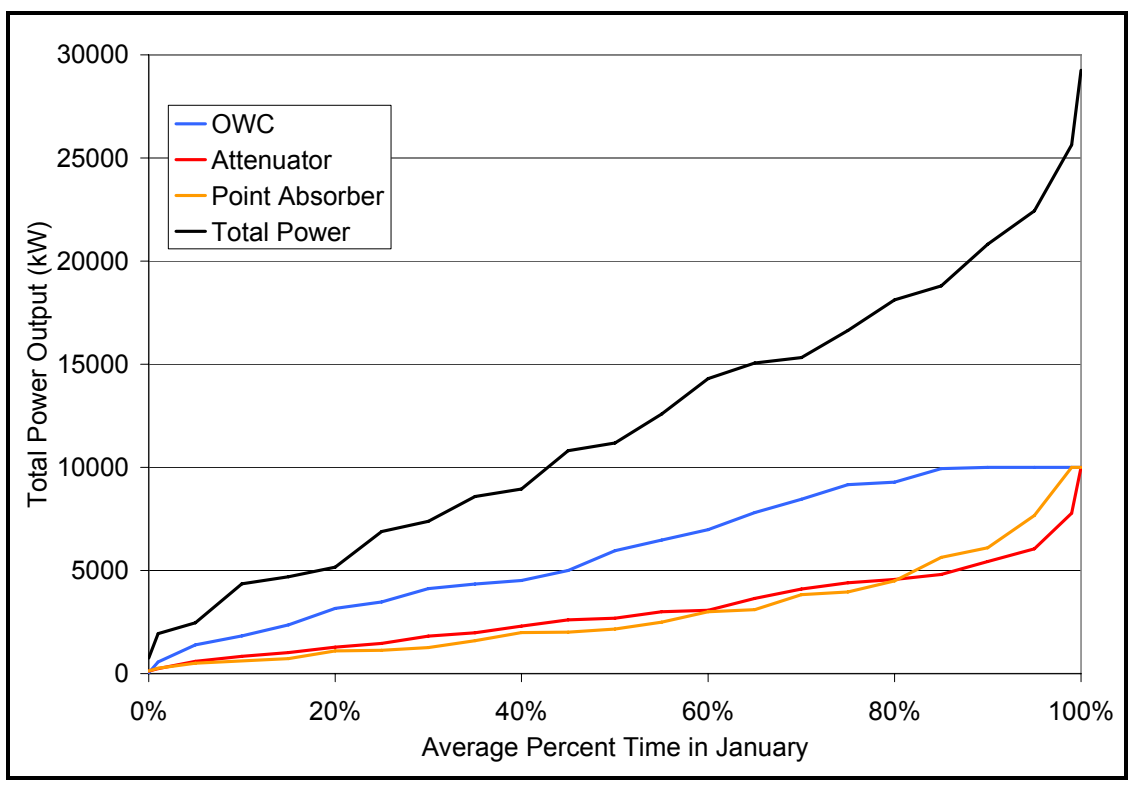

Figure ES-5: Cumulative power output for hypothetical WEC array in January

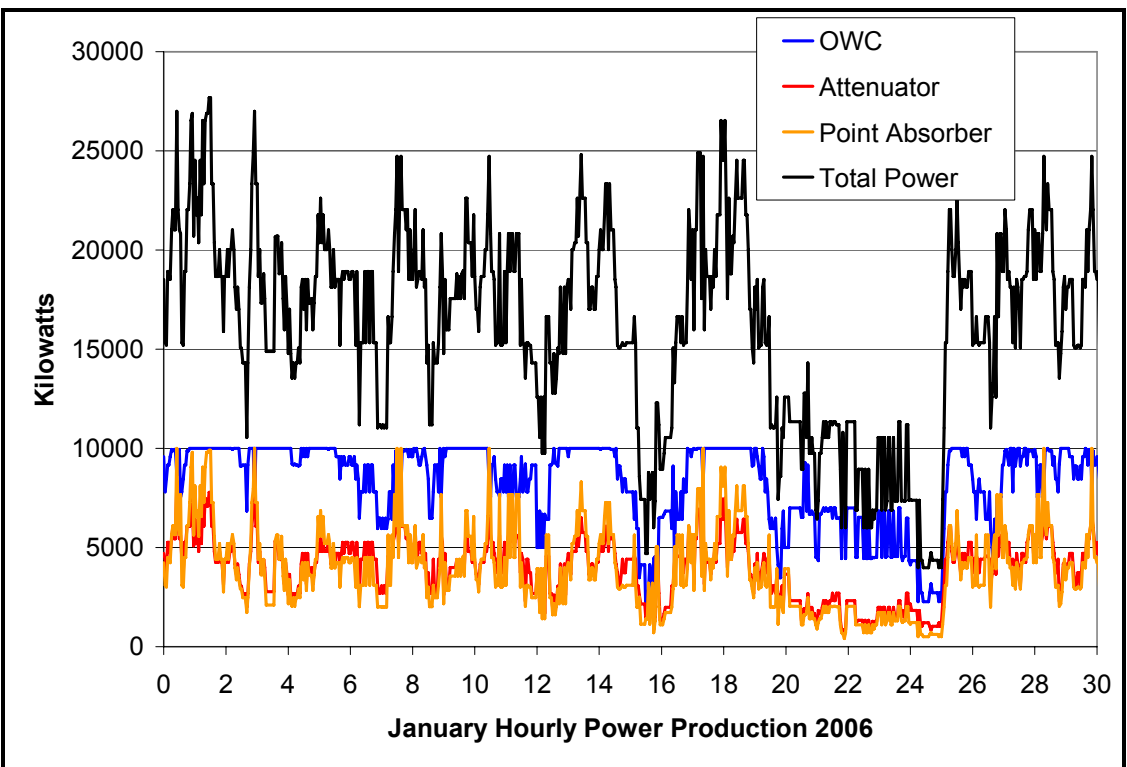

Figure ES-6: Hourly power output for hypothetical WEC array based on data from January 2006 
On a daily basis, the consistency of wave energy compares favorably to that of wind power. Key performance questions concern wave power's daily capacity factor and forecastability. This is significant because utilities must schedule power production to match demand. Unpredictable power is less valuable than reliable power, and power that must be purchased on short notice to make up for unexpected shortfalls is typically expensive. To assess variability, PG\&E used wave data collected at the Humboldt site to determine that the output of a hypothetical 30-MW facility showed no significant hour-to-hour change more than $44 \%$ of the time, and that step changes exceeding $5 \mathrm{MW}$ would occur just $1 \%$ of the time. PG\&E also found that the overall expected capacity factor for its hypothetical 30-MW WEC array was approximately $31.5 \%$. Electrical losses to the on-shore interconnection point were estimated to be approximately $2 \%$.

Because the Humboldt site had straightforward access to an existing substation and transmission infrastructure, the cost to upgrade from a 5-MW to a 40-MW facility was estimated to be relatively small. However, increases surpassing $40 \mathrm{MW}$ would require upgrades of on-shore facilities and reconductoring overhead transmission lines through coastal mountains that could be cost prohibitive. Potential costs at other California sites with better access to the state's transmission network were substantially less.

\section{Environmental Assessment}

One of WaveConnect's principal challenges involved uncertainty regarding its anticipated environmental effects. This uncertainty reflected both a lack of specific information about the WEC technologies and a relative lack of understanding about the complex marine environment. Critical baseline information in the project area was sparse, and it was fundamentally difficult to gather sufficient supplemental information with which to assess project effects for permitting. The magnitude of environmental effects was largely unmeasured and the effectiveness of specific mitigation measures untested. Compounding the uncertainty was the fact that WaveConnect involved a general program to permit a demonstration facility for several different types of WECs.

The siting and permitting activities completed prior to project suspension consisted of the following major phases:

- Critical Issues Analysis

- Preparation of environmental baseline information

- Conceptual design of the WaveConnect site and development of a generalized project description

- Identification of generic WEC devices selected for deployment

- Analysis of potential environmental effects

- Preparation and submittal of FERC Draft Pilot License Application

- Preparation of Monitoring and Adaptive Management Plans (MAMPs). 
FERC's pilot licensing procedures initially appeared to fit the needs of a demonstration facility consisting of several kinds of WECs that could be expanded to a larger facility. However, the process of selecting specific WEC manufacturers to participate in the program could not be completed until completion of site selection, preliminary design and other development activities to form the basis of a Request for Proposals for manufacturers. Consequently, to meet the FERC preliminary permit time restrictions, environmental permitting discussions had to begin before it would have been possible to describe the designs and mooring systems of particular WECs that would participate. It was therefore necessary to describe the project in initial permitting documents in terms of a more general permitting "envelope": a general description of project design types, intended to capture the entire range of possible devices and which would be refined with specific design information as devices were selected.

As noted, in addition to FERC approval, WaveConnect also required a number of additional permits and authorizations under the Federal Endangered Species Act, Marine Mammal Protection Act, National Historic Preservation Act, Clean Water Act, and Rivers and Harbors Act. Permits and authorizations under state law included those under the California Environmental Quality Act (CEQA), California Endangered Species Act, California Coastal Act, and Porter-Cologne Water Quality Control Act. Although the FERC permit could be considered the "master permit," several of the state-level permitting processes would clearly involve requirements or mitigation measures different than and independent of those called for in FERC's license. For example, the CSLC has independent permitting authority in connection with its submerged lands lease and had begun preparing an EIR to comply with the CEQA. Similarly, the California Coastal Commission would issue a Coastal Development Permit under the auspices of the California Coastal Act. Both of these processes involve the authority to condition the project substantially and independently of any federal process.

Perhaps the largest single challenge in permitting the Humboldt WaveConnect project was uncertainty over the potential "take" of special-status species listed under the Endangered Species Act and Marine Mammal Protection Act and the information required to document it. Among the biological resource issues of most concern were possible interference with gray whale migration, the potential hazard of fishing gear becoming entangled in mooring cables and trapping whales or diving birds such as the threatened marbled murrelet, the possibility that WEC devices could become fish attraction devices (FADs) that would in turn increase predation of salmon, and potential electromagnetic disturbances to a class of electrically sensitive sea life that includes sharks, rays and the threatened green sturgeon.

\section{Environmental Assessment Lessons Learned}

The FERC PPLP process offered an expedited means of "getting iron in the water" so that both the WEC industry and regulatory agencies could learn about new wave power technology and its actual environmental effects. It became apparent that regulatory agency responsibilities, particularly under the Endangered Species and Marine Mammal Protection Acts, do not easily allow for expedited permitting. Agency staff is required to develop very specific estimates of allowable take. If listed species are at risk, the assessment process is necessarily slow and methodical, and must be based on sound scientific evidence. Similarly, CEQA does not provide 
for expedited permitting under a limited-term license, although the license duration could be taken into consideration during CEQA review.

The easiest way to expedite permitting or avoid delays under the Endangered Species Act is to have detailed, recent, comprehensive scientific baseline data available to form the basis for any impact assessments and take estimates. Particularly in the marine environment, this type of data collection is expensive and time consuming. Coupled with the likely requirement for extensive monitoring and adaptive management due to the uncertainties of operating new technology in the ocean environment, the long-term costs of the environmental permitting component of a hydrokinetic project are likely to be relatively high as a percentage of capital cost. For a project at the scale of WaveConnect, the relatively short operational time of the pilot license (five years) would not allow the project to generate much revenue from electricity sales to offset these costs.

Humboldt WaveConnect was sited within territorial waters, which offered the advantage of reducing the distance from shore and length of electrical transmission and mooring cable needed, thus reducing cost. However, it became apparent during project development that there would be significant advantages to developing a wave energy farm farther from shore on the Outer Continental Shelf (OCS). A location 6 to 8 miles from shore would have largely avoided the twice-yearly gray whale migration and removed the project from the most productive Dungeness crabbing grounds, reducing or eliminating the potential conflict with crab fishers.

CEQA requires the mitigation of adverse effects to less-than-significant levels if feasible. CEQA decision makers can reach a finding of overriding consideration when the benefits of a project are compelling, but this requires a thorough analysis of project benefits versus uncertainties associated with a project's theoretical environmental impact. For new technologies, it may be difficult or impossible to document unequivocally that particular environmental impacts could be reduced to levels below significance when there is little or no experience implementing and operating such technologies and little understanding of the magnitude of impacts they may cause.

The "envelope" or "umbrella" programmatic approach to permitting could be a viable approach in more routine circumstances and, indeed, is often used in environmental permitting analyses of other types of projects. In the case of WaveConnect, the program plan was to install different types of WECs that could use different types of moorings. Given this envelope without specific WEC descriptions, construction methods, operational profiles and similar details, it was possible to effectively analyze some environmental effects in terms of the outer envelope or worst case scenarios. While this argument is sensible it does not remove all uncertainty, particularly for agencies unfamiliar with WEC technologies. Being able to describe the project in very specific terms is always preferable and increases regulatory confidence.

After the experiences of WaveConnect and other hydrokinetic project efforts, it is widely acknowledged that early wave energy projects in the United States and California will bear a much heavier burden for permitting until more experience is gained through operation of an actual facility in the ocean environment. As specific issues of potential concern prove to be benign in actuality or once mitigation solutions are agreed upon, the permitting hurdles and 
resulting cost implications are expected to decrease significantly, improving the economic viability of this technology for meeting renewable energy goals.

\section{Stakeholder Engagement}

Given the strong local interest in the proposed WaveConnect projects, lack of a clear regulatory regime governing licensing, and desire to minimize impacts to the environment and socioeconomic resources, PG\&E pursued a highly collaborative and inclusive stakeholder engagement process aimed at both local stakeholders and federal, state, and local agencies with a permitting role in the licensing process. The overall goal was to make sure all parties had a trusted and transparent forum to learn about the licensing process and the proposed project and, most importantly, for the development team to clearly understand the issues and regulations affecting the project early enough to substantively address potential issues of concern.

Prior to the formal start of the HWC project in early 2009, local PG\&E employees conducted informal outreach to local stakeholders and agencies, which laid the groundwork for establishing a formal stakeholder group named the Humboldt Working Group (HWG). The formal stakeholder engagement process proceeded through several interim steps to ensure that interested parties were aware of the opportunity to participate in the HWG and that that trusted representatives of these groups were nominated to the satisfaction of their constituents. This process resulted in a highly engaged stakeholder group of around 50 active participants who met approximately monthly with the primary purpose of helping develop the DPLA.

Subcommittees of the HWG formed to discuss particular issues in depth with the development team. One such subcommittee was the HWG Permitting Authority Subcommittee, which allowed permitting agencies to discuss their individual agency requirements with each other and the development team in real time, which was a critically important task. One key outcome of this effort was the development of a "roadmap" and integrated timeline of permitting requirements for all the agencies within the FERC licensing framework.

Other subcommittees involved siting and fishing interests, which led to fruitful discussions with fishing representatives about their operations, potential impacts to their activities, and potential solutions to resolve these issues. Commercial fishing emerged as the most significant and likely conflict of economic interest and use at the HWC site, and is likely to be a conflict that arises for future wave energy projects. This issue was further complicated by the lack of real-world experience with these technologies. The HWC program worked closely with the local commercial fishing community and recreational fishers. Although a formal agreement was not finalized with the fishers at the time of project suspension, the basic principles of a potential agreement had been discussed. In addition, PG\&E worked very closely with the fishing community to determine the final siting of the wave farm.

A key challenge for the HWG was selecting the specific types and number of WEC devices to be used in the WaveConnect project prior to the deadline to submit the DPLA. Local stakeholders and agencies were inclined to consider a wider range of potential impacts than PG\&E 
anticipated. These potential concerns and the associated costs of addressing them greatly disadvantaged the economic aspects of the project.

In summary, the stakeholder engagement process led to both process and project improvements, and helped avoid uninformed opposition to a new and unfamiliar technology by creating an environment to substantively address issues of concern. While some of these issues remained unresolved due to the suspension of project activity, the effort helped clarify the challenges of siting wave energy facilities, particularly in California. Had the HWC continued with the Final Pilot License Application, the HWG would have provided a vehicle to clarify and resolve outstanding and future issues.

\section{Central Coast WaveConnect}

Concurrent with the substantial effort dedicated to the Humboldt WaveConnect project, PG\&E explored a second site for a potential project to be developed simultaneously or subsequent to the HWC pilot project. A site with a number of advantages for a wave power project was identified off the coast of Santa Barbara County near Vandenberg Air Force Base (VAFB), for which a Preliminary Permit Application was submitted to FERC in December 2009. FERC granted PG\&E the requested Preliminary Permit for the proposed Central Coast WaveConnect (CCWC) project in May 2010.

The CCWC study site had several key features attractive to wave energy development: a strong wave energy resource, proximity to underutilized harbor infrastructure at VAFB, availability of extensive environmental baseline information for the region from decades of regional oil and gas exploration and base operations, an interested local community, and relatively little existing ocean use due to distance from public harbor facilities.

In late 2009, PG\&E staff met with Santa Barbara County supervisors to inform them of the potential project and discuss any questions or concerns. Two local public meetings were held to inform the public of PG\&E's desire to build a wave energy project off the coast of VAFB and its intent to convene a community stakeholder working group similar to the HWG. The Santa Barbara community is very interested in both environmental protection and developing green energy technologies; had the project moved forward, it would have been important to carefully address the full spectrum of environmental and economic interests.

PG\&E ultimately decided not to pursue a license for the project. It appeared to PG\&E that the interrelated difficulties faced by the Humboldt WaveConnect project would confront the proposed CCWC as well, and PG\&E had limited resources within the approved WaveConnect funding to resolve such issues. The Preliminary Permit was surrendered in May 2011. However, during the study period, review of the available environmental information, early-stage engineering design activities, and outreach to stakeholders continued to support the favorable assessment of this site for a potential wave energy facility for California. 


\section{Economic and Commercial Issues}

The ultimate objective of the WaveConnect program was to evaluate near-commercial WEC technologies representative of those that might be used in a commercial-scale wave power plant. This evaluation would enable PG\&E to make an informed decision as to whether, and to what extent, wave energy should be included in PG\&E's energy portfolio. The development budget provided by the DOE and the CPUC was intended to fund development activities through submittal of the final licensing application, possibly including some limited device testing.

For the HWC project, PG\&E and the WECoMs discussed a pilot project commercial concept in which PG\&E would serve as lead project developer and selected WECoMs would provide WECs for testing. PG\&E's responsibilities would include owning and operating infrastructure and licenses, obtaining site control, leading the process for selecting WEC devices, and conducting licensing studies for the entire facility. PG\&E would also be responsible for developing, owning and operating the basic electric infrastructure to evaluate, test, and deploy various WEC devices, including an interconnection point at or near the wave energy array.

WECoM responsibilities in the pilot project would include providing engineering, procurement and installation of their respective WEC devices and mooring/anchoring systems, operating and maintaining the WECs over the life of the project, and removing all WECoM-provided equipment after the pilot term was complete.

To offset some of their costs, WECoMs requested a power purchase agreement (PPA) or feed-in tariff for the duration of the project, an approach similar to that of other wave power demonstrations in Europe such as the European Marine Energy Centre (EMEC) or the Pentland Orkney Wave Energy Resource (POWER) Ltd. PG\&E agreed to consider this request, which would have required approval by the CPUC. PG\&E informed the WECoMs that approval would be more likely if the rate were close to current market prices for power. No approval was requested nor rate determined before the WaveConnect program was suspended.

As a result of the early-stage nature of the project and the constraints described, neither PG\&E nor the WECoMs expected the pilot project by itself to yield positive financial returns. However, future phases aimed to transition the project to a commercial scale within the given siting, environmental and permitting circumstances.

\section{WEC Commercial and Strategic Issues}

Some WECoMs were concerned that the HWC approach was not consistent with the pace and sequencing of their existing business models. Other concerns expressed by WECoMs included:

- WECoMs whose commercialization process was relatively advanced were concerned that the HWC approach was not consistent with their current business models. Some would have preferred larger-scale or more commercially structured projects in which PG\&E paid for WECs up-front to demonstrate the long-term viability of their technologies in the U.S. marketplace. All participants recognized that a small number of one-off devices in a pilot project could not repay their investment in that project. As a result, one WECoM declined to 
participate because it felt revenues would not have adequately offset project costs, and at least one other WECoM was undecided for the same reason.

- WECoMs were concerned by significant uncertainties over the project timing, structure, size, and other details regarding the pilot project's transition to commercial scale.

- The water depth at the HWC pilot site was not optimal for some WECs, necessitating a somewhat custom design for some devices and leading other WECoMs to lose interest in the Humboldt site. Others expressed stronger interest in the Central Coast WaveConnect site, whose deeper waters better suited their devices (see Chapter 6).

- Almost all WECoMs expressed concern over the cost recovery uncertainty. European-based WECoMs were used to high feed-in tariffs (e.g., \$500+/MWh) and/or up-front investment credits $(20 \%$ to $40 \%)$ offered by other (non-U.S.) marine energy demonstration programs. HWC was not designed to allow WECoMs to recover $100 \%$ of their costs.

- Most of the WECoMs did not have an established presence in California or other parts of the United States. Participation in HWC would have required a significant investment of time and money to support project development, installation and operations, with no assurance of future business opportunities in the United States.

However, the WECoMs consulted also perceived a number of potential advantages with the HWC project:

- The opportunity to take advantage of a "plug and play" test facility supported by PG\&E consistent with their technology development plans, with some offsetting of costs.

- The strategic benefits of early positioning in the high-profile and potentially profitable California market.

- Support for a transition to commercial-scale project or projects.

- Project timing consistent with their testing and development programs.

Virtually all of the WECoMs interviewed were still in the early stages of funding. Many would have needed investor capital or government grants to participate in the pilot. The ability of some WECoMs to deliver WECs to the project was dependent on their ability to obtain development funds. Only one interested WECoM that PG\&E was aware of had sufficient funding to fully participate in HWC without seeking additional support. While typical of early-stage development companies, this creates uncertainties with respect to technology development, capacity, cost structures, timelines, permitting and other key business planning issues.

From a developer's perspective, it is important to accurately define key inputs to the project economic model to determine the economic and commercial viability of a given technology. In the HWC project, very little reliable information was available with respect to the expected costs of a WEC plant, its support equipment and its operation and maintenance (O\&M), particularly in the harsh marine environment in which these plants would operate. Less uncertain, but also significant, were device and plant performance over the expected broad range of wave and climatic conditions. 
WEC demonstration projects are currently very expensive, driven primarily by the high cost of early-stage WEC devices, which is estimated to be greater than $\$ 10,000 / \mathrm{kW}$. PG\&E's economic modeling showed that wave energy is not currently economically feasible. Projections of future cost reductions need to be demonstrated and verified. A summary of the modeling results is presented in Figure ES-7.

As indicated, wave energy has the potential to achieve an LCOE project cost in the range of \$175-\$250/MWh if and when the WECoMs are able to reduce WEC installed costs to around $\$ 2500 / \mathrm{kW}$, a goal WECoMs generally said they hope to achieve within five to 10 years. As outlined in Chapter 7, these results are based on a number of cost assumptions that have yet to be verified. In addition to the WEC capital cost, the most significant model drivers are WEC O\&M and subsea cable costs, both of which decline as a proportion of overall cost as project scale increases. However, even when using the WECoM cost goal of $\$ 2,500 / \mathrm{kW}$ for the WEC, the lowest assumptions for balance of plant, the lowest permitting costs for a mature project, and the lowest-cost interconnection scenario in which no network upgrades are required, the LCOE for a large wave power project at the Humboldt site is approximately $\$ 175 / \mathrm{MW}$, which is not competitive in today's RPS market.

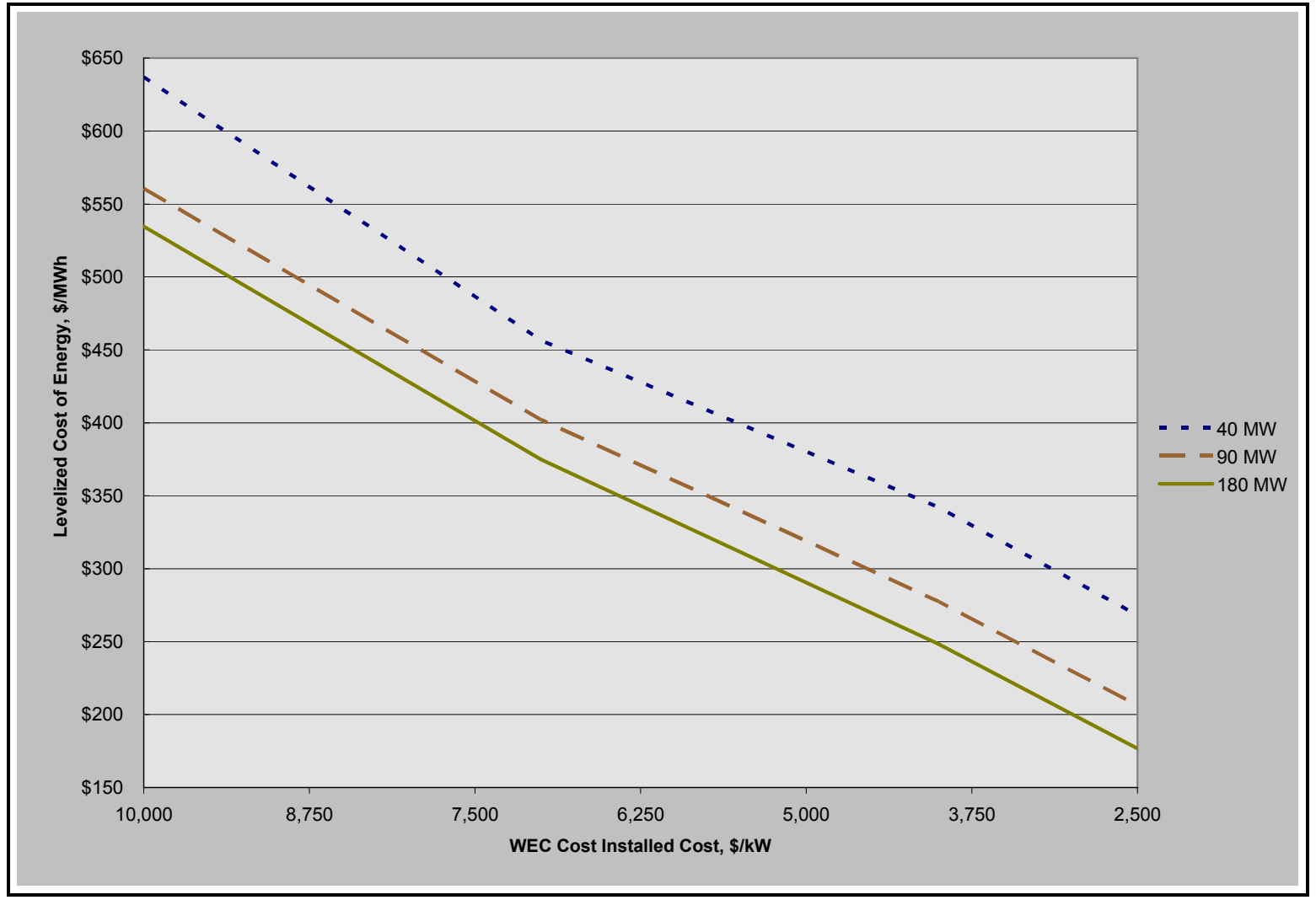

Figure ES-7: WEC LCOE for 40-MW, 90-MW and 180-MW Capacities

However, PG\&E's modeling effort and supporting HWC analysis identified several reasons to be optimistic about the future potential of wave energy: 
- Wave energy can be a baseload resource with a net capacity factor comparable to that of wind energy.

- Wave energy is a predictable resource.

- Assuming marine biological impacts are found to be negligible or readily manageable, WEC devices may offer a very environmentally benign form of power generation.

- As environmental impacts are better understood and verified, cost impacts for the permitting processes will likely drop considerably.

- Agencies indicated support for continuing the existing pilot process and looking for solutions to the permitting challenges that were identified.

- There are significant permitting and technical advantages in locating wave energy sites on the OCS, including deeper water resulting in greater net capacity factors for most WECs.

- Due to high infrastructure costs, commercial-scale economics improve significantly with project scale.

- Improvements in renewable incentives (PTC, ITC, other) would improve wave energy economics. However, until such time, PG\&E's current model reflects the more conservative existing rates.

Disadvantages and key risk areas of wave power projects include:

- Large facility footprint. PG\&E evaluated the overall size of each of the WECs, and found that although most devices have relatively small footprints, their effective footprint spreads over a much larger area. Larger footprints can cause greater impacts to groups such as the fishing industry.

- Technology maturity: WECoM's forecasted cost reductions have not yet been demonstrated.

- A key agency issue is the lack of complete descriptions of WEC devices and their impacts due to their early-stage status and evolving technology. A possible solution to this challenge was introduced during a problem-solving exercise with agencies in which the programmatic approach was promulgated.

- Site selection is complex and involves many variables; optimal sites are rare. After careful analysis, PG\&E concluded that while the Humboldt site might have been adequate for a small pilot project, size limitations related to interconnection capacity and the project's impact on the fishing community made the Humboldt location less attractive for a potential commercial project than other locations along the California coast or on the OCS. A Humboldt project on the OCS would have had less impact on the local fishing community, but would still have been limited in commercial scope to probably no more than $40 \mathrm{MW}$ without significant transmission network upgrades.

\section{Summary \& Conclusion}

The PG\&E WaveConnect project was intended to document the feasibility of a facility that converts wave energy into electrical power using wave energy conversion devices in the open 
ocean adjacent to PG\&E's service territory. WaveConnect was viewed as the first phase of a multi-stage development process that might ultimately lead to long-term megawatt-scale wave power production contingent on its economic performance, technological outcomes, environmental impacts, risks and other considerations that the WaveConnect program was structured to evaluate. The first stage was to include feasibility and licensing work, environmental studies, design and planning, and possibly culminate in the installation of a limited number of WEC devices. The second stage would have including development of infrastructure, undersea cabling, and deployment of more WECs. In the third stage, the most promising WEC devices could have been deployed in larger quantities and connected to the grid.

PG\&E considered developing WaveConnect projects in Mendocino, Humboldt, and Santa Barbara counties due to their favorable wave characteristics. Most of the project effort was focused on the Humboldt site, where PG\&E hoped to establish a 5-MW WaveConnect pilot facility to evaluate WEC devices from different manufacturers and supply clean renewable wave energy to the grid, with the possibility of future expansion.

As PG\&E engaged the regulatory and permitting process, several challenges emerged. Although the WaveConnect program was developed to take advantage of FERC's expedited PPLP, permitting proved to be more complicated, time-consuming, and potentially expensive than anticipated because of the uncertain impacts of WECs. As WaveConnect efforts proceeded, PG\&E learned that even under the PPLP the project would still require a full analysis under the California Environmental Quality Act (CEQA), including an Environmental Impact Report, as well as Monitoring and Adaptive Management Plans (MAMPs) and other requirements that had significant cost and scheduling implications. A majority of Stage One efforts were expended on permitting activities.

PG\&E ultimately decided that WaveConnect was untenable given the state of the technologies and the available funding and resources. PG\&E withdrew its DPLA for HWC in November 2010 and surrendered its preliminary permit for CCWC in May 2011, effectively discontinuing the WaveConnect project for the following combination of reasons:

- WECs are early-stage devices with evolving designs and little real-world operating experience. These characteristics made environmental impacts difficult to assess and permitting issues more challenging than originally anticipated. Stage One project funding of \$6 million proved insufficient to complete the necessary development and permitting work, which PG\&E determined would cost at least \$2 million to \$5 million more than originally budgeted.

- $\quad$ PG\&E found that the cost of developing a five-year, 5-MW WaveConnect pilot project at Humboldt Bay is much greater than the $\$ 15$ million to $\$ 20$ million originally estimated. Even assuming that vendors provide WEC devices at no cost to the utility, which was the proposed strategy with WaveConnect, PG\&E concluded that non-WEC capital costs would total approximately $\$ 28.1$ million. If escalation, financing, and non-WEC MAMP and O\&M costs are included, estimated project costs increase to \$50.9 million. Without AFUDC and G\&A, the project cost was estimated at $\$ 47$ million. If the WEC devices were purchased, as 
opposed to paying WECoMs under a PPA, the overall project cost would be on the order of $\$ 90$ million.

- It is unclear when or if wave power will become competitive with renewable energy alternatives. Significant additional investment in engineering, testing and demonstration will be needed to improve designs and reduce costs. Using a vendor-provided installed cost goal of $\$ 2500 / \mathrm{kW}$ for mature WEC devices in five to 10 years, PG\&E concluded that their LCOE would be in the range of $\$ 175-\$ 250 / \mathrm{MWh}$, which is not competitive with current or nearterm renewable alternatives such as wind or solar photovoltaics.

These conclusions are not definitive or absolute. Wave power manufacturers may be able to drive costs lower than they currently forecast. Although PG\&E discontinued the WaveConnect project and no WEC devices were deployed, WaveConnect accomplished a great deal in advancing PG\&E's understanding of the technological, engineering, regulatory, permitting, environmental, economic, stakeholder, and related issues involved in undertaking any wave power project now or in the future.

Despite the challenges, PG\&E gained extensive information and experience, which is outlined in this report and will be very useful for future wave power projects. As WEC technologies mature and environmental impacts become clearer, PG\&E believes that wave power will merit further evaluation, demonstration and deployment. 



\section{Contents}

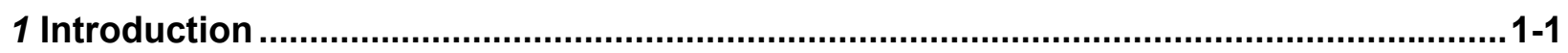

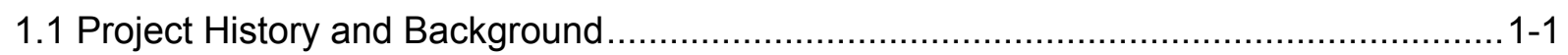

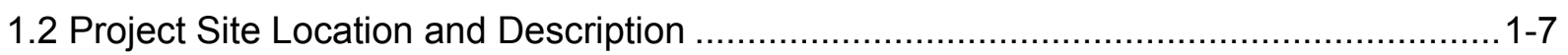

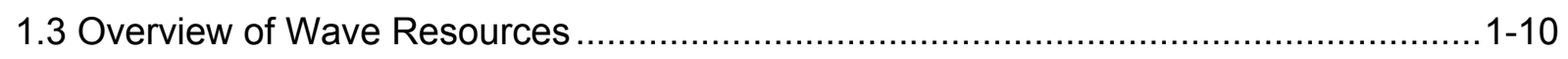

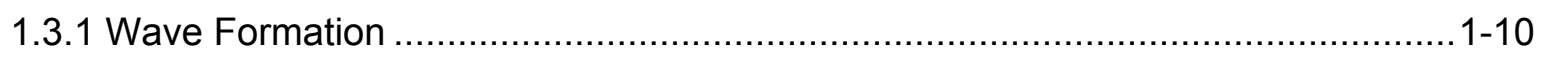

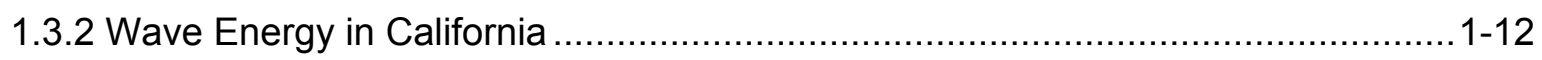

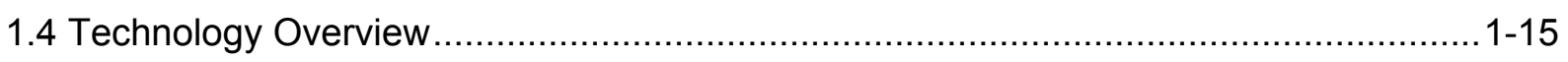

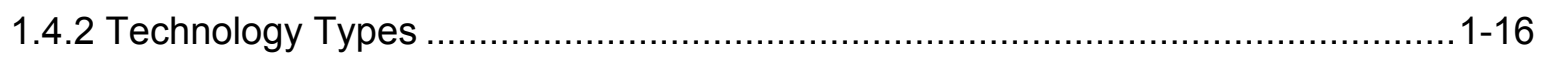

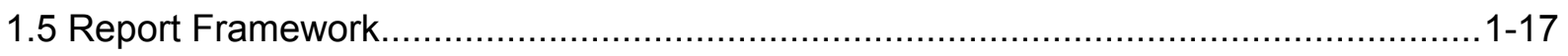

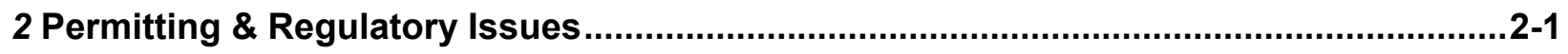

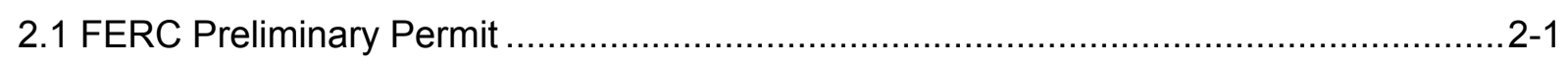

2.2 MMS/BOEMRE Lease Nomination ................................................................ $2-1$

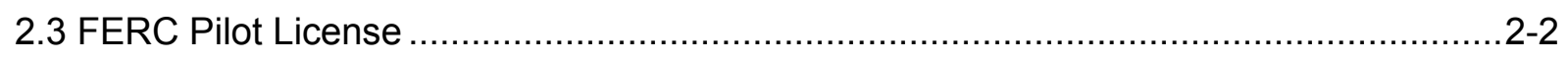

2.4 Draft Pilot License Application and Reactions.................................................... $2-3$

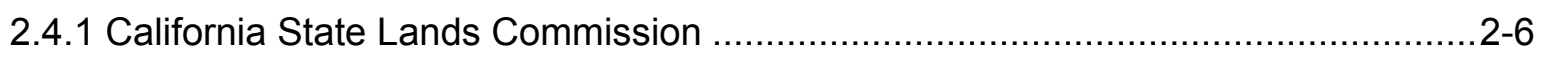

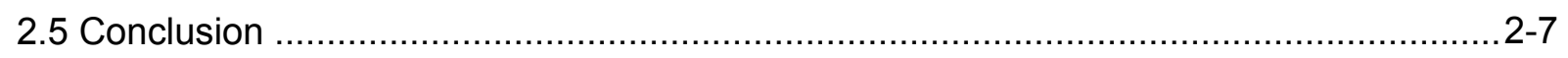

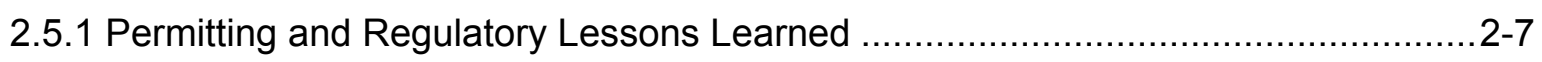

3 Engineering Technology Evaluation ...................................................................... 3

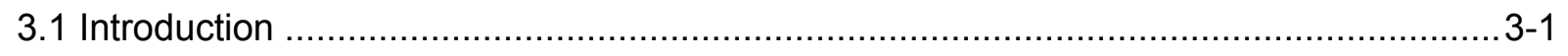

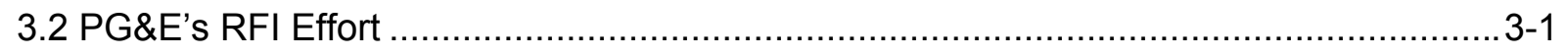

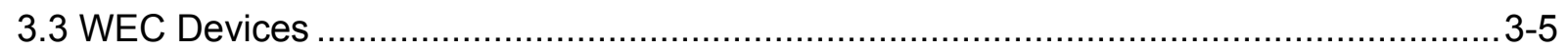

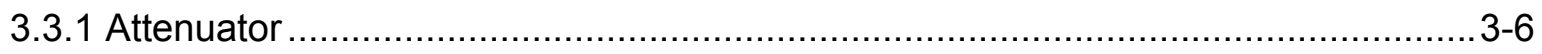

3.3.2 Point Absorber .....................................................................................

3.3.3 Oscillating Wave Surge Converter ....................................................... $3-14$

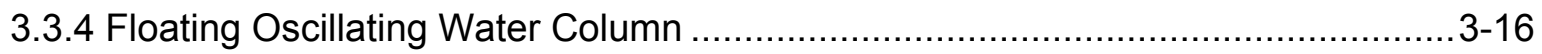

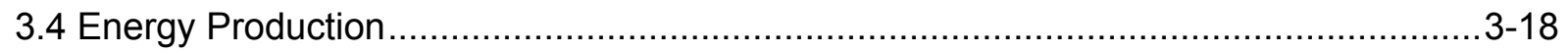

3.4.1 WEC Responses to Wave Energy Spectra ............................................... $3-24$

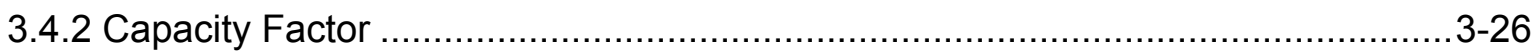

3.5 Site Options along the California Coastline ......................................................... $3-33$ 
3.5.1 North Coast

3.5.2 San Francisco Bay Area

3.5.3 Central Coast.

3.5.5 Overview

3.6 Humboldt WaveConnect Pilot Project Overview and Site Infrastructure......

3.6.1 Proposed Project Facilities

3.7 HWC On-Shore Infrastructure, Cable, and Grid Connection

3.7.1 On-site Monitoring and Power Conditioning Station

3.7.2 Waterfront Host Facility

3.8 Interconnection

3.8.1 Generator Tie-line

3.8.2 Electrical Substation

3.8.3 Off-site Control Center.

3.8.4 Horizontal Directional Drilling

3.9 Off-Shore Electrical Cable Connections.

3.9.1 Background

3.9.2 Submarine Cable

3.9.3 Undersea Umbilicals and Connectors

3.10 Mooring and Anchoring Systems

3.10.1 Return Time of Storms and Survivability

3.10.2 Mooring Costs

3.11 Capacity Factor and Availability

3-71

3.12 Cable Cost and Installation Estimates

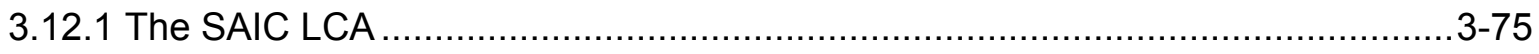

3.12.2 Cable Route Conceptual Scenarios ...........................................................

3.12.3 Cable Install Calculator and Installation Costs ............................................. 3-77

3.12.4 Subsea Cable Installation Scenarios ......................................................... 3-79

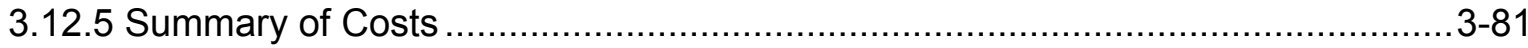

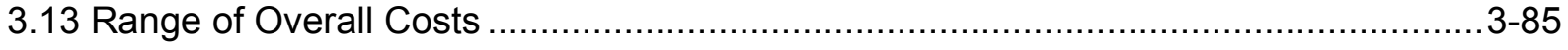

3.13.1 Cost Inputs for the Economic Model........................................................ 3-85

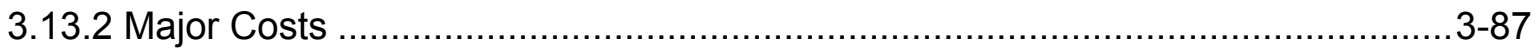

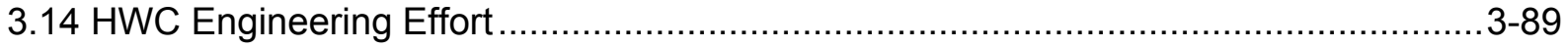

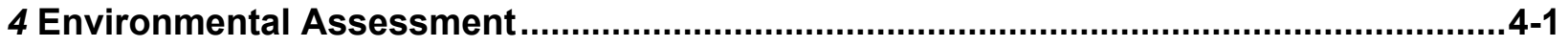




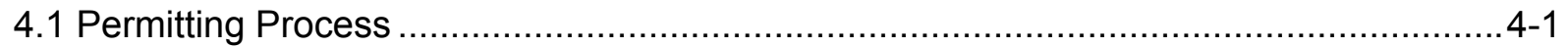

4.1.1 Lead Permitting Agency ..........................................................................

4.1.2 FERC Pilot License Procedures ................................................................. $4-2$

4.1.3 Permitting Processes and Phases............................................................... $4-3$

4.1.4 Critical Issues Analyses .........................................................................

4.1.5 Environmental Baseline Information.......................................................... $4-8$

4.1.6 Analysis of Environmental Effects ............................................................ 4-10

4.1.7 Monitoring and Adaptive Management Plans ..................................................4-23

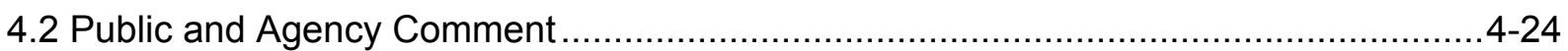

4.2.1 Comment Classification ............................................................................ 4-25

4.3 Additional Efforts Needed to Secure the Pilot License ..........................................4-30

4.4 Parallel Permitting Processes Required to Construct the Project ..............................4-34

4.5 Lessons Learned from Agency Interactions ....................................................... 4-36

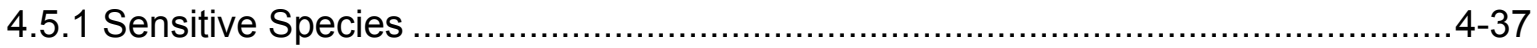

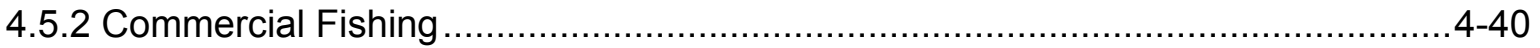

4.5.3 Permitting Lessons Learned ...................................................................... $4-42$

5 Stakeholder \& Community Engagement ………........................................................... 5-1

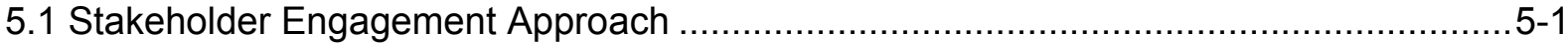

5.1.1 Goals for Stakeholder Engagement ………….........................................

5.2 Stakeholder Engagement Process ...................................................................

5.2.1 The Humboldt WaveConnect Pilot Project ………...........................................5-2

5.2.2 Establishing the Humboldt Working Group (HWG) ......................................... 5-3

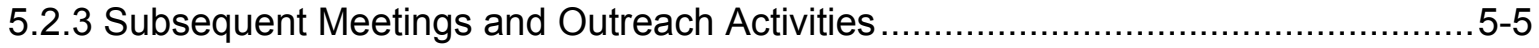

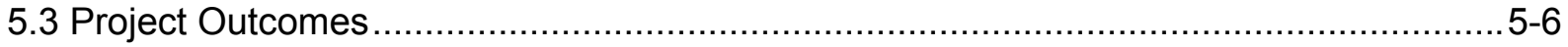

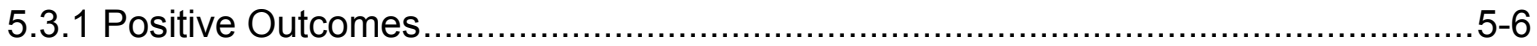

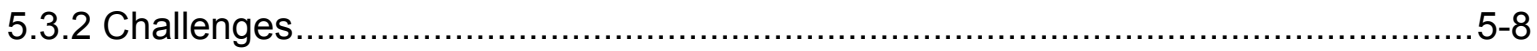

5.4 Conclusions: Lessons Learned and Process Recommendations ..................................5-9

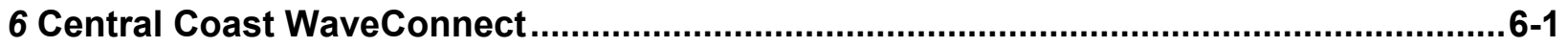

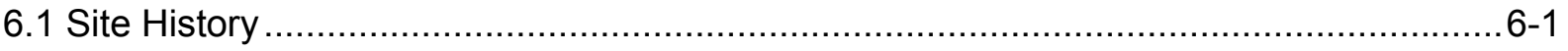

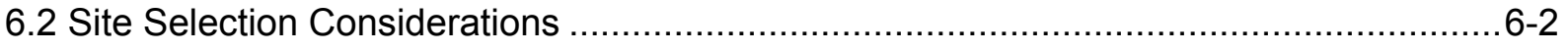

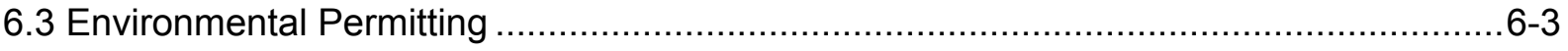

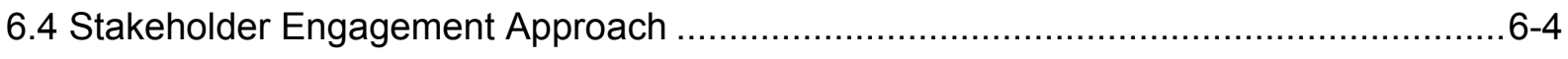


6.4.1 Outreach Activities before Filing Preliminary Permit Application ...........................6-4

6.4.2 Outreach Activities after Filing Preliminary Permit Application .............................6-4

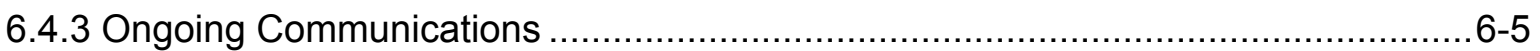

6.5 Evolving Engineering Efforts at the Central Coast WaveConnect Site ........................6-5

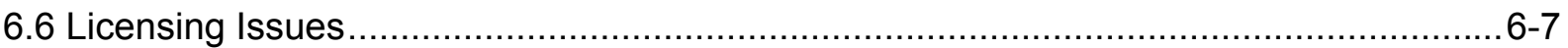

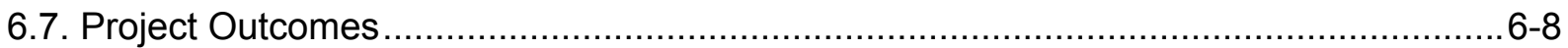

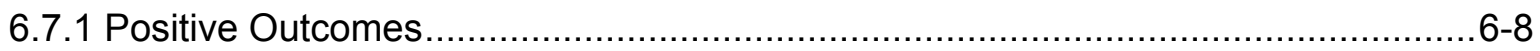

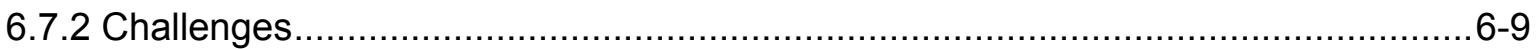

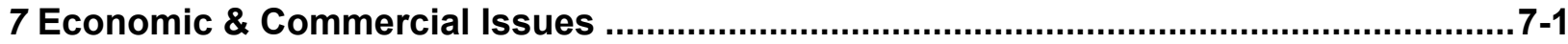

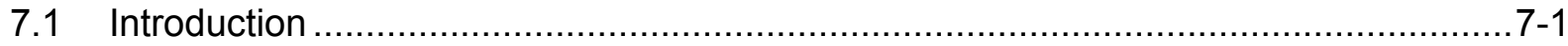

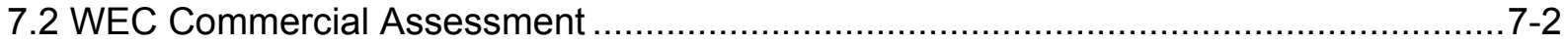

7.2.1 WECoM Perspective on Humboldt Wave Connect Pilot Approach ....................... 7-2

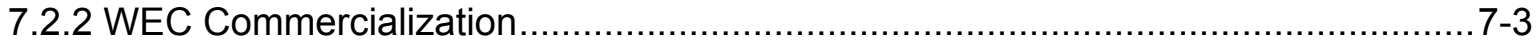

7.2.3 Pilot Project Commercial Concept ................................................................. $7-5$

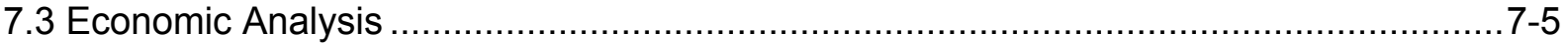

7.3.1 Assumptions and Key Model Drivers ........................................................... 7-6

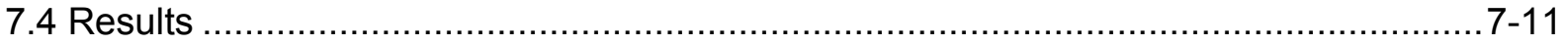

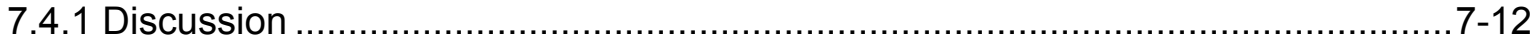

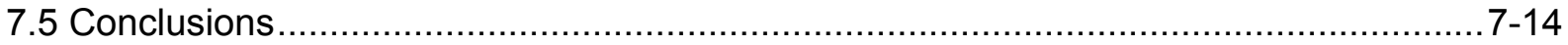

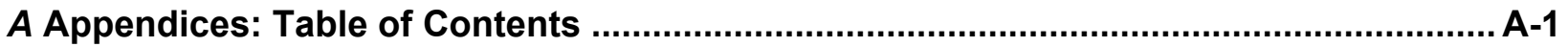




\section{List of Figures}

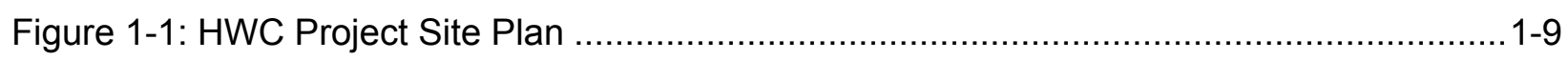

Figure 1-2: HWC Power Connection to Grid ..................................................................1-10

Figure 1-3: Interaction of Multiple Wave Trains from Various Directions ..............................1-11

Figure 1-4: Wave Shadowing Caused by the Channel Islands in Southern California ............1-13

Figure 1-5: Wave Depletion behind Poseidon WEC …...................................................1-13

Figure 1-6: Wave Power Worldwide (in units of $\mathrm{kW} / \mathrm{m}$ ) ...............................................1-14

Figure 1-7: Average Wave Power Found along the California Coast (California Energy

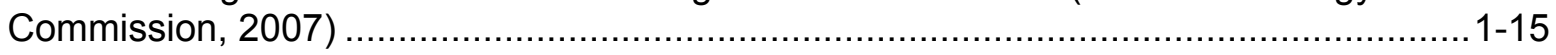

Figure 1-8: Wave Power Available at Eureka, California ..................................................1-15

Figure 1-9: Hypothetical Arrangement of OWSC and Point Absorber WECs ........................1-17

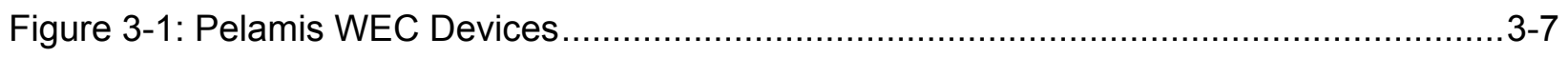

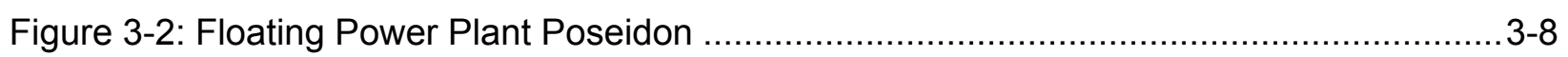

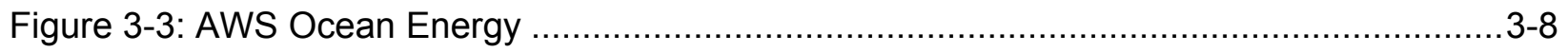

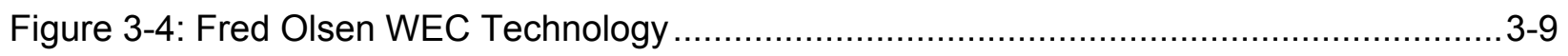

Figure 3-5: Perpetuwave Power Wave Harvester ..........................................................

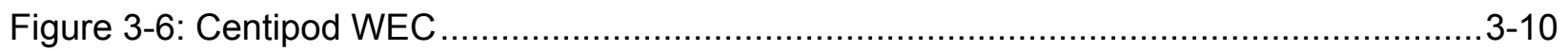

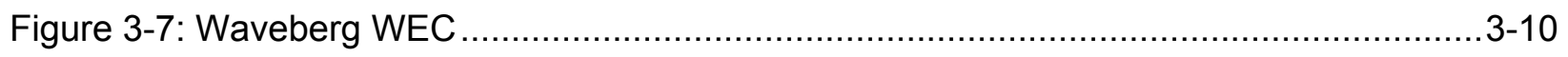

Figure 3-8: Ocean Power Technologies PowerBuoy System ................................................. $3-11$

Figure 3-9: Columbia Power Technologies...................................................................

Figure 3-10: WaveBob WEC Technologies ……................................................... $3-12$

Figure 3-11: Resolute Marine Energy Early-Stage Device ................................................... 3-13

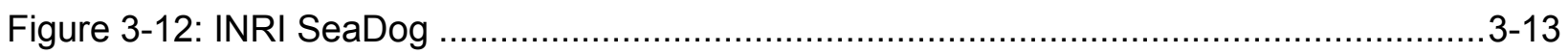

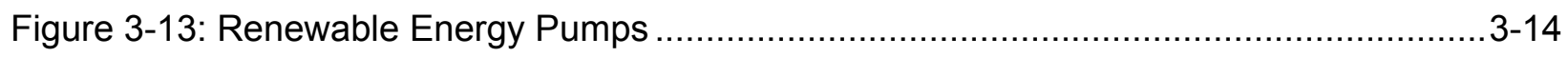

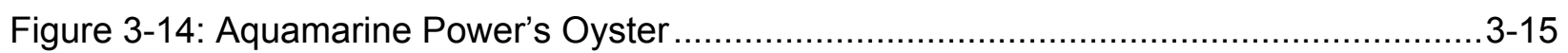

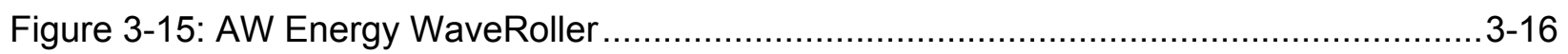

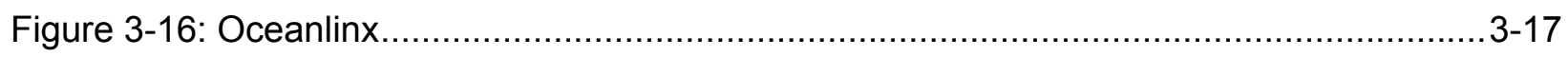

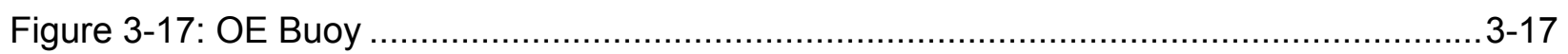

Figure 3-18: Wave Spectra for NDBC Station 46212-Humboldt Bay South Spit,

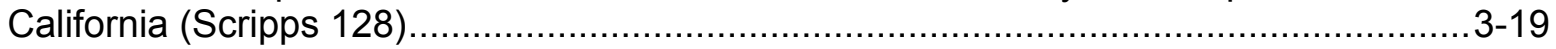

Figure 3-19: Wavelength vs. Period and Depth (using MACE) ...................................... 3-19

Figure 3-20: Distance from Coast at which $50 \mathrm{~m}$ Depth Occurs .......................................... 3-22

Figure 3-21: Pelamis Power Response Spectra ............................................................. 3-22

Figure 3-22: Hypothetical power production (based on Pelamis power spectra) at NDBC buoys along the California coast. Red indicates the $50 \mathrm{~m}$ demarcation...........................3-23

Figure 3-23: Hypothetical power production (based on Pelamis power spectra) at various NDBC buoys around the San Francisco Bay Area......

Figure 3-24: Hypothetical power production (based on Pelamis power spectra) at various NDBC buoys in Southern California waters 
Figure 3-25: Trend of hypothetical capacity factor in deeper waters (based on Pelamis power spectra) at various NDBC buoys

Figure 3-26: Point Absorber Power Response Spectra

Figure 3-27: Energetech/Oceanlinx Power Response Spectra (based on EPRI 2004, extrapolated).

Figure 3-28: Monthly Average Power Output for a Given Mix of Energetech, Pelamis, and Point Absorber in the Eureka Area (assuming a $10 \mathrm{MW}$ maximum rating for each type).

Figure 3-29: Monthly Average Capacity Factor for a Given Mix of Energetech, Pelamis, and Point Absorber in the Eureka Area.

Figure 3-30: Cumulative Power Output for the Three-Device Array in January and July (assuming a $10 \mathrm{MW}$ maximum production per device type).

Figure 3-31: Hourly Power Output for Hypothetical Three-Device Array in January and July over Four-Year Period (2005-2008).

Figure 3-32: Typical Daily Variability in Power Output for Wind (left) and for Wave (right) Power....

Figure 3-33: Step changes per hour (in kW) for a hypothetical 30-MW wave power facility in Humboldt, 2004-2011

Figure 3-34: Transmission Line Access Points and Estimated Capacities

Figure 3-35: HDD Profile and Cable Interconnection

Figure 3-36: Horizontal Directional Drilling in Progress

Figure 3-37: Typical Shielded Three-Phase Cable Cross-Section (JDR Cable Systems) ........3-55

Figure 3-38: Madeline Island Cable Installation (www.kerite.com)..... $3-56$

Figure 3-39: A Jet Plow (CapJet), Cable Plow, and Seabed Tractor ................................... 3-57

Figure 3-40: A ROV Plow in Operation ...................................................................... $3-57$

Figure 3-41: Cable Fault Rates by Year (Allen, 2001) .................................................. 3-58

Figure 3-42: AREVA Off-Shore Substation and Conceptual Central Station for WEC Array.

Figure 3-43: Windfarm Daisy Chain Configuration that Minimizes Risk (Underbrink et al, 2006)

Figure 3-44: Cable Connector for use at Wave Hub (JDR Cables)

Figure 3-45: Cable Connector Lowered into Place from Cable-lay Ship at Wave Hub, August 2010 (JDR Cables)

Figure 3-46: Wave Hub Project Cable Connector (JDR Cables)

Figure 3-47: Cable Joint Cutaway (Marc Jeroense, ABB AB High Voltage Cables)

Figure 3-48: Cable Joint Termination Cutaway (Marc Jeroense, ABB AB High Voltage Cables)

Figure 3-49: Cable Joiners (Marc Jeroense, ABB AB High Voltage Cables).

Figure 3-50: Joint Bending Restrictor in Operation (Marc Jeroense, ABB AB High Voltage Cables). 
Figure 3-51: Joint Bending Restrictor Cutaway (Marc Jeroense, ABB AB High Voltage Cables)

Figure 3-52: Joint Bending Restrictor (Marc Jeroense, ABB AB High Voltage Cables)...........3-64

Figure 3-53: Cable Stiffener for Attachment to Off-shore Platform (Marc Jeroense, $A B B$

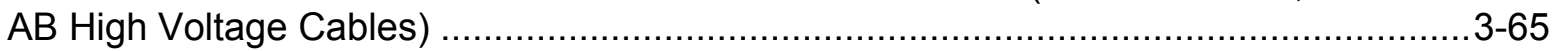

Figure 3-54: Cable Stiffener for Attachment to Off-shore Platform In Situ (Marc Jeroense, ABB AB High Voltage Cables)

Figure 3-55: Off-shore Cable Termination for Connection to WEC (JDR Cables) ................... 3-65

Figure 3-56: NCBC Buoy Locations along the U.S. West Coast (Komar and Allan, 2000)......3-67

Figure 3-57: Average Wave Height at NDBC Buoys (Komar and Allan, 2000).

Figure 3-58: Spectral Chart for NDBC Buoy Off-shore of Washington State (Komar and Allan, 2000)

Figure 3-59: 95\% Confidence Intervals for Washington and Oregon Buoys (Komar and

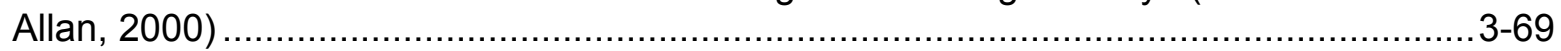

Figure 3-60: Diameter vs. Breaking Strength for Three Major Mooring Line Materials............ 3-70

Figure 3-61: Diameter vs. Cost per Foot for Three Major Mooring Line Materials..................3-70

Figure 3-62: Cost per Foot vs. Breaking Strength for Three Major Mooring Line Materials..... 3-71

Figure 3-63: Scenario 1—Project Site within the Pilot Area............................................. 3-76

Figure 3-64: Scenario 2-Project Site on Outer Continental Shelf .................................... 3-77

Figure 3-65: Cable and Installation Costs for Various Cable Runs (40-MW scenario comprises two 20-MW cables)

Figure 3-66: Average Off-shore Power Density near the Central Coast WaveConnect Site.

Figure 3-67: Dungeness Crab Fishing Activity in the Vicinity of WaveConnect Site.............3-104

Figure 3-68: Commercial Passenger Fishing Activity in the Vicinity of WaveConnect Site ...3-105

Figure 6-1: Proposed Overland and Off-shore Routes ..................................................6-6

Figure 6-2: Close-up Aerial View of Beach Access .......................................................6

Figure 7-1: Wave Energy Project LCOE for 40-MW, 90-MW and 180-MW Capacities, and Varying Installed Cost of WEC Devices ....

Figure 7-2: COE vs. Installed Capacity (EPRI 2005) 



\section{List of Tables}

Table 1-1: Feasibility Efforts to be Taken under CPUC Funding ........................................1-5

Table 3-1: Information Requested of WECoMs in PG\&E's RFI ..............................................

Table 3-2: Dependence of Wave Characteristics on Depth (Army Corps of Engineers Coastal Engineering Manual) ....................................................................................

Table 3-3: Summary of Potential Interconnection Points along California Coastline ................3-44

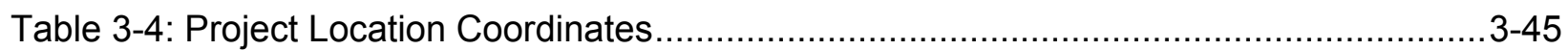

Table 3-5: Cost of installation for HDD borings (\$/linear meter) for various product diameters (Ariaratnam, et al. 1999).........................................................................

Table 3-6: Average productivity (linear meters/day) in various subsurface foundations based on an eight-hour day. The numbers in square brackets indicate the number of data points comprising the average (bold) (Ariaratnam, et al. 1999) ..........................3-52

Table 3-7: Off-shore Oil and Gas Platforms in Southern California with Electrical Cables to the Platform (Source: Ann Scarborough, BOEMRE)............................................

Table 3-8: Anticipated O\&M Activities for OPT Reedsport Project (OPT 2010) ......................3-73

Table 3-9: Summary of Estimated Initial Engineering Costs.................................................3-82

Table 3-10: Summary of Initial Capital Costs (Fixed) …................................................ 3-82

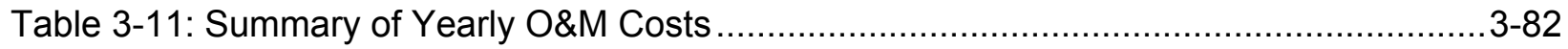

Table 3-12: Summary of Decommissioning Estimated Costs ............................................ 3-82

Table 3-13: Summary of Cable and Electrical Infrastructure Installation Costs $2.5 \mathrm{MW}$

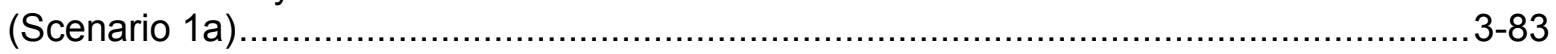

Table 3-14: Summary of Cable and Electrical Infrastructure Installation Costs 5 MW (Scenario 1b).

Table 3-15: Summary of Cable and Electrical Infrastructure Installation Costs 7.5 MW (Scenario 1c)...

Table 3-16: Summary of Cable and Electrical Infrastructure Installation Costs $10 \mathrm{MW}$ (Scenario 1d).

Table 3-17: Summary of Cable and Electrical Infrastructure Installation Costs $10 \mathrm{MW}$, Four 2.5-MW Cables (Scenario 1e)

Table 3-18: Summary of Cable and Electrical Infrastructure Installation Costs 30 MW 35-

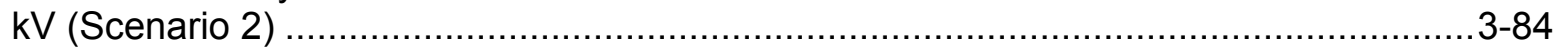

Table 3-19: Summary of Cable and Electrical Infrastructure Installation Costs 40 MW 35

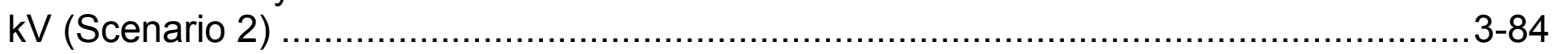

Table 3-20: Yearly Summary of WaveConnect Estimated Costs (Based on Medium Cost Estimate, with no change due to NPV).

Table 3-21: Summary of Cable and Electrical Infrastructure Installation Costs, $5 \mathrm{MW}$

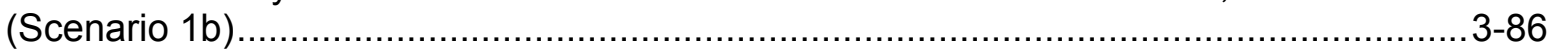

Table 3-22: Humboldt, Pilot-Capital Cost (Electrical Infrastructure), $10 \mathrm{MW}$.........................3-86

Table 3-23: Humboldt, OCS-Capital Cost (Electrical Infrastructure), $30 \mathrm{MW} . . . \ldots \ldots \ldots \ldots \ldots \ldots \ldots . . . . . . . .3-86$

Table 3-24: Central Coast-Capital Cost (Electrical Infrastructure), 40 MW........................... 3-86

Table 3-25: Central Coast-Capital Cost (Electrical Infrastructure), 90 MW............................ 3-87 
Table 3-26: Central Coast-Capital Cost (Electrical Infrastructure), $180 \mathrm{MW}$. $3-87$

Table 3-27: Range of Major Costs 3-88

Table 3-28: Engineering and Economic Consulting Reports . 3-90

Table 3-29: WaveConnect System Element Hierarchy. 3-92

Table 3-30: WaveConnect System Infrastructure Top-Level Functional WBS 3-93

Table 3-31: Output Point Statistics for the Central Coast WaveConnect Area 3-97

Table 3-32: Summary of Simulation Cases 3-99

Table 4-1: FERC Pilot License Procedures 4-4

Table 4-2: Significant Federal and State Regulatory Permits and Authorization (partial list)

Table 4-3: Key Environmental Issues Analyzed

Table 4-4: Effects Summary on Marine Mammals Likely to Occur in the HWCP Area

Table 4-5: Effects Summary of the HWCP Project on Invertebrates, Fish and Essential Fish Habitat

Table 4-6: Frequency of HWCP Agency Comments by Type.

Table 4-7: Comment Classification, and Cost and Schedule Implications for Addressing Significant Comments

Table 4-8: Monitoring and Adaptive Management (MAMP) Cost for 5-Year Pilot Project Operation

Table 4-9: Key Biological Resources Jurisdictions 4-36

Table 7-1: 5-MW Pilot Project Cost for Five Years of Operation

Table 7-2: Economic Model Assumptions and Key Inputs for Commercial Projects 


\title{
Acronyms \& Abbreviations
}

\author{
AIR: Additional Information Request \\ ATBA: Area to be Avoided \\ BOEMRE: Bureau of Ocean Energy Management, Regulation and Enforcement \\ CCC: California Coastal Commission \\ CCWC: Central Coast WaveConnect \\ CDFG: California Department of Fish and Game \\ CEQA: California Environmental Quality Act \\ CESA: California Endangered Species Act \\ COE: Cost of energy \\ CONOPS: Concept of Operation \\ CPUC: California Public Utilities Commission \\ CSLC: California State Lands Commission \\ CSWRCB: California State Water Resources Control Board \\ DCPP: Diablo Canyon Power Plant \\ DEIS: Draft Environmental Impact Statement \\ DOD: United States Department of Defense \\ DOE: United States Department of Energy \\ DPLA: Draft Pilot License Application \\ EIR: Environmental Impact Report \\ EMEC: European Marine Energy Centre \\ EMF: Electric and magnetic field \\ ERRP: Emerging Renewable Resource Program \\ ESA: Endangered Species Act \\ FAD: Fish attraction device \\ FBD: Functional block diagram \\ FERC: Federal Energy Regulatory Commission \\ FONSI: Finding of No Significant Impact \\ FPLA: Final Pilot License Application \\ GHG: Greenhouse gas \\ HAPC: Habitat Area of Particular Concern \\ HBMUD: Humboldt Bay Municipal Water District \\ HDD: Horizontal directional drilling \\ HSU: Humboldt State University \\ HVAC: High-voltage alternating current \\ HWC: Humboldt WaveConnect \\ HWG: Humboldt Working Group \\ ICS: Inner Continental Shelf \\ ILP: Integrated Licensing Process \\ ITC: Investment Tax Credit \\ KBO: Klamath Bird Observatory \\ LCA: Lifecycle cost analysis \\ LCOE: Levelized cost of energy \\ MAMP: Monitoring and Adaptive Management Plan \\ MLPA: Marine Life Protection Act
}


MMPA: Marine Mammal Protection Act

MMS: Mineral Management Service (U.S. Department of the Interior)

MND: Mitigated Negative Declaration

MOU: Memorandum of Understanding

MWC: Mendocino WaveConnect

NCF: Net capacity factor

NDBC: National Data Buoy Center

NEPA: National Environmental Policy Act

NMFS: National Marine Fisheries Service

NOAA: National Oceanic and Atmospheric Administration

O\&M: Operation and maintenance

OCS: Outer Continental Shelf

OSU: Oregon State University

OWC: Oscillating water column

OWSC: Oscillating wave surge converter

PG\&E: Pacific Gas \& Electric

PII: Power interconnect infrastructure

POWER: Pentland Orkney Wave Energy Resource Ltd.

PPA: Power Purchase Agreement

PPLP: Pilot Project Licensing Process

PTC: Production Tax Credit

PTO: Power take-off

R\&D: Research and development

RD\&D: Research, development and demonstration

REC: Renewable Energy Certificate

RFI: Request for information

RFP: Request for proposals

ROV: Remotely operated vehicle

RPS: Renewable Portfolio Standard

RSL: Redwood Sciences Laboratory

SAIC: Science Applications International Corporation

SBI: Sea-based infrastructure

SCADA: Supervisory Control and Data Acquisition

SCI: Submarine cabled infrastructure

SMCA: State Marine Conservation Area

SNL: Sandia National Laboratories

SOW: Scope of work

TLR: Top Level Requirements

TRL: Technology Readiness Level

USFWS: United States Fish and Wildlife Service

VAFB: Vandenberg Air Force Base

WEC: Wave energy conversion device

WECoM: Wave energy conversion device manufacturer 


\section{Introduction}

\subsection{Project History and Background}

Pacific Gas \& Electric (PG\&E) has a service area that covers the majority of Northern and Central California, with Pacific Coast access ranging from Humboldt County in the north to Point Conception in Santa Barbara County. This extensive coastline offers large potential for wave power, which involves deploying mechanical devices to convert the kinetic energy of ocean waves into electric power.

PG\&E's original concept for the WaveConnect project was to allow the testing and evaluation of market-ready and near-market-ready renewable ocean energy technologies, or wave energy convertors (WECs), the most successful of which could, in subsequent phases, graduate to longterm power production. PG\&E avoided specifying any particular WEC device in the permit application, but intended to permit and construct a site for full-scale array testing and operation of WECs from several manufacturers, and then to later extend the initial project to full power production if warranted. WEC developers could apply to PG\&E to test their devices at the WaveConnect facility. PG\&E would permit the entire facility and construct the subsea cable and on-shore facilities needed to connect with the wider grid.

In the early 1990s, PG\&E's Research and Development Division produced a report on the wave energy potential adjacent to its service territory along California's coast.1 This report examined the potential for the nascent WEC systems of the time, as well as the resource capacity (Appendix A). That assessment indicated a potential production capacity of 23,000 megawatts (MW) of electricity.

PG\&E began to devote greater effort to investigating the issue in 2004-2007, culminating in an application to the California Public Utilities Commission (CPUC) to assess the potential of wave energy. ${ }^{2}$ In 2006, PG\&E attempted to develop a Power Purchase Agreement (PPA) with Finavera Renewables employing their AquaBuOY technology. The CPUC denied the PPA due to the immaturity of the technology. In its decision the CPUC concluded:

"The Commission finds that the project is not viable, Finavera's bid does not compare favorably to other bids in PG\&E's 2006 solicitation and the contract price is not reasonable.... Through this PPA, PG\&E wants to assist in accelerating the commercialization of this technology. The Commission supports $P G \& E$ 's efforts to commercialize new technologies; however, considering that this particular technology is in such an early stage, we find that

\footnotetext{
${ }^{1}$ PG\&E Ocean Energy Technology Information Module (Advanced Energy Systems), Report 007.6-91.4, September 30, 1991.

${ }^{2}$ CPUC 07-07-015, July 18, 2007
} 
approving this PPA at this time is not the best way to move this wave technology toward commercialization."

In parallel, PG\&E began the WaveConnect Program in February 2007, with the filing of two Federal Energy Regulatory Commission (FERC) Preliminary Permit Applications to develop marine hydrokinetic (wave energy) facilities off-shore near Fort Bragg in Mendocino County (Mendocino WaveConnect, or MWC) and Eureka in Humboldt County (Humboldt WaveConnect, or HWC). The project PG\&E proposed in its February 27, 2007 application was to consist of:

- Eight to $200 \mathrm{WEC}$ devices having a total installed capacity of $40 \mathrm{MW}$

- A 40-kilovolt $(\mathrm{kV})$ submarine transmission cable

- Integrated generators

- Anchoring devices

- An on-shore transmission line

- Appurtenant facilities.

The project would generate an estimated 100 gigawatt-hours (GWh) annually. FERC issued the permits on March 13, 2008 and specified that they were for investigating the feasibility of the projects, including securing the necessary data to determine the viability of the proposed project and to prepare a license application.

The filing of these permits met with some opposition. Some local groups quickly opposed FERC's jurisdiction over this matter, including Mendocino and the City of San Francisco, which referred to PG\&E's efforts as "site-banking." FERC itself originally felt that the applications were too vague in describing the technology, and covered too much area. In addition, FERC itself had not finalized all its rules concerning this new technology, and would not even publish its pilot proposal until late 2007. Concern at the time was that the rule offered no advantage over traditional license processes. ${ }^{3}$

In a portent of issues that would emerge later, the Department of the Interior Office of Environmental Policy and Compliance, on behalf of the National Marine Fisheries Service $(\mathrm{NMFS})^{4}$, commented shortly after PG\&E filed its permit applications:

For new technologies, data needs may be considerably greater than for traditional hydropower technologies, and may require characterization of the baseline environment and uses that could potentially conflict with a full-scale development of a project. Requiring a permit holder to obtain whatever environmental permits federal, state, and local authorities may require before

\footnotetext{
${ }^{3}$ In practice, developers have no incentive to apply for a pilot license unless it saves a substantial amount of time and expense over the cost of a full license process. http://lawofficesofcarolynelefant.com/renewablesoff-shore/?p=98

${ }^{4}$ Review of Notice of Application for Preliminary Permit, PG\&E Humboldt WaveConnect project, FERC No. 12779-000, Humboldt County, California. June 15, 2007.
} 
conducting any studies or "land-disturbing" activities is questionable, if these processes do not include adequate opportunity for public involvement, agency consultation, consideration of cumulative impacts, and full removal of test apparatus and site restoration. "Land disturbing" should include activities that occur on the bed and banks of navigable waters. Demonstration projects that occur during the period of a preliminary permit should be fully removed and sites restored if the project is not licensed within a fixed period of time.

At the same time, the U.S. Minerals Management Service (now called the Bureau of Ocean Energy Management, Regulation and Enforcement, or BOEMRE) continued its interagency dispute with FERC over hydrokinetic issues, increasing the regulatory uncertainty over applications on the Outer Continental Shelf (OCS) beyond the $5.6 \mathrm{~km}$ boundary. BOEMRE claimed complete jurisdiction, protesting FERC's licensing stance and stating that federal law and interim policies gave it complete jurisdiction over any hydrokinetic leases on the $\mathrm{OCS}^{5}$. These interim policies stated that any leases within their jurisdiction must be competitively awarded, and that BOEMRE must handle the licensing as well. FERC issued a substantial denial of BOEMRE's claims by October 2008, and BOEMRE and FERC entered into negotiations to determine each agency's authority following a Memorandum of Understanding (MOU) that FERC drafted and submitted to BOEMRE in late 2008 and early 2009.

During this time, there was a general free-for-all for permit applications to FERC and BOEMRE. Ocean Power Technologies' (OPT) application to FERC for a 20-MW facility for the area around Humboldt arrived the day after PG\&E's application was received, and was denied due to it being no more substantive or detailed than PG\&E's. Several different WEC manufacturers (WECoMs) had technology offerings that appeared ready for market, including Orecon, Energtech, and Pelamis, and which seemed poised for application. Other groups that applied for permits along the California coastline at or near this time included Chevron, Greenwave and Sonoma County, among others. This was before the economic collapse in 2008, and investors and others were bullish on wave power technology and its possibilities. Additionally, there was a belief that cap-and-trade carbon-mitigation policies would make such technologies more cost effective, with both U.S. presidential candidates promising some level of cap-and-trade.

It is noted that WaveConnect was not the world's first attempt to establish a hydrokinetic facility. Several full-scale wave energy test sites with grid connections are currently in operation or are being developed, including the European Marine Energy Centre (EMEC) in Stromness, Orkney Islands, Scotland, which is an operational test site for wave power devices. Two additional sites, including WaveHub under construction near Hayle in southwest England, and another site on the west coast of Ireland, are planned. In addition, the Marine Institute has operated a one-third-scale non-grid-connected test facility in Galway Bay, Ireland for several years. The Limpet, an oscillating water column device built on shore, has been in operation for over a decade. Other WEC installation openings seemed imminent off the coast of Spain and Portugal, featuring Pelamis WEC devices.

\footnotetext{
${ }^{5}$ Request of U.S. Department of the Interior for rehearing of Commission's March 13, 2008 Order Issuing Preliminary Permit under P-12781-001 and P-12779-001. File number 20080414-5037(19094037).
} 
By mid-2008, PG\&E had applied for $\$ 1.2$ million in federal grants from the Department of Energy (DOE) to fund the initial environmental and engineering efforts for a WaveConnect project, conditional on matching funds. PG\&E at that time approached the CPUC to apply for the matching funds necessary to complete a first permitting and initial engineering phase. In early $2009^{6}$ the CPUC authorized PG\&E to examine the possibility of a wave power system off the coast of California. The CPUC found:

“...that there is sufficient justification for PG\&E's WaveConnect project. California is singularly situated to harvest this potentially enormous supply of baseload renewable generation. While there are a number of projects moving forward globally, no meaningful ocean energy project is currently in production along California's coast. In order to ensure that ratepayer funds are spent on the most promising and most effective technologies, a means of testing competing options should be established. Accordingly, this decision authorizes PG\&E to spend up to $\$ 4.8$ million in funds to cover the expenditures necessary to pursue WaveConnect."

The initiative seemed timely. By California law, 20\% of the state's energy portfolio was to be produced by renewable resources by $2010^{7}$, with a $33 \%$ renewable energy mandate ${ }^{8}$ by 2020 . To meet these aggressive targets, a wide range of energy sources must be considered. WaveConnect was PG\&E's initial wave power initiative, and the first major effort by a U.S. utility to plan and create the infrastructure necessary to evaluate and later deploy wave power technologies.

WaveConnect was to be funded in three stages. The first stage included all of the feasibility and licensing work for the two North Coast wave sites, which was estimated to cost $\$ 6$ million over three to five years. Those costs were to include fees for consultants, legal services, engineering and technical consultants, and environmental studies. The second stage, estimated in 2008 to cost between \$15-\$20 million per site over two to four years, included development of infrastructure, undersea cabling, and the installation of the initial WEC devices. During Stage 3, the most promising WEC devices were to be deployed in larger quantities of up to $40 \mathrm{MW}$ per site and connected to the grid.

The immediate aim of WaveConnect was not to develop a commercial generating facility to compete against other project developers, but to evaluate the feasibility of extracting energy from ocean waves. Given the uncertainties involved, PG\&E understood that a commercial plant may or may not be proposed. California legislation SB 1078, SB 107, and AB 32 encourage reasonable and cost-effective means to increase renewable development and mitigate greenhouse gas (GHG) emissions. PG\&E's feasibility effort was to include the issues summarized in Table 1-1. On that basis, the CPUC believed it was important to begin expanding California's knowledge and understanding of whether wave energy was a reasonable means for achieving initial feasibility goals now rather than waiting for the market to develop. This was logical, as

\footnotetext{
${ }^{6}$ Decision 09-01-036, January 29, 2009

7 PG\&E and other utilities in California were not able to meet the renewable portfolio standard by the required end date of 2010, although PG\&E came close at 17.7\%. Many of the contracts developed prior to the economic collapse of 2008 did not come to fruition, as the companies promising them failed to achieve funding.
}

8 California Executive Order S-14-08 
California's regulatory regime is significantly different than other states'. CPUC approval of the WaveConnect project was a means of furthering wave power development for California.

Table 1-1: Feasibility Efforts to be Taken under CPUC Funding

\begin{tabular}{|c|c|c|c|}
\hline $\begin{array}{c}\text { Year } 1 \\
\text { Initial Assessment }\end{array}$ & $\begin{array}{l}\text { Year 1-continued } \\
\text { Detailed Assessment }\end{array}$ & $\begin{array}{c}\text { Years 2-3 } \\
\text { License Application } \\
\text { Development }\end{array}$ & Years 4-5 \\
\hline $\begin{array}{l}\text { Begin discussions with } \\
\text { stakeholders }\end{array}$ & $\begin{array}{l}\text { Continue detailed } \\
\text { discussions with } \\
\text { stakeholders }\end{array}$ & $\begin{array}{l}\text { Continue discussions } \\
\text { with stakeholders }\end{array}$ & $\begin{array}{l}\text { Continue environmental } \\
\text { and other studies to } \\
\text { support license } \\
\text { application }\end{array}$ \\
\hline $\begin{array}{l}\text { Begin competitive } \\
\text { selection process }\end{array}$ & $\begin{array}{l}\text { Conduct detailed } \\
\text { resource analysis }\end{array}$ & $\begin{array}{l}\text { Finalize technology } \\
\text { selection and design }\end{array}$ & $\begin{array}{l}\text { Anticipate FERC } \\
\text { development license } \\
\text { granted }\end{array}$ \\
\hline $\begin{array}{l}\text { Begin wave resource } \\
\text { studies }\end{array}$ & $\begin{array}{l}\text { Identify and quantify site } \\
\text { constraints }\end{array}$ & $\begin{array}{l}\text { Perform technology } \\
\text { testing }\end{array}$ & \\
\hline $\begin{array}{l}\text { Begin initial siting } \\
\text { analysis }\end{array}$ & $\begin{array}{l}\text { Develop construction } \\
\text { and interconnection } \\
\text { strategy for potential } \\
\text { sites }\end{array}$ & $\begin{array}{l}\text { Continue environmental } \\
\text { and other studies } \\
\text { needed for license } \\
\text { activities }\end{array}$ & \\
\hline $\begin{array}{l}\text { Identify preliminary } \\
\text { shortlist of deployment } \\
\text { sites within permitted } \\
\text { area }\end{array}$ & $\begin{array}{l}\text { Begin WEC device } \\
\text { evaluation }\end{array}$ & File license application & \\
\hline \multirow[t]{4}{*}{$\begin{array}{l}\text { Identify preliminary } \\
\text { studies and begin } \\
\text { preliminary work on } \\
\text { those studies }\end{array}$} & $\begin{array}{l}\text { Continue and expand } \\
\text { environmental studies }\end{array}$ & $\begin{array}{l}\text { Possibly install limited } \\
\text { number of test devices } \\
\text { to support licensing } \\
\text { activities }\end{array}$ & \\
\hline & $\begin{array}{l}\text { Develop energy yield } \\
\text { analysis }\end{array}$ & & \\
\hline & $\begin{array}{l}\text { Develop initial financial } \\
\text { models }\end{array}$ & & \\
\hline & $\begin{array}{l}\text { Compile information for } \\
\text { and file NOI/PAD }\end{array}$ & & \\
\hline
\end{tabular}

Additionally, WaveConnect would provide the CPUC with a way to test or assess the relative viability of wave power technologies, providing useful information about the commercial viability of wave energy. The CPUC were particularly interested in investigating the potential of a promising renewable option such as ocean energy as renewable baseload generation, which California is particularly well-situated to cultivate. CPUC's funding was designed to cover costs associated with Year One, and the commission would later consider additional funding for Year Two through Year Five. 
By early 2009, PG\&E had to make a decision concerning the licensing route it would take. The interagency issues associated with FERC and BOEMRE, as well as the shortened time frame and concern that reapplying for a new permit or following the path of a FERC Integrated Licensing Process (ILP) could open up PG\&E to having its permits removed or overtaken, caused PG\&E to reconsider the 40-MW project and follow the limited FERC Draft Pilot License Application process, as reported on February $27,2009^{9}$. The pilot license was more limited, and placed a severe restriction on the project that was not completely understood at that time. However, it did seem to offer a shortened timeframe and a less expensive process, given the uncertainties of the environmental and technical issues. The issuance of the FERC/BOEMRE MOU on April 8, 2009 further restricted the project, as FERC asked PG\&E to relinquish its permit area on the OCS. Although this gave PG\&E the opportunity to re-apply for a new permit on the OCS with BOEMRE, it would have delayed the project by several years. Additionally, the newly adopted rulemaking regarding BOEMRE's role in leasing was still not well understood, and the FERC pilot license seemed attractive due to its streamlined nature. Consequently, in July 2009 the Humboldt WaveConnect permit area was reduced to inside the OCS, with only FERC as the major federal regulatory agency.

With funding in place, PG\&E assembled its team of internal support and external contractors, including SAIC as the primary engineering support and $\mathrm{CH} 2 \mathrm{M}$ Hill as the environmental and permitting consultant. Discussions with SAIC caused PG\&E to reconsider its Mendocino permit due to the harbor being incapable of receiving large WEC devices ${ }^{10}$. PG\&E surrendered its Mendocino Permit in June 2009.

Through the end of 2009 until March 2010, a series of meetings was held with local agencies and stakeholders that culminated in selecting a final location for the Humboldt WaveConnect facility, but also resulted in an implicit promise that the facility would eventually be removed, as the FERC pilot process suggested. This was another critical juncture in the project, removing WaveConnect even further from the original intent of an initial feasibility effort that could be expanded to $40 \mathrm{MW}$.

In October 2009, PG\&E released its RFI. Also in October, PG\&E met with CPUC staff to give an update of the project and inform the commission that a second site had potentially been chosen to replace Mendocino. The CPUC gave PG\&E preliminary permission to investigate the Central Coast site near Vandenberg Air Force Base (VAFB). CPUC expressed satisfaction over the project's progress, including approval of the soon-to-be-filed draft FERC application and initial investigation into the Central Coast WaveConnect (CCWC) site. The CPUC requested that PG\&E return to update the additional costs that would be incurred with the Central Coast site, and to provide an overall update on the project as a whole. An MOU was developed with VAFB to investigate the potential to assist them in meeting the U.S. Department of Defense's (DOD's) renewable energy goals using wave energy. A 100-MW facility was envisioned as a first step, which would have fulfilled a majority of VAFB's electricity demand.

\footnotetext{
${ }^{9}$ Humboldt Wave Connect Project, Six-Month Progress Report.

${ }^{10}$ This later turned out not to be a consideration for all WEC devices, as will be discussed in the Engineering Technology Evaluation chapter.
} 
At a peer review conference in November 2009, PG\&E requested from DOE an additional \$1.6 million to move forward with the Central Coast site. DOE stated that there would be no additional funds in the 2010 time period, but that future funding was a strong possibility. PG\&E later informally informed DOE that the CCWC project was on a go-slow approach, pending CPUC approval and possible additional DOE funding. None was forthcoming.

On March 1, 2010, PG\&E officially submitted its Draft Pilot License Application (DPLA) to FERC. The entire DPLA is found as Appendix B, and draft Monitoring and Adaptive Management Plans (MAMPs) as developed through the agency stakeholder interaction process prior to the DPLA submittal are found in Appendix C. Comments received from the agencies prior to the DPLA submittal were contradicted by their strong comments on the plan itself (Appendix D). For example, agencies that had agreed during discussions to certain courses of action reversed course, requiring efforts that were well beyond the scope of a simple pilot project. Many of the MAMPs were abandoned, with a request for greater monitoring and baselines. Some objections were unanswerable under the California Environmental Quality Act (CEQA), which requires that any possible environmental impact be completely mitigated.

Had PG\&E located WaveConnect the OCS, BOEMRE would have used its Draft Environmental Impact Statement (DEIS) as a basis and performed a National Environmental Policy Act (NEPA) assessment on the project. The NEPA does not require complete mitigation for every possible unknown occurrence, and in retrospect would have offered an easier route than CEQA to a final lease and license for new technologies of uncertain impact. Further meetings in the summer of 2010 between PG\&E and the involved agencies confirmed that the only permit process that was realistic and would not result in unacceptable project costs or removal of the WaveConnect facility after five years would involve relocation to the OCS, which would have required an additional \$3 million in application fees to BOEMRE. Although much of the work developed for the DPLA could have been used in an application to BOEMRE, the application would still have had to be rewritten in light of the substantial agency comments, likely requiring at least an additional \$500,000. In late October 2010, PG\&E reported back to the CPUC on the issues associated with the site and technology. The CPUC then withdrew $\$ 1.4$ million of the remaining funding, crippling the project. With no additional funds, the Humboldt WaveConnect project was cancelled. By early 2011, PG\&E also surrendered Central Coast permit due to lack of funds.

\subsection{Project Site Location and Description}

Site selection is intertwined with complex issues of resource availability, environmental impacts, stakeholder response, and consideration of alternatives, all of which have to be presented to FERC as part of any larger application package. PG\&E made its initial decision to apply for a permit by concentrating on its north coastal area due to an excellent match in wave energy potential and a corresponding electrical demand curve. A number of sites along California's coastline were evaluated by PG\&E. Two sites in particular were initially identified as primary locations suitable for the WaveConnect project: (1) the coastline adjacent to Fort Bragg in Mendocino County, and (2) the coastline of Humboldt Bay north of the Eel River estuary and west of Eureka in Humboldt County. Eureka and the surrounding areas are somewhat isolated from the PG\&E distribution system as a whole, and so the potential production from a wave 
power facility would be a good match. The Eureka area has excellent landfall and cabling considerations and good proximity to transmission and distribution systems, as well as good port facilities and infrastructure. Consequently, that site was chosen to host the Humboldt WaveConnect project.

Figure 1-1 shows the HWC site plan, and Figure 1-2 details its cable arrangement and on-shore facilities. The proposed site for all HWC off-shore system components, cables, anchors, and navigational aids was within state territorial waters, generally defined as within $3 \mathrm{~nm}(5.6 \mathrm{~km})$ from shore. The WEC deployment area consisted of a rectangle approximately $3.7 \mathrm{~km}$ long and $0.9 \mathrm{~km}$ wide oriented parallel to the coastline. Electrical transmission cables would have extended southwest from the WEC deployment area, remaining in water deeper than $36 \mathrm{~m}$ until reaching a location opposite the proposed cable shore landing site. ${ }^{11}$ At that point, the cables would have turned to the southeast, toward the shore. The generator tie-line would have connected with the existing PG\&E Fairhaven Substation.

The HWC would have comprised:

- WECs including multi-point catenary moorings and anchors

- Marker buoys, navigation lights, and environmental monitoring instruments

- Submarine electrical cables extending underground on-shore to land-based power conditioning equipment

- An aboveground transmission line and interconnection to the electrical grid

- Data acquisition and telemetry equipment

- Security and safety equipment.

The boundaries of the WEC deployment area would have been marked with appropriate lighting and annotated on nautical charts. Marker buoys would have provided a physical on-water designation of potential hazards, operational areas, and safe passage locations. Typical marine activities that the HWC must consider are ship navigation, vessel anchoring, and fishing.

\footnotetext{
${ }^{11}$ The cable routing was planned in conjunction with representatives of the crabbing and fishing communities through the HWG. Crab fishers indicated that they would prefer that the cable run be located in water $36 \mathrm{~m}$ or deeper, because the majority of the crab fishing takes place at depths shallower than $36 \mathrm{~m}$. PG\&E agreed to this routing in order to avoid conflicts that could arise if crab fishing gear were to become entangled in exposed submarine cables. (Although the cables will be buried, the Humboldt Bay Littoral Cell is a dynamic sediment environment, and it is possible that even buried cables could become exposed.). Negotiations as to the exact area of the site were hampered by the release of the area in the OCS and the use of the pilot license.
} 
PG\&E WaveConnect Program, Final Report

Introduction

DOE/GO/18170-1

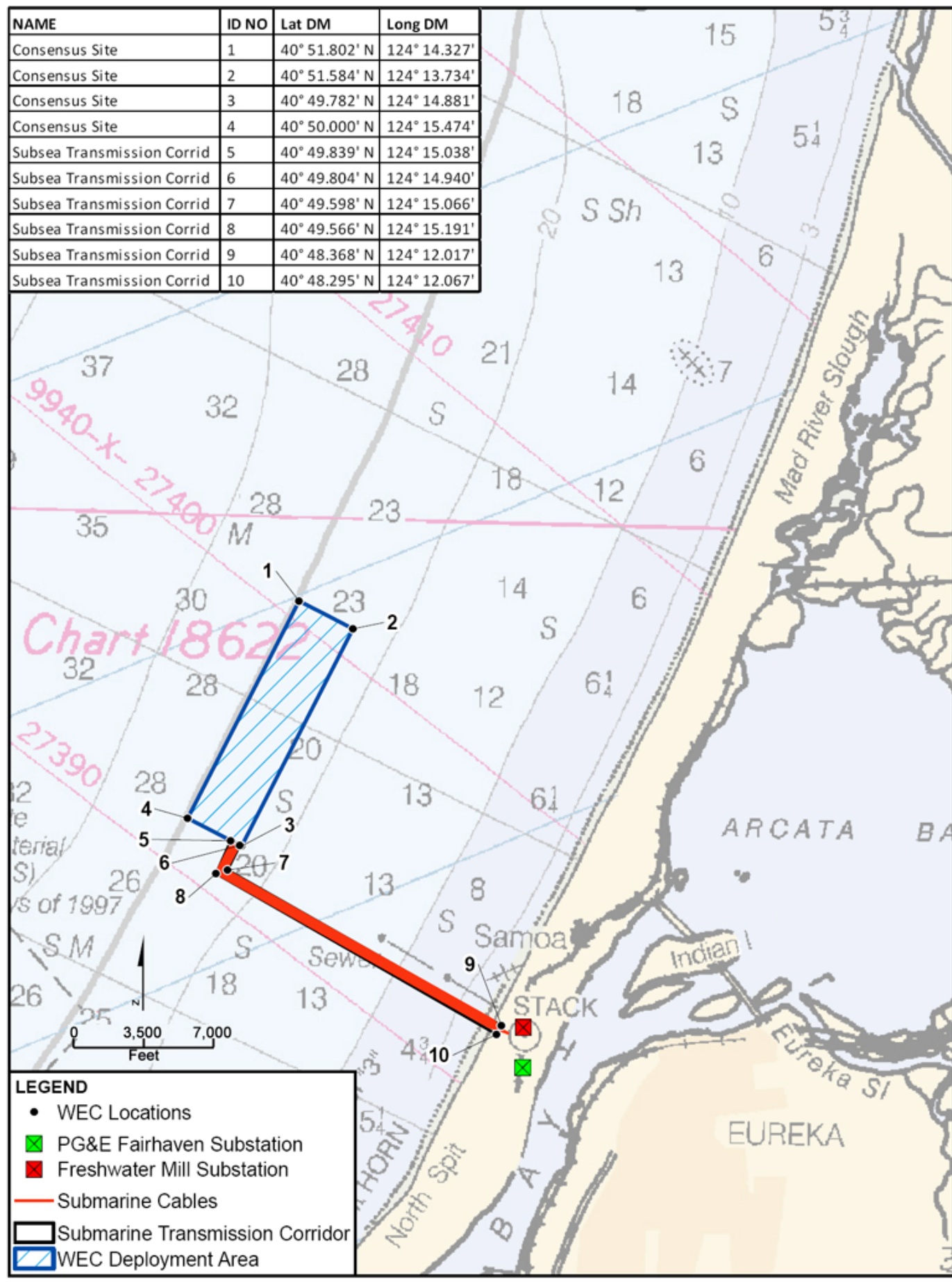

FIGURE 2

PROJECT SITE PLAN

WAVECONNECT PROJECT

This map was compiled from various scale source data and maps

Figure 1-1: HWC Project Site Plan 


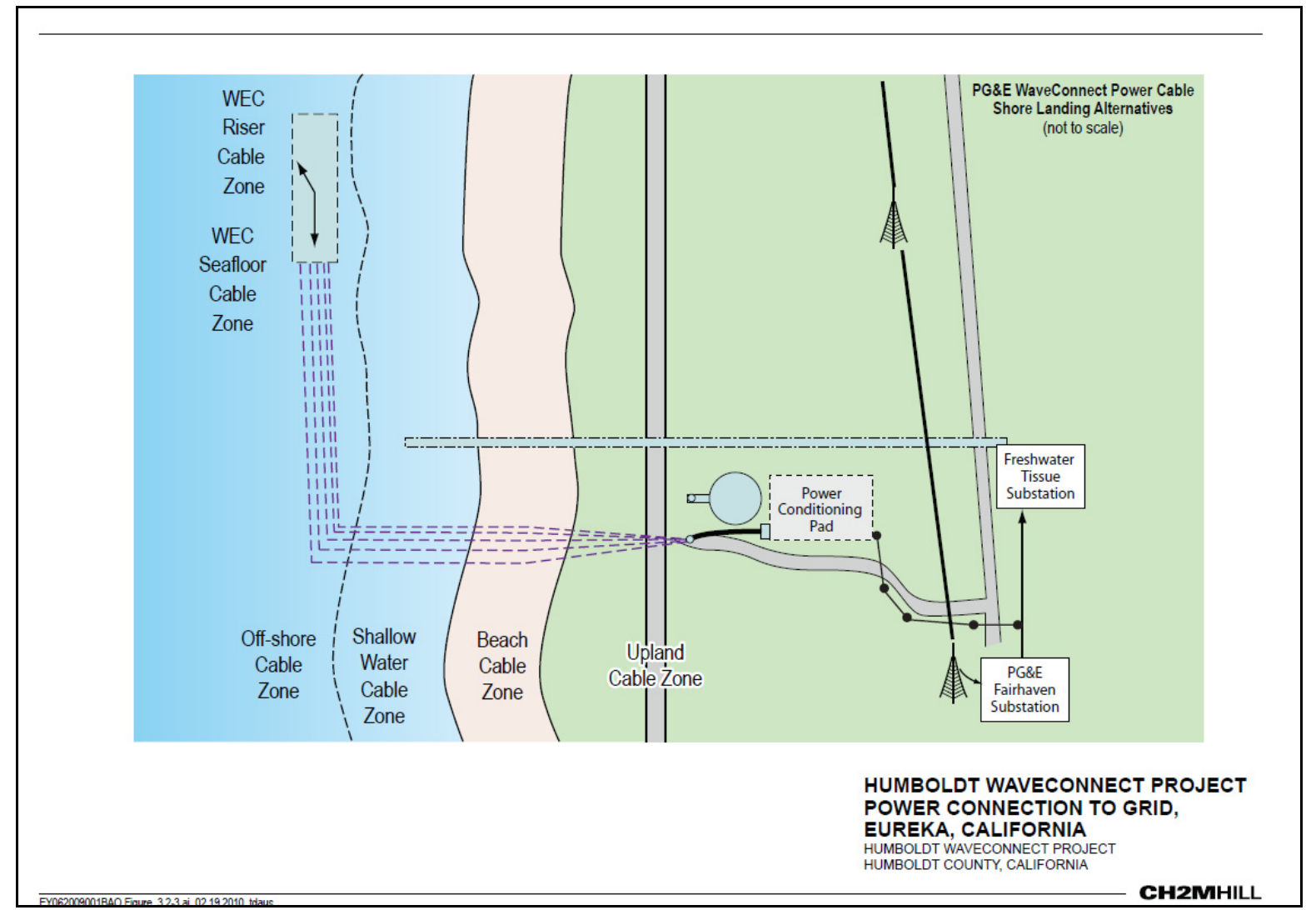

Figure 1-2: HWC Power Connection to Grid

\subsection{Overview of Wave Resources}

There are more than $800 \mathrm{~km}$ of useable wave energy resources along the California coast. Areas considered unusable due to environmental or commercial concerns exist around the mouth of San Francisco Bay and in the Monterey Bay Area. Areas south of PG\&E's service territory (Santa Barbara County to San Diego County) are considered unusable due to the reduced wave energy that would be uneconomical to exploit with existing WEC technologies.

This makes the combined average annual deep-water wave energy flux along the PG\&E territory equal to 20,000 MW. Assuming a 20\% conversion efficiency and $80 \%$ device availability, an average of $3.2 \mathrm{GW}$ or $28 \mathrm{TWh} /$ year could be extracted from California's wave energy resource. In 2005, California's total electric energy consumed was $272 \mathrm{TWh}$. In other words, it is theoretically possible to meet about $10 \%$ of California's electricity needs with wave power available along PG\&E's service territory.

\subsubsection{Wave Formation}

Wave formation is a complex interaction among waves that have already been generated, sometimes hundreds of kilometers away, and local wind patterns (Figure 1-3). Water particles 
are moved from their position by the wind by frictional drag forces, and then returned to their original position by gravity, which is the restoring force. These are called gravity waves. The result is a circular motion by the water particles. Energy is transported by a wave oscillation rather than through the water itself, which does not move like a current in a stream.

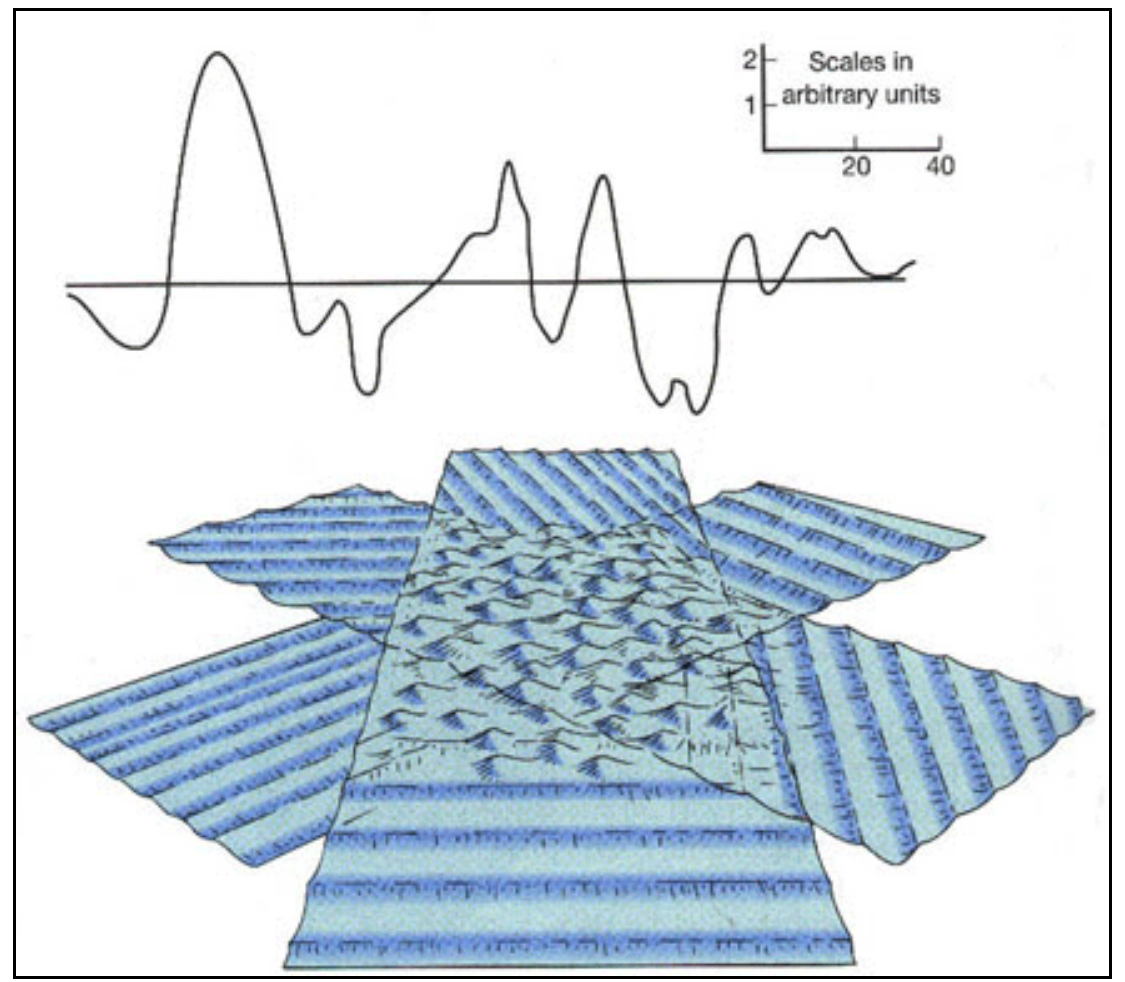

Figure 1-3: Interaction of Multiple Wave Trains from Various Directions

There are many good resources that explain the movement of waves in more detail. ${ }^{12}$ Waves are defined by their wave heights and average period, with the significant wave height $\left(\mathrm{H}_{\mathrm{s}}\right)$ being defined as the average of the highest one-third of waves in a group. The size of the waves resulting from the energy transfer is governed by the velocity of the wind (W), the fetch (F) or distance over which the wind blows, and the duration (D) of time that the wind blows. These are maximum wave heights, which depend upon a large fetch, sustained duration of wind, and a depth of approximately $300 \mathrm{~m}$ for maximum heights to be generated ${ }^{13}$.

For lower wind speed (e.g. $10 \mathrm{~m} / \mathrm{s}$ ), it only requires approximately $300 \mathrm{~km}$ to reach a fully developed wave height of $3 \mathrm{~m}$. To form larger wave heights, extreme sustained winds over thousands of kilometers and multiple days are necessary. These are much rarer events that would be considered comparable to a 100 -year-plus storm.

\footnotetext{
${ }^{12}$ http://www.uwgb.edu/dutchs/EarthSC102Notes/102Marine\%20Geology.HTM

${ }^{13}$ The relationship between the fetch, the duration, and the wind speed can be explored using Adobe Flash at the PBS Web Site, “The Savage Seas” http://www.pbs.org/wnet/savageseas/multimedia/wavemachine.html.
} 
Waves lose energy in the ocean as well. The drop-off is rapid for larger waves, which can lose up to $50 \%$ of their height in $1000 \mathrm{~km}$ if there are no sustaining winds. Since the ocean effectively acts as a large integrator of wind energy, there will always be waves that are losing energy to dispersion and angular spreading while gaining energy from local winds.

In shallow water, waves lose much energy through frictional interaction with the sea floor bottom. Larger waves are reduced at greater depths, so that the largest waves with the greatest energy begin to be dissipated long before they reach the coast. Steeper coastlines have less time to reduce these waves, and therefore larger waves with more energy can hit the shore. Where the seafloor is shallow and extends greater distances, these larger waves are more completely reduced. Islands and coastline geometry can also act to reduce wave energy, as can be seen in Figure 1-4, which shows modeled shadowing by the Channel Islands and Point Conception on the California coast. Such shadowing is why the wave regime there is not as economically attractive as it is along other portions of the California coastline.

\subsubsection{Wave Energy in California}

Wave power density is defined as the flux of energy across a vertical plane intersecting the sea surface and extending to the depth of no sub-surface orbital motion (which is half the wavelength of the longest harmonic component). For a 16-second wave, this depth is $200 \mathrm{~m}$, which is the approximate depth of the continental shelf edge. The energy contained within the wave drops off in an exponential fashion, so that the majority of the energy is concentrated near the ocean surface.

If wave energy is extracted from some volume of the surface, that energy is reduced in the "downstream" wave regime. Figure 1-5 shows an example of this, with choppier waves being smoothed out by the WEC device Poseidon ${ }^{14}$.

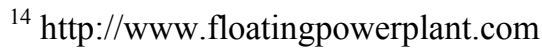




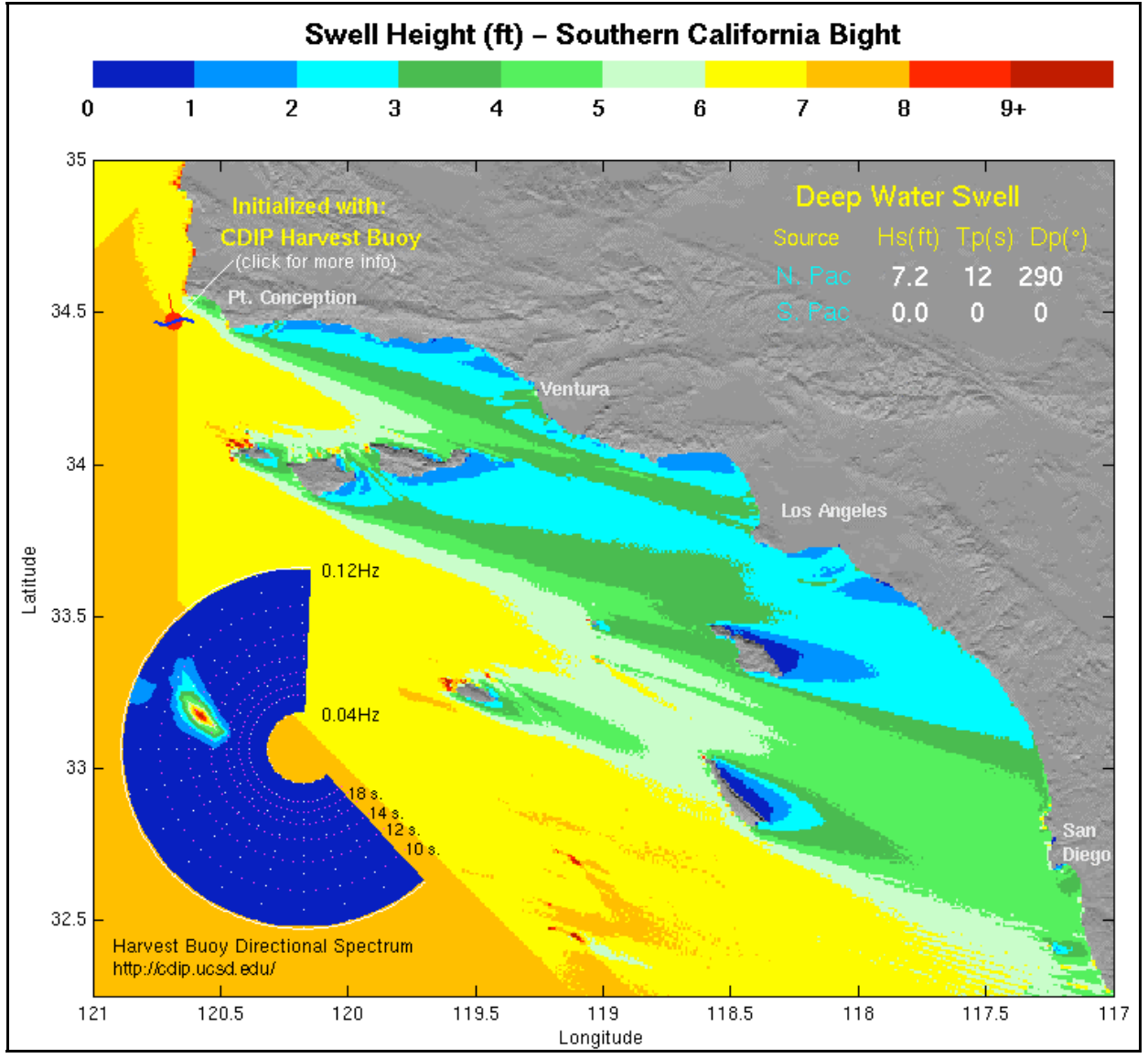

Figure 1-4: Wave Shadowing Caused by the Channel Islands in Southern California

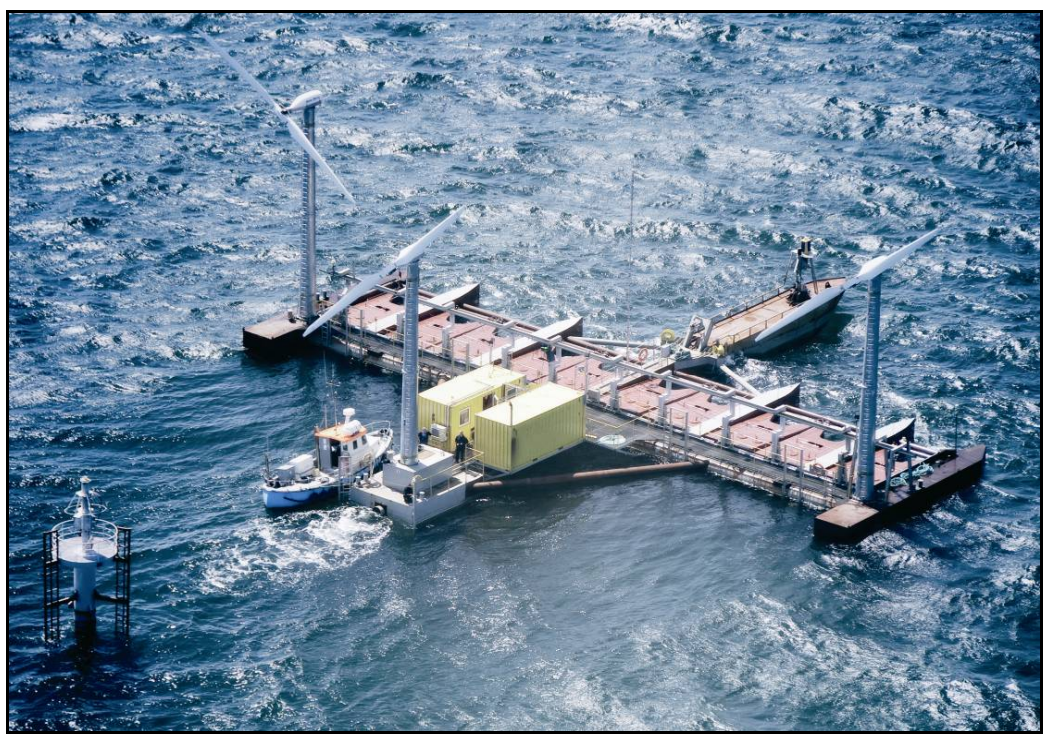

Figure 1-5: Wave Depletion behind Poseidon WEC 
Compared to the wave energy potential of the rest of the world, California's resources can only be described as average (Figure 1-6). Northern Europe has substantial wave energy resources, meaning that, excluding considerations of the survivability costs associated with a more extreme environment, the potential energy extraction per meter is significantly greater. Figure 1-7 shows that the wave potential along the California coast is, on average, greater than $27 \mathrm{~kW} / \mathrm{m}$ along all of PG\&E's service territory.

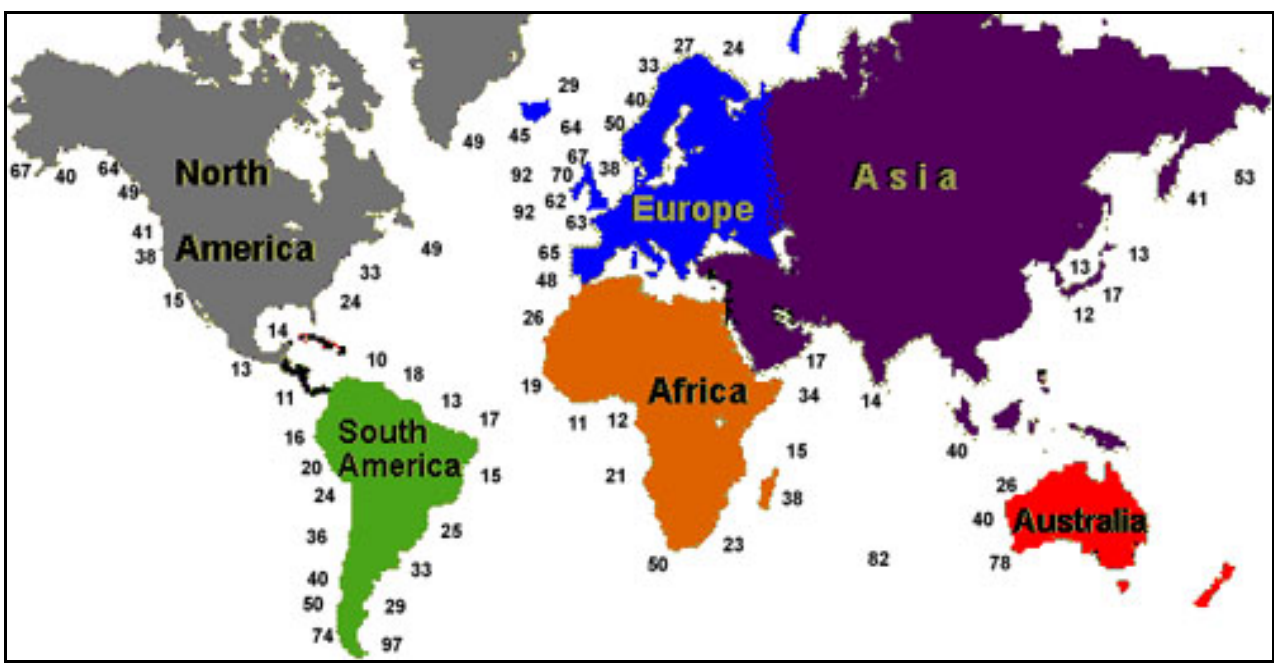

Figure 1-6: Wave Power Worldwide (in units of kW/m)

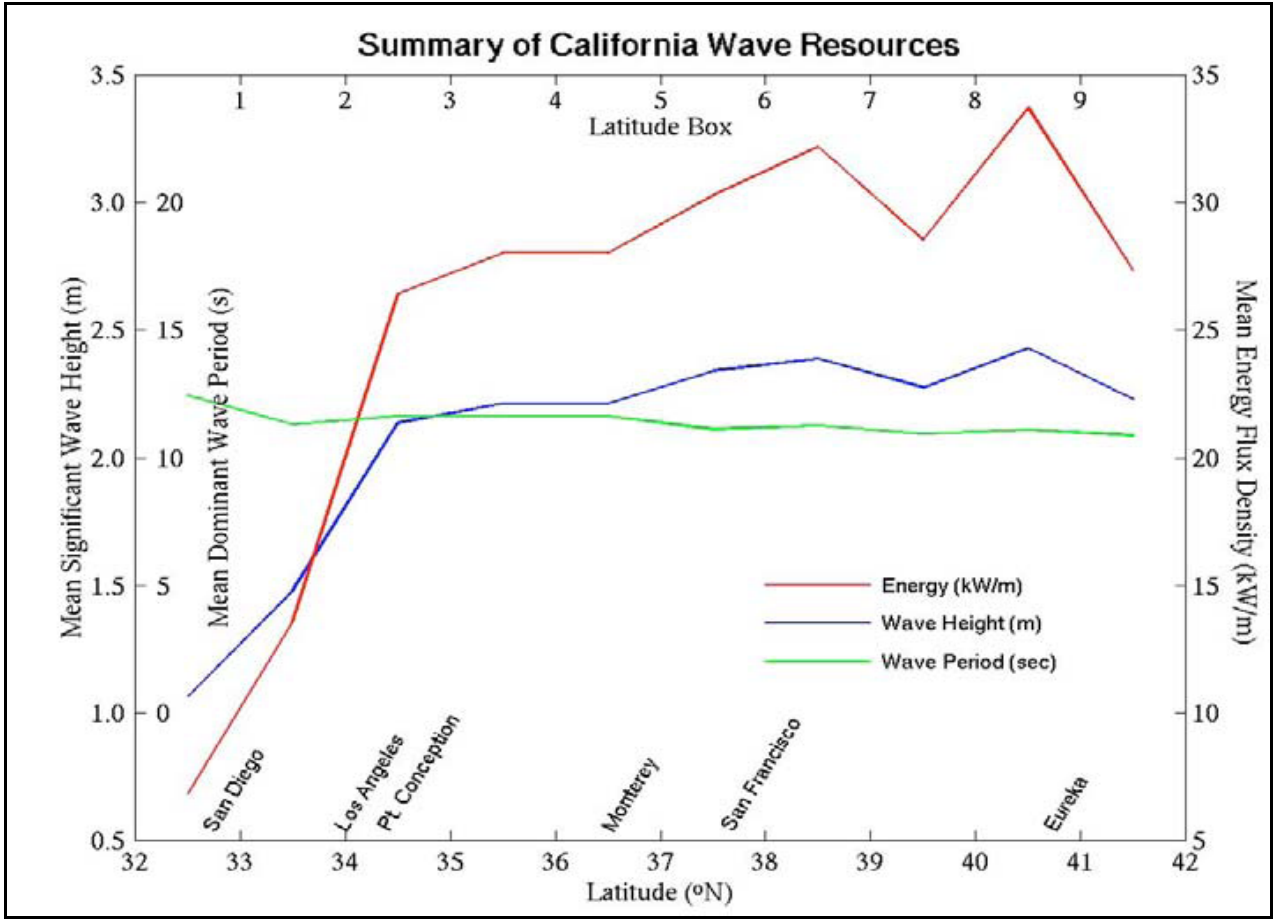


Figure 1-7: Average Wave Power Found along the California Coast (California Energy Commission, 2007) ${ }^{15}$

However, Figure 1-8, which graphs the wave energy potential near Eureka, California, shows that for $50 \%$ of the time, the average is closer to $18 \mathrm{~kW} / \mathrm{m}$. This is representative of the available energy along the California coast during the peak demand summer months. A system that could economically harvest this energy resource could be successful in California. The challenges involved will be discussed in later chapters.

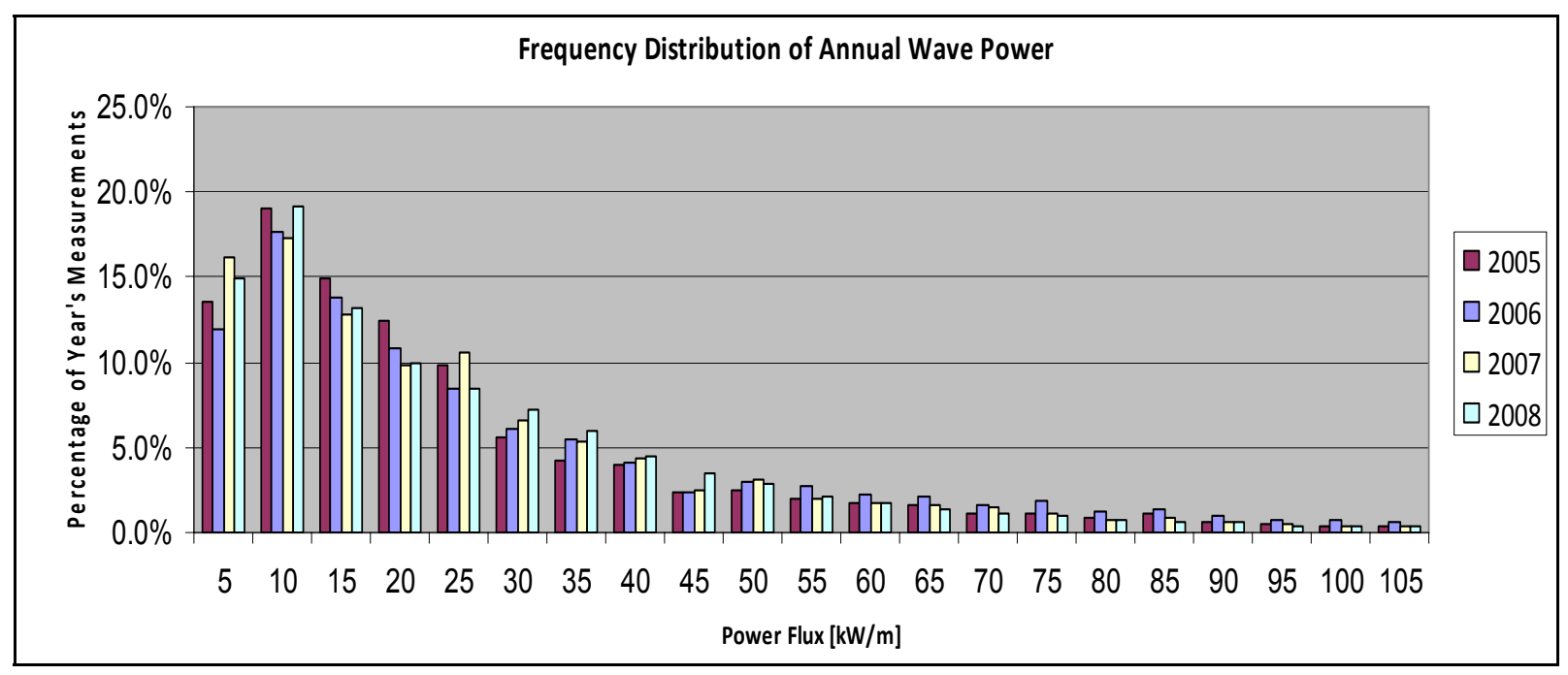

Figure 1-8: Wave Power Available at Eureka, California

\subsection{Technology Overview}

As part of the effort to understand the state of the industry, PG\&E developed a Request for Information (RFI) that was sent to all major WEC manufacturers and posted on the PG\&E WaveConnect website. ${ }^{16}$ The RFI was intended to solicit pertinent information about WEC equipment and WECoMs to determine the most qualified WEC systems available to the pilot project.

The technical specifications split the system into two major responsibility areas. Responsibility for interconnects, cable landing, and tie-ins to the PG\&E grid rested with PG\&E. The manufacturers were responsible for the WEC devices and power conditioning. PG\&E would be responsible for managing the installation of the system, as well as acquiring all needed regulatory permits. PG\&E was to be the sole and exclusive interface for all stakeholder interaction including the environmental and regulatory permitting, with support from the successful suppliers. This included interaction with all pertinent California and federal agencies,

\footnotetext{
${ }^{15}$ California Ocean Wave Energy Assessment DRAFT REPORT. Publication \# CEC-500-2006-119, May 2006 http:/www.energy.ca.gov/2006publications/CEC-500-2006-119/CEC-500-2006-119-D.PDF

${ }^{16} \mathrm{http}: / / w w w . p g e . c o m / w a v e c o n n e c t /$
} 
including the CPUC. As the RFI stated, " $P G \& E$ 's efforts will accelerate entry into California's market and should enable the highest probability of business success for PG\&E's WECS suppliers."

The specifications called for up to five 1-MW transmission cables (with one acting as a spare), each rated at $12 \mathrm{kV}$. It was up to the manufacturers to decide how they wanted to condition and transmit the power. Part of the reason for this was a change in focus to a pilot project. As the WaveConnect project evolved, it became clear that this was not an optimum solution.

The RFI requested general company information as well as detailed technical specifications. From more than 50 solicitations, PG\&E received responses from 16 firms. Many of the respondents had not tested their devices in the water at large scale (at least $25 \%$ of full scale), and their devices were either hypothetical or very early stage. PG\&E determined that of the initial respondents, only eight met the criteria of having a device that was close enough to market to potentially include in the final site plans to FERC. Of these, only a few stated that they could provide a device in the immediate future. Most felt that a PG\&E licensing effort and collaboration would enable them to acquire capital for their devices.

Part of the challenge of developing and demonstrating wave power technologies is that, unlike with wind or solar power, there is limited nearby grid infrastructure for taking power from the offshore generators. Infrastructure to interconnect with the grid may cost many millions of dollars, along with additional costs associated with regulations and permitting. An additional challenge is the limited amount of reliable data on technologies, performance and risks of the devices.

\subsubsection{Technology Types}

The RFI respondents included WECoMs whose devices are based on the four best-known and most technologically advanced types of WEC design, including attenuators, point absorbers, floating oscillating water columns, and oscillating wave surge converters (OWSC).

Each type, with representative examples from device manufacturers, is described in detail in Chapter 3. WEC dimensions vary, and depend on the type of design employed. Figure 1-9 shows how a mix of representative devices might have been arranged at the HWC site, with the dashed green outlines indicating the watch circle for each device, the " $\mathrm{Y}$ " shapes representing mooring lines, and the dashed gray and red lines indicating umbilical and transmission cables. 


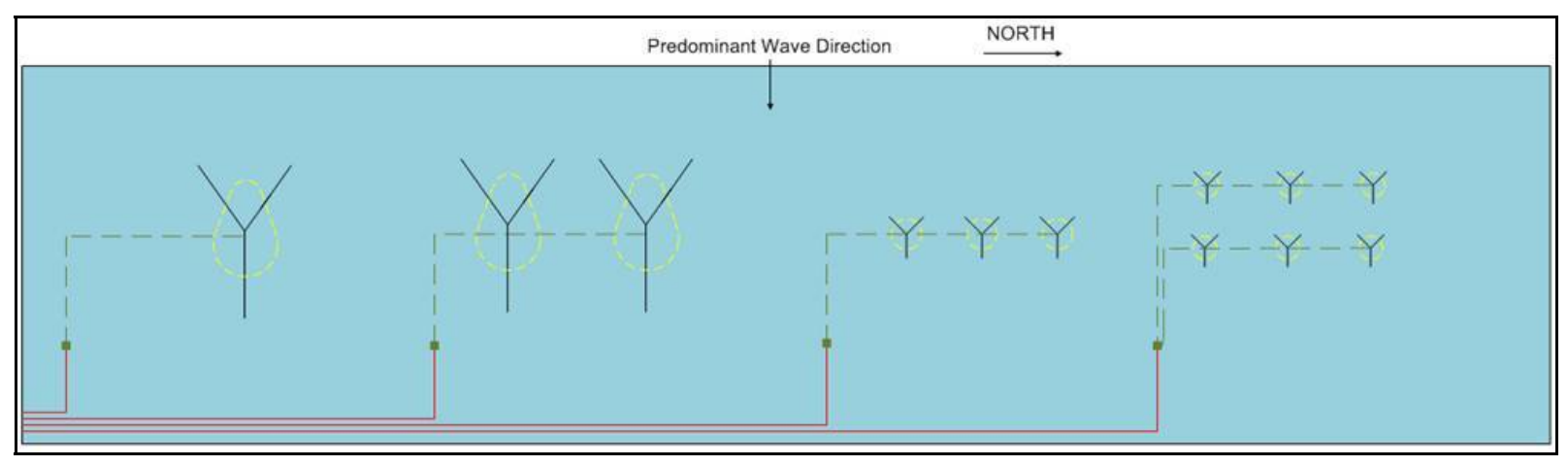

Figure 1-9: Hypothetical Arrangement of OWSC and Point Absorber WECs

\subsection{Report Framework}

This report summarizes PG\&E's experience and lessons learned during the WaveConnect project. Chapter 2 addresses permitting and regulatory issues. Chapter 3 details the engineering technology evaluations pertaining to the WECs, site infrastructure, and site considerations. Chapter 4 reviews the issue of environmental assessment, including the DPLA and MAMP processes. Chapter 5 describes WaveConnect stakeholder and community outreach interactions.

Although some of the information provided in the chapters described above is sufficiently general to apply to any wave energy project, much of it is in the context of the Humboldt WaveConnect project, which was the primary focus of most WaveConnect activities. However, as it appeared less likely that the HWC project would proceed as planned, PG\&E turned its attention to an alternative site on the Central Coast of California near Vandenberg Air Force Base; that Central Coast WaveConnect (CCWC) project is the subject of Chapter 6. Chapter 7 discusses overall project economics and commercialization issues in light of PG\&E's WaveConnect experience. The report concludes with extensive Appendices that document the activity and outcomes described in the body of the report. 



\section{Permitting \& Regulatory Issues}

PG\&E encountered several challenges in its attempts to obtain a FERC license and other associated permits required to construct and operate its proposed Humboldt WaveConnect pilot project.

\subsection{FERC Preliminary Permit}

On February 26, 2007, PG\&E applied to FERC for a Preliminary Permit for the project site. The purpose of a Preliminary Permit is to provide the applicant with three years of exclusive rights to the site without the threat of a competing permit or license application being filed on the site. A Preliminary Permit also gives its holder a priority over all other applicants in a subsequent license application proceeding.

PG\&E’s Preliminary Permit Application proposed a project consisting of:

- Eight to $200 \mathrm{WECs}$ having a total installed capacity of $40 \mathrm{MW}$;

- A 40-kV submarine transmission cable;

- Integrated generators;

- Anchoring devices;

- An on-shore transmission line; and

- Appurtenant facilities.

On March 13, 2008, FERC issued PG\&E a Preliminary Permit for the project. The project area was originally proposed to be located on both state submerged lands and on the Outer Continental Shelf (OCS). However, on July 31, 2009, at PG\&E's request, FERC issued an order reducing the Preliminary Permit boundary to state submerged lands only.

The Preliminary Permit gave PG\&E the exclusive right to prepare a Final Pilot License Application (FLPA) and file it with FERC within three years of the March 1, 2008 effective date of the issuance of the Preliminary Permit, which would have been by February 28, 2011. For the reasons summarized below, PG\&E did not file an FPLA and the Preliminary Permit expired. PG\&E did file a final Six-Month Progress Report with FERC on February 28, 2011.

\subsection{MMS/BOEMRE Lease Nomination}

On January 4, 2008, PG\&E submitted a nomination for a lease for alternative energy resource assessment and technology testing for the proposed WaveConnect project. PG\&E sought to 
obtain a limited-term lease on the OCS pursuant to interim policies of the Department of the Interior's Minerals Management Service (MMS), later known as the Bureau of Ocean Energy Management, Regulation, and Enforcement (BOEMRE).

On April 28, 2008, MMS nominated PG\&E's project for an alternative energy lease. However, uncertainty associated with MMS's interim policy, the high costs of obtaining a MMS lease, and conflicts regarding FERC versus MMS jurisdiction on the OCS resulted in PG\&E withdrawing from the MMS Interim Leasing Process on August 27, 2009.

\subsection{FERC Pilot License}

On August 31, 2007, FERC issued a white paper on Hydrokinetic Pilot Project Licensing Procedures (PPLP) to encourage projects to test wave conversion technologies. FERC's intent for the PPLP was to allow developers to test new hydrokinetic technologies, determine appropriate siting of these technologies, and - based on the premise that environmental effects were less than significant - confirm this presumption while maintaining FERC oversight and agency input. Another goal was to streamline the FERC licensing process to as few as six months to allow for project installation, operation, and environmental testing as soon as possible, versus the five-plus years which is more typical for licensing via FERC's default Integrated Licensing Process (ILP).

However, FERC put significant limitations on projects eligible to use the PPLP. Eligible projects were to be small (generally less than $5 \mathrm{MW}$ ), be able to be shut down or removed on short notice if environmental effects were found to be significant, and avoid sensitive locations. The resulting license would be short-term (generally five-year terms covering construction, operation, and project removal and site restoration), include appropriate environmental monitoring and safeguards, and require project removal before the license term expired unless an application for a full license was subsequently filed. While FERC indicated that it would entertain requests for license terms longer than five years and evaluate them on a case-by-case basis, it expected that pilot projects would have terms of five years.

FERC envisioned that a pilot license application would require a description of the project and the existing environmental setting, collection of existing available environmental data, and "basic" pre-application surveys. Not requiring an applicant to conduct extensive pre-application environmental studies and data gathering was a significant departure from FERC's ILP licensing procedure. In place of the pre-application environmental work, applicants were required to develop appropriate Monitoring and Adaptive Management Plans (MAMPs) in collaboration with the resource agencies and other interested parties. The MAMPs were to ensure that the installed project would operate in an environmentally safe manner, that any significant effects would be effectively mitigated and, if mitigation was not possible, that the project would be removed. The short term of the pilot license required the licensee to either remove the project at the end of the license term or apply for a full operating license. 
When the PPLP became available, PG\&E thought it could use the process to quickly and costeffectively license a small test project. However, use of the PPLP for the HWC project revealed a number of significant challenges to acquiring a FERC license under this new process.

Major resource agencies involved in FERC's licensing of hydrokinetic projects in California include the U.S. Fish and Wildlife Service (USFWS), the National Marine Fisheries Service (NMFS), California Department of Fish and Game (CDFG), and the California State Lands Commission (CSLC). Others involved include the U.S. Army Corps of Engineers, U.S. Coast Guard, California Coastal Commission, California State Water Resources Control Board, California Office of Historic Preservation, as well as local agencies to a lesser degree. In addition, any interested tribe, non-governmental organization, or other potentially interested parties are encouraged by FERC to participate in the licensing process.

However, none of the entities were obligated or necessarily able to modify their regulatory procedures, statutory requirements, or way of doing business because FERC issued its PPLP. In addition, the USFWS and NMFS are charged with ensuring that projects comply with the federal Endangered Species Act (ESA) and Marine Mammal Protection Act (MMPA), which typically requires significant pre-project data collection to determine whether a project will have significant adverse effects on ESA-listed species. This is in conflict with the intent of the PPLP, which envisioned less-than-significant environmental effects and minimal pre-project data collection.

\subsection{Draft Pilot License Application and Reactions}

On March 1, 2010, PG\&E filed a Draft Pilot License Application (DPLA) with FERC. The DPLA included a generalized project description, a description of the environmental setting, existing environmental data, and MAMPs for fish and invertebrates, marine mammals, and seabirds. In a letter dated April 30, 2010, FERC stated the draft application largely met its regulatory requirements for a Pilot License Application; however, FERC requested more information on the project description, including detailed descriptions of the WECs that PG\&E proposed to use, and included an Additional Information Request (AIR) directing PG\&E to provide more information on a number of topics. In addition, FERC required PG\&E to significantly revise two of the MAMPs. FERC directed PG\&E to address all agency comments, including its own, and submit revised MAMPs within 120 days, or by August 30, 2010. FERC advised PG\&E that its approval for using the PPLP for the project would be based on the adequacy of PG\&E's response to the comments and the revised MAMPs.

In addition to FERC's comments on the DPLA, within 30 days of PG\&E's filing the draft DPLA, the resource agencies and other interested parties submitted written responses that yielded more than 300 individual comments on specific issues, a majority of which requested more detailed information on the WECs or the project description, or requested pre-project data on potential effects on environmental resources including species listed under the Federal Endangered Species Act (ESA). These requests were largely driven by information needs required by NMFS and USFWS to initiate Section 7 consultation under the ESA or consultation with NMFS under the Magnuson-Stevens Fisheries Conservation and Management Act. 
Addressing FERC's comments and revising the MAMPs would have required multiple consultation meetings with the resources agencies and other interested parties - a costly and time-consuming exercise for all involved. PG\&E hoped that such meetings could reduce the amount of additional pre-project data collection needed and produce reasonable scopes for the MAMPs. However, given the agencies' numerous comments on the project and their regulatory obligations, PG\&E came to realize that expectation was not reasonable.

PG\&E's attempt to license the HWC project through the PPLP revealed a fundamental conflict between the intent of the PPLP to streamline the process by requiring minimal pre-project data collection and the mandates of resource agencies such as NMFS that require more extensive data collection. In its comments on the DPLA, NMFS stated:

FERC's short-term criterion is presumably in place as a required safeguard because of the experimental nature of the technology and the streamlined pilot project permitting process. In the pilot license process, an applicant may (and PG\&E has, in this case) request a waiver from completing certain steps normally required within the Integrated Licensing Process (ILP) to develop project information. However, additional emphasis is placed on monitoring and adaptive management during the pilot project license term, and the project may be shut down immediately in the case of unforeseen consequences.

With respect to NMFS's regulatory processes, a five-year license term may be a fundamentally different temporal frame of reference for analysis during NMFS Section 7 consultation and MSA consultation than either an eight or thirteen year license term. Assuming two years for procurement and construction and one year for decommissioning is constant regardless of the period of WEC operation, then the actual period of in water operation would vary between two years (for a five [year] license), five years (for an eight year license), and ten years (for a 13-year license). Thus, exposure and risk to a Pacific salmon or green sturgeon ESU/DPS escalates significantly as the operational period is extended. Such an extended time of operation increases level of potential risk to the species. Hence, additional environmental analyses and scrutiny is required if license terms are increased. The difference includes not just the project's scale in time and space, but also the degree of repeated exposure and risk associated with direct and indirect effects to the number of generational cohorts affected. . .

NMFS regulatory requirements are not different with respect to the pilot project license process than any other action: An applicant can apply for a longer license term; however, it is the applicant's responsibility to provide a project description that is adequate to initiate consultation. As license term and therefore exposure and risk to NMFS' trust resources increases, detail in the project description will need to increase for NMFS to be able to responsibly assess risk. Greater risk requires increased certainty in risk assessment. In addition, an eight or ten year term would appear inconsistent with the intended purposes of the pilot license process unless baseline information and monitoring requirements were commensurately increased. 
... For NMFS to complete Section 7 consultation, the proposed action needs to be deconstructed, all potential stressors (effects) associated with the activities identified; the spatial and temporal exposure of individuals or habitats to the stressors described, the response of the individuals to the stressor described, and the risk of harm, injury or mortality to the individuals determined, and the effects of the action on the listed species populations, and ultimately the evolutionarily significant unit/distinct population segment, are analyzed.

For consultation under the MSA, the horizontal and vertical footprints of an individual $W E C$, as well as the combined footprints of WEC Arrays, needs to be provided in order to determine the amount and nature of project alteration of the benthic habitat as well as habitat in the water column. In addition, the FPLA will need to identify what effect, if any, the presence (as well as operation and maintenance) of the WECs has on organisms that are currently existing in pelagic habitat without structures. The relationship of project-generated EMF values to ambient or background EMF, the ability to detect the values, and how project-generated EMF values from transmission lines in both the water column and in the benthic substrate may affect fish behavior needs to be discussed further before developing a final monitoring plan.

... North American Green Sturgeon: A thorough discussion between the Applicant and NMFS is warranted regarding the monitoring and adaptive management plan for green sturgeon. NMFS appreciates that a great deal is unknown about the migration of green sturgeon, and that the draft plan represents a legitimate starting point for discussions. The plan, which will be an integral part of the ESA consultation for green sturgeon, will need extensive development before it is acceptable to NMFS. Key discussion issues include the proposed seasonal deployment of sensors which will miss a substantial portion of the migration (if not the majority), inappropriate thresholds, and possible proactive mitigation. As currently drafted, the plan is inadequate to detect potential adverse effects on green sturgeon because of test design and threshold issues. It is incumbent upon the Applicant to prove the absence of project adverse effects on ESAlisted species. In the absence of the development of adequate information regarding baseline conditions and potential project effects, NMFS will apply a precautionary principle towards the protection of listed species.

CDFG expressed similar concerns, though in the context of their trust resources and jurisdictional authority:

... Given the paucity of data and myriad of potential effects, studies and monitoring are necessary to provide a context for project-related effects in anticipation of future construction of large-scale and long-duration wave energy facilities. Therefore, the Department's most substantial environmental concerns relate to potentially significant project-related impacts on populations of fish, invertebrates, seabirds, pinnipeds, and cetaceans, and how the HWCP will effectively avoid, minimize, mitigate and monitor these impacts. Consequently, the Department recommends robust monitoring for the life of the $H W C P$. . . 
... The Department is concerned that the proposed action described in the DPLA for the $H W C P$ deviates from the concept of a five year time frame, citing installation and operating uncertainties that may lead to additional time being requested in the final pilot license application. Within recent stakeholder meetings, $P G \& E$ has contemplated a possible 13 year license term, including ten years of operation and three years for installation and decommissioning (February 2, 2010 Permitting Authority Subcommittee Meeting Summary). If a thirteen year pilot license is granted, followed by a multi-year relicensing phase to build-out the installation into a commercial scale project, the HWCP could be in place impacting marine resources for much more than the five years originally envisioned as part of the expedited pilot license process. The Department recommends that pilot license durations in general be limited to the original five year period with the option for a Licensee to seek extensions if necessary. . .

... There are three Adaptive Management and Monitoring Plans presented in the DPLA: Fish and Invertebrates, Seabirds, and Marine Mammals. All three plans have limited sampling periods of one to two years with decision points to end the monitoring. The Department believes that the project should be monitored the entire period of operation, regardless of number of years or outcome of sampling. If sampling results indicate a significant adverse effect the HWCP would be evaluated for potential shutdown. Otherwise, the HWCP would continue with possible modifications. Monitoring must continue to evaluate potential effects over time, especially from modifications to WECs or arrays...

Based on PG\&E's experience with the HWC, it appears that resource agencies do not agree with FERC that a PPLP project would meet the requirements of Section 7 consultation under the ESA, nor would it result in less-than-significant effects to listed species under the federal and state ESA. Until resource agencies embrace the concept of a pilot license or are required to modify their regulatory processes, such a project will likely not receive the permits necessary for construction or will result in rigorous environmental monitoring and mitigation.

\subsubsection{California State Lands Commission}

Because the CSLC acts as the manager of state sovereign lands, it has a fiduciary responsibility to manage them for the benefit of the state rather than issuing a permit for impacts to habitat, as would a resource agency such as the CDFG. The California Environmental Quality Act (CEQA) requires very specific information and analysis of potential impacts to be determined in an Environmental Impact Report (EIR). The CSLC has no process in place to accommodate the streamlined FERC PPLP.

Consequently, CSLC advised PG\&E that it was required to perform a CEQA analysis of projects proposed on state lands. Because CEQA does not provide for a pilot project, the HWC would have required a full analysis and likely an EIR. However, according to information received from CSLC, a project in which the WECs were in federal waters with only a power cable located in state waters could result in a Mitigated Negative Declaration (MND). FERC and CSLC indicated willingness to work together to create a joint National Environmental Policy Act (NEPA)/CEQA 
document. The CSLC estimated that analysis would take about 12 months, with approximately $\$ 650,000$ in up-front costs to be paid by PG\&E. A MND would have taken about six months and cost approximately $\$ 300,000$. Furthermore, the CEQA analysis had the potential to require mitigation for potential impacts on state submerged land.

In addition, CSLC leases usually have a 30-year term and require a construction bond, a performance bond, and a Mitigation Monitoring Plan bond. PG\&E was advised by CSLC that the lease for the HWC site would likely include WEC maintenance reports and possible WEC performance reports. Lease valuation is based on "across the fence" values, but CSLC indicated it would work with PG\&E to determine a fair value for the lease for HWC. While PG\&E appreciated CSLC's efforts, such high costs and extended timelines were problematic for a relatively modest test project.

\subsection{Conclusion}

In order to obtain priority over competing applicants, PG\&E needed to file a FPLA with FERC no later than February 28, 2011. However, for all the reasons noted above, on November 30, 2010, PG\&E formally withdrew its NOI and DPLA for the project.

PG\&E hoped to use the PPLP process to quickly and cost-effectively license the Humboldt WaveConnect site to serve as a test platform for new hydrokinetic technologies. However, the relevant resource agencies often had their own mandatory processes, pre-project data requirements, and permitting concerns that conflicted with or exceeded the demands of the PPLP. While PG\&E could have addressed the DPLA comments and revised its MAMPs as requested by FERC, this effort would have required a level of continued consultation with resource agencies and other interested parties that exceeded the expectations of using the PPLP and had significant cost and time implications.

The high cost of completing the PPLP process at FERC and the CEQA process at the CSLC, combined with the limitations and requirements of any pilot license that might be issued by FERC (including its short term, implementation of mitigation measures, and requirement to remove a project at any time if there were any adverse environmental effect), plus the likely requirements of a CSLC lease, led PG\&E to conclude that it should cease to pursue the HWC project.

\subsubsection{Permitting and Regulatory Lessons Learned}

PG\&E gained valuable experience regarding FERC's PPLP, the process that CSLC follows to grant leases to hydrokinetic projects seeking to use state submerged lands, and the process that MMS/BOEMRE uses for granting leases for such projects on the OCS. PG\&E also developed a network of key contacts from the relevant agencies and other stakeholders with respect to hydrokinetic matters. 
Many of the comments and concerns submitted in response to PG\&E's DPLA were driven by PG\&E's inability to precisely describe technical features of the WECs it proposed to use due ongoing WEC design changes as their development continued. Until the hydrokinetic industry matures and applicants can more specifically identify the characteristics of the WECs they plan to deploy, agencies and other stakeholders will continue to have concerns about such projects.

Agencies other than FERC have not developed procedures to expedite hydrokinetic applications comparable to FERC's PPLP, and in some cases (e.g., USFWS and NMFS in carrying out their ESA and MMPA responsibilities) may not be able to do so.

Because hydrokinetic technology is new and largely untested, and the potential environmental impacts of WECs are largely unknown, agencies and other stakeholders tend to be conservative in their assessments of potential environmental impacts and demand higher levels of information on environmental resources and impacts.

\section{Key Takeaways}

- Until experience is gained with specific WECs, it is unlikely that use of FERC's expedited PPLP to obtain licenses for hydrokinetic projects will be successful.

- The high costs of navigating the PPLP, CEQA, and other processes do not currently justify pursuing the limited and restrictive licenses that can be issued under the PPLP.

- Use of FERC's ILP, under which larger projects can be licensed with longer license terms (up to 50 years), may prove to be a more efficient way to pursue projects using hydrokinetic technologies.

Significantly, the WaveConnect program and Humboldt WaveConnect project provided a firstof-its-kind opportunity to test the regulatory process and work with local, state and federal agencies to attempt a real-world project of a type never before done. Gaining greater understanding of the difficulties and successes that emerged is a key outcome of WaveConnect that will inform policy making and wave power projects in the future. 


\section{Engineering Technology Evaluation}

\subsection{Introduction}

This chapter presents engineering details of the Humboldt WaveConnect site as of the time of the DPLA, as well as assessments made by PG\&E in the months following its submittal to FERC. Section 3.2 describes the Request for Information (RFI) and PG\&E's considerations in initiating discussions with wave energy convertor manufacturers (WECoMs). Section 3.3 briefly describes the WECoMs that responded to the RFI by general technology type. Section 3.4 describes the wave energy resource along the California coast, using several technologies as bases for comparison. Section 3.5 discusses possible alternative sites and considerations regarding the placement of future wave power facilities. Section 3.6 describes the overall project plan, while Sections 3.7 through 3.12 describe, in order of site installation phases, the required infrastructure for the basic facility. Section 3.13 briefly discusses briefly the range of overall costs, while Section 3.14 describes the detailed engineering plans developed for the facility.

\subsection{PG\&E's RFI Effort}

PG\&E sent an RFI to more than 50 WECoMs worldwide. The companies contacted are listed, with the RFI itself, in Appendix PG\&E RFI. After the official RFI period ended, PG\&E also held discussions with other manufacturers, based on the status of their technology. Of the 50, 14 WECoMs responded, and PG\&E later added two officially to the list who made contact after the official close date of the RFI period. The reasoning for the RFI was discussed briefly in Section 2.6.1. Table 3-1 shows the major criteria requested in the RFI.

The RFI process was designed to collect information required for the FERC licensing process without having to enter extensive non-disclosure agreements, and improved PG\&E's knowledge of the state of the industry. Of the WECoMs that responded, some requested that their data be kept confidential, although all companies stated that PG\&E could publicly list them among the RFI respondents. The WEC device descriptions provided in this chapter have been collected from publicly available sources to ensure confidentiality of manufacturers' data submissions. 
Table 3-1: Information Requested of WECoMs in PG\&E's RFI

\begin{tabular}{l|l}
$\begin{array}{l}\text { The principal of operation of the WECS } \\
\text { Physical characteristics of the system (dimensions, } \\
\text { mass, etc) }\end{array}$ & $\begin{array}{l}\text { Power Take Off (PTO) } \\
\text { Theoretical or measured power output matrix } \\
\text { based on Tp and Hs } \\
\text { Preferred or optimal operating depth }\end{array}$ \\
$\begin{array}{l}\text { Expected production based on } 45 \mathrm{~m} \text { depth and } \\
\text { provided sea states }\end{array}$ & $\begin{array}{l}\text { Operating capacity factors on an annual basis. } \\
\text { WEC mechanical and electrical efficiency }\end{array}$ \\
$\begin{array}{l}\text { Downtime events, activities and durations when } \\
\text { Power conditioning and grid interconnect } \\
\text { characteristics (general type) }\end{array}$ & $\begin{array}{l}\text { WEC interconnection with each other and the } \\
\text { WaveConnect system }\end{array}$ \\
$\begin{array}{l}\text { The electrical power umbilical } \\
\text { Shore side logistics requirements for O\&M }\end{array}$ & $\begin{array}{l}\text { Monitoring and telemetry methods } \\
\text { Deployment history or any pilot or operational tests } \\
\begin{array}{l}\text { Major lessons learned for installation, O\&M, and } \\
\text { decommission. }\end{array}\end{array}$ \\
$\begin{array}{l}\text { Installation and maintenance method } \\
\text { units and identification of the organizations that will } \\
\text { support this project. }\end{array}$ & $\begin{array}{l}\text { Specific permitting or licensing efforts } \\
\text { installation and the uncertainty } \\
\text { Overall assessment of Technology Readiness } \\
\text { Level (as described by DOE) Must Be judged to be } \\
\text { TRL } 6 \text { or higher }\end{array}$ \\
\hline
\end{tabular}

PG\&E interviewed WECoMs to better understand their technologies, commercial readiness, costs, and interest in participating in the pilot project. As a guide, PG\&E used DOE's Technology Readiness Levels (TRLs). The TRLs are:

\section{DOE TRL 1-3: Discovery/Concept Definition/Early Stage Development, Design and Engineering}

- TRL 1-2: Lowest levels of technology readiness. Basic scientific research begins to be translated into applied research and development where basic principles are observed and reported. Stage is characterized by paper studies, concept exploration, and planning.

- TRL 3: In this stage, active research is initiated, including engineering studies and laboratory studies to physically validate analytical predictions of separate elements of the technology.

\section{DOE TRL 4: Proof of Concept}

- TRL 4: Basic technological components of a sub-scale model are integrated to validate design predictions and system level functionality. The models, or critical subsystems, are tested in a laboratory environment.

- Model size is expected to be 1:10 or smaller.

- $\quad$ Testing such as 2D flume, 3D basin, tow tank. 
- Foundation concepts should be incorporated into model testing.

\section{DOE TRL 5/6: System Integration and Technology Laboratory Demonstration}

- TRL 5: Basic technological components are fabricated at a scale relevant to full scale and integrated to establish and verify subsystem and system level functionality and preparation for testing in a simulated environment.

- TRL 6: Representative model or prototype system at a scale relevant to full scale, which is beyond that of TRL 5 , is tested in a relevant environment. This stage represents a major step up in a technology's demonstrated readiness and risk mitigation and is the stage leading to open water testing.

- Model size is expected to be 1:1-1:5 where feasible, as mentioned above.

- Testing is to be performed in a test facility capable of producing simulated waves/currents and other operational conditions while monitoring device response and performance.

- Foundation concept shall be incorporated and demonstrated.

\section{DOE TRL 7/8: Open Water System Testing, Demonstration, and Operation}

- Model scale is expected to be at or near full scale (1:1-1:2).

- Testing to be initially performed in water at relatively benign location and then moved to the open water in fully exposed and representative operating environments.

- Final foundation/mooring design shall be incorporated into model testing.

Since the goal of the feasibility effort was to examine commercial or near-commercial technologies, PG\&E used the TRL 6 as the basic criterion for initiating discussions. Later WECoMs who contacted PG\&E after the RFI period closed were asked to state if they had performed any form of in-water testing. If so, they were then invited to respond to the RFI. The RFI as presented was substantially reduced in scope from typical RFIs that are produced by PG\&E, in that PG\&E did not request substantial information concerning the financial health of the companies. That information was requested later and is discussed in Chapter $7 .{ }^{17}$

Additional criteria used to determine if further discussions were warranted were environmental impact and regulatory acceptance. In this case, WECs that had exceptionally large footprints on the ocean floor were felt to be unacceptable both to the local and the regulatory communities at this stage of the technology. Local communities generally object to any footprints interfering in fishing and crabbing activities. This is a concern for all wave energy devices, but particularly a concern where the footprint takes up large amounts of sea floor and shows potential to catch

\footnotetext{
${ }^{17}$ In retrospect, PG\&E's agreement to keep certain critical information from the WECoMs confidential hindered its application to state and federal agencies in the DPLA. PG\&E's initial intent was to minimize the need for industry to disclose information that they felt was confidential. Despite that intent, many WECoMs requested further confidentiality. Although PG\&E later signed confidentiality agreements with multiple WECoMs, such agreements are not standard in the electric industry for basic technical information needed for permitting.
} 
fishing or crabbing gear. The footprint issue with the regulatory community was one of possible major impacts to benthic organisms, as well as to marine mammals that could become entangled in fishing gear that itself had become entangled in the sea-floor-based devices. These issues are not unique to sea-floor-based devices, but PG\&E once again felt it was best to avoid more complex regulatory complications at the early state of the technology.

In consideration of the device manufacturers that PG\&E did not enter into discussions with, PG\&E will not specify which device types met its criteria. The information of specific technologies that PG\&E felt were appropriate will be communicated to DOE in a confidential fashion.

In general, PG\&E found that many of the manufacturers were protective of their technology and reluctant to provide all the information PG\&E hoped to obtain through the RFI process, which made it difficult to fully evaluate their systems. Although secrecy is common and understandable among companies developing early-stage technologies, it also affects the confidence of potential buyers and the regulatory community. Some data and specifications must be disclosed during any licensing process. In the case of WECs, information such as device dimensions, technical descriptions of mooring arrangements, safety factors for the mooring lines, and assumptions on storm return time are critical for assessing the facility's risk and the risk it may pose to other devices. Additionally, knowledge such as a WEC device's maximum power production and its power response spectrum are necessary for licensing with FERC, as well as for leases with agencies such as BOEMRE and the California State Lands Commission (CSLC).

Many of the devices that PG\&E observed are similar in construction or behavior to earlier technologies. The internal details of the device may be significantly different, but the outward exposure all have familiarity with many other types of devices, including the mooring configurations, which are of major concern to the regulatory community. Confidential information that may also be required includes device response to certain sea states. The regulatory agencies are in general not interested in how the device converts waves into electricity (unless said devices are considered to have intakes of some sort, which would bring power plant intake rules into consideration). But such knowledge of how the device interacts with the ocean environment is essential to gauge the impact of WECs on multiple issues, including coastal sediment transport, a potentially major environmental concern, as well as their impact on the surfing community.

PG\&E was sensitive to the confidentiality requests from the WECoMs during the regulatory process associated with the DPLA, but the manufacturers must to be aware that certain data will be required by the regulatory community, and thus will become publically available as part of any future overall licensing effort. The lack of outward device details had a significant impact on PG\&E's application to FERC, in that almost all agencies require a detailed project description. PG\&E attempted to create a "bounded" problem, but the agencies rejected this approach. WECoMs should in the future be aware that any licensing effort will require them to release some basic information to both FERC and other regulatory agencies, and that no guarantee of confidentiality can be given once that has been done. 


\subsection{WEC Devices}

Pending a final selection of the WEC technologies to be tested, PG\&E proposed a conservative

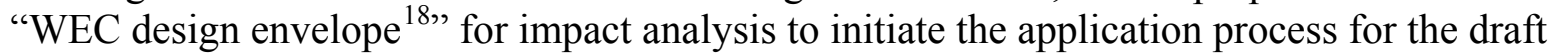
license. As was described previously, PG\&E received RFI responses from 14 WEC manufacturers interested in participating in the Humboldt WaveConnect Project. PG\&E had issued its Request for Proposals in early 2010, with a plan to select participants based on the merits of these proposals. The manufacturers that would be selected for participation in HWC would then be eligible to operate and test their equipment by deploying an appropriate number of generating units in an array for the 5-year term of the license. PG\&E hoped that any WEC technologies that proved to be technically and economically viable could then continue to operate as renewable energy resources for additional evaluation after the initial licensing term.

The responses from the RFI included manufacturers whose devices are based on the four bestknown and most technologically advanced types of WEC design, including:

- Attenuator (four respondents)

- Point absorber (seven respondents)

- Floating oscillating water column (one respondent)

- Oscillating wave surge converter (two respondents)

Because the oscillating wave surge converter design type requires water depths that are not available within the HWC preliminary permit area it was not considered feasible for the Humboldt WaveConnect site, although PG\&E did not dismiss it as an option for other locations. Some devices were not deemed to be of sufficient Technology Readiness Level for consideration, and so were also eliminated.

Overall, PG\&E found that the minimum average water depth required for all WEC devices (excluding those that involved near-shore pumping systems) was $50 \mathrm{~m}$ (76 m, 90th percentile; 26 $\mathrm{m}, 10$ th percentile). The preferred average depth for all devices was $80 \mathrm{~m}(100 \mathrm{~m}, 90 \mathrm{th}$ percentile; $68 \mathrm{~m}$, 10th percentile). Since the WaveConnect site had a depth of approximately $45 \mathrm{~m}$, PG\&E asked WECoMs whose devices had deeper preferred depths if they would still consider using the site, and most responded that they would. Of the near-shore pumping devices, most had preferred depths of approximately $10 \mathrm{~m}$.

To determine areas of coverage, PG\&E asked the manufacturers for their estimate of the area needed to generate $2.5 \mathrm{MW}$. The synopsis of their results (excluding near-shore devices and Oceanlinx, where a single device can produce $2.5 \mathrm{MW}$ ) was a sea floor area coverage of 0.32 $\mathrm{km}^{2}\left(0.69 \mathrm{~km}^{2}\right.$, 90th percentile; $0.07 \mathrm{~km}^{2}, 10$ th percentile). The sea surface area coverage was

\footnotetext{
18 This envelope was to protect the confidentiality of the various WEC designs. In hindsight, this added to project uncertainty and agency lack of cooperation in the pilot process. Clarity in issues such as the device shape, mass, mooring line, mooring anchors, and other outward appearances are critical to any licensing effort.
} 
$0.15 \mathrm{~km}^{2}\left(0.32 \mathrm{~km}^{2}\right.$, 90th percentile; $0.02 \mathrm{~km}^{2}$, 10 th percentile). These estimates were for an approximate depth of $50 \mathrm{~m}$.

The original intent of the DPLA was to provide FERC with specific design details, such as more precise device dimensions, once PG\&E chose the project participants. HWC was intended to host any feasible combination of four arrays developed by manufacturers of attenuators, point absorbers, or floating oscillating water column devices. Initially, it was decided that all WaveConnect components should be capable of surviving a 50 -year storm ${ }^{19}$.

The following subsections describe attenuator, point absorber, oscillating wave surge converter, and floating oscillating water column devices in general and list several of their prominent developers. There are many more technologies than those that applied to WaveConnect. Many of these are highlighted at the EMEC research website ${ }^{20}$.

\subsubsection{Attenuator}

An attenuator is a floating device which works parallel to the wave direction and effectively rides the waves. Movements along its length can be selectively constrained to produce energy. It has a lower area parallel to the waves in comparison to a terminator, so the device experiences lower forces. Most attenuators consist of long and narrow or shorter multi-axis devices that are segmented and float on the surface while tethered to the sea floor. Other designs fix several floating attenuators to a larger floating platform.

\section{Pelamis (http://www.pelamiswave.com/)}

The Pelamis (Figure 3-1) absorbs the energy of ocean waves and converts it into electricity. The machine sits "snake-like" on the surface of the water, comprising a number of cylindrical sections joined together by hinged joints. As waves pass down the length of the machine these sections flex relative to one another. The motion at each joint is resisted by hydraulic cylinders which pump fluid into high pressure accumulators allowing electrical generation to be smooth and continuous. Control of the resistance applied by the hydraulic cylinders allows generation to be maximized when waves are small, and the machine response to be minimized in storms. All generation systems are sealed and dry inside the machines and power is transmitted to shore using standard subsea cables and equipment.

The Pelamis has had a comparatively long history and has multiple devices under test, some of which have been purchased by power companies such as EON. Its capacity is $750 \mathrm{~kW}$. Due to the manufacturer's desire to show transparency in their technology, much is known about it, including its power spectra (although it is likely that there are improvements on said spectra

\footnotetext{
${ }^{19}$ This was a point of extensive discussion among the PG\&E engineering team. The issue of storm return times will be discussed in detail later, in light of the WaveDragon and Oceanlinx mooring failures.

${ }^{20} \mathrm{http}: / /$ www.emec.org.uk/wave_energy_developers.asp
} 
since it was first published several years ago). Due to this transparency, PG\&E has used it as an example in discussing mooring and in power output.

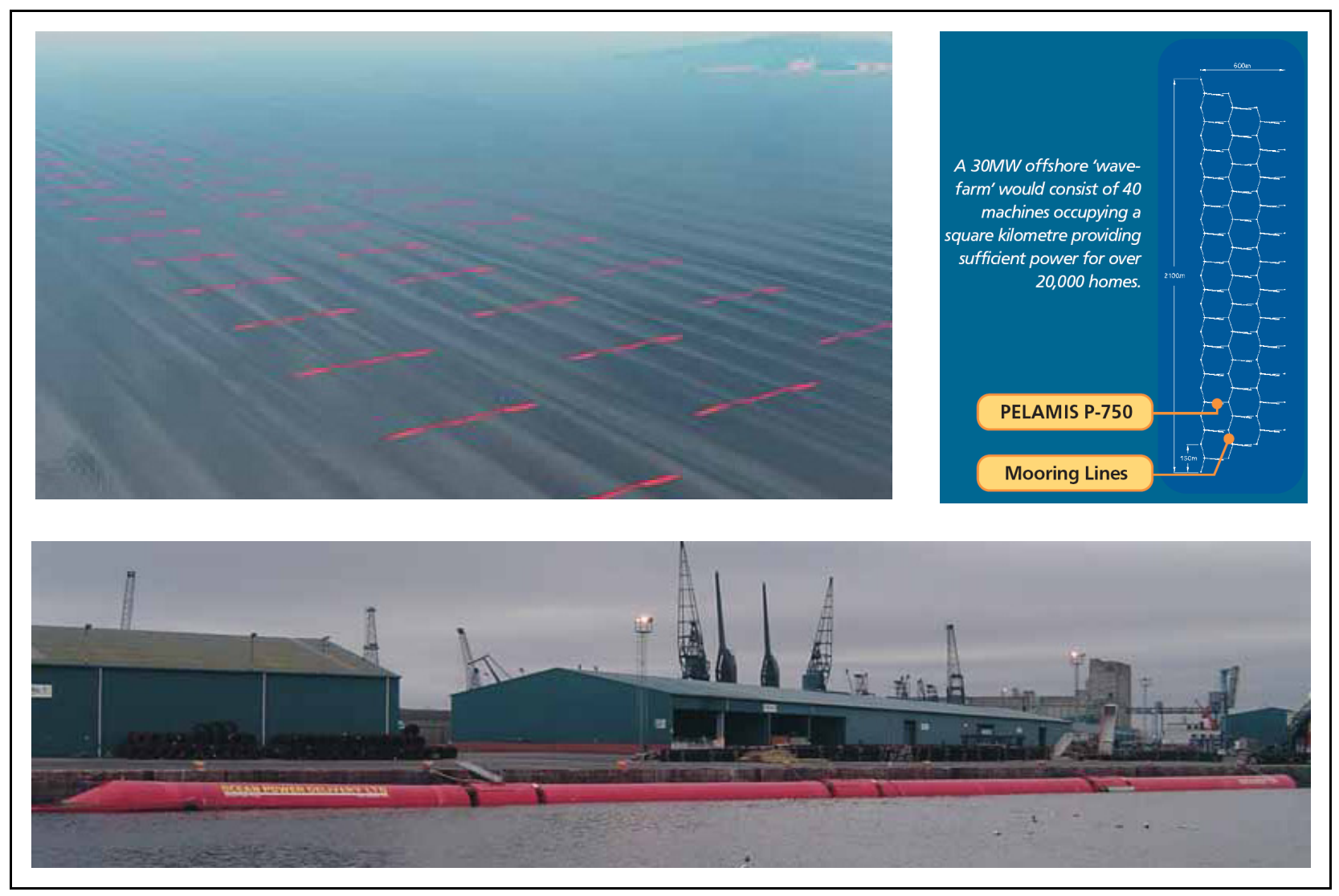

Figure 3-1: Pelamis WEC Devices

\section{Floating Power Plant (http://www.floatingpowerplant.com/)}

The Floating Power Plant Poseidon (Figure 3-2) is one of the few grid-connected wave technologies in the world. This technology is advancing toward having a 7.5-MW combined wave and wind generating capacity. The wave technology operates through interaction with dynamically ballasted floats (in order to change the resonance absorption of oncoming waves) which transfers power hydraulically through a turbine. It has already undergone multiple at sea tests, and is currently working to transform to a direct drive technology.

\section{AWS (http://www.awsocean.com/)}

AWS Ocean Energy (originally Archimedes Wave Swing) technology (Figure 3-3) uses air bellows and reaction from oncoming waves to produce power (through air turbines, as opposed to using water as its moving fluid). After receiving over $\$ 5$ million in development funds from Shell Oil and the Scottish Government in 2010, it is continuing testing and development of its AWS-III device, a ring-shaped multi-cell surface-floating wave power system. AWS Ocean 
Energy is aiming to deploy a full-system 12-cell, 2.5-MW pre-commercial demonstrator prototype AWS-III during 2012 and a pre-commercial demonstrator plant during 2013. Subject to financing and planning consents, the company plans to have a $10-\mathrm{MW}$ pre-commercial demonstration farm operating in 2014.
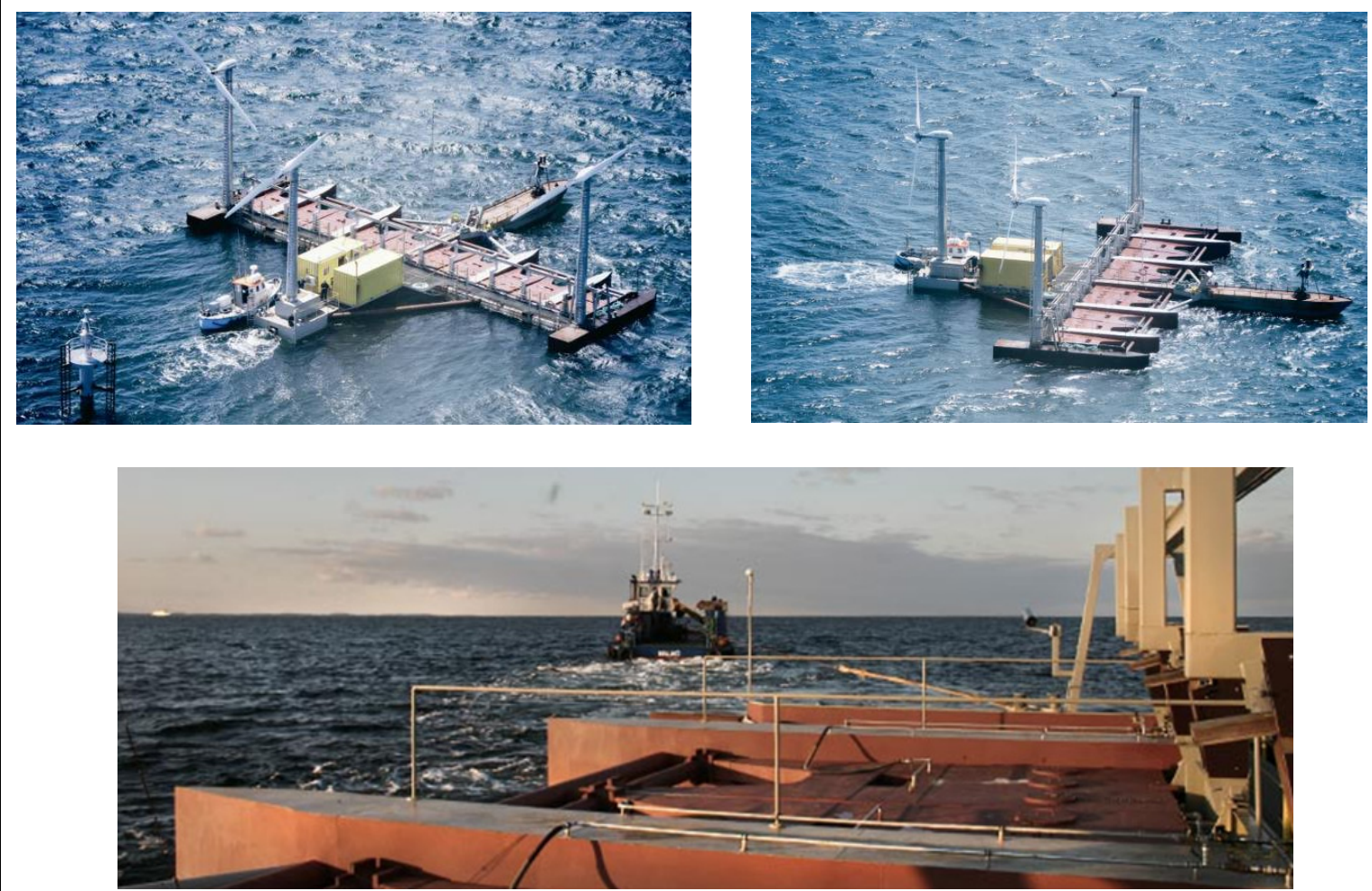

Figure 3-2: Floating Power Plant Poseidon
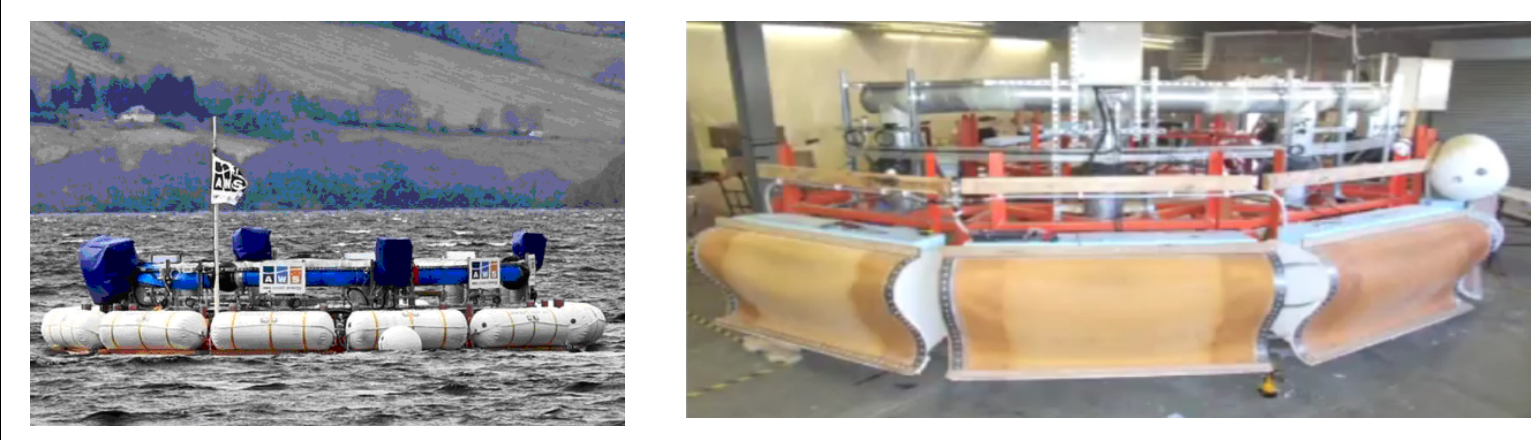

Figure 3-3: AWS Ocean Energy

\section{Fred Olsen (http://www.fredolsen-renewables.com/)}

Fred Olsen is a multinational Norwegian shipping and energy company that has been supporting the development of wave energy. They are involved in several consortiums, as well as partially funding at least one of the other devices mentioned herein. The development of their own WEC 
(Figure 3-4) is kept under strict confidentiality, but pictures of various devices have made their way into the public domain. Among those is a device that appears similar to a semi-submersible platform with multiple point absorbers attached to it, as well as a single point absorber device. Fred Olsen has evolved this design beyond that shown in the figure in the last year.

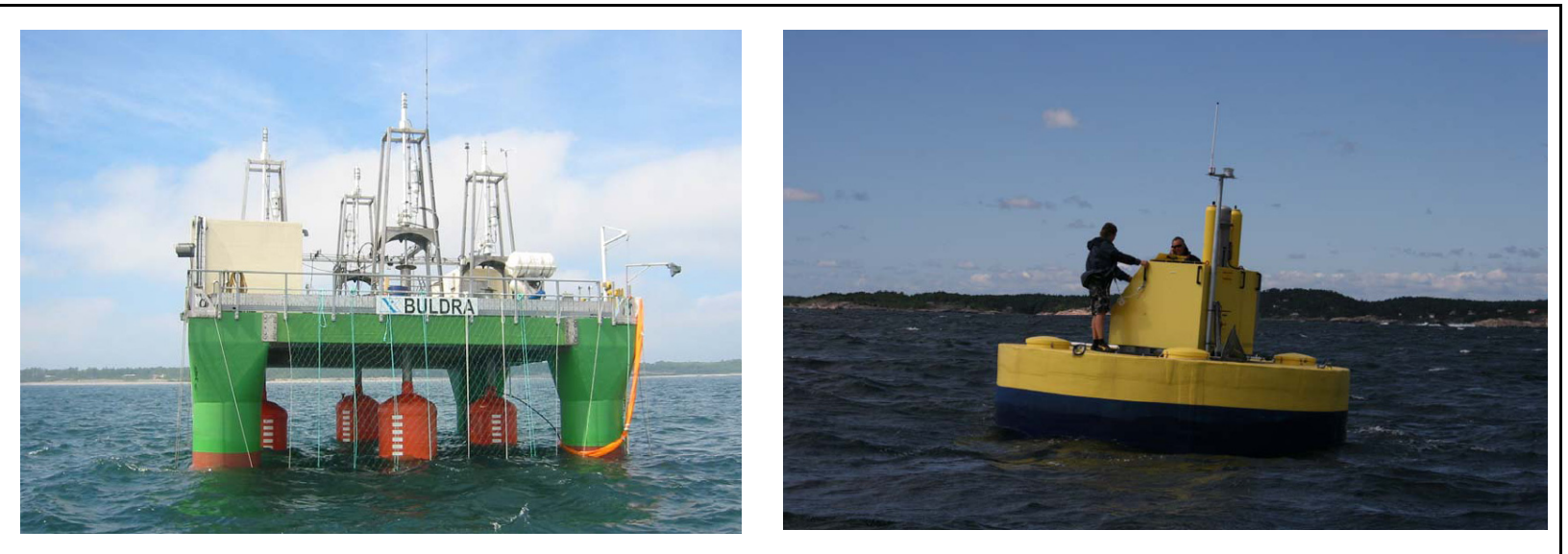

Figure 3-4: Fred Olsen WEC Technology

\section{Perpetuwave Power (http://perpetuwavepower.com/)}

The Perpetuwave Power "Wave Harvester" technology (Figure 3-5) is conceptually aimed at producing consistent power (with module sizes estimated to be of $500 \mathrm{~kW}, 1 \mathrm{MW}$, and $1.5 \mathrm{MW}$ ) that is not interrupted by the time periods between waves. The Wave Harvester design achieves this by using a number of large elongated floats that independently move up and down via a unique trailing arm design from the structure above. The movement of the paddles runs generators through a direct drive system. They are currently in development of a $20-\mathrm{kW}$ developmental unit. It can operate in the WaveConnect depth regime $(45 \mathrm{~m})$, and uses a multipoint mooring system (two forward and two rear).
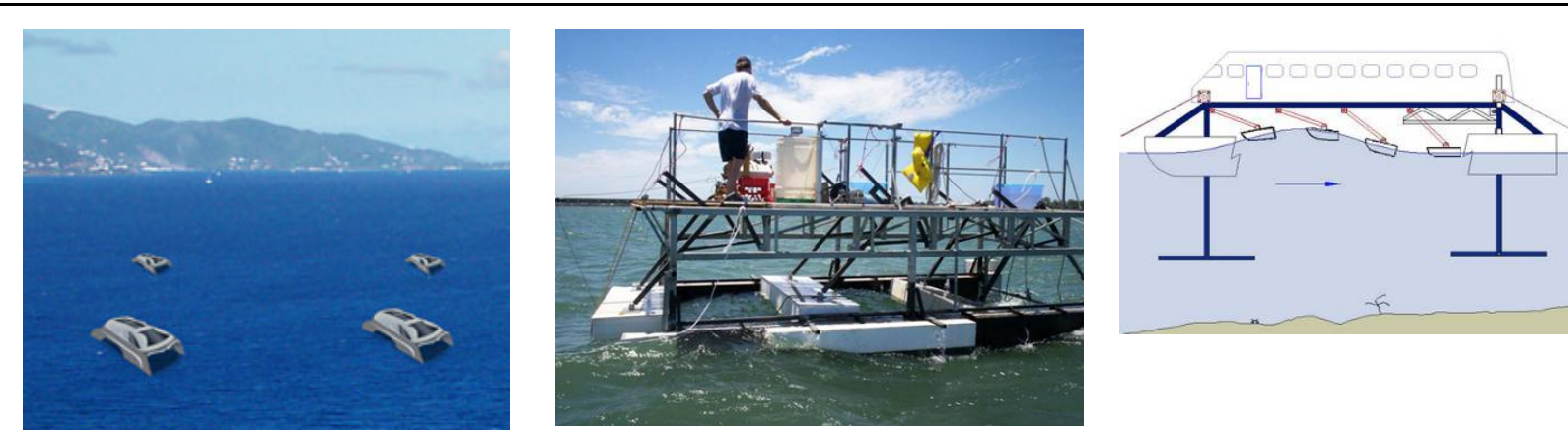

Figure 3-5: Perpetuwave Power Wave Harvester 


\section{Centipod (http://ecomerittech.com/centipod.php)}

The Centipod is a Wave Energy Conversion device currently under construction by Dehlsen Associates, LLC (Figure 3-6). It operates in water depths of 40-44m and uses a two-point mooring system with four mooring lines. It received a SBIR grant in 2010 for its 4.5-MW Centipod ocean wave generating system. The Centipod is a horizontally stable floating platform optimally yawed (active) to wavefront exposure possessing $5680-\mathrm{kW}$ flotation pods. As waves travel across the Centipod, pods rise and fall, driving hydraulic rams to generate electricity. New funding in the last year will allow for detailed engineering of the commercial prototype within a two-year timeframe.

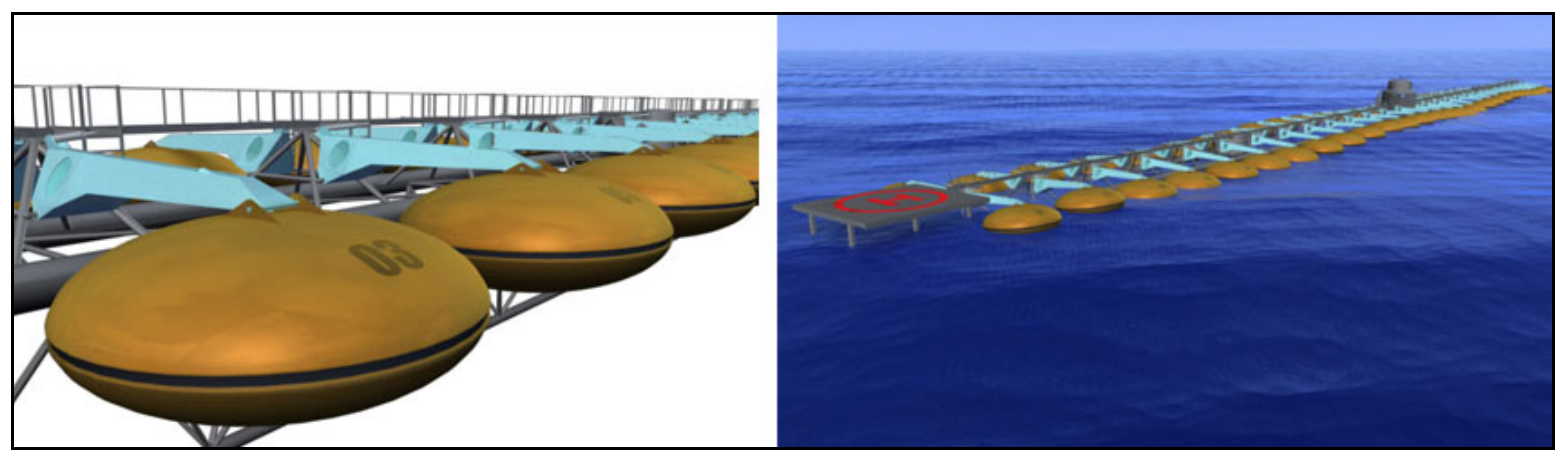

Figure 3-6: Centipod WEC

\section{Waveberg (http://www.waveberg.com/)}

The Waveberg is an articulated set of connected floats that flex as the waves pass under them, using this bending motion to pump seawater (Figure 3-7). The resulting high-pressure water is brought ashore through piping from the Waveberg and can be translated into power on-shore. Engineered plastic pipe and fiberglass are the main materials. A full-scale, 50-meter-long Waveberg will generate more than $100 \mathrm{~kW}$ of power under normal conditions. The Waveberg device has not been active for several years, and PG\&E has seen no indication of current funding.
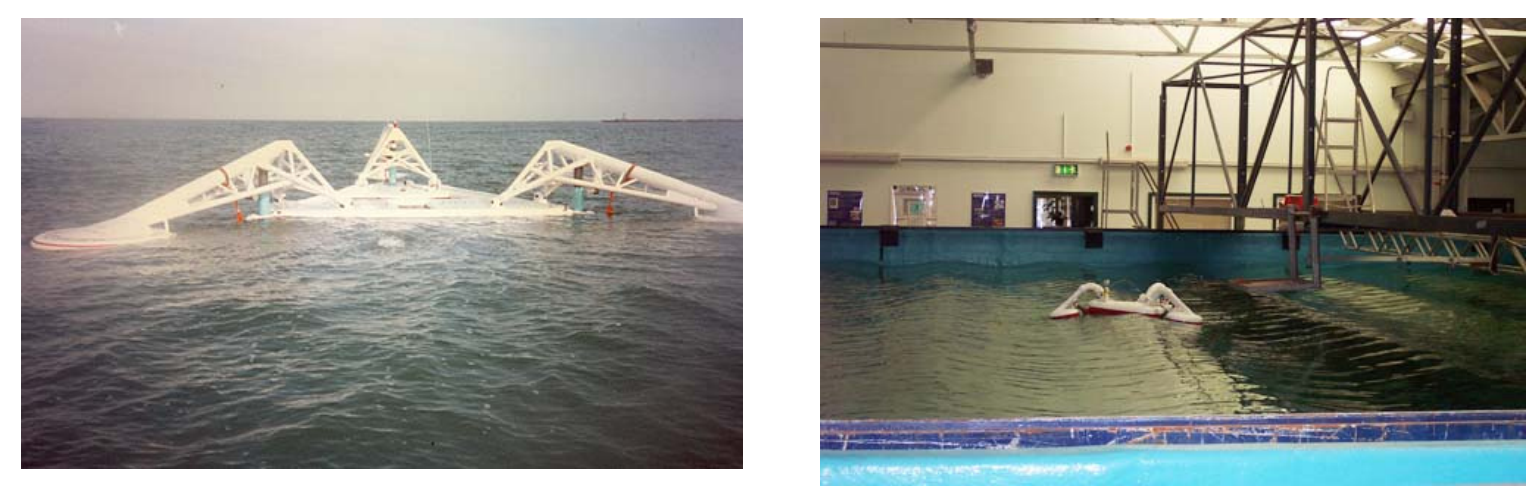

Figure 3-7: Waveberg WEC 


\subsubsection{Point Absorber}

Point absorbers capture the energy of waves by resisting the up-and-down motion of a floating object or buoy with a damper plate positioned below the surface. As the damper resists the upand-down motion of the buoy or float, it pushes hydraulic fluid that, in turn, drives a turbinegenerator. Most point absorber designs would involve arrays of buoys, each with a damper assembly extending down into the water and tethered to the sea floor.

\section{Ocean Power Technologies (OPT) (http://www.oceanpowertechnologies.com/)}

Ocean Power Technologies is an investor-owned manufacturer that has been a leader in the industry. It has projects supporting the military, is developing the first U.S. commercial wave energy facility at Reedsport, Oregon (1.5 MW), and has proposed a 100-MW facility at Coos Bay, Oregon. They have been developing both ocean wave energy converters and underwater substations to tie such facilities together. OPT has either deployed or is planning to deploy its devices in Spain, England, and Scotland. Their current device is a $150-\mathrm{kW}$ system, but they received funding from DOE in 2010 to develop direct-drive technologies, which should allow for larger power outputs than the current technology, which is based on hydraulic transfer.

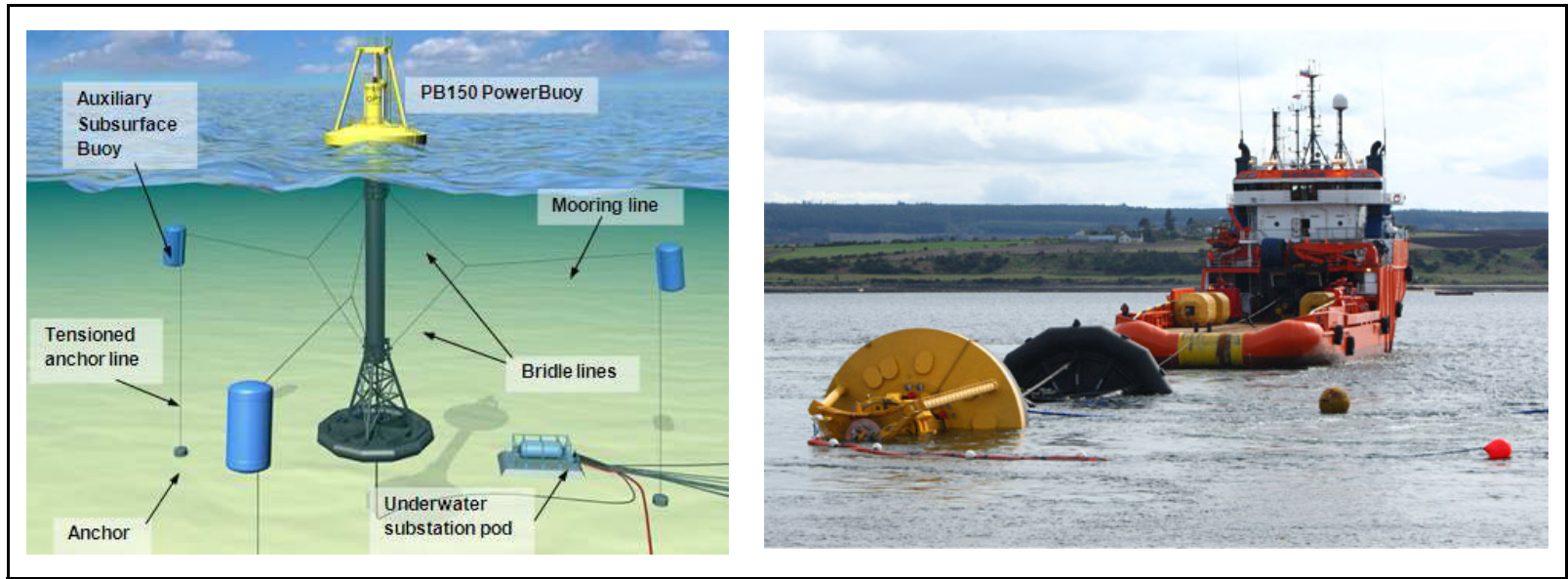

Figure 3-8: Ocean Power Technologies PowerBuoy System

\section{Columbia Power Technologies (CPT) (http://www.columbiapwr.com/)}

Columbia Power Technologies (CPT) has focused from the start on developing a direct-drive technology. Initially, it had hoped to use a magnet surrounding a series of coils in order to generate electricity, but it was found this did not scale up well. It has since gone to a clam arrangement with its "Sea Ray" technology, recently tested in Puget Sound. It has also received several grants, including a recent SBIR grant, but is largely self-funded, as its founders had major interests in the wind industry, and are very focused on using their experience to become the leader in wave energy. 

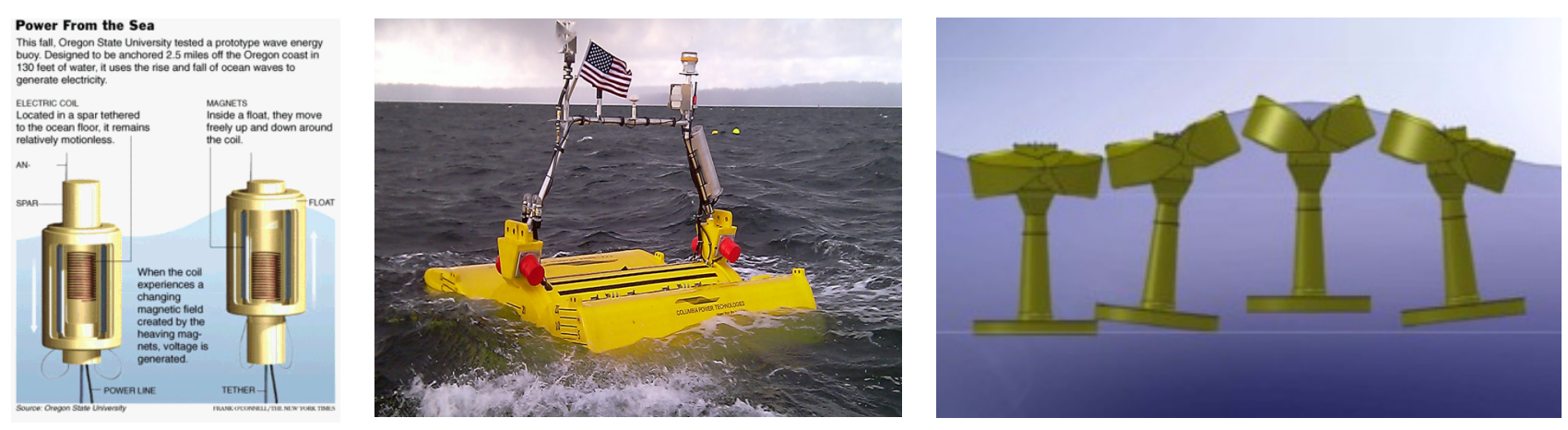

Figure 3-9: Columbia Power Technologies

WaveBob (http://www.wavebob.com/)

WaveBob is a competitor to Ocean Power Technologies, with a similar device (although there are differences in the wave conversion technology). An Irish firm, WaveBob secured almost \$5 million in funding in 2010. Their strategy is focusing on technology development with the intention of eventually licensing their technology to developers. Its system is also hydraulic, and developing a direct-drive system is a priority.

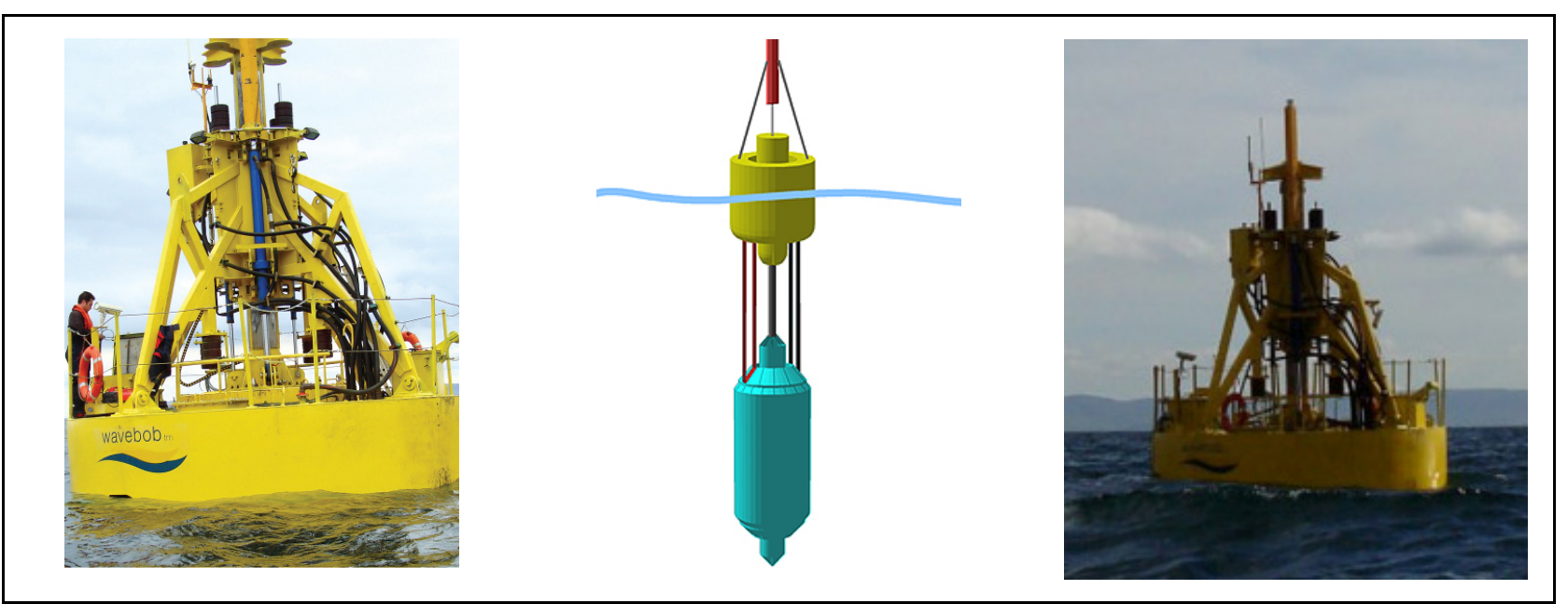

Figure 3-10: WaveBob WEC Technologies

\section{Resolute Marine Energy (RME) (http://www.resolutemarine.com/)}

Minimal information on Resolute Marine Energy's technology is available publicly, but the company is made up of various academic and other partners, including professors from MIT. A photo of an early stage device was found on the web, but in a private communication PG\&E was informed by Resolute that the photo "May not be representative of final design." Comments made on the MIT professor's website also support this. Resolute is still in the developmental stage, but received DOE SBIR funds in 2010. 


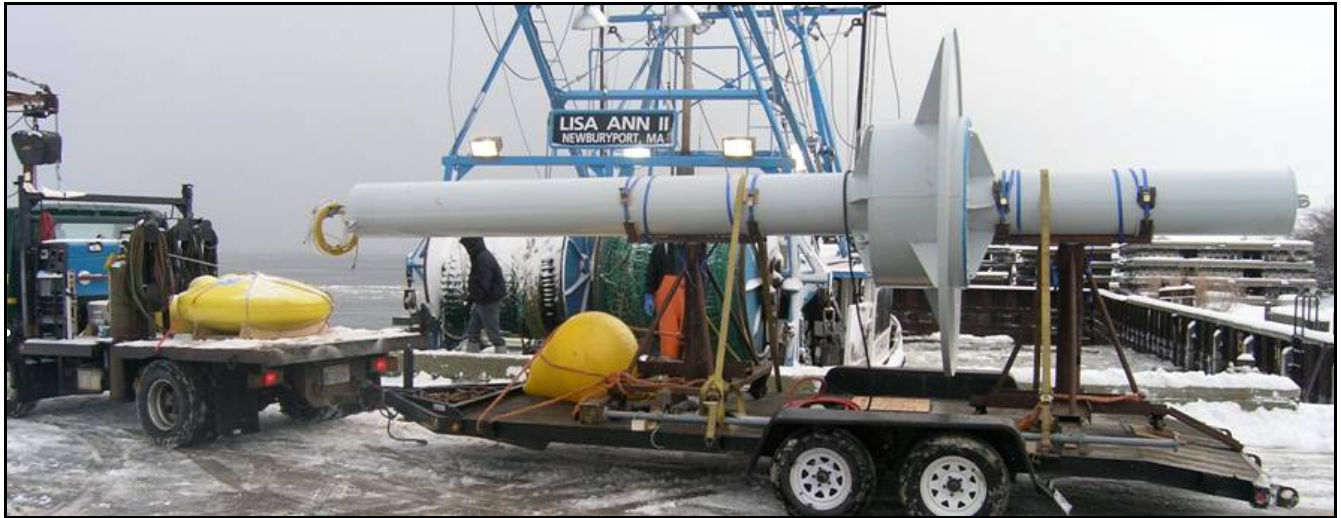

Figure 3-11: Resolute Marine Energy Early-Stage Device

Independent Natural Resources Inc. (INRI) SeaDog (http://www.inri.us/)

The INRI SeaDog Pump captures ocean-wave energy to pump large volumes of seawater. The pump uses buoyancy to convert wave energy to mechanical energy.
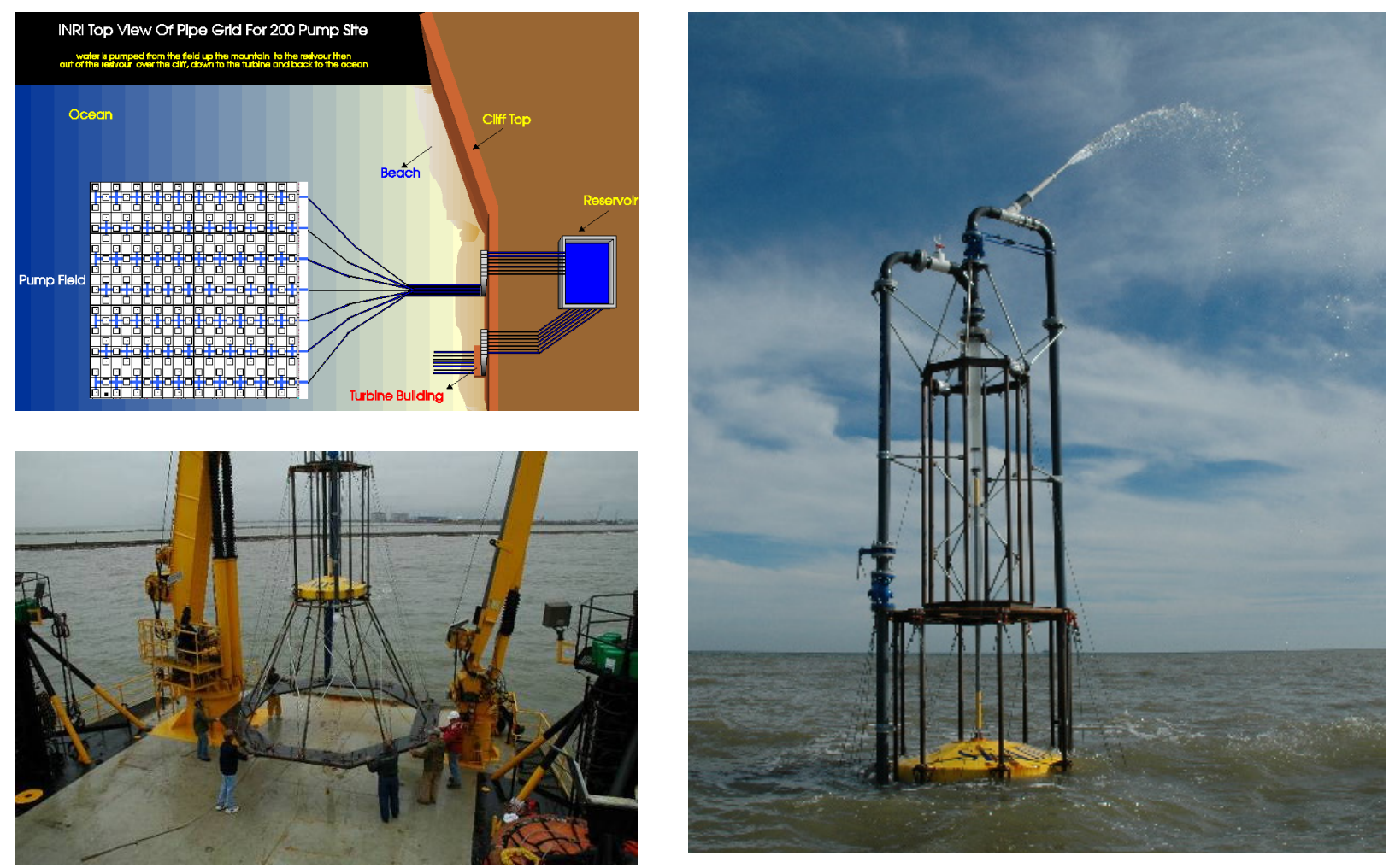

Figure 3-12: INRI SeaDog

The main components of the SeaDog Pump include a buoyancy chamber, buoyancy block, piston assembly, piston shaft, piston cylinder, and intake and exhaust valves. When positioned in the 
water the buoyancy block (filled with air) floats within the buoyancy chamber, moving up and down in relation to the ocean waves and swells. The buoyancy block is connected to the piston shaft which in-turn moves the piston assembly through the piston cylinder. It has recently been reported that INRI is involved in a Texas desalination project.

\section{Renewable Energy Pumps (http://www.renewableenergypumps.com/)}

Renewable Energy Pumps has a system similar in nature to INRI's SeaDog. The company does not appear to have any projects currently.

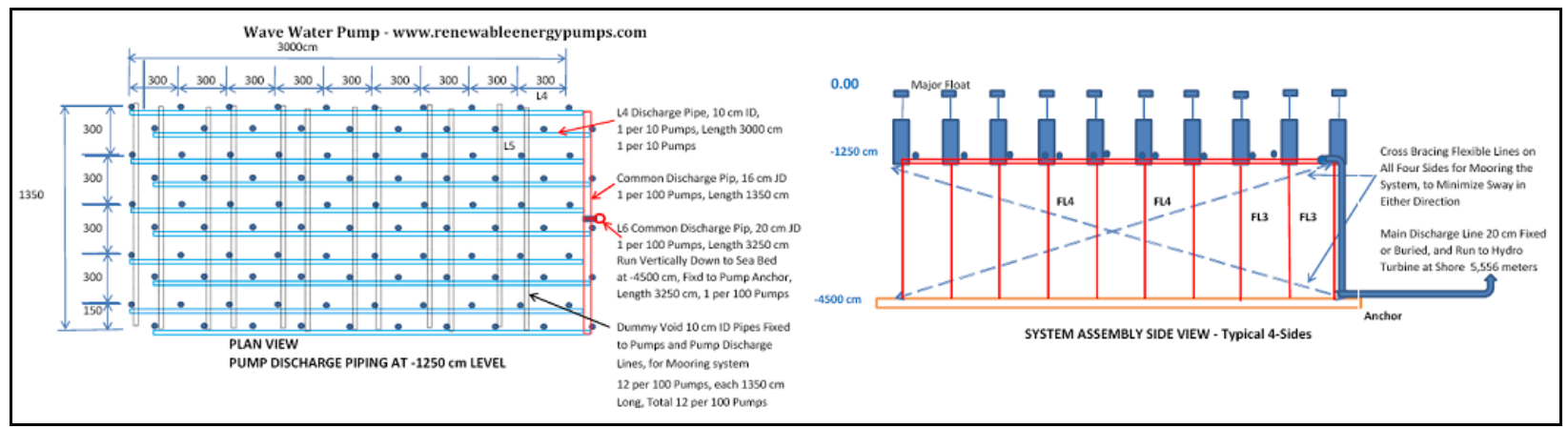

Figure 3-13: Renewable Energy Pumps

\subsubsection{Oscillating Wave Surge Converter}

This form of device extracts the energy contained in wave surges and the movement of water particles within them. The arm oscillates as a pendulum mounted on a pivoted joint in response to the movement of water in the waves. These devices are designed to be deployed in shallower waters to take advantage of the wave motion there.

\section{Aquamarine Power (http://www.aquamarinepower.com/)}

Aquamarine Power's Oyster is designed to harness wave energy in a near-shore environment. It is composed primarily of a simple mechanical hinged flap connected to the seabed at a depth of about 10-15 meters and is gravity moored (Figure 3-14). Each passing wave moves the flap, driving hydraulic pistons to deliver high pressure water via a sub-sea pipeline. On-shore, conventional hydro-electric generators convert this high-pressure water into electrical power. 


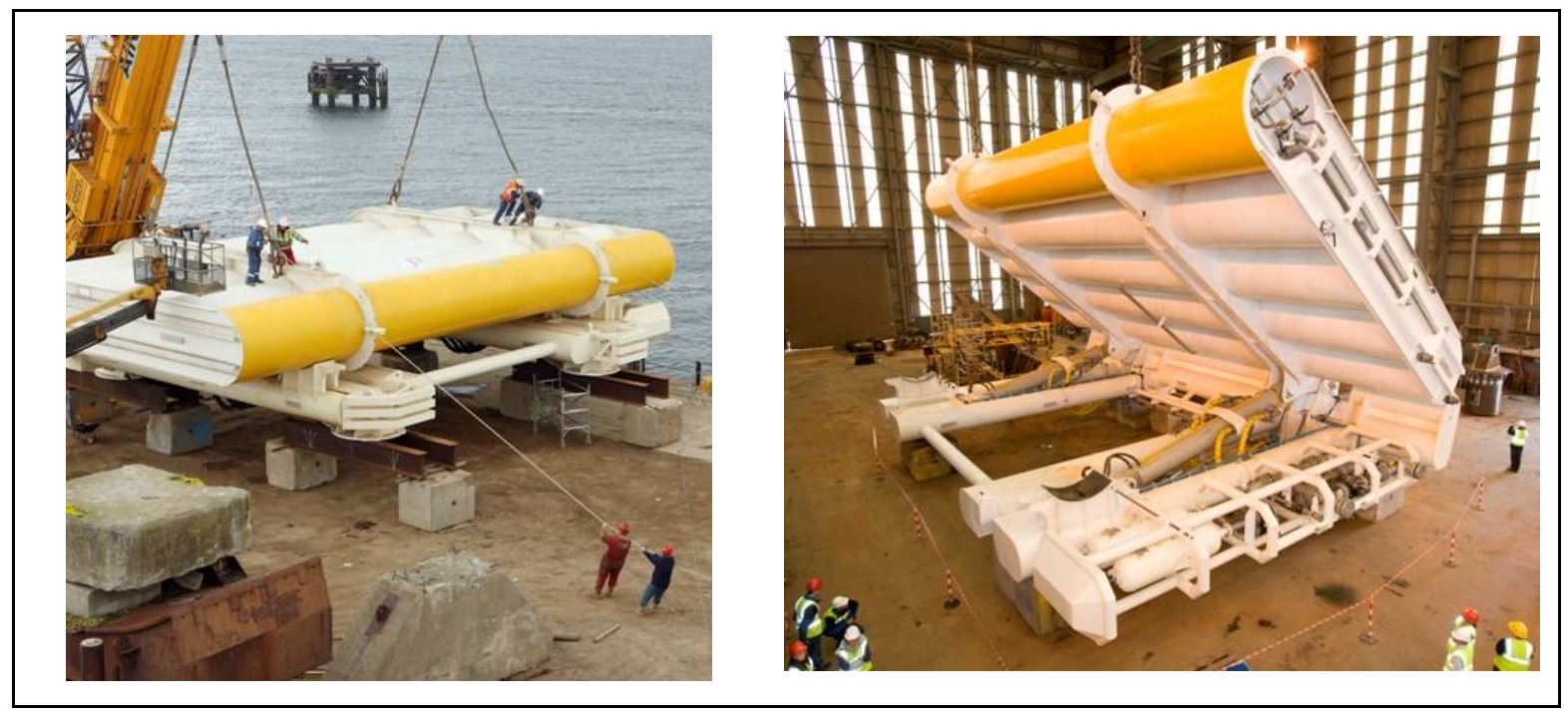

Figure 3-14: Aquamarine Power's Oyster

The peak power output per Oyster is $300-600 \mathrm{~kW}$. The Oyster benefits from the more consistent seas and narrower directional spread of waves found near shore, where reduced wave height and load enhance survivability. Aquamarine has several projects installed or in development, including a 315-kW device installed at Orkney, Scotland, with additional plans to develop up to $40 \mathrm{MW}$ at North West Lewis. The company is also exploring projects in Ireland and the West Coast of the United States.

\section{AW Energy (http://www.aw-energy.com/)}

The AW Energy WaveRoller device is a waving plate anchored on a plate that is placed directly on the sea bed. The back and forth movement of the surge moves the plate, using kinetic energy to drive a piston pump. The technology has evolved following numerous laboratory tests as well as marine tests conducted in the European Marine Energy Centre (EMEC), Scotland, and in Peniche, Portugal. A series of plates can be used to create an element farm and produce a larger power output. In this kind of element farm a series of piston pumps create a great deal of pressure, which is fed into a collection system that then drives hydraulic motor/generator combination(s) to produce electricity. 


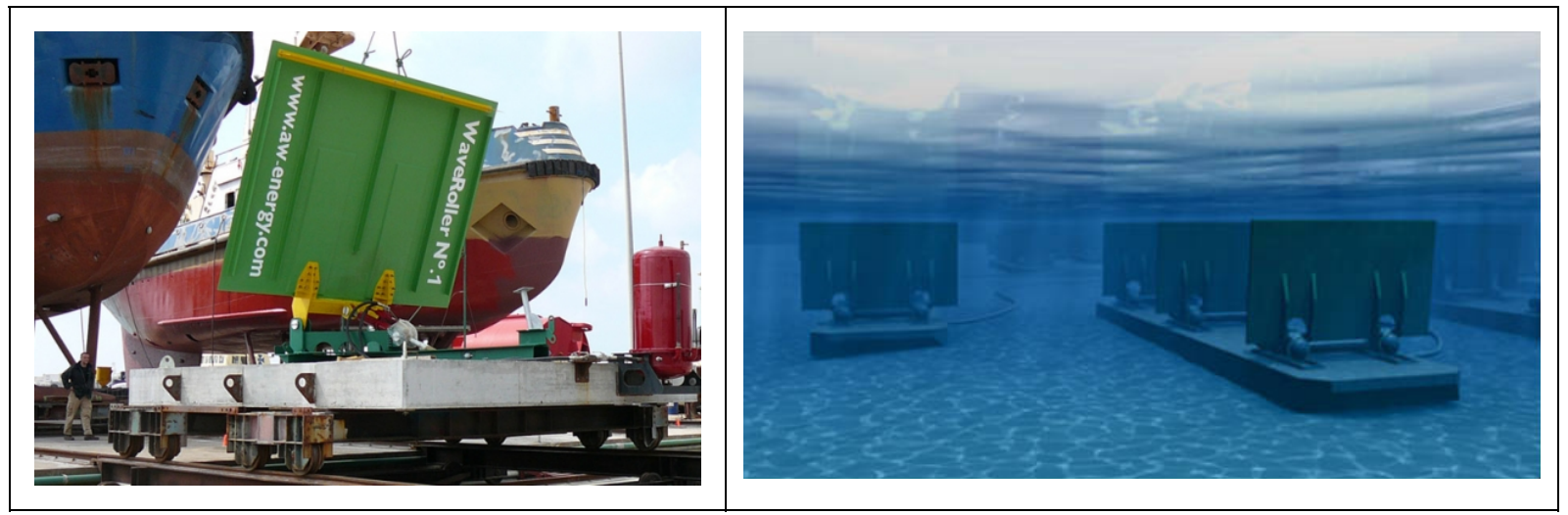

Figure 3-15: AW Energy WaveRoller

An individual production-sized plate is designed to produce a nominal capacity of up to 600$800 \mathrm{~kW}$ of electrical power depending on the site. Since the plant construction is modular and there is no natural upper limit to the number of plates that can be used, the WaveRoller offers a high level of scalability.

\subsubsection{Floating Oscillating Water Column}

The oscillating water column design generates power by using the oscillation of ocean waves to drive a column of pressurized air through a fan blade turbine. These devices can be configured on a floating platform with cavities that lead from the water surface to the open air. As ocean waves surge up through the cavities they push the air column through the turbine blades, which turns the generator. As waves fall back through the cavity, they create suction, which also forces air through the blades. The turbine is designed so that the blades turn the same direction regardless of the direction of air flow. The platform is moored to the sea floor using cables.

\section{Oceanlinx (http://www.oceanlinx.com)}

Oceanlinx, originally referred to as the Energetech, is one of the older WEC technologies, and has been evolving over the last decade. The company has produced multiple generations of devices and is now preparing to launch a 2.5-MW system. Oceanlinx is exploring its own Wells (reversible) air turbine as well as exploring one that has been developed by Dresser Rand. It is currently trying to acquire FERC permits for a Hawaii effort, and is exploring development in its home country of Australia. 


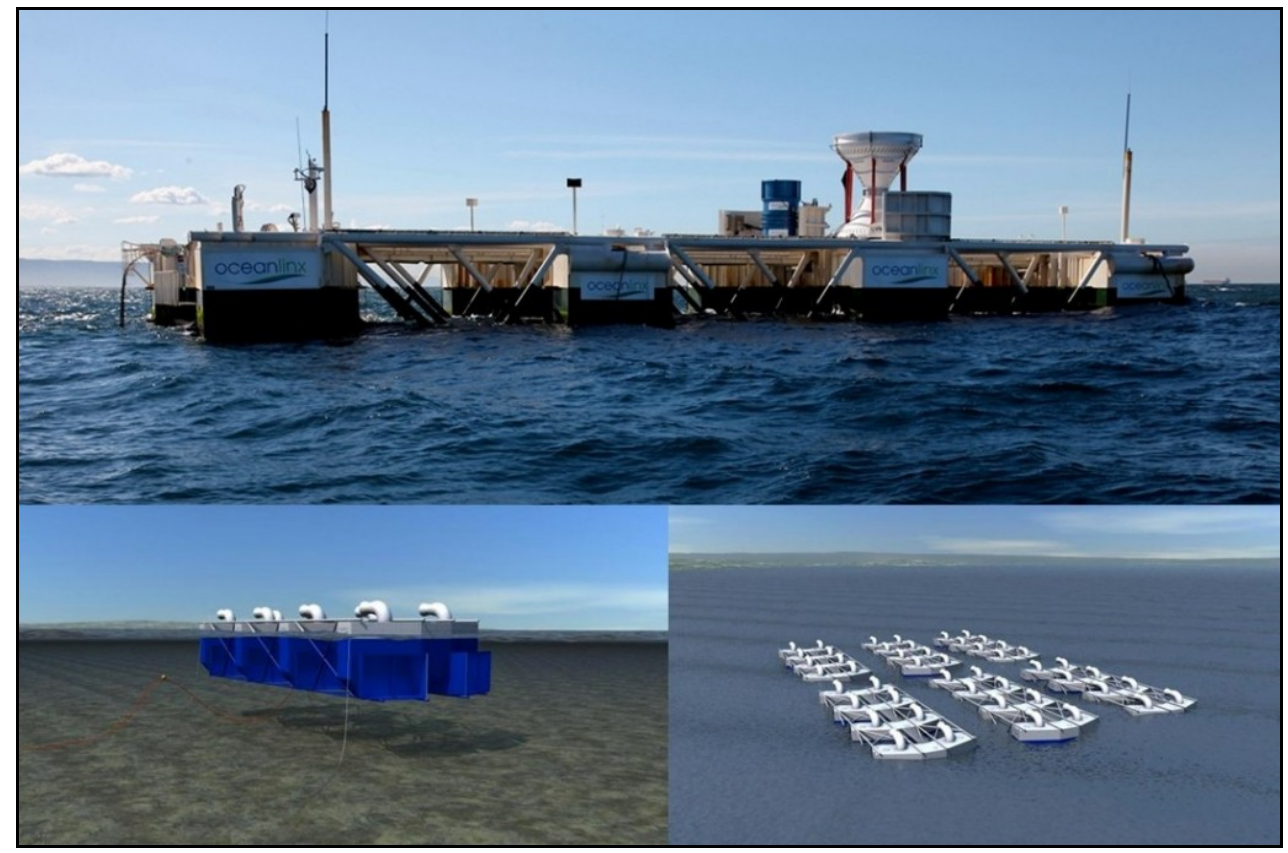

Figure 3-16: Oceanlinx

\section{OE Buoy (www.oceanenergy.ie/)}

The Irish company Ocean Energy has deployed its OE Buoy in Atlantic waves and demonstrated the ability to generate power and survive the rigors of the ocean, including surviving a 40-yearequivalent storm. Like Oceanlinx, Ocean Energy uses the Dresser-Rand Wells turbine. After testing a quarter-scale 300-kW design, the next generation OE Buoy is expected to produce approximately 1.2 MW. Ocean Energy has significant backing from the European Union, which is planning to use the current $\mathrm{OE}$ Buoy as part of a $€ 4.5$ million test facility.

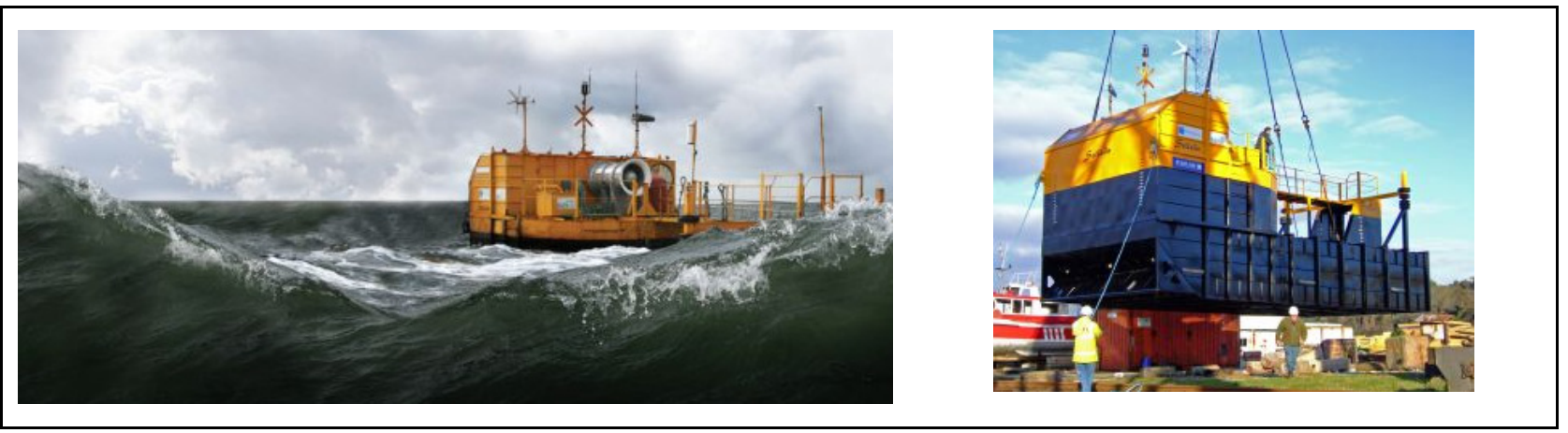

Figure 3-17: OE Buoy 


\subsection{Energy Production}

Forecasting the potential energy production of a WEC or array of WECs is difficult. There are many types of WEC devices, each with unique construction, operating strategies and properties. There are also many different ocean environments and wave characteristics, many of which will prove more suitable for some WECs than others.

In most cases, published data on WEC power response spectrums provide insufficient detail to assess power production claims. EPRI $2003^{21}$ discussed this in detail, and this section serves as an update on that effort. As stated by EPRI, the off-shore wind energy industry routinely publishes turbine performance data in the form of curves and/or tables depicting generated power as a function of wind speed, yet wave energy developers rarely provide similar data on generated power as a function of sea state. More transparent and forthcoming performance and cost data are necessary to support investment decisions and satisfy regulatory, environmental and permitting requirements.

The lack of power performance documentation makes it difficult to compare the likely performance of different WEC devices in a given wave climate. The underlying assumptions of how the WECoMs generate their power production estimates are not public. As the most immediately available data is in the form of significant wave height and period (as found in the NOAA NDBC database), this form of wave height and period should be the basis for preliminary estimates. It is understood that there are other assessments (including direction and spectrum) but, for rapid estimation purposes, utilities require a three-dimensional performance data chart such as has been produced by Pelamis (this is the equivalent of the power/wind speed graph as available for most wind powered generators). Such data provides the baseline with which the industry can be benchmarked and power utilities and investors can make purchasing decisions.

In order to estimate of the number of devices and possible configurations, PG\&E used historical records of wave states, combined with several available performance spectrums, to estimate total power production and availability. PG\&E used three datasets to make these estimates. For Humboldt, PG\&E used NDBC buoy 46212 (which has historical data back to mid-2004). PG\&E also used data collected from its Diablo Canyon Power Plant (DCPP) WaveRider Buoy (NDCP 46215), which has over 20 years of historical data, and Buoy 46218, located near Vandenberg Air Force Base.

The capacity of a wave energy device is dependent upon two parameters: significant wave height and wave period, referred to as the wave spectrum. Not all wave devices respond to the same conditions in the same way. For example, the approximate wave spectrum for Humboldt, based on the data collected by NOAA Buoy 46212, is shown in Figure 3-18. As can be seen, it has a bimodal pattern, with most of the energy residing in the 7- to 15-second range and the 1- to 5meter wave height range. It should be emphasized that this is the significant wave state and period, and that these are merely common measurement parameters of wave forms. The actual underlying wave states and periods that comprise the significant wave height and period are a

\footnotetext{
${ }^{21}$ EPRI 2003. Guidelines for Preliminary Estimation of Power Production by Off-shore Wave Energy Conversion Devices. E2I EPRI - WP - US - 001. December 22, 2003.
} 
much more complex wave form. Their determination is not discussed here, but discussions can be found in a number of resources, with the U.S. Army Corps of Engineers Coastal Engineering Manual $^{22}$ being an excellent starting point.

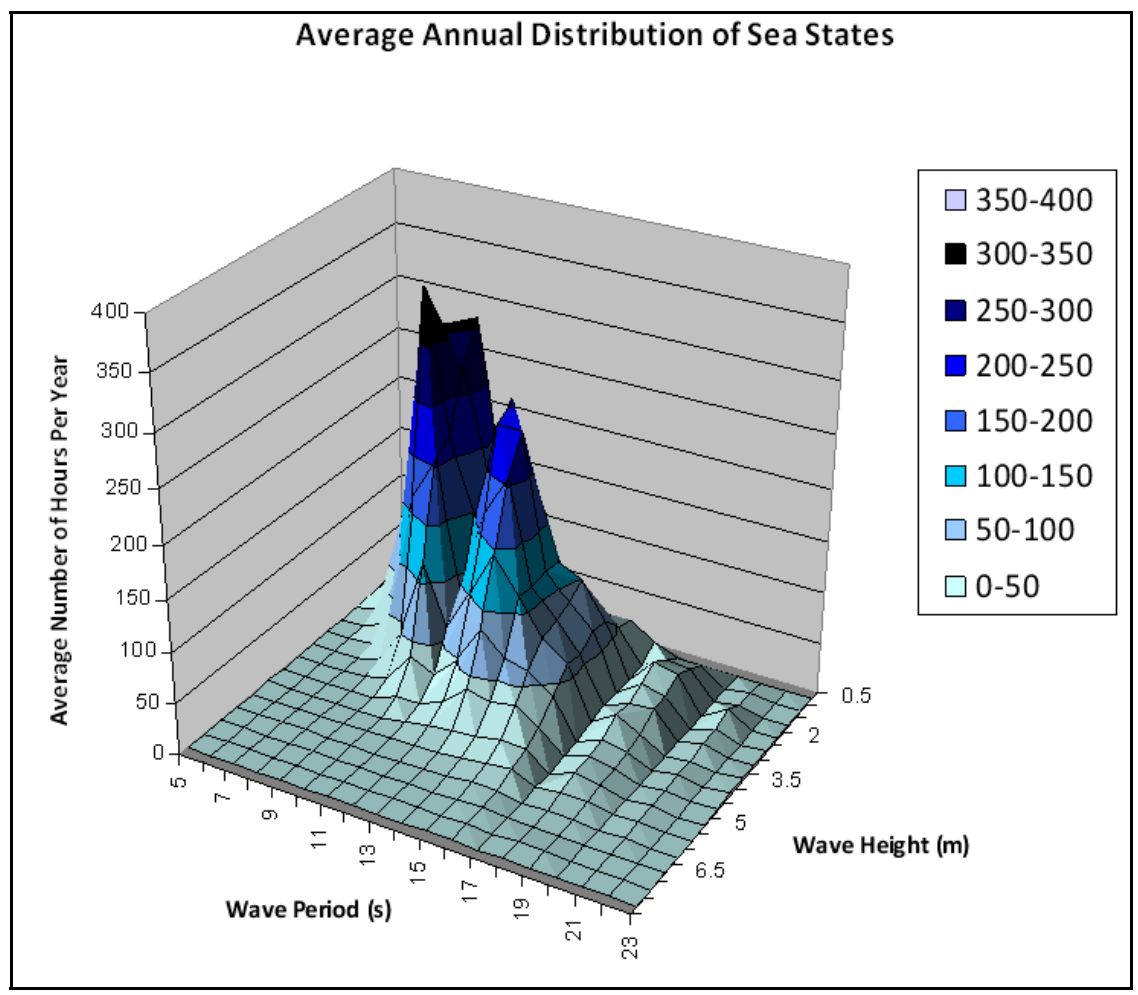

Figure 3-18: Wave Spectra for NDBC Station 46212-Humboldt Bay South Spit, California (Scripps 128)

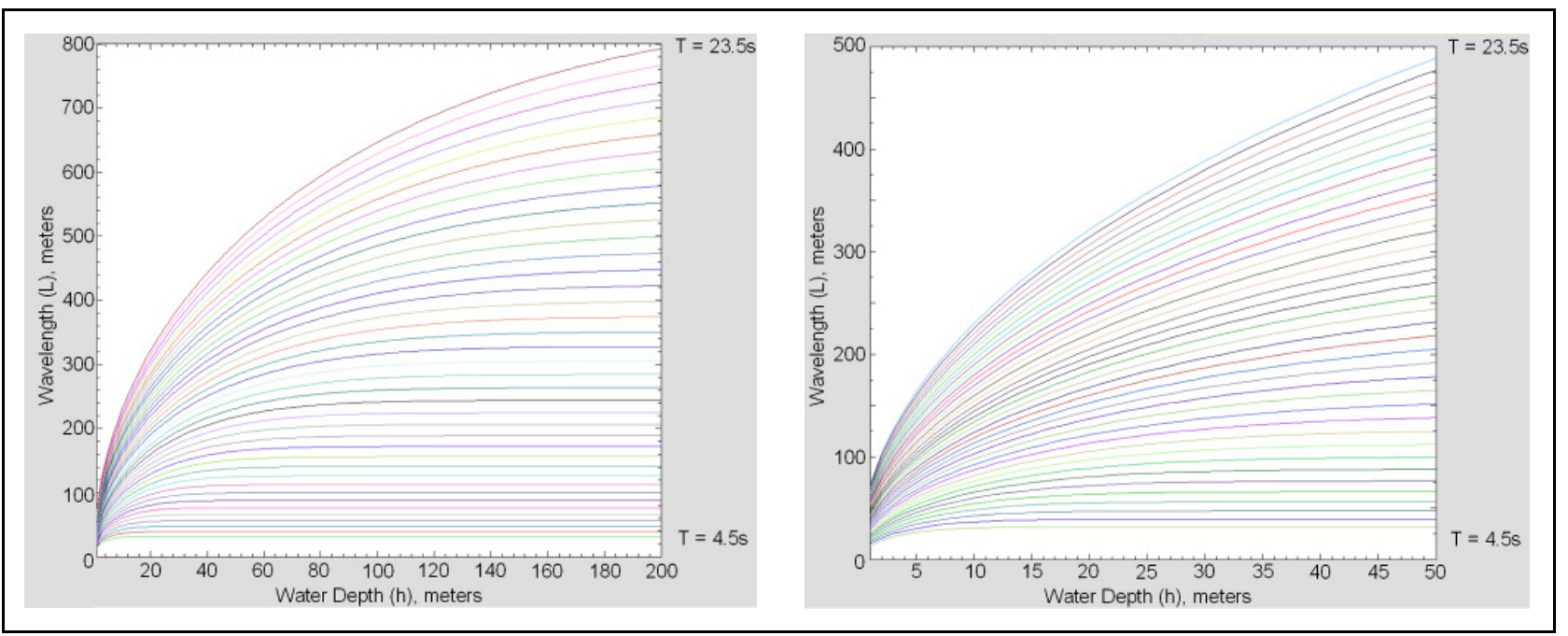

Figure 3-19: Wavelength vs. Period and Depth (using $\mathrm{MACE}^{23}$ )

${ }^{22}$ U.S. ACE Coastal Engineering Manual (EM 1110-2-1100) August 2008. http://chl.erdc.usace.army.mil/cem 
Figure 3-19 shows, for wave periods (T) ranging from 4.5 seconds to 23.5 seconds, how the wavelength changes as water depth varies from 0 to $200 \mathrm{~m}$ (left), with a close-up focusing on the 0 to $50 \mathrm{~m}$ range (right). For small periods, wavelength is relatively unaffected until fairly shallow depths. But for long-period waves that contain significant energy, the wave begins to be affected by the seafloor at very large depths.

Table 3-2 shows the influence of depth on various wave parameters (wavelength, velocity, etc). Depth has a very large influence on the various wave states. This is one reason that many WECoMs prefer deeper depths for their WECs. As longer waves interact with the seafloor they lose energy, depleting profitable power spectra.

For the 15-second period waves mentioned earlier, wavelengths are impacted starting around 120 meters of water depth. Water depth changes the spectrum of significant wave height vs. period, extracting energy as the waves approach the coast. Figure 3-20 shows the distance from the California coast at which the depth of the seabed reaches $50 \mathrm{~m}$.

The bimodal spectrum seen in Figure 3-18 would be different in deeper waters. In order to evaluate this variable, PG\&E used the wave spectra found at multiple NOAA buoys along the California coast and energy absorption spectra for the Pelamis device (Figure 3-21) ${ }^{24}$. Figures 322 through 3-24 show the amount of produced energy, based on the Pelamis spectra, that a Pelamis device would produce at the current location of these buoys. The red area is the $50 \mathrm{~m}$ demarcation interval. Each color change represents 10 meters in seawater depth.

\footnotetext{
${ }^{23}$ Created using Matlab and Wavelenvsth.m by Gabriel Ruiz Martinez, http://www.oceanwave.jp/softwares/mace/index.php?MACE\%20Softwares\#tcdfee88

${ }^{24} \mathrm{http}$ ://www.pelamiswave.com/wp-content/uploads/2010/05/diagram03.jpg It could be hypothesized that Pelamis can tune their device by changing the draft of the Pelamis itself (by bringing water onboard). A reverse method is used by catamarans to keep them away from their natural frequency as would be associated with different wave regimes. Such a method could be used to absorb more energy, by tuning the Pelamis (and other types of resonant response devices) to different wave regimes. It is, however, unknown, if such an approach is used by Pelamis.
} 
Table 3-2: Dependence of Wave Characteristics on Depth (Army Corps of Engineers Coastal Engineering Manual ${ }^{25}$ )

\begin{tabular}{|c|c|c|c|}
\hline Relative Depth & Shallow Water & Transitional Water & Deep Water \\
\hline & $\frac{d}{L} \leq \frac{1}{20}$ & $\frac{1}{20}<\frac{d}{L} \leq \frac{1}{2}$ & $\frac{1}{2}<\frac{d}{L}$ \\
\hline & $k d \leq \frac{\pi}{10}$ & $\frac{\pi}{10}<k d \leq \frac{\pi}{2}$ & $\frac{\pi}{2}<k d$ \\
\hline 1. Wave Profile & & $\eta=\frac{H}{2} \cos \left(\frac{2 \pi x}{L}-\frac{2 \pi t}{T}\right)=\frac{H}{2} \cos \theta$ & \\
\hline 2. Wave Celerity & $C=\frac{L}{T}=\sqrt{g d}$ & $C=\frac{L}{T}=\frac{g T}{2 \pi} \tanh \left(\frac{2 \pi d}{L}\right)$ & $C=C_{0}=\frac{L}{T}=\frac{g T}{2 \pi}$ \\
\hline 3. Wavelength & $L=T \sqrt{g d}=C T$ & $L=\frac{g T^{2}}{2 \pi} \tanh \left(\frac{2 \pi d}{L}\right)$ & $L=L_{0}=\frac{g T^{2}}{2 \pi}=C_{0} T$ \\
\hline 4. Group Velocity & $C_{g}=C=\sqrt{g d}$ & $C_{g}=n C=\frac{C}{2}\left[1+\frac{4 \pi d / L}{\sinh (4 \pi d / L)}\right]$ & $C_{g}=\frac{C}{2}=\frac{g T}{4 \pi}$ \\
\hline \multicolumn{4}{|l|}{$\begin{array}{l}\text { 5. Water Particle } \\
\text { Velocity }\end{array}$} \\
\hline (a) Horizontal & $u=\frac{H}{2} \sqrt{\frac{g}{d}} \cos \theta$ & $u=\frac{H}{2} \frac{g T}{L} \frac{\cosh [2 \pi(z+d) / L]}{\cosh (2 \pi d / L)} \cos \theta$ & $u=\frac{\pi H}{T} \exp \left(\frac{2 \pi x}{L}\right) \cos \theta$ \\
\hline (b) Vertical & $w=\frac{H \pi}{T}\left(1+\frac{z}{d}\right) \sin \theta$ & $w=\frac{H}{2} \frac{g T}{L} \frac{\sinh [2 \pi(z+d) / L]}{\cosh (2 \pi d / L)} \sin \theta$ & $w=\frac{\pi H}{T} \exp \left(\frac{2 \pi x}{L}\right) \sin \theta$ \\
\hline \multicolumn{4}{|l|}{$\begin{array}{l}\text { 6. Water Particle } \\
\text { Acceleration }\end{array}$} \\
\hline (a) Horizontal & $a_{x}=\frac{H \pi}{T} \sqrt{\frac{g}{d}} \sin \theta$ & $a_{x}=\frac{g \pi H}{L} \frac{\cosh [2 \pi(z+d) / L]}{\cosh (2 \pi d / L)} \sin \theta$ & $a_{x}=2 H\left(\frac{\pi}{T}\right)^{2} \exp \left(\frac{2 \pi x}{L}\right) \sin \theta$ \\
\hline (b) Vertical & $a_{z}=-2 H\left(\frac{\pi}{T}\right)^{2}\left(1+\frac{z}{d}\right) \cos \theta$ & $a_{z}=-\frac{g \pi H}{L} \frac{\sinh [2 \pi(z+d) / L]}{\cosh (2 \pi d / L)} \cos \theta$ & $a_{z}=-2 H\left(\frac{\pi}{T}\right)^{2} \exp \left(\frac{2 \pi x}{L}\right) \cos \theta$ \\
\hline \multicolumn{4}{|l|}{$\begin{array}{l}\text { 7. Water Particle } \\
\text { Displacement }\end{array}$} \\
\hline (a) Horizontal & $\xi=-\frac{H T}{4 \pi} \sqrt{\frac{g}{d}} \sin \theta$ & $\xi=-\frac{H}{2} \frac{\cosh [2 \pi(z+d) / L]}{\sinh (2 \pi d / L)} \sin \theta$ & $\xi=-\frac{H}{2} \exp \left(\frac{2 \pi x}{L}\right) \sin \theta$ \\
\hline (b) Vertical & $\zeta=\frac{H}{2}\left(1+\frac{z}{d}\right) \cos \theta$ & $\zeta=\frac{H}{2} \frac{\sinh [2 \pi(z+d) / L]}{\sinh (2 \pi d / L)} \cos \theta$ & $\zeta=\frac{H}{2} \exp \left(\frac{2 \pi x}{L}\right) \cos \theta$ \\
\hline $\begin{array}{l}\text { 8. Subsurface } \\
\text { Pressure }\end{array}$ & $p=\rho g(\eta-z)$ & $p=\rho g \eta \frac{\cosh [2 \pi(z+d) / L]}{\cosh (2 \pi d / L)} \cos \theta-\rho g z$ & $p=\rho g \eta \exp \left(\frac{2 \pi x}{L}\right)-\rho g z$ \\
\hline
\end{tabular}

${ }^{25}$ Vincent, L., and Demirbilek, Z. (editors), Water Wave Mechanics. Coastal Engineering Manual, Part II, Hydrodynamics, Chapter II-1, Engineer Manual 1110-2-1100, U.S. Army Corps of Engineers, Washington, DC. 
50 m depth line

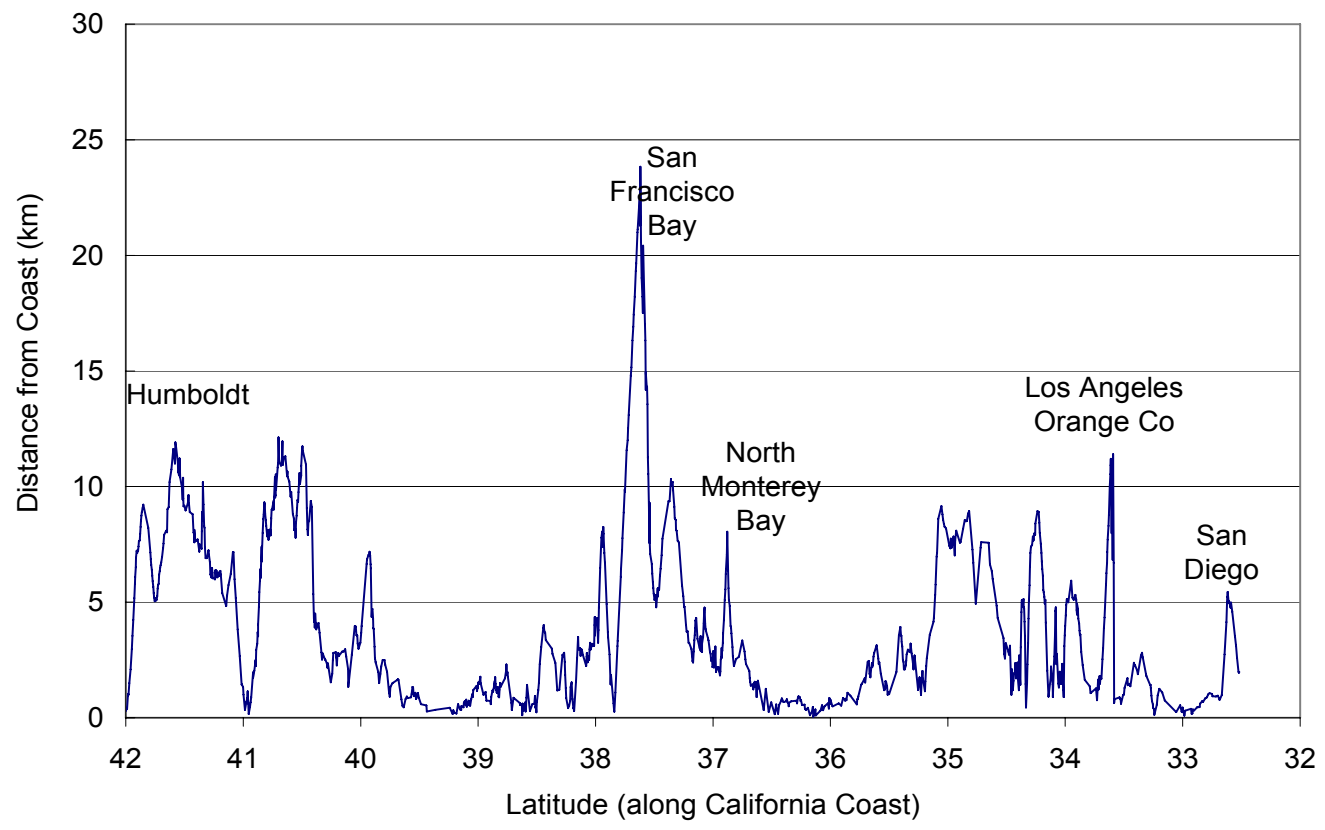

Figure 3-20: Distance from Coast at which $50 \mathrm{~m}$ Depth Occurs

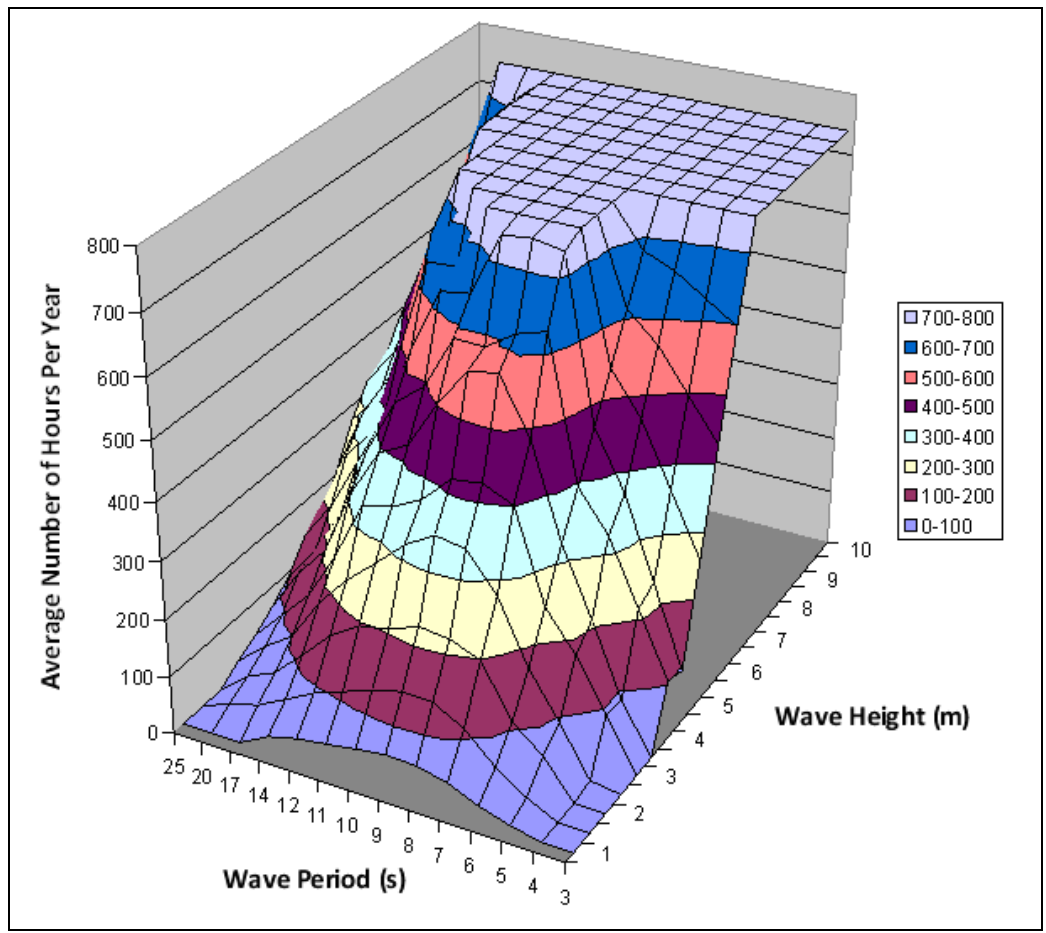

Figure 3-21: Pelamis Power Response Spectra 


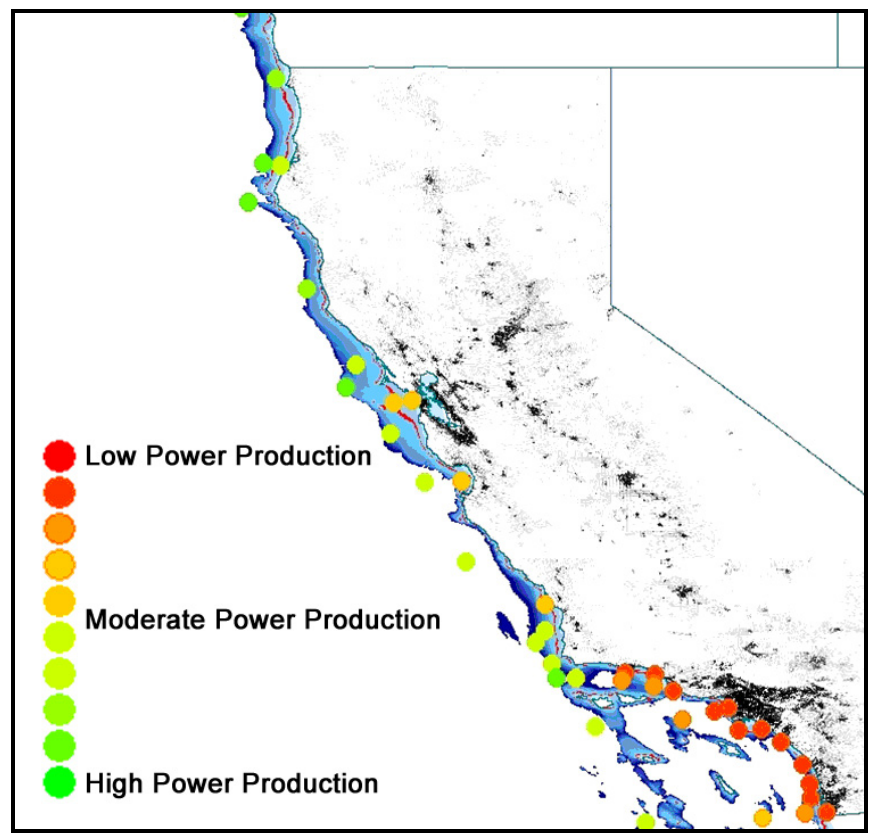

Figure 3-22: Hypothetical power production (based on Pelamis power spectra) at NDBC buoys along the California coast. Red indicates the $50 \mathrm{~m}$ demarcation.

Figures 3-23 and 3-24 show the hypothetical power production in Northern and Southern California based on the Pelamis power spectra, with a marked decrease in production capability due to the sheltering effect of the Channel Islands and the shallow depths of the continental shelf found off the Los Angeles and San Diego coastlines. Figure 3-25 graphs the estimated capacity factor by latitude, once again based on the Pelamis spectra and data from the NOAA buoy network, showing a general decline from north to south.

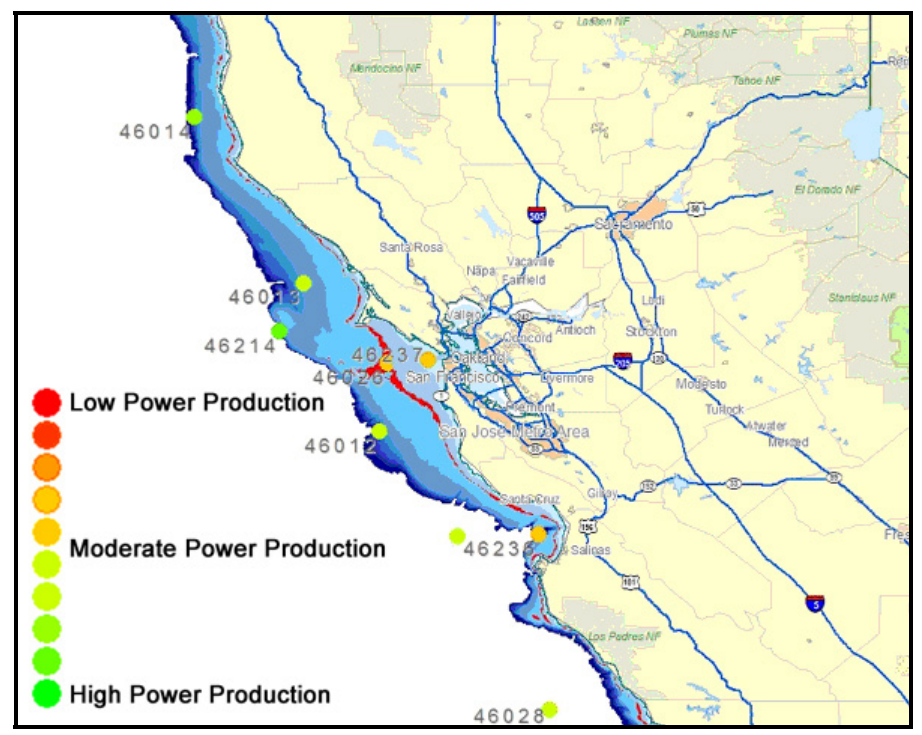

Figure 3-23: Hypothetical power production (based on Pelamis power spectra) at various NDBC buoys around the San Francisco Bay Area 


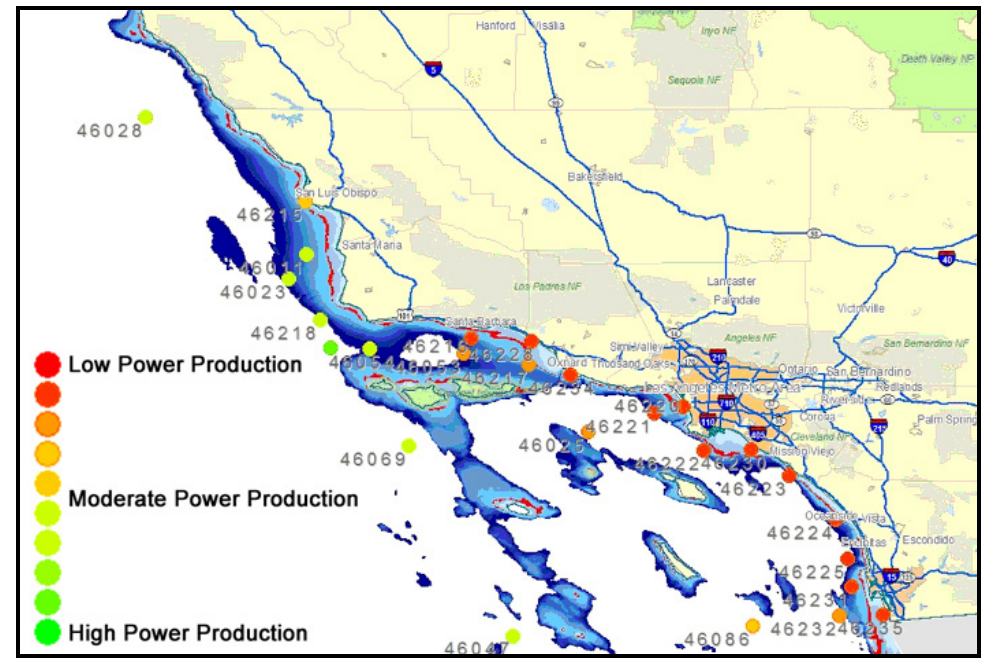

Figure 3-24: Hypothetical power production (based on Pelamis power spectra) at various NDBC buoys in Southern California waters

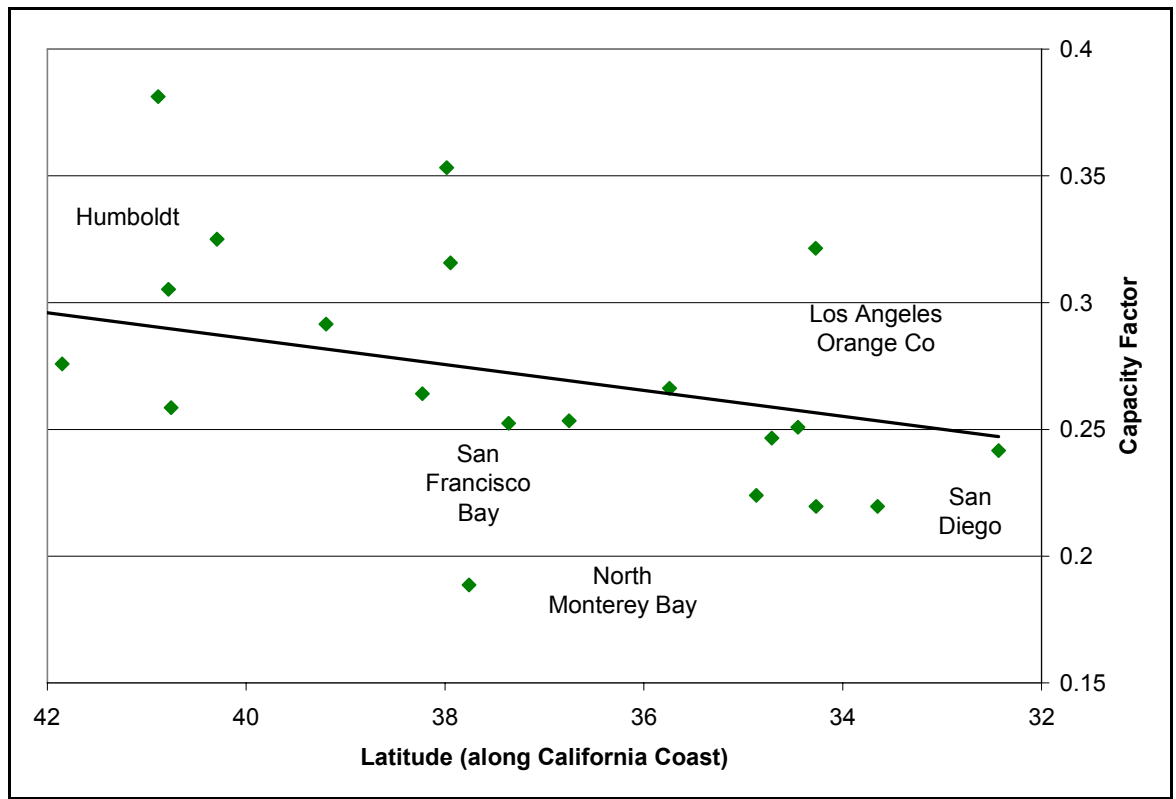

Figure 3-25: Trend of hypothetical capacity factor in deeper waters (based on Pelamis power spectra) at various NDBC buoys

\subsubsection{WEC Responses to Wave Energy Spectra}

WEC devices respond differently to different wave states. Some respond to low-period high wave heights, while others are more responsive to high-period lower wave heights. Figures 3-26 and 3-27 show power spectra for an unnamed point absorber device and the 
Energetech/Oceanlinx Power Matrix ${ }^{26}$ oscillating water column device. Comparing these to the Pelamis, PG\&E notes that each reacts differently to different wave heights and periods.

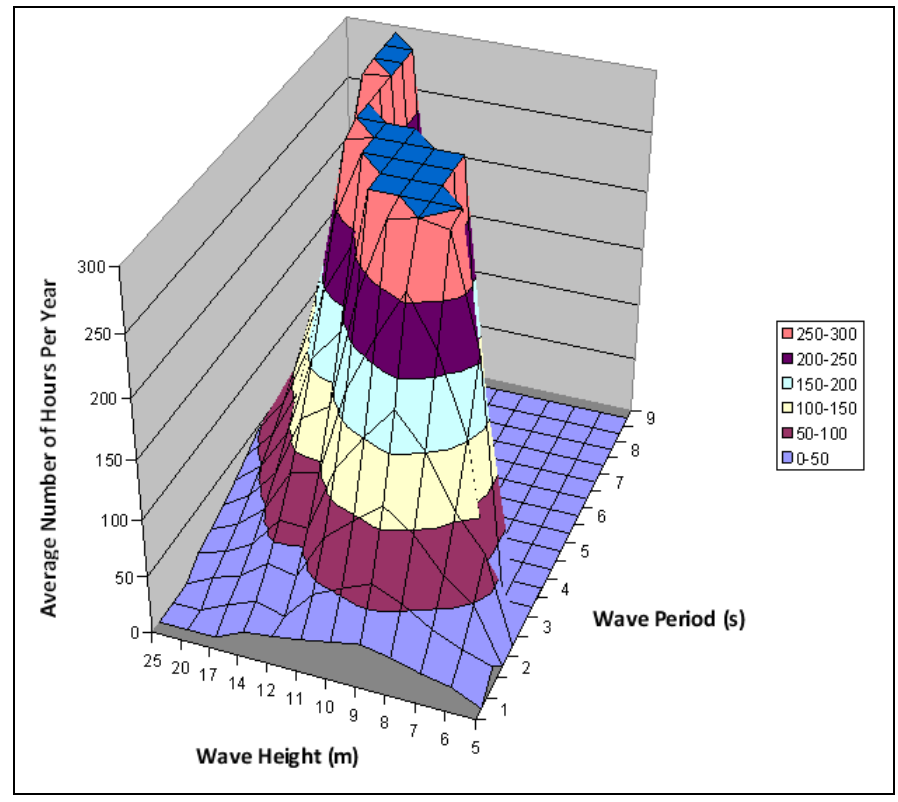

Figure 3-26: Point Absorber Power Response Spectra

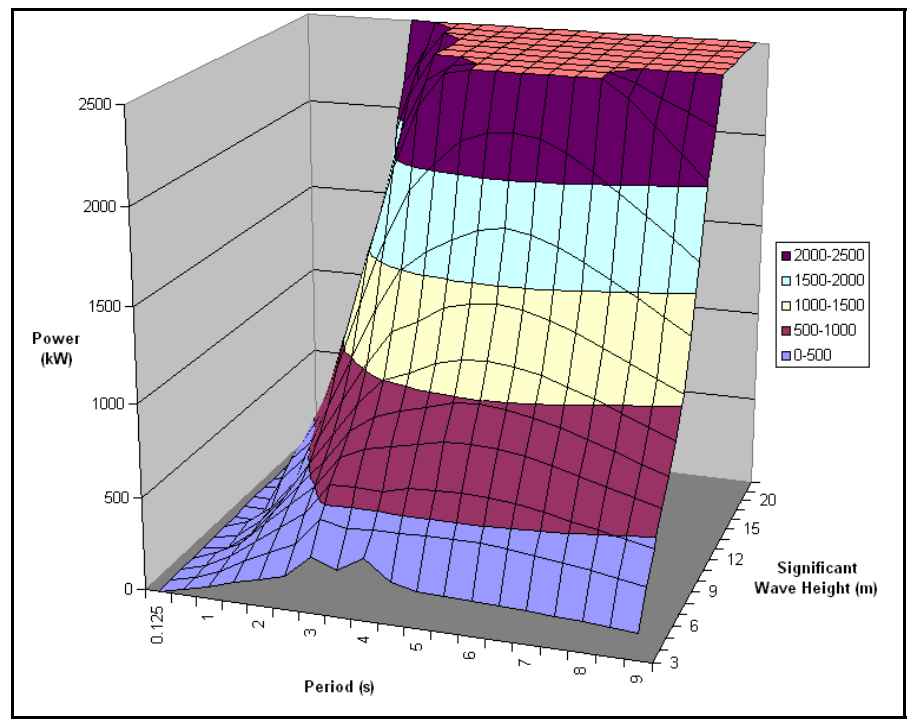

Figure 3-27: Energetech/Oceanlinx Power Response Spectra (based on EPRI 2004, extrapolated).

\footnotetext{
${ }^{26}$ Figure 3-27 is a modification of the Energetech matrix found in the EPRI wave reports, scaled to a 2.5-MW maximum production. The actual Oceanlinx output is not included.
} 
Applying a typical local wave spectrum, PG\&E found that even though the Pelamis is rated as a $750-\mathrm{kW}$ device it is less responsive to the wave spectrum zone found along the California Coast than the smaller point absorber device. The greater efficiency of the point absorber device is due to its resonant response, while the Pelamis device (based on the spectra published by Pelamis) operates more on a wave-frequency-capture mode that is somewhat independent of wave height. However, changing the mass of the Pelamis by pumping water in or out of the device may open the possibility of tuning it to respond better at lower periods.

In comparison, oscillating water column devices like Energetech's capture more of the lowperiod, high wave events and require the resonant chamber to be sized correctly to the wave spectrum. It is therefore possible that the generic spectrum as developed here is not representative of any final design for California.

\subsubsection{Capacity Factor}

The net capacity factor of a power plant is the ratio of its actual output over a period of time to its potential output if it had operated at full nameplate capacity the entire time. Almost all known WEC devices are designed to maximize power production in the winter months, although in California the actual system demand during the winter is significantly less than in the summer, when wave power is at its minimum. The reason for maximizing winter power is that the cost of the generator is relatively small compared to that of a total WEC installation, and so it is worthwhile for most manufacturers to maximize the output per device.

It is possible to calculate the approximate maximum power using linear wave theory. As was seen earlier, as waves approach the near-shore environment, non-linear effects start to dominate and waves lose energy to the underlying sea flow. However, the total wave power (before losses) can be calculated using the deep-water equation to calculate power density. This equation will yield maximum power results:

$$
P_{0}=0.49 T_{e}\left(H_{m 0}\right)^{2}
$$

where $\mathrm{T}_{\mathrm{e}}$ is the wave period in seconds and $\mathrm{H}_{m 0}$ is the wave height in meters.

The real power that can be absorbed is less, as many of the devices are only exposed to a portion of the wave spectrum from the sea surface to where the wave energy drops off at depth, and the devices themselves respond in different fashions to the incoming wave spectra.

To explore this, PG\&E created a hypothetical mix of three different wave energy devices. Each set was designed to produce a maximum of $10 \mathrm{MW}$ per technology, for a total maximum production of $30 \mathrm{MW}$. For the hypothetical setup, the system requires four Energetech devices, 14 Pelamis, and 34 point absorber systems. 
Figure 3-28 shows the average monthly power output by time of year for the hypothetical array based on wave data from the Humboldt site. The Energetech ${ }^{27}$ Oceanlinx does very well in tracking monthly wave height. This is unsurprising, as its power absorption spectra is more dependent upon wave height, and so it responds well to the higher winter swells and less well to the lower summer swells. The point absorber has the most consistent capacity.

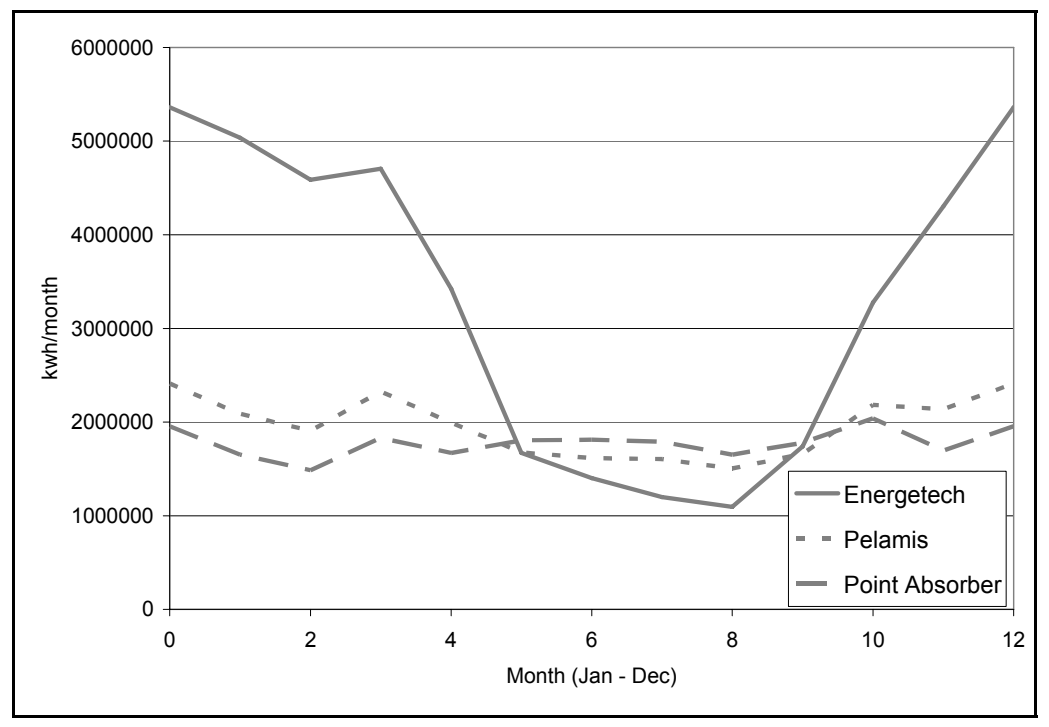

Figure 3-28: Monthly Average Power Output for a Given Mix of Energetech, Pelamis, and Point Absorber in the Eureka Area (assuming a $10 \mathrm{MW}$ maximum rating for each type).

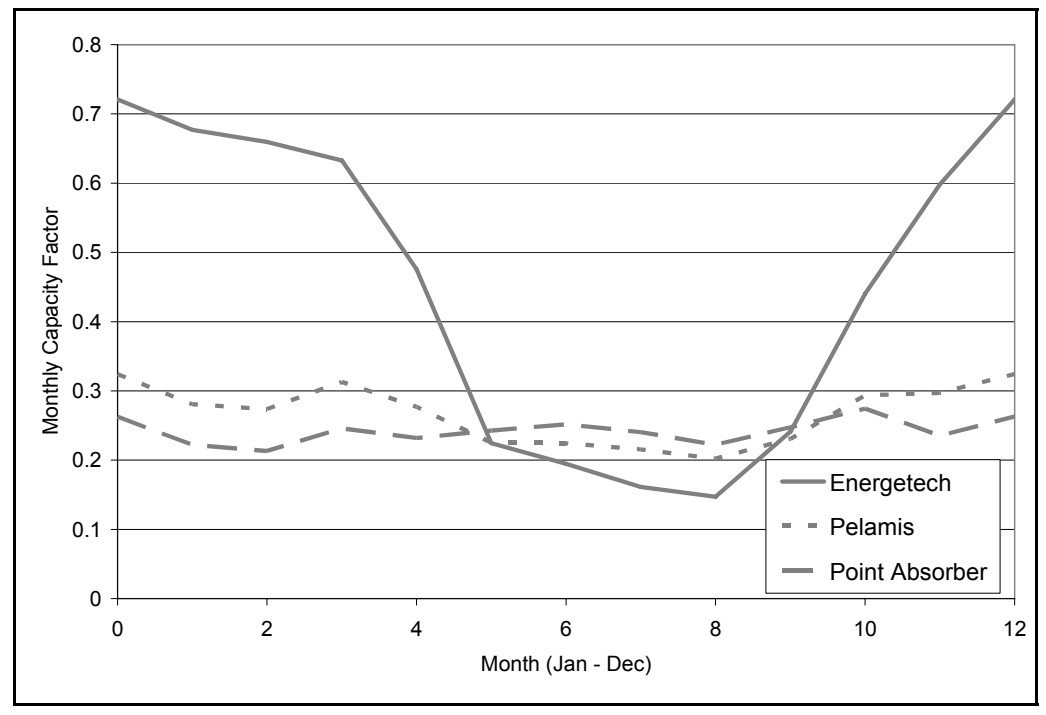

Figure 3-29: Monthly Average Capacity Factor for a Given Mix of Energetech, Pelamis, and Point Absorber in the Eureka Area

${ }^{27}$ As stated earlier, the Energetech (Oceanlinx) response spectra is based upon the one found in EPRI's report (EPRI 2004) and likely does not represent current capabilities, which may have evolved due to significant work on the power output device. 
Pelamis devices, which have a wide power absorption spectrum (that is more dependent upon period) produces slightly greater output in winter months than the point absorber and slightly lower output in summer months. Figure 3-29 shows the monthly average capacity factor based on the maximum device power output. The overall capacity factor based on this setup of different WECs was approximately $31.2 \%$.

Another consideration is the fact that the summer high-demand months are when the WECoMs may prefer to do maintenance due to the calmer sea states, conflicting with utilities' need for maximum production. Consequently, maintenance will need to be fit in either during spring (preferably) or fall (if spring storms make the devices inaccessible).

Figure 3-30 shows the cumulative forecast power production for January and July based on a five-year period of historical wave data.

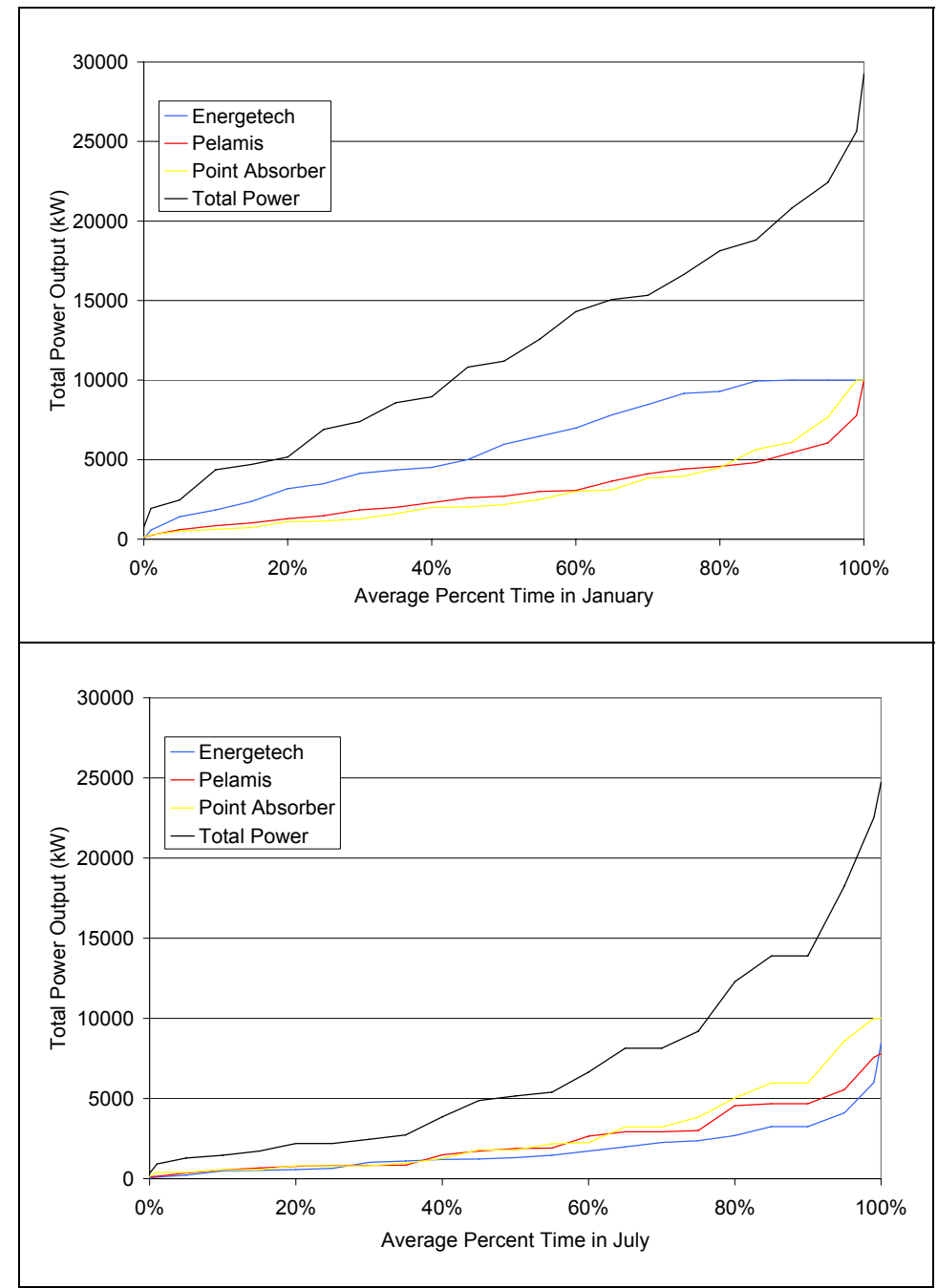

Figure 3-30: Cumulative Power Output for the Three-Device Array in January and July (assuming a $10 \mathrm{MW}$ maximum production per device type). 
These figures support the previous estimate of average power output and indicate that the threedevice array rarely achieves its total $30 \mathrm{MW}$ of generation (only $2 \%$ of the time in January). However, $50 \%$ of the time in January and July it produces at least $12 \mathrm{MW}$ and $5 \mathrm{MW}$, respectively. Also, 25\% of the time in January and July it produces at least $17.5 \mathrm{MW}$ and $8 \mathrm{MW}$, respectively.

Considering the expense of the initial electrical cable array, these figures indicate that, at least for earlier generation WEC systems, having a cable with an overall carrying capability less than the maximum power rating for all the devices may be a more cost-effective option.

Figure 3-31 shows hourly production for the hypothetical wave device array in January and July based on historical wave data gathered over a four-year period. Although its output appears very variable over the course of a month, and is very different in winter (January) than summer (July), on a daily basis its consistency compares favorably to wind. 


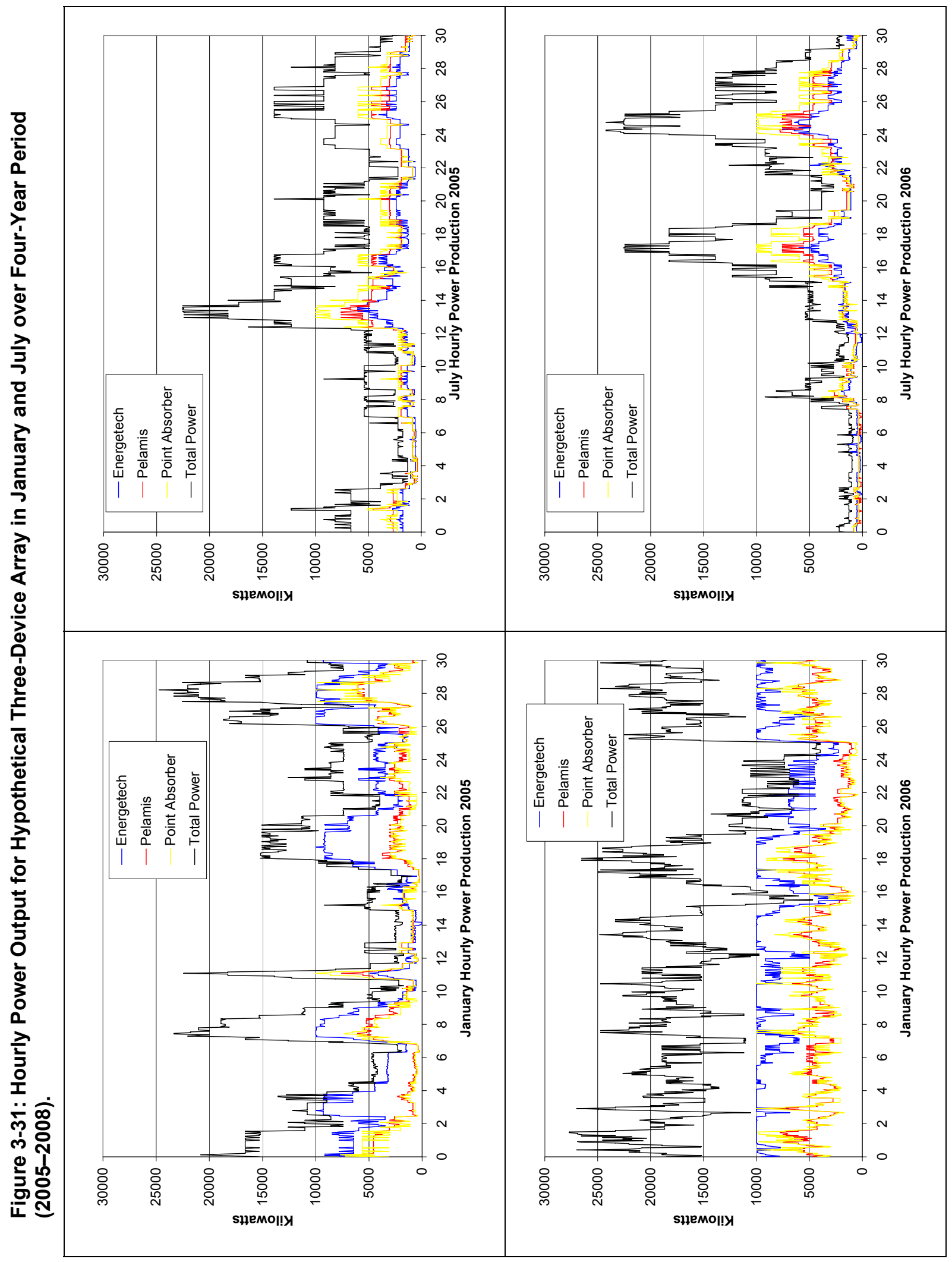




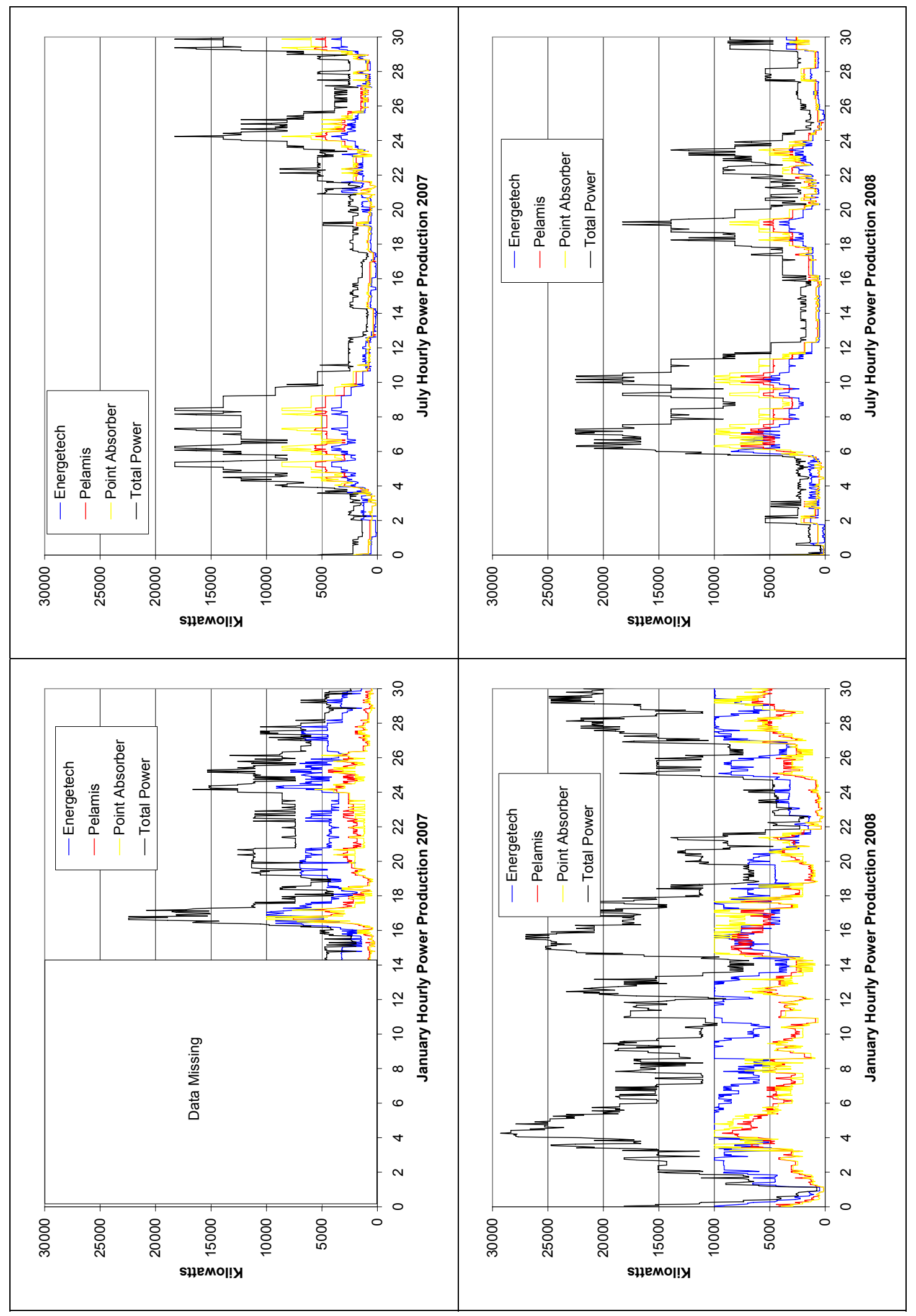


Figure 3-32 shows a typical daily wind power production curve versus a typical July daily wave energy production curve. The challenge then is to determine the "daily" capacity factor and the forecastability of the power output. This is of significance because PG\&E attempts to provide power production that matches expected demand using weather forecasting. Power that must be purchased at the last minute is typically expensive; power that is unpredictable is valued less. For example, wind power can be somewhat unpredictable up until the day or sometimes even within a few hours of its planned usage, which lessens its value to a utility. Wave power is no more variable, and it is more consistent in that it can be forecast several days in advance, making it more valuable to a utility. These results do suggest that a mix of technologies with different wave power absorption spectra may be advantageous.
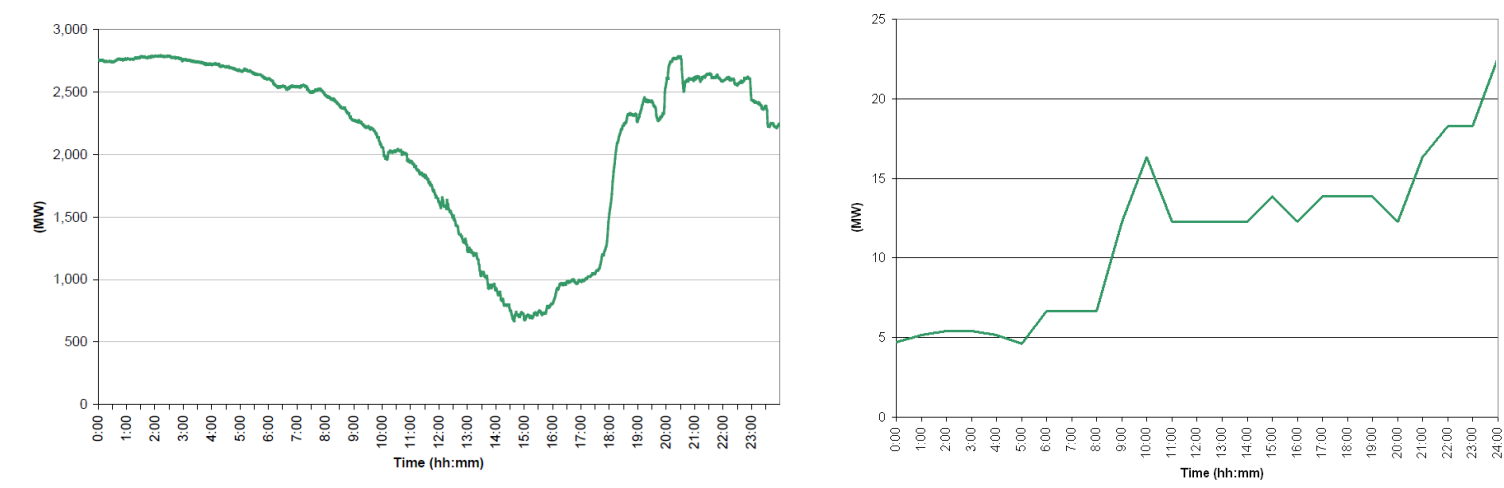

Figure 3-32: Typical Daily Variability in Power Output for Wind ${ }^{28}$ (left) and for Wave (right) Power

To examine variability, PG\&E assessed the step change per hour for the hypothetical 30-MW facility based on the total wave spectra at Humboldt from early 2004 to 2011 (Figure 3-33).

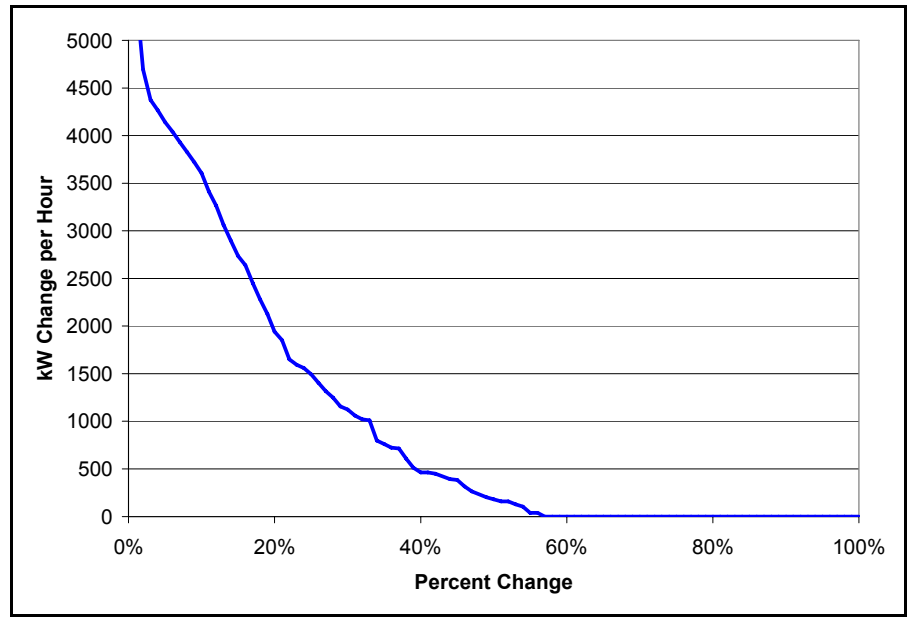

Figure 3-33: Step changes per hour (in kW) for a hypothetical 30-MW wave power facility in Humboldt, 2004-2011

${ }^{28}$ 2008, Wan, Y-H. Summary Report of Wind Farm Data. NREL/TP-500-44248, May, 2009. 
More than $44 \%$ of the time the hourly output was "flat," meaning no significant change from hour to hour, which demonstrates good consistency. An additional $23 \%$ of the time, step changes in hourly output were less than $1 \mathrm{MW}(1000 \mathrm{~kW})$. Step changes from $1 \mathrm{MW}$ to $2 \mathrm{MW}$ occurred approximately $13 \%$ of the time, with step changes exceeding 2 MW occurring $20 \%$ of the time. Only $1 \%$ of the total step changes exceeded $5 \mathrm{MW}$. Combined with forecastability, step changes of this magnitude are not significant, and show that wave power can be considered to be a fairly consistent performer.

\subsection{Site Options along the California Coastline}

There are multiple suitable wave energy sites along the California coastline, and multiple variables associated with each alternative. All are highly individualistic in terms of distance and depth. Among the issues that must be examined in siting are those associated with site depth, distance from shore, transmission access and expandability, ports available for construction, and emergency response. Although the final decision analysis would be best served by incorporating the various aspects into a GIS framework and then applying a ranking score to each attribute, this effort focuses on a qualitative assessment of each of the components. A goal for developing future sites should include incorporating these various choices into a decision tree to develop a logical basis for action.

A brief discussion of regulatory oversight and how it could impact a final decision was included in Chapter 2. It suffices to say that there are multiple regulatory regimes and the success or failure of getting a permit or lease through them affects any overall final decision as to where to place a facility. For purposes of discussion here, two distance characteristics are examined: one on the Inner Continental Shelf (ICS) and one on the Outer Continental Shelf (OCS). Any facility built on the OCS has the immediate cost disadvantage of requiring a much longer electrical cable, although devices placed on the OCS would have access to more of the full wave regime than devices placed closer to shore. The influence of depth was discussed earlier in Section 3.4.

Of interest is why Humboldt and Fort Bragg (and later Central Coast) were chosen. It was felt that the electrical demands in Humboldt and Fort Bragg — which both experience high electricity demand in the winter months because most homes in the area are electrically heated-were good fits to the yearly output of many WEC technologies. Fort Bragg was excluded due to its poor port access for towing in wave devices (Appendix $S A I C B$ ). As was learned in later discussions with the WECoMs, many manufacturers felt that repairs to their devices could be accomplished with a small fishing boat or helicopter, meaning that port access was no longer as big a consideration (although it is still true that some devices may need a local port). Central Coast was chosen due to its proximity to VAFB and the excellent grid capabilities in the Central Coast area.

Grid access and capacity for delivery to the main transmission line corridors are major considerations in wave project site selection, since wave energy potential is generally similar along the entire coast. Port and ship access is likely a secondary consideration (and is discussed in Appendix SAIC $W$ for the North Coast area), but is itself dependent upon the technology type. 


\section{Access to Transmission Corridors and Substations}

There are currently few transmission line access points to the ocean environment within PG\&E's service territory. Most of these are located around San Francisco Bay and to the south. Any initial wave energy development effort should focus on access points that take advantage of current transmission capacity, since the expense of building new transmission lines can be substantial, especially in the mountainous and rugged environs of the California coast.

An estimated capacity available for various configuration options is included in the analysis, as well as a preliminary interconnection plan/cost estimate in order to determine an initial size. No consideration was given to proposed projects in the CAISO queue, or to local power needs that may act as a "sink." All initial estimates are based around multiples of $30 \mathrm{MW}$, as that is considered to be an initial cost-effective cable capacity for any of the first build-outs. It is capped at $180 \mathrm{MW}$, under the assumption that there would be a requirement for understanding the impact of smaller-capacity systems before any system is proposed at larger capacities.

\subsubsection{North Coast}

Along the North Coast south of Humboldt from Sonoma to Fort Bragg is an almost continuous run of $60-\mathrm{kV}$ transmission line (Figure 3-34).

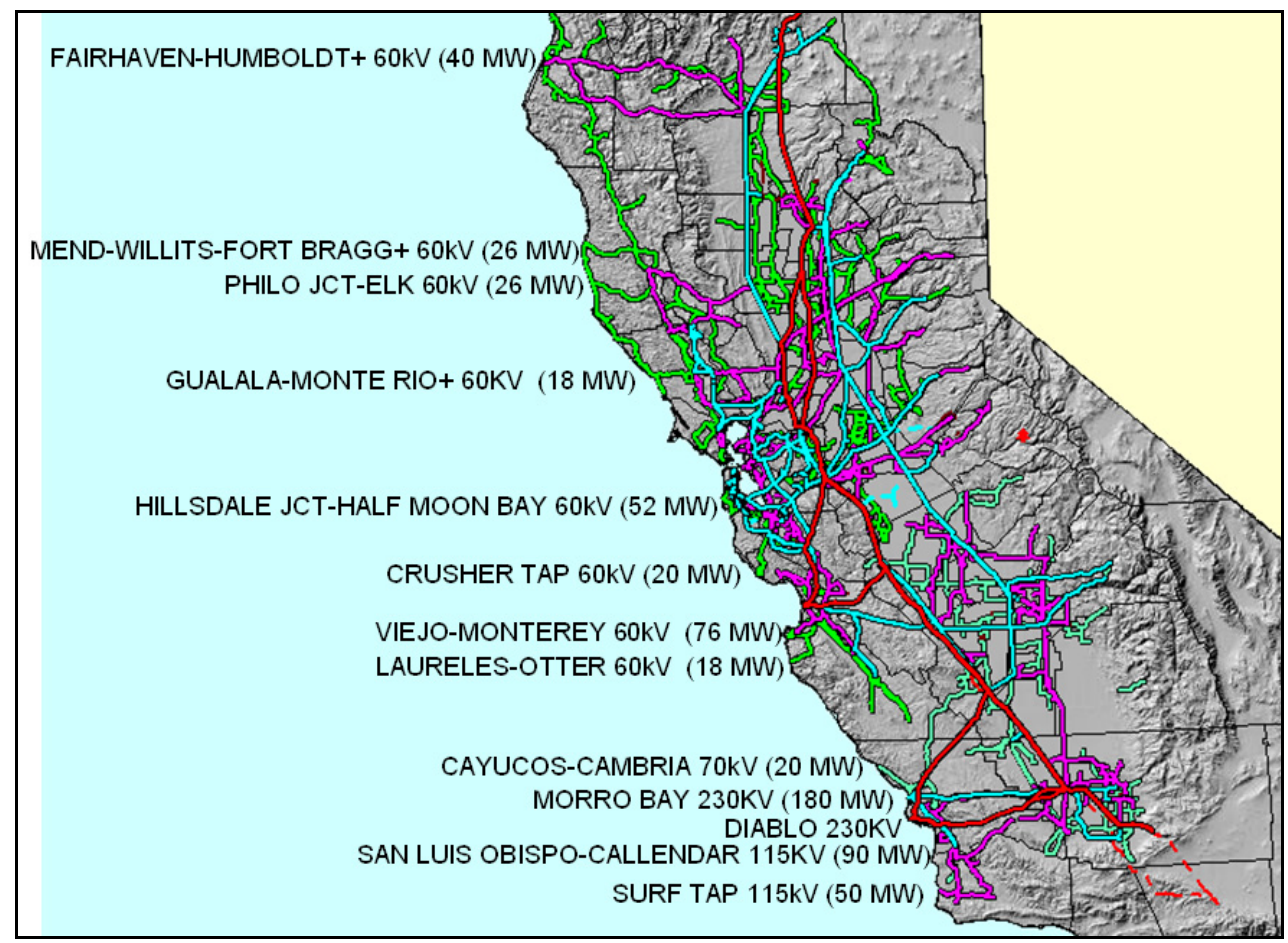

Figure 3-34: Transmission Line Access Points and Estimated Capacities 
Although this area has been evaluated and shown to be initially unacceptable due to lack of good harbor facilities (Appendix SAIC C), many of the WEC devices may not require a large nearby harbor access. These include such devices as the FPP, Oceanlinx, OE Buoy, AWS, and FO, which can all be maintained by helicopter or small ship at the device itself. Devices such as the Pelamis, OPT, CPT, and WaveBob may initially require towing to a harbor access for repair. Although there are no large harbors nearby, there is the potential for over $100 \mathrm{MW}$ located at the various substation points in the region north of San Francisco. Fort Bragg would be very acceptable for devices that only require small ship or helicopter access, with Humboldt being the major port associated with these larger devices.

\section{Fairhaven-Humboldt $60 \mathrm{kV}$}

There are three $60-\mathrm{kV}$ lines connected to Fairhaven Substation, with sufficient capacity to accommodate the addition of $5 \mathrm{MW}$ at Fairhaven. Currently, the highest line flow expected on these lines is $41 \mathrm{MW}$. With an additional $5 \mathrm{MW}$ at Fairhaven, the highest flow on the line would be $46 \mathrm{MW}$. The 60-kV lines there have 397 ACC conductor, which has a capacity of 51 MVA.

Fairhaven has one 60/12-kV distribution transformer rated at 12.5 MVA. The existing transformer has sufficient capacity to accommodate $12.5 \mathrm{MW}$ of WaveConnect generation. The interconnection plan was to install a new $12-\mathrm{kV}$ breaker at the Fairhaven $12-\mathrm{kV}$ bus and connect a dedicated $12-\mathrm{kV}$ feeder from the WaveConnect generating site to Fairhaven. The existing distribution transformer is protected by a set of fuses. The interconnection system impact study would likely require that the fuse be replaced by a circuit breaker or circuit switcher.

The cost to upgrade the on-shore substation to a 5-MW facility was approximately $\$ 5$ million. PG\&E also examined the costs to upgrade to $40 \mathrm{MW}, 90 \mathrm{MW}$ and $180 \mathrm{MW}$ at this location, with the cost breakdowns listed below. As can be seen, a 40-MW facility would not have cost significantly more than a 5-MW facility, while an increase to $90 \mathrm{MW}$ would have been significant. It was estimated that the cost to upgrade the on-shore facility and reconductor the overhead lines through the rugged mountains separating Humboldt from the central west coast transmission spine was $\$ 324$ million, of which $\$ 314$ million would have been for reconductoring alone. The next jump to $180 \mathrm{MW}$ is of similar order, with an estimated cost of $\$ 549$ million.

\section{$\underline{40-M W ~ O u t l o o k}$}

Interconnection Plan

- Build a substation with 60/12-kV 50-MVA transformer on land.

- Build $3.2 \mathrm{~km}$ of $60-\mathrm{kV}$ gen tie line from the substation to Fairhaven Substation.

- Install $60-\mathrm{kV}$ breaker at Fairhaven and connect the $60-\mathrm{kV}$ gen tie line there.

Network Upgrade Scope 
- Suggested size: $30 \mathrm{MW}$; significant network upgrades would be required for the next 60-MW increment.

- Miscellaneous special protection scheme (SPS).

Cost:

- Substation: $\$ 6$ million

- $\quad 3.2 \mathrm{~km} 60-\mathrm{kV}$ line: $\$ 2$ million

- Breaker at Fairhaven: \$1 million

- SPS: $\$ 1$ million

- Total: \$10 million

\section{0-MW Outlook}

Interconnection Plan

- Build a substation with 115/35-kV 100-MVA transformer on land.

- Build $26 \mathrm{~km}$ of $115-\mathrm{kV}$ gen tie line from the substation to Humboldt Bay Substation.

- Install 115-kV breaker at Humboldt Bay Substation and connect the gen tie line there.

Network Upgrade Scope:

- Reconductor $145 \mathrm{~km}$ of Humboldt-Trinity 115-kV line

- Reconductor $90 \mathrm{~km}$ of Humboldt-Bridgeville 115-kV line

- Miscellaneous SPS

Cost:

- Substation: $\$ 7$ million

- $26 \mathrm{~km}$ 115-kV line: \$24 million

- Breaker at Humboldt Bay Substation: \$2 million

- 145 km of Humboldt-Trinity Reconductoring: \$180 million

- $90 \mathrm{~km}$ of Humboldt-Bridgeville Reconductoring: \$110 million

- SPS: \$1 million

- Total: \$324 million 


\section{$\underline{180-M W \text { Outlook }}$}

Interconnection Plan

- Build a substation with 115/35-kV 100-MVA transformer on land.

- Build $26 \mathrm{~km}$ of double circuit $115-\mathrm{kV}$ gen tie lines from the substation to Humboldt Bay Substation.

- Install two 115-kV breakers at Humboldt Bay Substation and connect the gen tie lines there.

Network Upgrade Scope:

- Reconductor $145 \mathrm{~km}$ of Humboldt-Trinity 115-kV line

- Reconductor $90 \mathrm{~km}$ of Humboldt-Bridgeville 115-kV line

- Reconductor $40 \mathrm{~km}$ of Trinity-Cottonwood 115-kV line

- Reconductor $96 \mathrm{~km}$ of Bridgeville-Cottonwood 115-kV line

- Voltage support devices at various locations

- Major SPS

Cost:

- Substation: $\$ 9$ million

- $26 \mathrm{~km}$ doubt circuit 115-kV lines: $\$ 40$ million

- 2 Breakers at Humboldt Bay Substation: $\$ 5$ million

- $55 \mathrm{~km}$ of Humboldt-Trinity Reconductoring: \$180 million

- $90 \mathrm{~km}$ of Humboldt-Bridgeville Reconductoring: \$110 million

- $40 \mathrm{~km}$ of Trinity-Cottonwood Reconductoring: $\$ 50$ million

- $96 \mathrm{~km}$ of Bridgeville-Cottonwood Reconductoring: \$120 million

- Voltage support devices at various locations: $\$ 30$ million

- Major SPS: \$5 million

- Total: $\$ 549$ million

\section{Fort Bragg-Elk $60 \mathrm{kV}$}

The line along the coast is the Fort Bragg-Elk 60-kV line. It is sized at $57 \mathrm{MVA}$, as is the Mendocino-Willits-Fort Bragg 60-kV line. The largest project that can be tapped into this line is approximately $45 \mathrm{MW}$. If an interconnection is made at the Fort Bragg Substation, the project size could increase to approximately $55 \mathrm{MW}$. 
Interconnection plan: Tap the Fort Bragg- Elk $60-\mathrm{kV}$ line. Although interconnecting directly to Fort Bragg allows for a larger project, it does not allow the project size to increase by a multiple of $30 \mathrm{MW}$. Additionally, it would require a rebuild of Fort Bragg Substation to a ring bus at a cost of approximately $\$ 5$ million.

Suggested size: $30 \mathrm{MW}$. Significant network upgrades required to reach $60 \mathrm{MW}$.

\section{Elk-Gualala $60 \mathrm{kV}$}

The transmission line at Elk Substation that runs along the coast is the Elk-Gualala $60-\mathrm{kV}$ line, sized at 57 MVA. The situation at Elk Substation is similar to that of Fort Bragg. If the interconnection is to tap the $60-\mathrm{kV}$ line, the maximum project size is approximately $45 \mathrm{MW}$. However, if the interconnection can be made at Elk Substation the project size can increase to 55 MW.

Interconnection plan: Tap the Elk-Gualala $60-\mathrm{kV}$ line.

Suggested size: 30 MW. Significant network upgrades required to reach $60 \mathrm{MW}$.

Added note for total capacity of Fort Bragg to Gualala path: Although each of the Fort Bragg-Elk and Elk-Gualala 60-kV lines may be able to accommodate $30 \mathrm{MW}$ individually, the system cannot accommodate $30 \mathrm{MW}$ at BOTH sites, since they share common paths to export excess generation. The combined generation that this system can accommodate before triggering significant network upgrades is approximately $50 \mathrm{MW}$.

\section{Gualala-Monte Rio 60 kV}

The Gualala-Monte Rio $60-\mathrm{kV}$ line is composed of a smaller conductor type than the other lines in this area and has a capacity of 38 MVA. The estimated capacity here is about $34 \mathrm{MW}$.

Although the $60-\mathrm{kV}$ path is continuous from Fort Bragg heading south to Gualala, the circuit is operated open at Gualala. This means Gualala is operated radially and any power generated on the Gualala-Monte Rio 60-kV line will head back toward Fulton Substation. Therefore a project connected at Gualala Substation or further south is not subject to the total combined generation limit of $50 \mathrm{MW}$ mentioned in the Fort Bragg and Elk area analysis.

Interconnection plan: Tap the Gualala-Monte Rio 60-kV line. Interconnecting within Gualala Substation provides no additional capacity and is more expensive.

Suggested size: $30 \mathrm{MW}$. Significant network upgrades required to reach $60 \mathrm{MW}$. 


\subsubsection{San Francisco Bay Area}

Around the mouth of San Francisco Bay there are multiple excellent access points, but the wave regime is greatly reduced due to land shielding of incoming waves, as well as kilometers of sediment buildup that further reduce the wave energy (through interaction with this shallow sea bed). Although there are systems that could operate here, set up would potentially require cables of substantial length, and could compete with major fishing and shipping traffic. Therefore, although the electrical grid connections around the mouth of San Francisco Bay are excellent, cable costs and the potential of interaction with major shipping traffic reduce the attractiveness of this area. Some details of access are described in both the EPRI $2004^{29}$ and SFPUC $2009^{30}$ reports, but PG\&E feels that the risk aspects were not adequately assessed in these studies.

Immediately to the south of San Francisco Bay are three major connection points that may be usable. The northern two, Hillsdale Jct.-Half Moon Bay $60 \mathrm{kV}$ and Crusher Tap $60 \mathrm{kV}$, are very close to major transmission line corridors. Further advantages are the nearby port of Oakland/San Francisco, as well as Monterey. The southern-most location is the site of the former PG\&E Moss Landing power plant, which has the potential for $180 \mathrm{MW}$ of wave-based capacity.

South of this area is a long section of coast where there are no PG\&E transmission lines. In addition, the slope of the off-shore sea floor is rocky and steep, and likely prone to landslides ${ }^{31}$. Seafloor stability would be a major factor for consideration, and the technology will likely require extensive maturation before any devices might be situated there.

\section{Hillsdale Jct.-Half Moon Bay 60 kV}

Half Moon Bay Substation is the closest interconnection point to the coast. Two transmission lines are terminated here, Martin \#1 and Hillsdale Jct.-Half Moon Bay 60 kV. However, Martin \#1 $60 \mathrm{kV}$ is operated as open at Half Moon Bay and only closed in during contingency events. With a minimum load of $10 \mathrm{MW}$ at Half Moon Bay and the Hillsdale Jct.-Half Moon Bay 60-kV line sized for $57 \mathrm{MVA}$, approximately $60 \mathrm{MW}$ of capacity is available here.

Martin \#1 $60 \mathrm{kV}$ is sized for 57 MVA and could accommodate up to an additional $50 \mathrm{MW}$. However, this would require an additional (separate) interconnection point, and this additional generation would be required to curtail under contingencies in which the line is closed in to Half Moon Bay. The recommendation would be to choose one site or the other, but not both.

\footnotetext{
${ }^{29}$ ERPI 2004b. System Level Design, Performance and Costs - San Francisco California Pelamis Off-shore Wave Power Plant. E2I EPRI - 006A - SF. December 11, 2004

ERPI 2004c. System Level Design, Performance and Costs - San Francisco California Energetech Off-shore Wave Power Plant. E2I EPRI - 006B - SF. December 20, 2004

${ }^{30}$ SFPUC, 2009. Wave Power Feasibility Study Report. Prepared for the City and County of San Francisco. URS Job No. 28067508. December 14, 2009. 49 pages.

${ }^{31} \mathrm{http}: / /$ walrus.wr.usgs.gov/research/projects/landslides.html; http:/walrus.wr.usgs.gov/geotech/
} 
Interconnection plan: Gen-tie line directly to Half Moon Bay Substation. May require rebuild to ring bus at cost of approximately $\$ 5$ million.

Suggested size: $60 \mathrm{MW}$.

\section{Lone Star Tap 60 kV}

The Lone Star Tap $60 \mathrm{kV}$ may be the better interconnection point at this location, as it is closer to the coast and has higher capacity. Although the Lone Star Tap $60 \mathrm{kV}$ is sized for $57 \mathrm{MVA}$, the two Lone Star-Burns $60-\mathrm{kV}$ lines are the limiting components. There is approximately $37 \mathrm{MW}$ of available capacity on this path before triggering the reconductoring of the two lines, which are approximately $8 \mathrm{~km}$ each.

Interconnection plan: Tap onto the Lone Star Tap $60 \mathrm{kV}$.

Suggested size: $30 \mathrm{MW}$. Approximately $16 \mathrm{~km}$ of $60-\mathrm{kV}$ reconductoring (approximately $\$ 10$ million) to reach $50 \mathrm{MW}$. Significant upgrades required to reach $60 \mathrm{MW}$.

\section{Viejo-Monterey $60 \mathrm{kV}$}

There are a few options in Monterey Bay. There is a $60-\mathrm{kV}$ transmission loop fed by Del Monte Substation. Both Navy School and Monterey substations are very near the bay and could be interconnection points. The Del Monte-Monterey $60-\mathrm{kV}$ line also runs along the bay and could be tapped into. Interconnecting at any of these points could accommodate $75 \mathrm{MW}$ of generation. Del Monte Substation would be ideal from a capacity standpoint due to the $115-\mathrm{kV}$ bus. This location could accommodate $180 \mathrm{MW}$.

Interconnection plan: Extend the $115-\mathrm{kV}$ bus at Del Monte Substation by one bay (approximately $\$ 2$ million) and build $1.6 \mathrm{~km}$ gen-tie line (approximately $\$ 1$ million).

Suggested size: $180 \mathrm{MW}$.

\section{Laureles-Otter $60 \mathrm{kV}$}

The radial Laureles-Otter $60-\mathrm{kV}$ line is sized for 34 MVA under normal conditions. With a minimum load at Otter Substation of $2 \mathrm{MW}$, this path can accommodate approximately $36 \mathrm{MW}$ of generation.

Interconnection plan: Tap the Laureles-Otter $60-\mathrm{kV}$ line.

Suggested size: $30 \mathrm{MW}$. Significant network upgrades required to reach $60 \mathrm{MW}$. 


\subsubsection{Central Coast}

PG\&E transmission line access picks up at the Morro Bay Power Plant, with the potential for substantial transmission out of the area.

Ironically, the Central Coast area (with slightly less wave potential) has the best potential for any initial build-out. There has been substantial environmental baseline data collected here as part of the multiple oil and gas leasing operations over the last several decades.

Finally, there is the potential to build at Diablo Canyon Power Plant (DCPP). Any build-out there would not be recommended for a first attempt, as approval would likely be necessary from the Nuclear Regulatory Commission.

\section{Cayucos-Cambria $70 \mathrm{kV}$}

The radial Cayucos-Cambria $70-\mathrm{kV}$ line is sized for 40 MVA under normal conditions. With a minimum load at Cambria Substation of $1 \mathrm{MW}$, this path can accommodate $40 \mathrm{MW}$ of generation.

Interconnection plan: Tap the Cayucos-Cambria 70-kV line.

Suggested size: $30 \mathrm{MW}$. Significant network upgrades required to reach $60 \mathrm{MW}$.

\section{Morro Bay $230 \mathrm{kV}$ and Diablo $230 \mathrm{kV}$}

Although these sites are considered to be capped at $180 \mathrm{MW}$, the $230-\mathrm{kV}$ systems at these two locations are very robust and could well accommodate past this level.

Interconnection plan: Both locations would require extending the $230-\mathrm{kV}$ buses by one bay for an approximate cost of $\$ 2.5$ million.

Suggested size: $180 \mathrm{MW}$.

\section{San Luis Obispo-Callendar $115 \mathrm{kV}$}

Oceano Substation and Callendar Switching Station are two viable potential substation locations for interconnection. Oceano can accommodate up to $90 \mathrm{MW}$ of generation, although limited physical space within the substation may make this a difficult task. The San Luis ObispoCallendar 115-kV line, which Oceano is looped into, could also accommodate up to $90 \mathrm{MW}$ of generation despite being rated to 73 MVA due to the high minimum load at Oceano Substation. Tapping this line may be the superior option.

Interconnection plan: Tap the San Luis Obispo-Callendar 115-kV line between Oceano Substation and Callendar SW Station. 
Suggested size: $90 \mathrm{MW}$. Significant network upgrades required to reach $120 \mathrm{MW}$.

\section{Surf Tap 115 kV}

The Surf tap line spans approximately $18 \mathrm{~km}$ from the ocean to where it taps into the $115-\mathrm{kV}$ system. The tap line is rated to $110 \mathrm{MVA}$. This location can accommodate approximately 100 MW of generation.

Interconnection plan: Tap the Surf $115-\mathrm{kV}$ tap line.

Suggested size: 90 MW. Reconductor the 18 km Surf Tap to reach 120-MW size. Approximate cost of $\$ 11$ million.

\subsubsection{Central Coast WaveConnect (Vandenberg Air Force Base Site)}

PG\&E also assessed the cost for connecting the Central Coast WaveConnect site to Surf Substation for three configurations (40 MW, $90 \mathrm{MW}$ and $180 \mathrm{MW}$ ).

\section{0-MW Outlook}

Interconnection Plan

- Build a substation with 115/12-kV 500-MVA transformer on land.

- Build $15 \mathrm{~km}$ of 115-kV line from the substation toward Surf Substation and connect tap the $115-\mathrm{kV}$ line off the Surf 115-kV tap line.

Network Upgrade Scope:

- Miscellaneous protection upgrades at Divide and Cabrillo

Cost:

- Substation: $\$ 6$ million

- $\quad 15 \mathrm{~km}$ 115-kV line: $\$ 15$ million

- Protection: $\$ 1$ million

- Total: \$22 million

\section{0-MW Outlook}

Interconnection Plan

- Build a substation with 115/35-kV 100-MVA transformer on land. 
- Build $15 \mathrm{~km}$ of $115-\mathrm{kV}$ line from the substation toward Surf Substation and connect tap the $115-\mathrm{kV}$ line off the Surf $115-\mathrm{kV}$ tap line.

Network Upgrade Scope:

- Miscellaneous protection upgrades at Divide and Cabrillo

Cost:

- Substation: $\$ 7$ million

- $15 \mathrm{~km}$ 115-kV line: \$15 million

- Protection: $\$ 1$ million

- Total: \$23 million

180-MW Outlook

Interconnection Plan

- Build a substation with 115/35-kV 200-MVA transformer on land.

- Build $15 \mathrm{~km}$ of $115-\mathrm{kV}$ line from the substation toward Surf Substation and connect tap the $115-\mathrm{kV}$ line off the Surf $115-\mathrm{kV}$ tap line.

Network Upgrade Scope:

- Reconductor $20 \mathrm{~km}$ of Surf 115-kV tap from 397 AAC conductor with 795 AAC conductor.

- Miscellaneous protection upgrades at Divide and Cabrillo.

Cost:

- Substation: $\$ 9$ million

- $15 \mathrm{~km} 115-\mathrm{kV}$ line: $\$ 15$ million

- $20 \mathrm{~km}$ of Surf $115-\mathrm{kV}$ tap reconductor: $\$ 15$ million

- Protection: $\$ 1$ million

- Total: $\$ 40$ million

\subsubsection{Overview}

Table 3-3 shows the interconnect points along the California coastline that correspond to the locations in Figure 3-34. Monterey, Morro Bay, and Diablo are capped at $180 \mathrm{MW}$, although there is potential for higher power production at all these locations. It is assumed that upgrading some of the corridors would be easier than others - for example, Northern Californian corridors are in remote locales with extremely rugged and mountainous terrain. Overall, there is better 
transmission line access in the San Francisco Bay Area and Central California areas than along the California coastline north of San Francisco. Development of wave energy in the North Coast may actually be better completed after development in the Central Coast, perhaps using a single HVDC cable spine, as has been proposed for East Coast wind developments, which would supply power to the San Francisco Bay Area and perhaps to Oregon. The logic of such a DC spine approach is discussed later in the section on HV cables.

Table 3-3: Summary of Potential Interconnection Points along California Coastline

\begin{tabular}{|l|c|c|}
\hline Transmission Line & $\begin{array}{c}\text { MW Est } \\
\text { Capacity }\end{array}$ & $\begin{array}{c}\text { Using } \\
\text { 30-MW } \\
\text { Increments }\end{array}$ \\
\hline Fairhaven-Humboldt+ 60KV & 35 & 30 \\
\hline $\begin{array}{l}\text { Mend-Willits-Fort Bragg+ 60KV and Philo Jct - Elk } \\
\text { 60 kV combined total }\end{array}$ & 50 & 30 \\
\hline Gualala-Monte Rio+ 60KV & 34 & 30 \\
\hline Hillsdale Jct-Half Moon Bay 60KV & 60 & 60 \\
\hline Crusher Tap 60KV & 37 & 30 \\
\hline Viejo-Monterey 60KV & 180 & 180 \\
\hline Laureles-Otter 60KV & 36 & 30 \\
\hline Cayucos-Cambria 70KV & 40 & 30 \\
\hline Morro Bay 230KV & 180 & 180 \\
\hline Diablo 230KV & 180 & 180 \\
\hline San Luis Obispo-Callendar 115KV & 90 & 90 \\
\hline Surf Tap 115KV & 100 & 90 \\
\hline Total & $\mathbf{1 0 2 2}$ & $\mathbf{9 6 0}$ \\
\hline
\end{tabular}

\subsection{Humboldt WaveConnect Pilot Project Overview and Site Infrastructure}

The Humboldt WaveConnect Pilot Project was proposed to be located near Eureka, Humboldt County, California. Off-shore facilities would be located 2.5 to $3.0 \mathrm{~nm}(3.7$ to $5.6 \mathrm{~km})$ off-shore from the unincorporated community of Manila on the Samoa Peninsula of Humboldt Bay, also called the North Spit of Humboldt Bay. The proposed site for all off-shore system components, cables, anchors, and navigational aids was to be within state territorial waters, generally defined as within $3 \mathrm{~nm}(5.6 \mathrm{~km})$ from shore. The proposed site was to produce no more than $5 \mathrm{MW}$ at maximum power output.

The WEC deployment area was defined as a rectangle approximately $3.7 \mathrm{~km}$ long and $0.9 \mathrm{~km}$ wide oriented parallel to the coastline. The coordinates for the four corners of the WEC deployment are shown in Table 3-4. Electrical transmission cables were to extend southwest from the WEC deployment area, remaining in water deeper than $33 \mathrm{~m}$ until reaching a location 
opposite the proposed cable shore landing site. ${ }^{32}$ At this point, the cables were to turn at approximately a right angle to the southeast, toward the shore. From a location immediately beyond the surf zone, the submarine cables were to be installed using horizontal directional drilling (HDD) to a landing location on-shore.

Table 3-4: Project Location Coordinates

\begin{tabular}{|l|c|c|}
\hline Corner & West Latitude & North Longitude \\
\hline NW & 40.921725 & -124.209263 \\
\hline NE & 40.919257 & -124.198767 \\
\hline SE & 40.887382 & -124.211767 \\
\hline SW & 40.889849 & -124.222258 \\
\hline
\end{tabular}

On-shore facilities power-conditioning equipment and portions of an aboveground transmission line (generator tie-line) were to be installed on land belonging to the Humboldt Bay Municipal Water District (HBMWD) adjacent to New Navy Base Road. The generator tie-line was to connect with the existing substation located at the Freshwater Tissue Mill.

The on-shore project facilities were located in Township 5N, Range 1W, Sections 20 and 21, Humboldt Base Meridian. The on-shore facilities would include the beach area west of New Navy Road and the HBMWD land east of New Navy Road.

\subsubsection{Proposed Project Facilities}

The pilot effort was to install and test WECs, or hydrokinetic devices, of up to $5 \mathrm{MW}^{33}$ maximum production, with the intention of evaluating the overall technology's readiness. The pilot had three major parts: the WEC devices, the off-shore wave energy project site where the devices were to be installed, and the shore site that would have received electric power through submarine cables from the off-shore site. The HWC Project would have been installed in state territorial waters (within $3 \mathrm{~nm}$ of land) off-shore the North Spit of the Humboldt Bay peninsula near Eureka, California. When installed, WaveConnect was to provide PG\&E with the capability for the side-by-side evaluation of WEC devices from different manufacturers.

\footnotetext{
${ }^{32}$ The cable routing was planned in conjunction with representatives of the crabbing and fishing communities through the Humboldt Working Group. Crab fishers indicated that they would prefer that the cable run be located in water $33 \mathrm{~m}$ or deeper, because the majority of the crab fishing takes place at depths shallower than this. PG\&E agreed to this routing in order to avoid conflicts that could arise if crab fishing gear were to become entangled in exposed submarine cables. (Although the cables will be buried, the Humboldt Bay Littoral Cell is a dynamic sediment environment, and it is possible that even buried cables could become exposed.)

${ }^{33}$ The FERC Pilot License stated that the facility was to be $5 \mathrm{MW}$ in production. Throughout most of the discussion with stakeholders, PG\&E referred to a " $5 \mathrm{MW}$ average production" as the actual energy values varied widely throughout the year. However, FERC finally stated that PG\&E must state a maximum production, regardless of how the actual output may have varied throughout the year. This is in keeping with FERC requirements for hydro license developments. FERC did state that they would consider up to $10 \mathrm{MW}$ maximum, but discussions never reached that stage. The issue of maximum energy output and configuration of WECs will be discussed later.
} 
The pilot facility would have consisted of: (1) WECs including multi-point catenary moorings and anchors; (2) marker buoys, navigation lights, and environmental monitoring instruments; (3) submarine electrical cables extending underground on-shore to (4) land-based power conditioning equipment; (5) an aboveground transmission line and interconnection to the electrical grid; (6) data acquisition and telemetry equipment; (7) security and safety equipment.

The WEC manufacturers were to deploy their WEC arrays within the area described above, which measured $2.0 \mathrm{~nm}$ by $0.5 \mathrm{~nm}(3.7 \mathrm{~km}$ by $0.9 \mathrm{~km})$ oriented roughly northwest, perpendicular to the prevailing wave direction. The key parameters of this area were:

- Sea surface area: less than $3.4 \mathrm{~km}^{2}$

- Footprint on the sea floor: less than $3.4 \mathrm{~km}^{2}$

- Maximum number of submarine power cables: 5

- Maximum number of WEC arrays: 4

- Maximum number of WEC devices: 30

- Maximum number of environmental and wave measurement buoys: 6

- Maximum number of boundary marker buoys: 6

The off-shore infrastructure was to comply with all U.S. Coast Guard regulations for navigation lighting and marking. The site would be identified on navigation charts using USCG Notice to Mariners and its boundaries designated and marked on charts as an Area to be Avoided (ATBA). The WEC devices would be moored or anchored within the off-shore site and connected to shore by undersea cables that land near water tower of the Humboldt Municipal Water District ${ }^{34}$. The shore-based monitoring station would receive and condition ${ }^{35}$ the electrical output before routing it to an existing substation that is connected to the electrical grid. The HWC Project would operate according to formal plans for operations, maintenance, safety, security, monitoring, and adaptive management. The WaveConnect pilot was intended operate for five years ${ }^{36}$.

\footnotetext{
${ }^{34}$ The original intention as stated to the CPUC and DOE was for a single cable, capable of $40 \mathrm{MW}$, but with the original project only using a portion of the cable's capability. As the project progressed, it was decided that there would be five 1.25 MW cables (with one acting as a spare) giving the WECs four "berths". However, the concept of a spare cable is not a cost effective or even useful one, nor is the concept of five cables. This issue will be discussed in the section on cable configurations.

${ }^{35}$ When the RFI was released, it was unknown what voltage levels the WECoMs would wish to use. As PG\&E entered into discussions with the WECoMs, it was determined that all device manufacturers could produce a standard $12 \mathrm{kV}$, configured to meet system voltage requirements, with no on-shore conditioning required. PG\&E subsequently found that they could also provide $34.5 \mathrm{kV}$.

${ }^{36}$ The five-year duration was based on the pilot license. That was not the plan as originally intended in discussions with the CPUC and DOE, but came about due to the apparent simplicity of following the FERC pilot licensing effort. The five-year duration did not have the force of regulation but ongoing verbal discussions with stakeholders assumed this duration, to the extent that federal agencies such as NMFS stated in their comments on the DPLA that the five-year duration should be the total license period, which would include a year of project work prior to operation.
} 


\subsection{HWC On-Shore Infrastructure, Cable, and Grid Connection}

Humboldt WaveConnect's on-shore facilities were to be designed to connect, monitor, and control the electrical power from the WEC arrays. The facilities were to include: (1) on-site monitoring and power conditioning station, (2) waterfront host facility, (3) generator tie-line, (4) electrical substation, and (5) Supervisory Control and Data Acquisition (SCADA) systems to an off-site PG\&E control center.

Shore installations were to be constructed during the first phase of construction. The submarine cable(s) would have been installed during a second phase, using specialized barges modified for cable installation, and other on-water assets (such as dive teams). The cable installation company was to do a highly detailed bathymetric survey assessment of the cable route prior to the installation date, to ensure that all obstacles were known. Thus, the route of the deployed cables would have avoided any environmentally sensitive areas identified. In a third phase of construction, after the HWC infrastructure was made ready, the WEC anchors and moorings were to be installed and the WECs placed into the moorings.

Construction of the on-shore monitoring and conditioning station involved preparing the compacted gravel, asphalt, or concrete pad and installing the prefabricated buildings containing electrical, computer, telephone, and heating, ventilation, and air conditioning systems, which would have been connected with the on-shore underground transmission cable and the generator tie-line.

New, wooden power poles were to be installed to support the generator tie-line conductors and connect the monitoring and conditioning station to the existing Freshwater Tissue Mill substation. The installation of power poles and connection to the substation were to follow PG\&E standard operating procedures for transmission lines.

\subsubsection{On-site Monitoring and Power Conditioning Station}

On-site monitoring and power conditioning stations function as a command and control gateway between WECs at sea and the electrical grid. They perform two major functions: (1) house the on-shore equipment used to monitor aspects of WEC operation and (2) house equipment that will accept the electrical power coming separately from the WEC arrays and condition it so that it can be transmitted to the wider electrical grid. The monitoring and power conditioning station would have been built on a 100-foot by 100-foot compacted gravel, asphalt, or concrete pad near the shore landing for the submarine cables. The station was intended to include structures to house the communications and power conditioning equipment. The station would not have been staffed; operations were to be conducted remotely from the PG\&E control center and the station would have only been visited for maintenance purposes. Instrument recording and control were to take place at an existing off-site PG\&E control center with communications to the HWC Project monitoring and conditioning equipment. The on-site monitoring station would have been fenced and monitored with security cameras. 
The power conditioning equipment was to convert power received directly from the WEC arrays into a form that can be synchronized and transmitted to the grid $^{37}$. The HWC power measurement equipment would have been installed, calibrated, and tested to ensure that electrical power exported from each submarine power cable was assessed prior to the electrical conditioning stage. During construction, power conversion modules would have been housed in the on-site monitoring station and tested for conformance to PG\&E standards for interconnection, access, and adequacy of all support requirements.

The HWC data acquisition and telemetry infrastructure was to be installed in the off-shore components and on-shore facilities. Communications to/from the marine environment would have connected to the on-site monitoring station. These communications were to include network links, radio communications, telemetry, telephone/modem, video, and SCADA systems.

\subsubsection{Waterfront Host Facility}

The WEC manufacturers participating in HWC were to be responsible for shipping their devices and assembling them in the project area for deployment. PG\&E's pilot was to provide a waterfront host facility with the industrial services developers require for WEC assembly.

The waterfront host facility would have been an existing industrial site leased by PG\&E, located on Humboldt Bay with a pier, work area, storage space, and infrastructure to support the installation and subsequent maintenance of HWC components. The host facility would have served as an on-shore facility for mooring, staging, periodic building, and loading of HWC equipment. The facility was to have the capability to load components onto an installation vessel or unload components from the ship to the pier.

In addition to the marine assets, the host facility was to provide dry work areas such as a warehouse, office space, outside laydown space, and receiving services. PG\&E would have negotiated a contract with a local facility to provide these services.

\subsection{Interconnection}

\subsubsection{Generator Tie-line}

A $12-\mathrm{kV}$ distribution line would have extended for approximately $460 \mathrm{~m}$ from the on-site monitoring and power conditioning station to the Freshwater Tissue Mill substation. This

\footnotetext{
${ }^{37}$ Discussions with WECoMs have indicated that the most mature technologies already have the capability to perform grid synchronization on the device. This is no different than what is found at wind generation facilities. After discussing with multiple WECoMs, PG\&E came to the conclusion that any on-shore substation at this stage of technology development should be $34.5 \mathrm{KV}$, consistent with voltage levels as used by wind-powered generation facilities. PG\&E has been informed that it is difficult to deal with this voltage level in marine environments, yet PG\&E and other utilities have underground transformers that regularly flood. PG\&E does not expect this to occur on a WEC, and believes additional study and outreach to larger engineering and manufacturing concerns that have experience in these areas will be beneficial.
} 
generator tie-line was to be installed on standard wooden poles adjacent to the existing access road that leads from HBMWD's water tank to Vasco Road. All tie-line routing, installation, and testing would have followed PG\&E standard operating procedures and best practices.

\subsubsection{Electrical Substation}

The generator tie-line was to connect the monitoring and power conditioning station with the wider electrical grid through a connection at a PG\&E substation located within the fence line of the grounds of the Freshwater Tissue Mill.

\subsubsection{Off-site Control Center}

The monitoring and power conditioning station would have been connected by telecommunication infrastructure to an existing PG\&E power plant operational control center at the recently constructed Humboldt Bay Generating Station. Power plant operators at the control center would have had access to all of the power plant monitoring equipment information flow. PG\&E planned to establish a monitoring and management protocol for HWC's operation.

\subsubsection{Horizontal Directional Drilling}

Horizontal directional drilling (HDD) is used to connect electrical transmission cable between the shallow water zone and the on-shore zone. The submarine cables are then drawn through conduits drawn through the drill bore, connecting the seafloor transmission cable with an onshore cable vault adjacent to the monitoring and conditioning station. Advantages of HDD include its minimal environmental impact, as the cables are buried entirely underground or under the seafloor, with surface disturbance only at the entry and exit pits. Disadvantages include greater cost and the risk that drilling mud may escape the drilling site and leak to the surface, potentially fouling water bodies with sediment (drilling muds are of non-toxic mineral composition).

The HDD process creates a pathway for horizontal subsurface conduits, normally 6 to $15 \mathrm{~m}$ under the surface, through which the submarine power cables are then routed. These conduits are subsurface from the on-shore cable vault to a point off-shore in nominally $15 \mathrm{~m}$ of water. The off-shore outlet must be on a mostly flat plane allowing for transition of the cable between the conduit and the sea floor (Figure 3-35). 


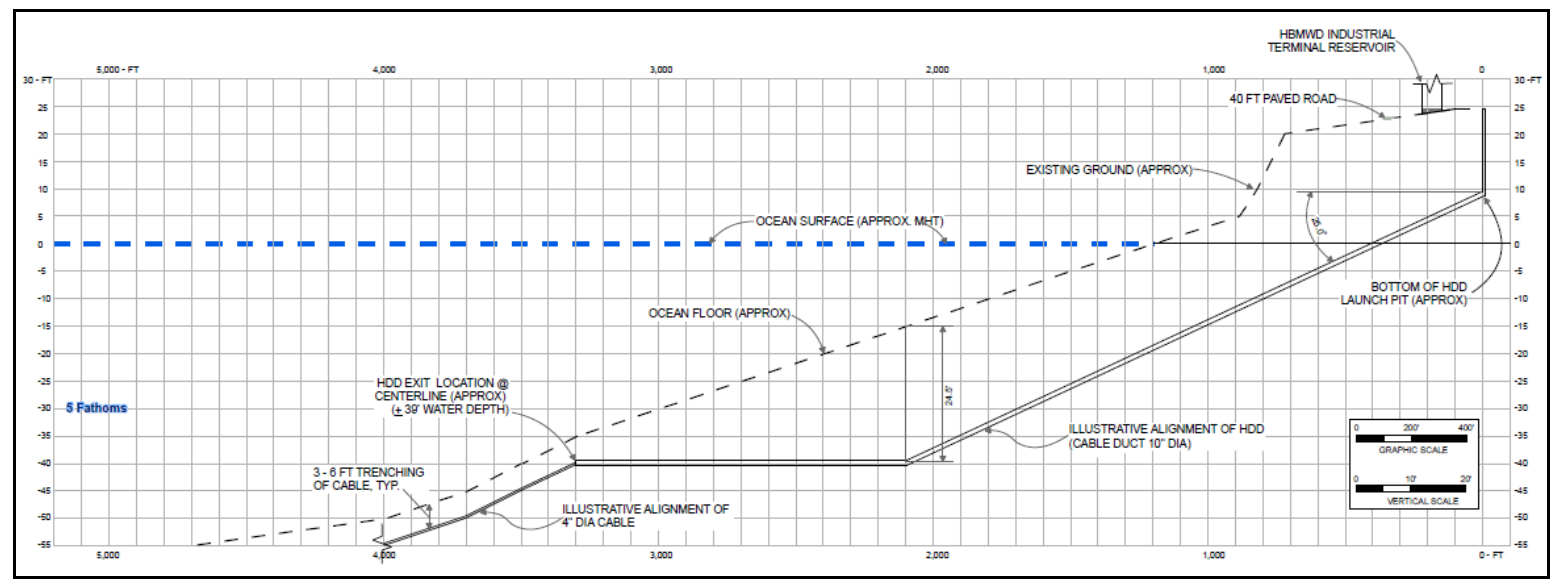

Figure 3-35: HDD Profile and Cable Interconnection

The HDD process is completed primarily from shore. A directional drilling rig would have been set up near the on-site monitoring station east of the HBMWD water tower. The operator would have conducted a detailed survey and then sent a pilot drill out along the planned route. The route is planned based on site selection and core sample results (typically one sample per array site, and along the cable route). The pilot drill is a small horizontal path from the shore site to the planned exit point at sea. Once drilled, the drill bore is removed and a reamer is then attached to the drill string and sent back through the pilot hole. The reaming is accomplished in one or more increments, depending on soil structure and final diameter of the HDD conduit diameter. With the final ream, a messenger line is pulled through the conduit, which allows cables to be connected to it and pulled through from sea to shore. After reaming is complete, the conduits can either be left as is (if the soil is deemed to be hard enough to avoid collapse) or can be lined with PVC. The PVC conduits would be left in place after decommissioning. In an environment such as Humboldt, PVC conduits would almost certainly have been used.

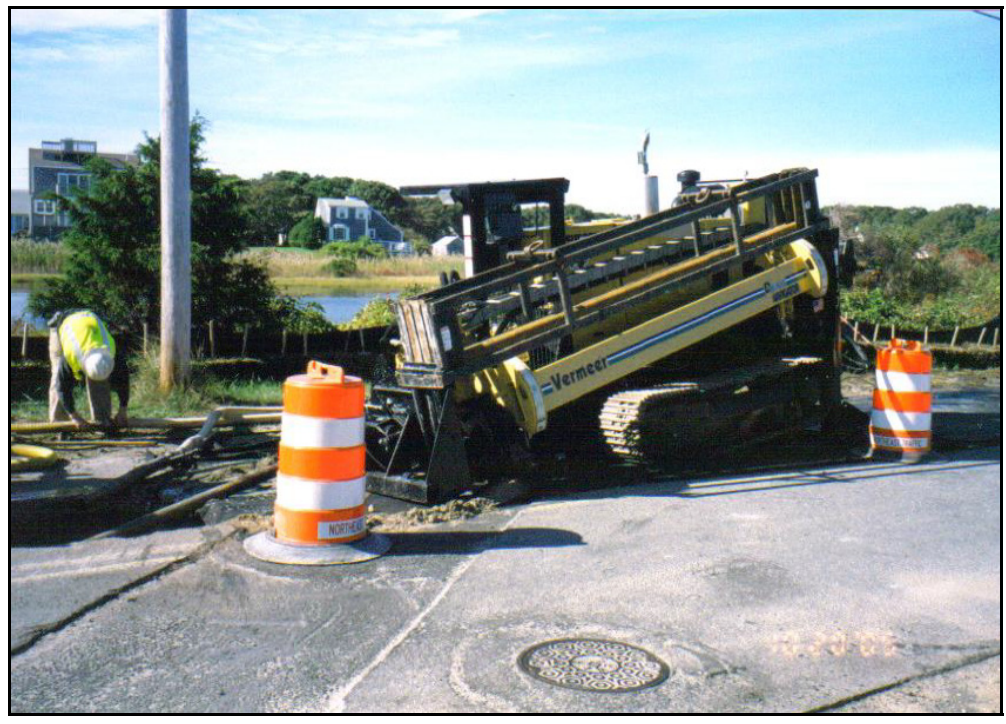

Figure 3-36: Horizontal Directional Drilling in Progress 
In order to keep the reamer lubricated during the drilling process, a lubricant such as bentonite (a naturally occurring fine clay), guargum (an organic polymer manufactured from seeds of a bean), or similar material will be used. Approximately $95 \%$ of the lubricant used in the drilling process will be recovered, while 5\% could escape during the final punch-out off-shore. In addition to the $5 \%$ lost during the punch-out, HDD in sand increases the risk of what is known as a "frac out." This happens when the reamer encounters a weakness in the sand or fission in the rock and the lubricant is lost through this weakness and into the water. This risk cannot be avoided but mitigation efforts, such as monitoring the lubricant pressure, are made to ensure the drilling is stopped as quickly as possible if a frac out were to occur.

After completion of the HDD conduit, the cable is pulled through the conduit from the sea side. The cable is fed from a deployment vessel (which in an environment such as Humboldt could be a sea going barge, for smaller cables, or a much larger specialty built or modified ship for larger cables) to a diver at the exit point of the HDD. The diver attaches the cable-pulling eye to the messenger line and the cable is pulled ashore using on-shore assets. The cable would have then been laid to the WEC siting area.

Several alternative cable shore landing methods were discussed during the planning efforts. One such method is to trench the cable ashore from the low tide line to above the high tide line. Conventional land-based earthmoving equipment would be used to make a trench for each cable or pair of cables. The cable would be pulled ashore from the off-shore marine equipment and routed through directional drilled bores to the on-site monitoring station. After being laid in the shore trench, a specially designed subsea cable plow would be used to plow in the cable through the shallow water area and out to sea. Advantages of this method are its relatively low cost and the accessibility of the cable if needed. Disadvantages are the amount of surface disturbance required which, without proper mitigation measures, can cause environmental impacts to sensitive species and habitats.

Another method is to use outfalls ${ }^{38}$ that may already be in existence. This is the method that was proposed in EPRI 2004a and as part of OPT's Reedsport project. However, there are significant costs and dangers in such a method. The cable cost is such that the outfall must be carefully screened, so as to make sure that there are no sharp or rough areas that could damage the cable. This may involve danger to divers that are not associated with a fresh HDD effort. Additionally, movement of objects through the outfall during large storms could damage the cable. Finally, since the outfall does not belong to PG\&E, using it for such an effort could involve liability for possible environmental contaminants that have collected at the outfall exit. So, for reasons of liability, control, and cable care, PG\&E felt that this method was inappropriate, considering the cost of the base cable and the overall risk.

HDD cost is has been found to be dependent upon both the diameter and the cost per linear meter of the bore ${ }^{39}$ (Table 3-5). Ariaratnam et al. (1999) is an excellent resource for understanding the

\footnotetext{
${ }^{38}$ An outfall is a large diameter sewage conduit that transmits treated wastewater away from the shoreline.

${ }^{39}$ Ariaratnam, S.T., E.N. Allouche, and J.S. Lueke (1999). An Industry Survey of Horizontal Directional Drilling Practices in North America, in "Proceedings of No-Dig '99" (ppa. 231-243). Orlando, FL.
} 
issues that come into play. These costs are 10 years out of date but can act as guides, not only for general cost estimation but, more importantly, for estimating the time required to produce the bore (which itself will reflect on the final cost and on the project timeline). Table 3-6 gives an overview of linear meters per day drilled based on the desired bore diameter.

Table 3-5: Cost of installation for HDD borings (\$/linear meter) for various product diameters (Ariaratnam, et al. 1999).

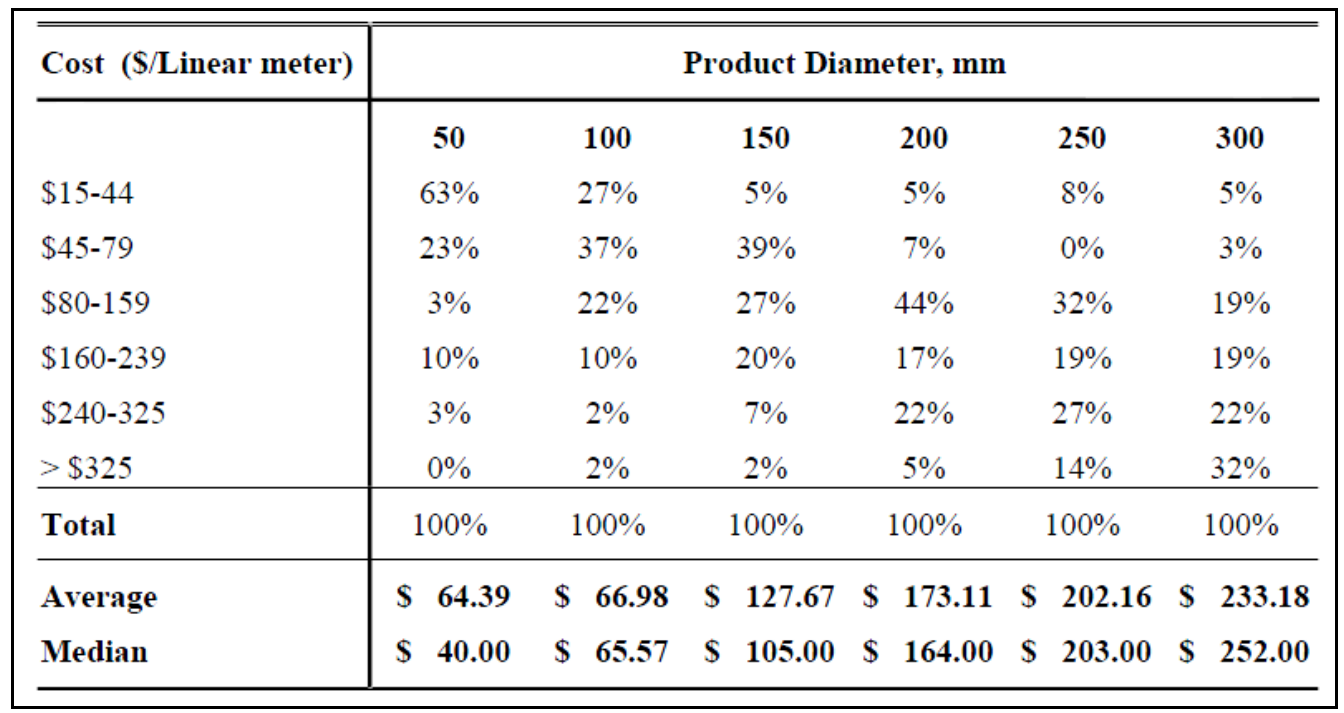

Table 3-6: Average productivity (linear meters/day) in various subsurface foundations based on an eight-hour day. The numbers in square brackets indicate the number of data points comprising the average (bold) (Ariaratnam, et al. 1999)

\begin{tabular}{|c|c|c|c|c|c|c|c|c|}
\hline Diameter & Clay & $\begin{array}{l}\text { Silty- } \\
\text { Clay }\end{array}$ & Sand & Gravel & Cobbles & $\begin{array}{c}\text { Hard } \\
\text { Pan }\end{array}$ & Sandstone & Bedrock \\
\hline $50-100 \mathrm{~mm}$ & $\begin{array}{l}\mathbf{1 8 0} \\
{[26]}\end{array}$ & $\begin{array}{l}221 \\
{[3]}\end{array}$ & $\begin{array}{l}\mathbf{1 3 3} \\
{[17]}\end{array}$ & $\begin{array}{r}\mathbf{8 0} \\
{[8]}\end{array}$ & $\begin{array}{l}\mathbf{3 8} \\
{[3]}\end{array}$ & $\begin{array}{l}\mathbf{9 5} \\
{[6]}\end{array}$ & $\begin{array}{l}\mathbf{1 4 9} \\
{[2]}\end{array}$ & $\begin{array}{l}103 \\
{[2]}\end{array}$ \\
\hline $150-200 \mathrm{~mm}$ & $\begin{array}{l}\mathbf{1 2 8} \\
{[27]}\end{array}$ & $\begin{array}{l}\mathbf{1 3 1} \\
{[4]}\end{array}$ & $\begin{array}{l}\mathbf{1 0 0} \\
{[16]}\end{array}$ & $\begin{array}{l}49 \\
{[7]}\end{array}$ & $\begin{array}{l}\mathbf{2 3} \\
{[1]}\end{array}$ & $\begin{array}{l}\mathbf{4 1} \\
{[5]}\end{array}$ & $\begin{array}{c}\mathbf{8 0} \\
{[2]}\end{array}$ & $\begin{array}{c}\mathbf{6 9} \\
{[2]}\end{array}$ \\
\hline $250-300 \mathrm{~mm}$ & $\begin{array}{l}\mathbf{1 0 2} \\
{[20]}\end{array}$ & $\begin{array}{c}\mathbf{N} / \mathbf{A} \\
{[0]}\end{array}$ & $\begin{array}{c}\mathbf{9 0} \\
{[16]}\end{array}$ & $\begin{array}{l}\mathbf{4 1} \\
{[5]}\end{array}$ & $\begin{array}{l}\mathbf{2 3} \\
{[1]}\end{array}$ & $\begin{array}{l}35 \\
{[4]}\end{array}$ & $\begin{array}{c}\mathbf{4 5} \\
{[2]}\end{array}$ & $\begin{array}{c}\mathbf{4 5} \\
{[2]}\end{array}$ \\
\hline$>300 \mathrm{~mm}$ & $\begin{array}{c}67 \\
{[17]}\end{array}$ & $\begin{array}{c}\mathbf{N} / \mathbf{A} \\
{[0]}\end{array}$ & $\begin{array}{c}\mathbf{6 5} \\
{[14]}\end{array}$ & $\begin{array}{l}\mathbf{4 0} \\
{[5]}\end{array}$ & $\begin{array}{l}\mathbf{2 3} \\
{[1]}\end{array}$ & $\begin{array}{l}\mathbf{2 3} \\
{[4]}\end{array}$ & $\begin{array}{c}\mathbf{4 5} \\
{[2]}\end{array}$ & $\begin{array}{c}\mathbf{2 3} \\
{[2]}\end{array}$ \\
\hline
\end{tabular}

\subsection{Off-Shore Electrical Cable Connections}

Submarine umbilical cables interconnect individual WEC devices, each of which is generally equipped with its own transformer and power conditioning equipment to produce a common voltage. Some form of standardized connector ties umbilical cables to a submarine distribution 
cable, which connects the entire installation to facilities on the shore. This chapter examines these various apparatus and functions.

\subsubsection{Background}

In Europe, the wind power industry is increasingly turning to utilization of off-shore wind resources. This is also occurring on the East Coast of the United States. It is logical to use the experience gained there, as well as that gained from off-shore oil platforms, to assess the proper and most cost-effective power and voltage levels for off-shore generation. The challenge of offshore grid connection has been substantially discussed in several forums ${ }^{40}$ and will continue to be a costly challenge. There are several good cable installation manufacturers and contractors, both in the United States and internationally. However, in PG\&E's discussions with many of them, only a few seemed to have experience with the wave power industry. There are also multiple manufacturers producing electrical components that work at sea, having developed such applications for the oil and the maritime industry.

The off-shore oil-and-gas industry in Southern California use medium-voltage (16- to 35-kV) as well as much higher voltage power cables for their North Sea platforms (many of which are direct current (DC) as opposed to alternating current (AC)). Specifically in Southern California, there are multiple cable access points to off-shore oil and gas platforms, 14 of which, according to BOEMRE $^{41}$, are at $34.5 \mathrm{kV}$ (Table 3-7).

Regretfully, all platforms but one are situated in areas where wave energy potential is marginal ${ }^{42}$. However, all are potential test platforms for wave energy devices, allowing for the possibility of a return on investment and a test of devices in areas of high visibility to the public and investors (and without having to develop a FERC permit). There are also multiple examples of $115-\mathrm{kV}$ and higher off-shore cables to windfarms, especially in the UK.

\footnotetext{
${ }^{40}$ EU EESD (2003). WaveNet: Results from the work of the European Thematic Network on Wave Energy. March, 2003. ERK5-CT1999-20001 2000-2003. (http://ordis.europa.eu/documents/documentlibrary/66682851EN6.pdf)

${ }^{41}$ Personal communications from Ann Scarborough, PhD (Chief, Environmental Studies, Pacific Region, BOEM) to B.P. Dooher on 8 July 2010.

${ }^{42}$ The exception is Platform Irene, which has a connection just to the north of Vandenberg Air Force Base. Its power capacity is $30 \mathrm{MW}$, with a $34.5-\mathrm{kV}$ voltage level, making it an ideal candidate for a wave energy test center.
} 
Table 3-7: Off-shore Oil and Gas Platforms in Southern California with Electrical Cables to the Platform (Source: Ann Scarborough, BOEMRE).

\begin{tabular}{|c|c|c|c|c|c|c|c|c|}
\hline Platform & Operator & Destination & $\begin{array}{l}\text { Length } \\
\text { (ft) }\end{array}$ & $\begin{array}{c}\text { Water } \\
\text { Depth } \\
\text { Range } \\
\text { (ft) }\end{array}$ & $\begin{array}{l}\text { Electrical } \\
\text { Cable to } \\
\text { Platform }\end{array}$ & $\begin{array}{l}\text { Electrical } \\
\text { Provider }\end{array}$ & Capacity & Unit/Field \\
\hline$A, B, \& C$ & DCOR LLC & Shore & 31680 & $160-0$ & Yes & SCE & $34.5 \mathrm{kV}$ & $\begin{array}{c}\text { Dos } \\
\text { Cuadras }\end{array}$ \\
\hline B & DCOR LLC & C & 2640 & $190-192$ & Yes & SCE & $34.5 \mathrm{kV}$ & $\begin{array}{c}\text { Dos } \\
\text { Cuadras }\end{array}$ \\
\hline Edith & DCOR LLC & Shore & 52800 & $160-0$ & Yes & SCE & $34.5 \mathrm{kV}$ & Beta \\
\hline Ellen $^{\wedge}$ & $\begin{array}{l}\text { Beta } \\
\text { Operating Co. }\end{array}$ & & & & Yes & PLF Elly & $34.5 \mathrm{kV}$ & Beta \\
\hline Eureka & $\begin{array}{l}\text { Beta } \\
\text { Operating Co. }\end{array}$ & Ellen (2) & $15297^{+}$ & $700-265$ & Yes & PLF Elly & $34.5 \mathrm{kV}$ & Beta \\
\hline Gilda & DCOR LLC & Shore & 52800 & $205-0$ & Yes & Reliant & $16.5 \mathrm{kV}$ & Hueneme \\
\hline Gina & DCOR LLC & Shore & 33792 & $90-0$ & Yes & Reliant & $16.5 \mathrm{kV}$ & Hueneme \\
\hline Habitat & DCOR LLC & P/F A & 19008 & $290-188$ & Yes & SCE & $34.5 \mathrm{kV}$ & Pitas Point \\
\hline Henry & DCOR LLC & Hillhouse & 13200 & 173-190 & Yes & SCE & $34.5 \mathrm{kV}$ & $\begin{array}{c}\text { Dos } \\
\text { Cuadras }\end{array}$ \\
\hline Hillhouse & DCOR LLC & Shore & 33792 & $175-0$ & Yes & SCE & $34.5 \mathrm{kV}$ & $\begin{array}{c}\text { Dos } \\
\text { Cuadras }\end{array}$ \\
\hline Hogan & POO LLC & Shore & 20774 & $154-0$ & Yes & SCE & $17 \mathrm{kV}$ & Carptineria \\
\hline Houchin & POO LLC & Hogan & 3800 & $163-154$ & Yes & SCE & $17 \mathrm{kV}$ & Carptineria \\
\hline Hondo & ExxonMobil & Harmony (2) & $47520^{+}$ & $\begin{array}{l}842- \\
1198\end{array}$ & Yes & XOM & $34.5 \mathrm{kV}$ & $\begin{array}{l}\text { Santa } \\
\text { Ynez }\end{array}$ \\
\hline Harmony & ExxonMobil & Shore (2) & $108768^{+}$ & $1198-0$ & Yes & XOM & $34.5 \mathrm{kV}$ & $\begin{array}{l}\text { Santa } \\
\text { Ynez }\end{array}$ \\
\hline Heritage & ExxonMobil & Harmony & 39072 & $\begin{array}{l}1075- \\
1198\end{array}$ & Yes & XOM & $34.5 \mathrm{kV}$ & $\begin{array}{l}\text { Santa } \\
\text { Ynez }\end{array}$ \\
\hline Heritage & ExxonMobil & Shore & 104544 & $1075-0$ & Yes & XOM & $34.5 \mathrm{kV}$ & $\begin{array}{l}\text { Santa } \\
\text { Ynez }\end{array}$ \\
\hline Irene & PXP & Shore & 49767 & $242-0$ & Yes & PG\&E & $34.5 \mathrm{kV}$ & $\begin{array}{c}\text { Pt. } \\
\text { Pedernales }\end{array}$ \\
\hline A & DCOR LLC & B & 2640 & $188-190$ & & SCE & $34.5 \mathrm{kV}$ & $\begin{array}{c}\text { Dos } \\
\text { Cuadras }\end{array}$ \\
\hline
\end{tabular}

\subsubsection{Submarine Cable}

Submarine power cables have an armored layer and a protective jacket to prevent damage from trawling ships or anchors. During installation, the cables are buried by a subsea cable plow to keep them safe from possible anchor strikes or other damage. From a water depth of approximately $12 \mathrm{~m}$, outside of the surf zone, the cables would have been installed under the sea floor using HDD techniques, extending underground on-shore to the power conditioning and monitoring station located east of the HBMWD water tank, approximately $260 \mathrm{~m}$ from the water line, east of New Navy Base Road. The extent of the HDD portion of the cable run would have been approximately $0.8 \mathrm{~km}$. Each of the cables was to be installed individually in a cable sleeve.

The submarine power cable would have terminated at the monitoring station on-shore. The station was to monitor the cables for proper operation, ground faults, and power output, and relay 
this information to the PG\&E control center. At the shore, the cable end was to be secured and terminated in a locked enclosure.

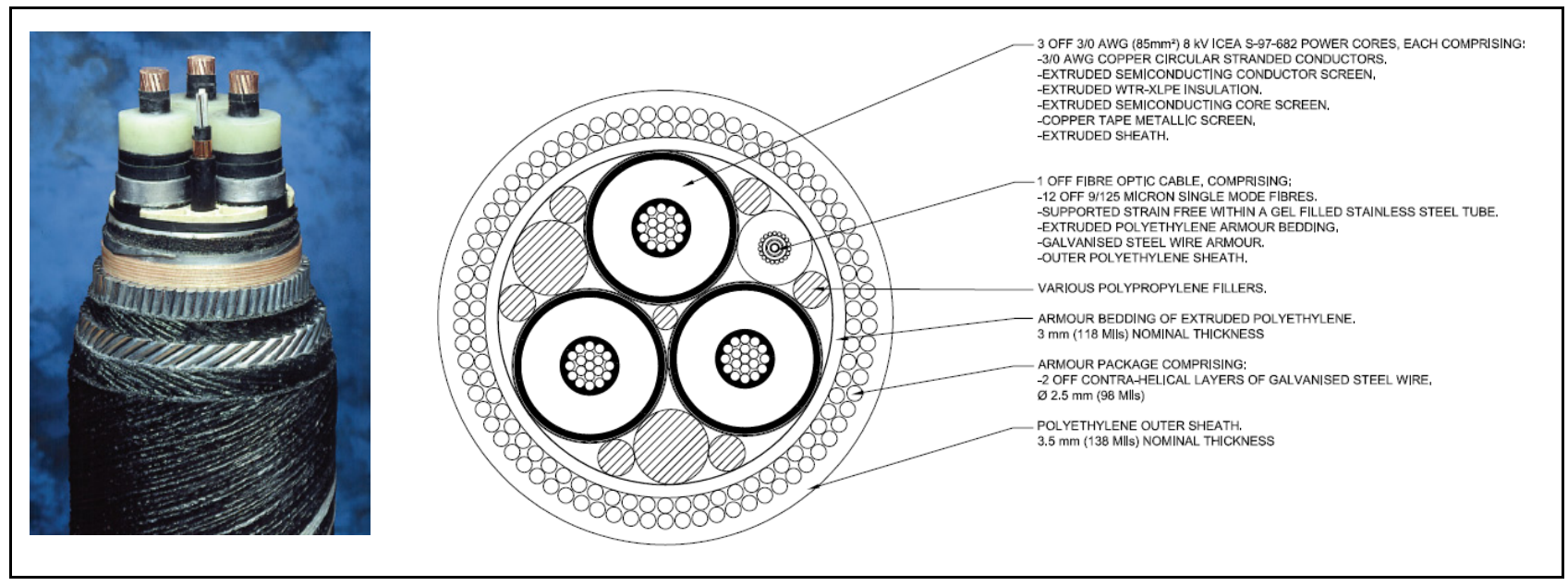

Figure 3-37: Typical Shielded Three-Phase Cable Cross-Section (JDR Cable Systems)

AC cables tend to have high losses due to capacitance, as there is a large voltage differential between the copper conductor and the surrounding shielding, seabed, and water: the longer the distance, the greater the loss. It is reported ${ }^{43}$ that the capacitance induced is on the order of 100$150 \mathrm{kVAR} / \mathrm{km}$ for 33-kV XLPE cable and $1000 \mathrm{kVAR} / \mathrm{km}$ for $132-\mathrm{kV}$ XLPE cable, and that for any length extending beyond $10 \mathrm{~km}$ that a reactive power compensation would be required (perhaps even for any cable distance). As most wave facilities need to be built relatively close to shore to avoid large mooring costs, this is not a huge consideration. But it does indicate that if an extensive industry were to develop, a DC cable spine should be considered as an option.

As an example, for a $30 \mathrm{MW}$ facility on a $34.5-\mathrm{kV}$ cable, the overall power loss is described by a vector where the reactive power is 90 degrees off-cycle from the real power. The resulting loss, for a $6 \mathrm{~km}$ cable, would be no more than $0.5 \%$ for $10-\mathrm{MW}$ of power production and inconsequential for the full 30-MW of production. Much higher capacitance may be expected from a WEC device with an induction generator.

Grainger et al. ${ }^{44}$ (1998) report that the maximum practical conductor size for operation in the $34.5-\mathrm{kV}$ range appears to be $300 \mathrm{~mm}^{2}$. This was also confirmed in discussions with some of the cable manufacturers, and has to do with such parameters as the bend radius, insulation, shielding, and overall construction. PG\&E did not release an official RFI to the cable industry, so much of this information is based on literature and informal discussions. PG\&E believes that cable specifications should be discussed through an international forum such as the IEC, or that DOE should fund a specific study on this important aspect.

\footnotetext{
${ }^{43}$ Wright, S.D., Rogers, R.L., Manwell, J.F. and Ellis, A. Transmission Options for Off-shore Windfarms in the United States. AWEA 2002.

${ }^{44}$ September 1998. Grainger, W., Jenkins, N., “Off-shore windfarm electrical connections,” Proceedings of 20th BWEA conference, Cardiff,.
} 
Both Grainger et al. (1998) and Wright et al. (2002) should be examined for a more in-depth discussion of the tradeoffs on equipment and cables.

\section{Installation}

Submarine transmission cable should be buried using an industry standard subsea cable plow selected based on the seafloor conditions. The cable will be pulled ashore using specialized winches, standard construction equipment, a cable rigged through a swivel pulling head, and cable stopper. Figure 3-38 shows the off-shore barge and on-shore cable pull. In the case of WaveConnect, the on-shore cable pull would be far from the beach area to avoid impact to sensitive species, which was the rationale to use HDD in the first place.

In the off-shore cable zone, power cables would have been buried to a depth of 1 to $2 \mathrm{~m}$, in individually plowed trenches, separated by a maximum of $30 \mathrm{~m}$ (if multiple cables were to be used). The cables were to proceed southwest in water deeper than $33 \mathrm{~m}$, as described earlier, to a location immediately off-shore of the monitoring and conditioning station. The cable routing would have then turned approximately 90 degrees to the southeast, toward the shore.

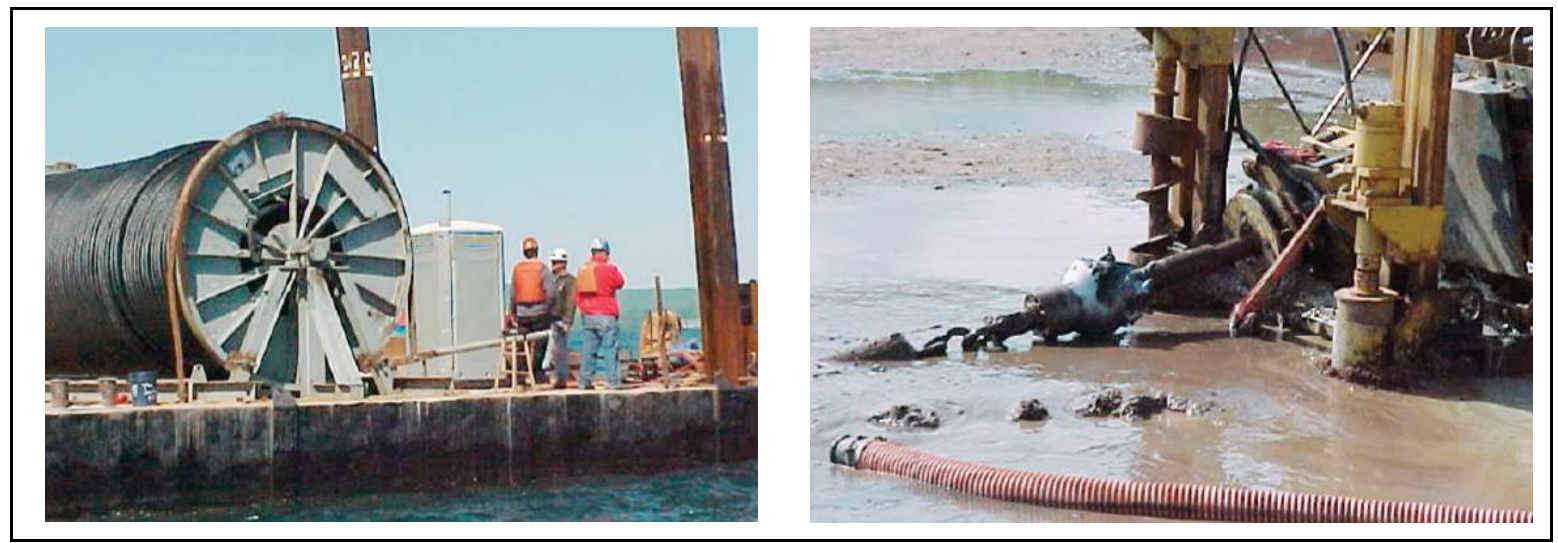

Figure 3-38: Madeline Island Cable Installation (www.kerite.com)

An alternative cable laying method would have been to plow the cables out from the shore to the point at which the cable reaches $33 \mathrm{~m}$ deep and turns at a right angle to the north, and then surface-lay the cable through the turn and to the WEC deployment site. In the plowed portion of the route, the cables would have been installed using a conventional subsea cable plow and each cable would be buried to a depth of 1 to $2 \mathrm{~m}$ in an individual trench. In this alternative, the cables would rest on the seafloor bottom for the majority of the route. Post-installation inspections would have been planned for every 6 months after installation until decommissioning, to determine if the cables had self-buried in the sediment and to ensure the cables were not scouring the seafloor.

If, during the post-installation inspections, it was determined that the cables were scouring the seafloor or causing other undesirable damage, they would have been buried using conventional subsea water-jetting cable plows. In this method, the subsea water jet cable plow would use pressurized sea water to create a trough in the seafloor, and then pull the cable into the trough. 
The trough would be naturally backfilled through the settling jetted sand and natural sand movement.

Trenching is done with various types of remotely operated vehicles (ROVs) (Figure 3-39) such as the "CapJet" jet plow. The CapJet uses a water jet to fluidize most sea-bottom surfaces and simultaneously buries the cable. The fluidized material falls back into the trench, covering the cable. Figure 3-40 shows an ROV in operation. For hard rock bottoms, there are also remotely operated vehicles that use rock-cutting chainsaws to excavate a trench; alternatively, a flexible "concrete" cover (concrete plates held together with chain links or cable) can be used to protect the cables. Rock excavation or concrete covers are by far the most expensive protective options. In some cases, the cables have double armor or "rock armor," which affords greater protection

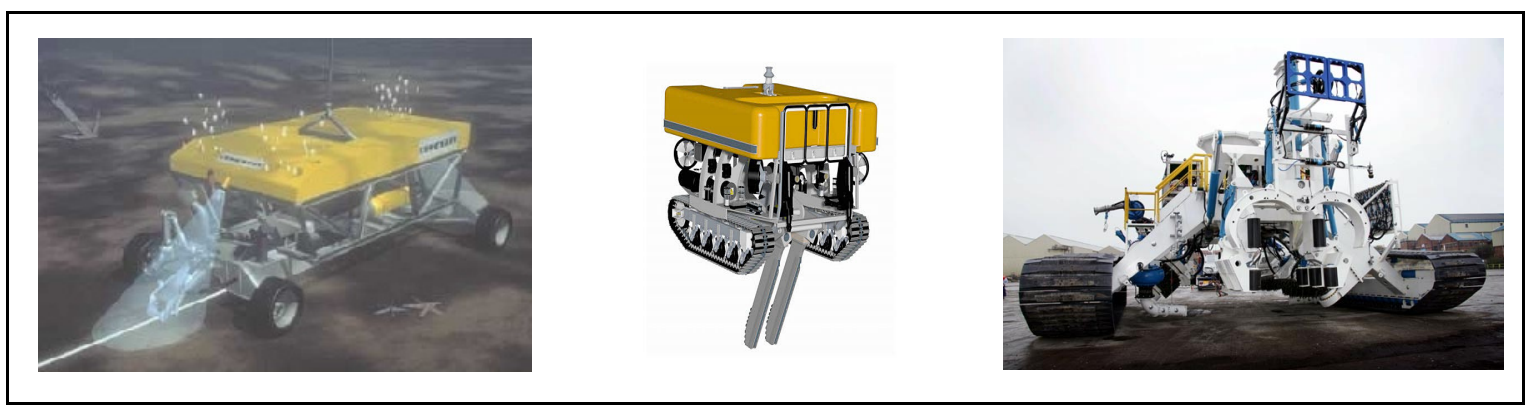

Figure 3-39: A Jet Plow (CapJet), Cable Plow, and Seabed Tractor

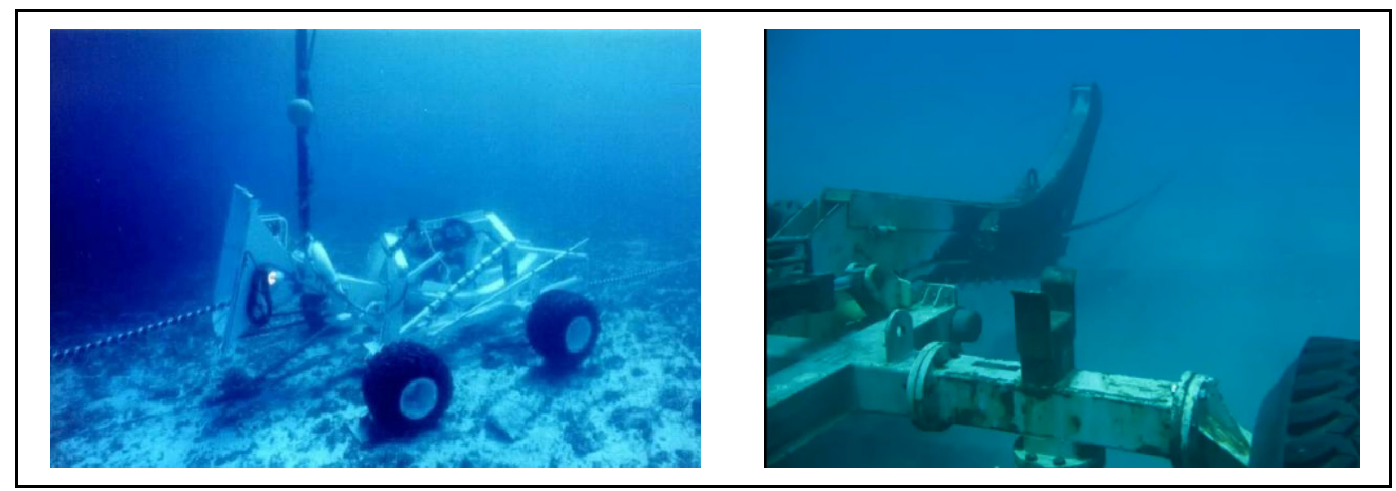

Figure 3-40: A ROV Plow in Operation

Installation by surface lay is not a preferred industry alternative due in part to the high failure rate of submarine cables, which decreased substantially after the cable industry began to actively bury cables $^{45}$. Allen (2001) has reported that most damage occurs from fishing trawlers and anchors, with an additional number of cables being damaged through movement over rocks or other rough surfaces. The largest impacts occur from fishing activity, which accounts for about $67 \%$ of all cable faults recorded from 1958 to 2008 (IPCP 2009). Anchor dragging or direct impacts result in $8 \%$ of failures. Current abrasion accounted for about $5 \%$ of impacts, and dredging for about $2 \%$. Natural events resulted in $18 \%$ of failures. Manmade impacts are most

\footnotetext{
${ }^{45}$ Allen, PG. 2001. Hydrographic Information and the Submarine Cable Industry. Presented at Norwich, Hydro Conference, March 2001.
} 
significant in water depths of less than $50 \mathrm{~m}$, with $60 \%$ of all failures occurring in depths of less than $200 \mathrm{~m}$. Figure 3-41 shows the failure rate over time for cables, with a significant drop occurring when the cable industry began to use burial as opposed to surface lay for shallow depths. Prior to burial of cables, fault rates were around 5 per $1000 \mathrm{~km}$ per year. However, as cable systems were increasingly buried, fault rates fell to an average of less than 1 per $1000 \mathrm{~km}$ per year.

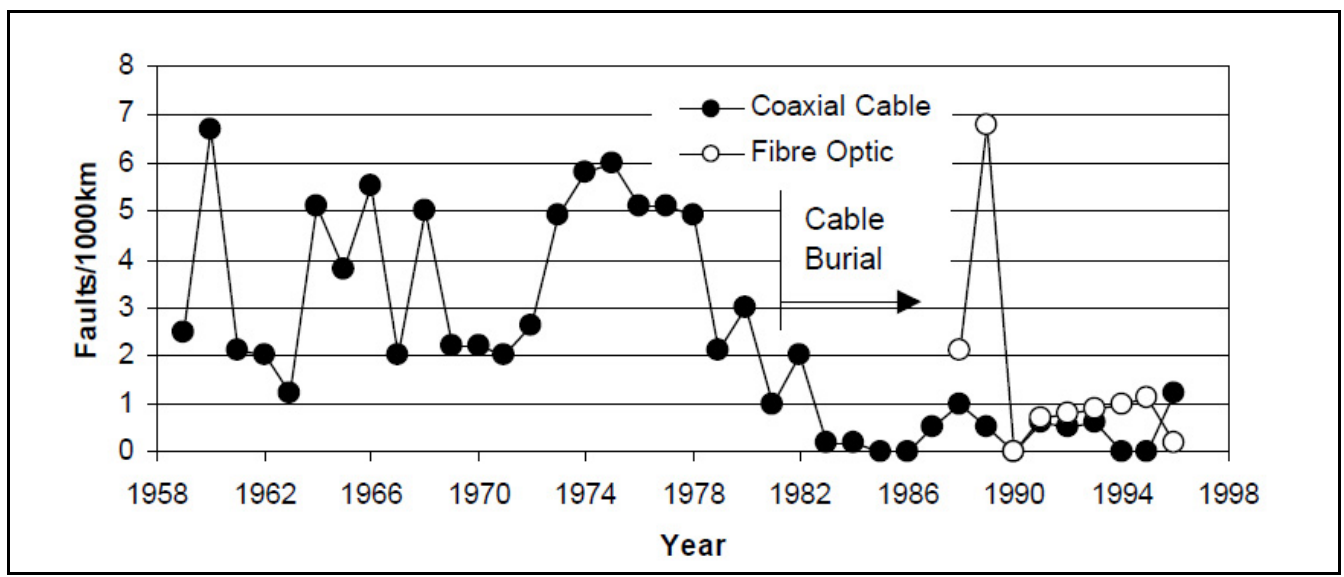

Figure 3-41: Cable Fault Rates by Year (Allen, 2001)

In areas where waves move deep sands, greater cable burial depths are necessary to keep the cable from rising back to the surface. As part of PG\&E's research effort, researchers at HSU observed sediment transport in the off-shore area in Humboldt. Although no final report was released, a summary of the report is made available in Appendix HSU C. Additionally, as part of its research into off-shore renewables, BOEMRE had Fugro perform a scour study for off-shore wind developments on the East Coast, the results of which are available (Fugro, 2011) ${ }^{46}$. This report by itself is incredibly valuable to the industry, and should be used as a basis for wave energy development ${ }^{47}$. It goes into significant detail of the physics that occur in sediment transport, as well as discussing interactions of sediments with anchors, cables, and other material/sea-bed interaction.

\section{Multiple Cable Option}

For the pilot, the intent was to have five separate submarine power cables: one for each of four WEC arrays and one spare cable. Each cable would run from the off-shore site to the on-site monitoring station power-conditioning pad in one continuous length. The cables were to be three-phase AC submarine transmission cables designed with three conductors and up to 12

\footnotetext{
${ }^{46}$ BOEMRE, 2011. Seabed Scour Considerations for Off-shore Wind Development on the Atlantic OCS, February 2011, Thomas McNeilan and Kevin R. Smith, Fugro Atlantic, Norfolk, Virginia.

(http://www.boemre.gov/tarprojects/656.htm)

${ }^{47}$ The appendix seems to be incomplete in its calculation of $U_{w}$, in that it does not take into account actual depth dependency (as seen in Table 3-2), as the previous scour discussions had depths that could well be described as shallow to moderate as well as deep.
} 
single-mode glass fiber-optic cables, with an overall cable diameter of four inches. The fibers are used to transmit operational and performance data to the shore monitoring station. A few smaller conductors would be included for independent powering, control, and monitoring of sensors.

The off-shore end of each submarine power cable was to have a termination for connection to a WEC array. These terminations were to be placed on the sea floor within the WEC deployment area and equipped with a recovery device, such as an acoustic release and pop-up buoy, to retrieve the cable end when it was necessary to connect it to the WEC manufacturer's cable.

\section{Single Cable Option}

During discussions with WECoMs, it became apparent that the original intention of having a single cable capable of handling up to $40 \mathrm{MW}$ of power was actually a more cost-effective and better long-term solution. There were several issues associated with using a 40-MW cable, including the distance that it would have to traverse. This was discussed earlier, and PG\&E feels that for any initial effort, cables should be laid in at least 30-MW increments. For much larger facilities (100-MW or larger), it is likely that an off-shore substation would be required. PG\&E received estimates from a large electrical engineering firm for a larger cable install for which that company, based on its experience, gave a cost that included a lifetime warranty for a 100-MW system. This company has had extensive experience in large-scale off-shore power systems, and PG\&E believes that such experts are critical to the industry's development and should be included in the overall conversation. Their view on ocean systems such as these is that they will engineer them to have minimal failures, as the cost of having emergency response ships would make a project economically unacceptable.

The original model for off-shore wind started with separate home run cables, and then graduated to off-shore substations with a set of cable "spokes" leading out to the various devices. Figure 342 shows an AREVA off-shore substation on a jack-up platform, and an artist's conception of a semi-submersible platform that might be used as a central location for a WEC array. In our discussions with the WECoMs, PG\&E learned that many of their devices could in effect serve as platforms for large transformers. It was mentioned earlier that OPT has developed underwater transformers, but it is unknown whether such systems can handle loads approaching $30 \mathrm{MW}$ or larger. 

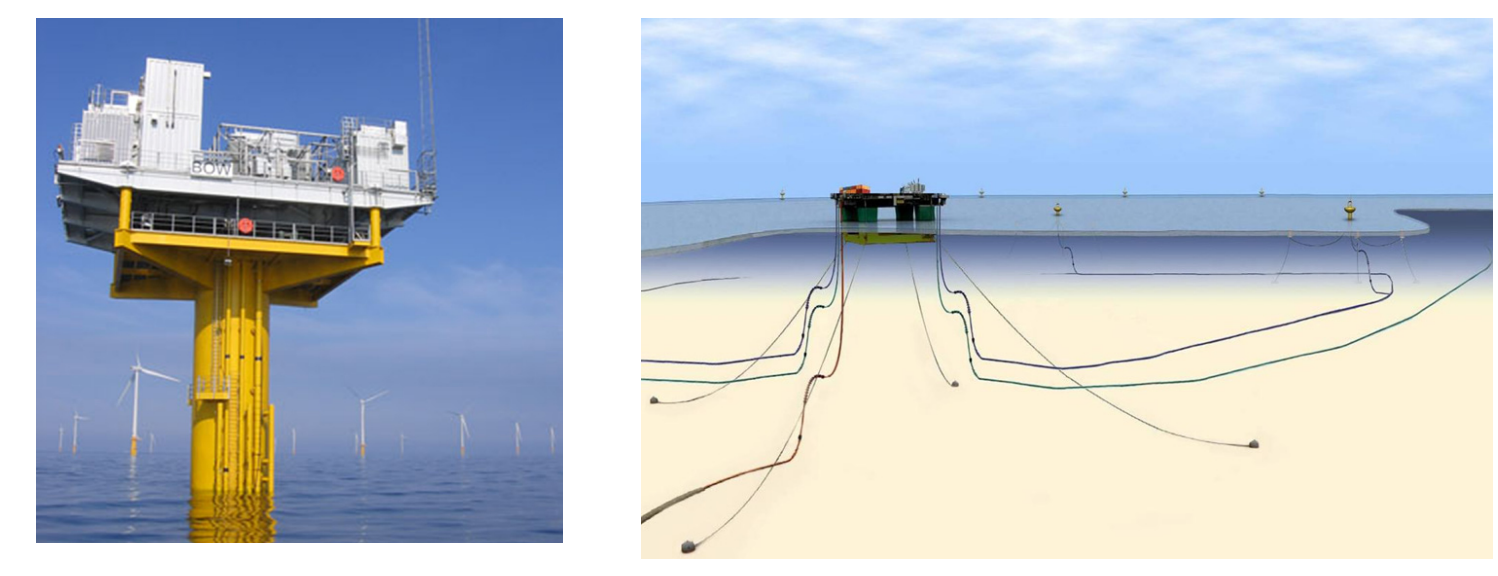

Figure 3-42: AREVA Off-Shore Substation and Conceptual Central Station for WEC Array

\subsubsection{Undersea Umbilicals and Connectors}

Undersea connectors are a major consideration in going forward. There are several different cable companies, all of which have different approaches. PG\&E had discussions with one manufacturer which felt that umbilicals could be placed as part of the main line as the installation. Another alternative is to never have a break in the line, and to have dual connectors in a daisy chain.

Regardless, PG\&E's perspective is that a single underwater connector increases the chance for failure. The wind industry actually uses the daisy chain approach, returning the overall cable to the main off-shore substation so that two ends are available. If a link is broken, the other cable end can be activated through on-board switchgear, minimizing down time. PG\&E feels that this issue is one that needs significant discussions before even moderately sized wave farms are developed. Figure 3-43 shows a schematic of such a windfarm daisy chain arrangement that PG\&E concluded presents minimal risk when used with an off-shore platform due to the system's ability to continue to supply power if one of the legs is cut at midpoint. In contrast, centralized hubs are at significant risk of a single point of failure that would result in the entire system going down. 


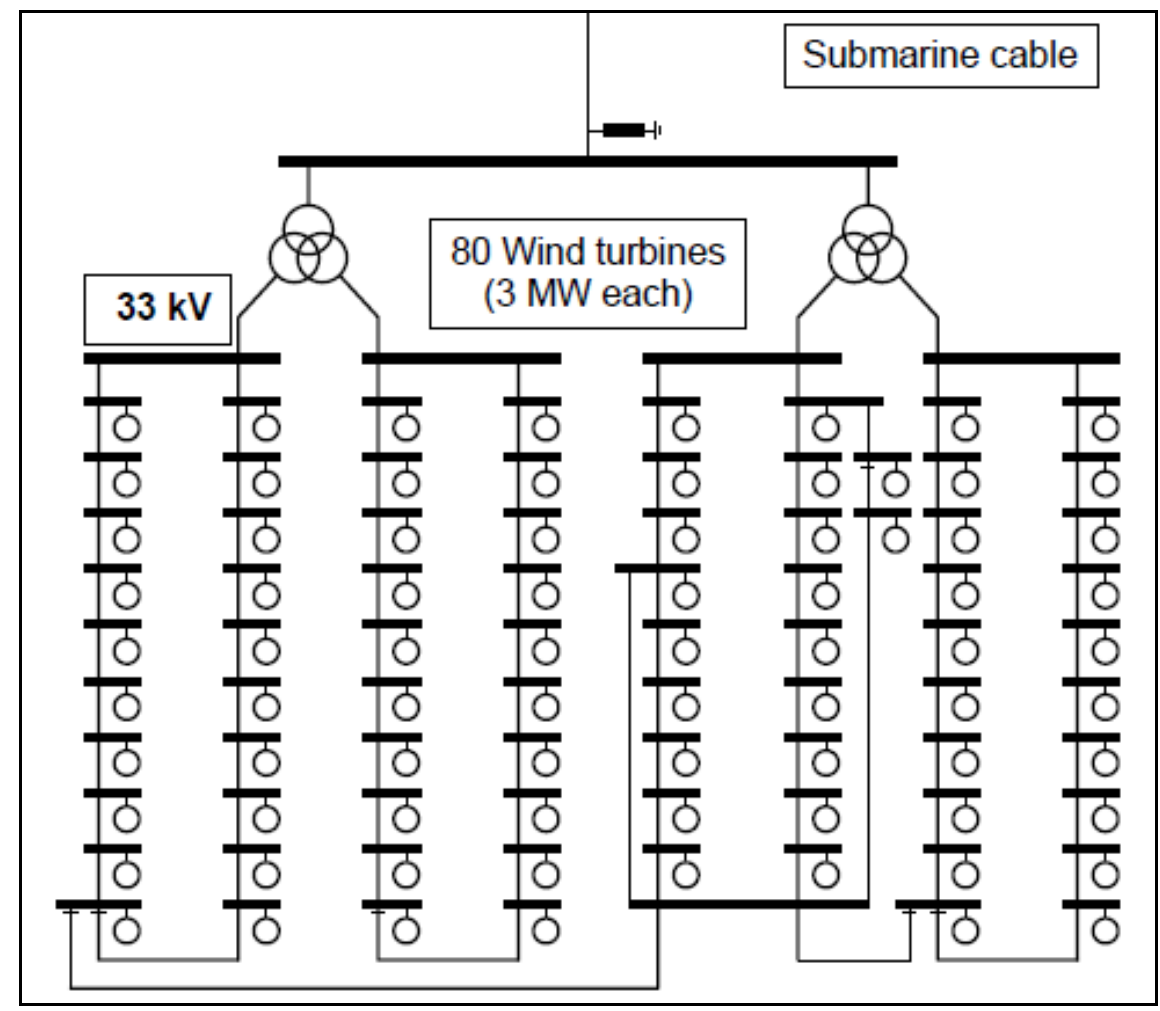

Figure 3-43: Windfarm Daisy Chain Configuration that Minimizes Risk (Underbrink et al, $2006^{48}$ )

Each WEC device, regardless of design, will require a cable to transmit electricity from the WEC down through the water column to the sea floor, where it will connect with other, similar cables from the other units in a given WEC array and convey the power to the interconnection point, where the transmission cables terminate. The following figures show some of the current industry standard cable interconnects. Figures 3-44 through 3-46 depict JDR's cable connector approach that is being used at Wave Hub. Figures 3-47 through 3-49 showed examples of ABB's approach to relieving stress on underwater cable interconnects. Figures 3-50 through 3-52 show bending restriction stress relievers that minimize impact to the overall connector, while Figures 3-53 and 3-54 show stress relievers that might be needed at the interface of the WEC and the cable. Figure 3-55 shows an actual physical interconnect to a WEC designed for rapid attachment. PG\&E believes that such a standard connector should be created so that different WECs could be interchanged at a facility without having to reconfigure the power connector.

\footnotetext{
48 2006. Underbrink, A., Hanson, J., Osterholt, A., and Zimmermann, W. Probabilistic Reliability Calculations for the Grid Connection of an Off-shore Wind Farm. $9^{\text {th }}$ International Conference on Probabilistic Methods Applied to Power Systems, KTH, Stockholm, Sweden, June 11-15, 2006.

$\mathrm{http} / / /$ www.neplan.ch/html/e/pdf_e/probabilistic_reliability_calculations_grid_connection_off-shore_wind.pdf
} 


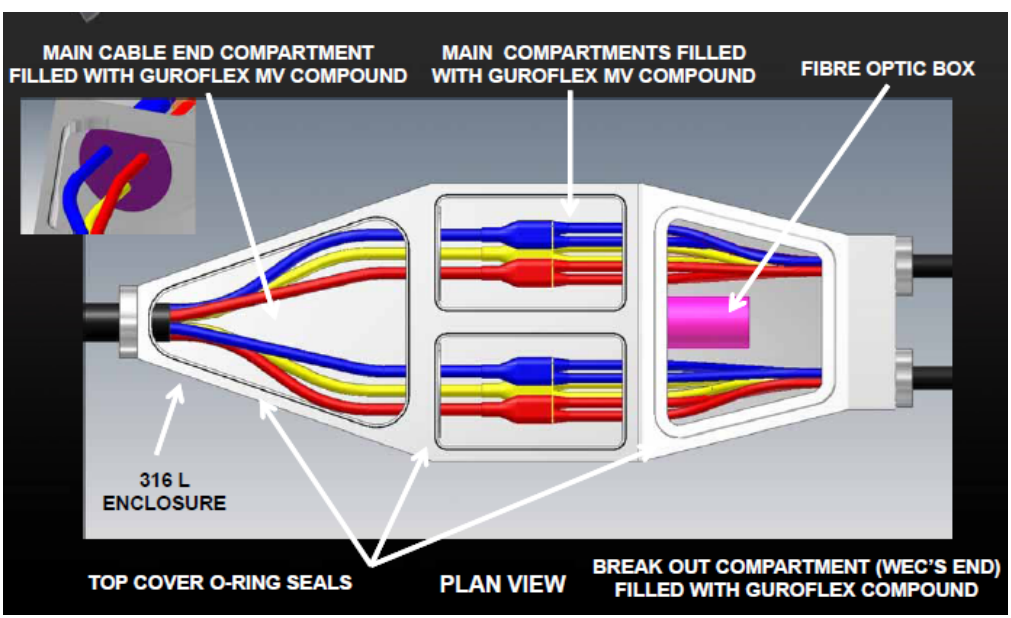

Figure 3-44: Cable Connector for use at Wave Hub (JDR Cables)

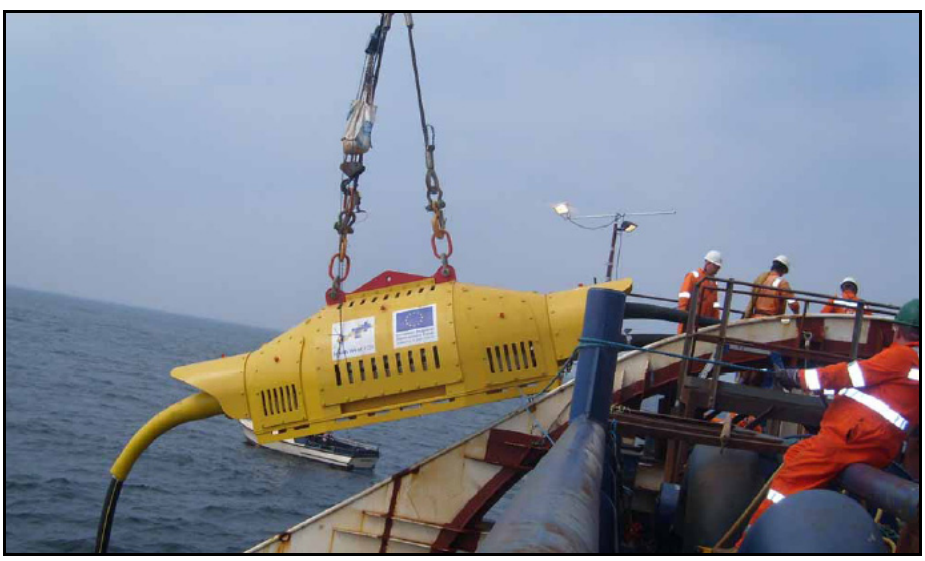

Figure 3-45: Cable Connector Lowered into Place from Cable-lay Ship at Wave Hub, August 2010 (JDR Cables)

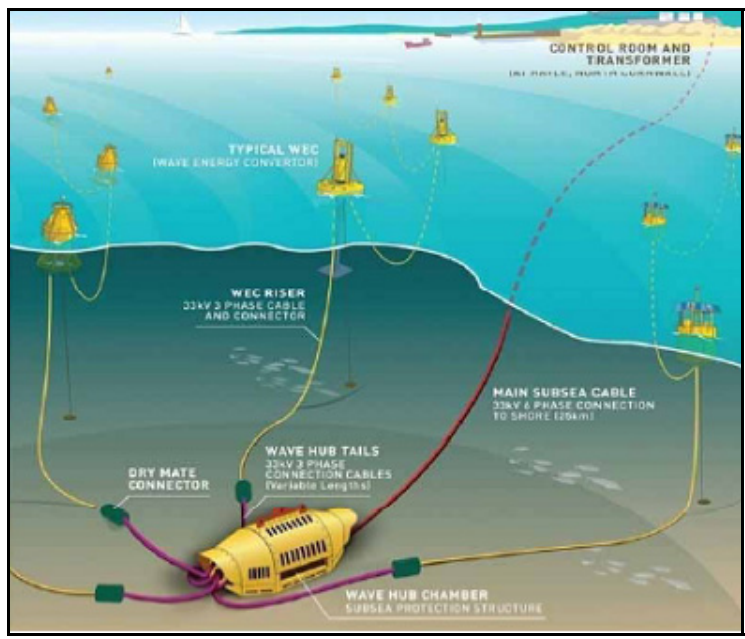

Figure 3-46: Wave Hub Project Cable Connector (JDR Cables) 


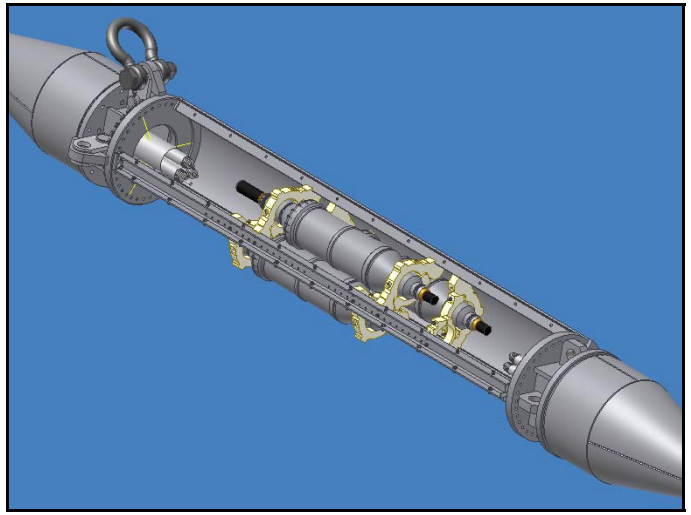

Figure 3-47: Cable Joint Cutaway (Marc Jeroense, ABB AB High Voltage Cables)

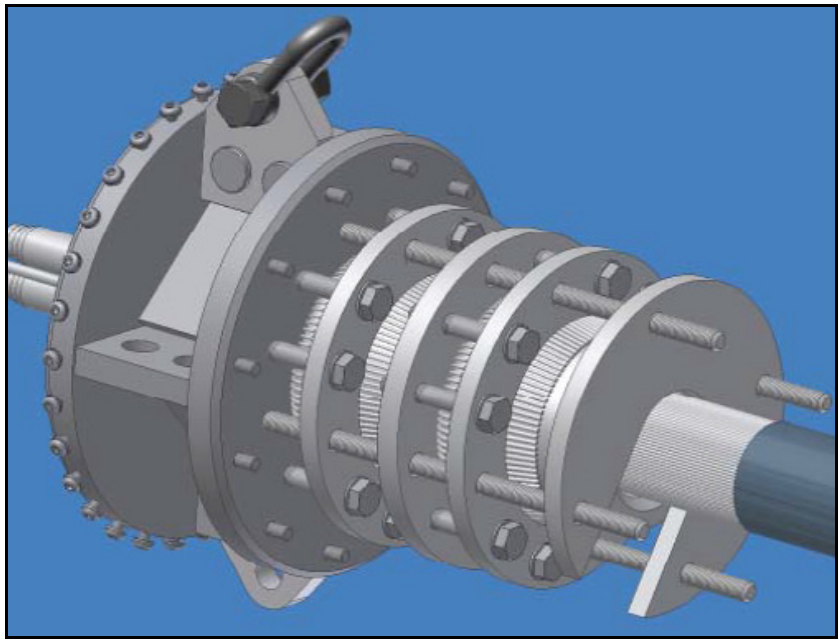

Figure 3-48: Cable Joint Termination Cutaway (Marc Jeroense, ABB AB High Voltage Cables)

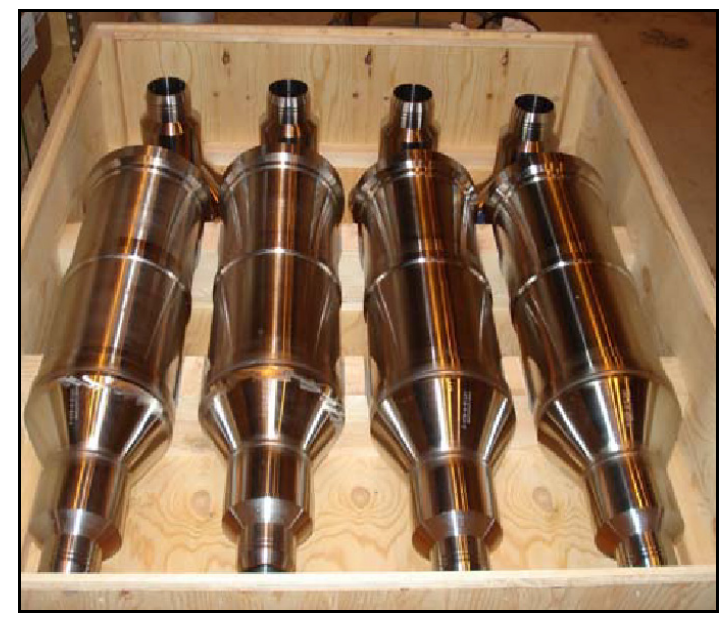

Figure 3-49: Cable Joiners (Marc Jeroense, ABB AB High Voltage Cables) 


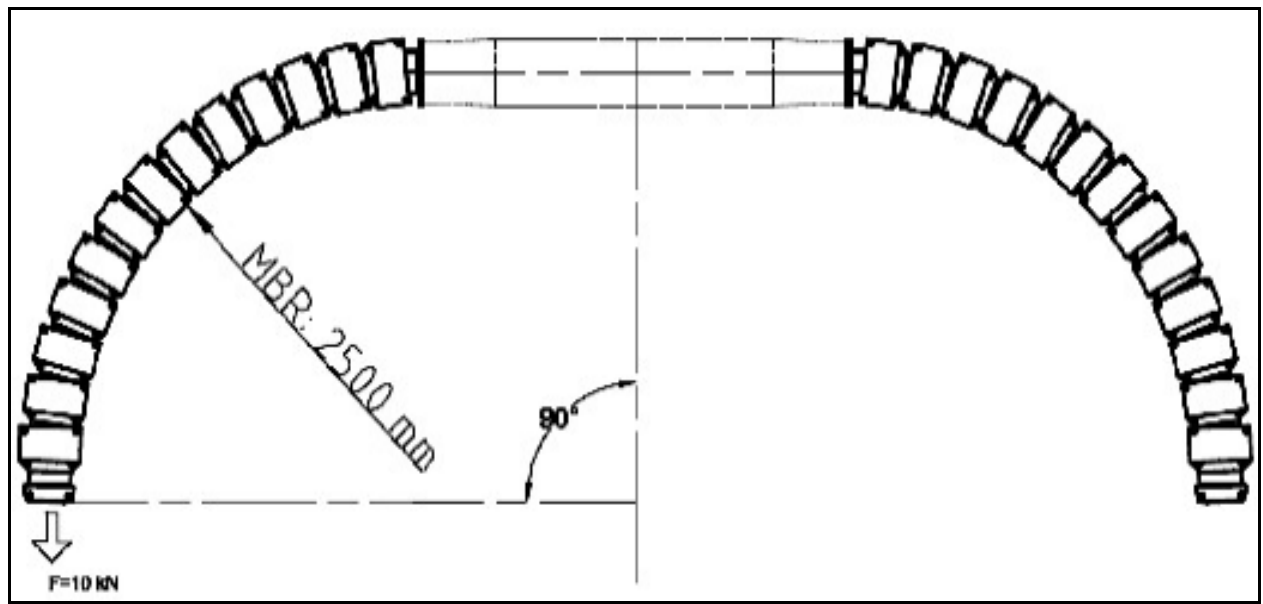

Figure 3-50: Joint Bending Restrictor in Operation (Marc Jeroense, ABB AB High Voltage Cables)

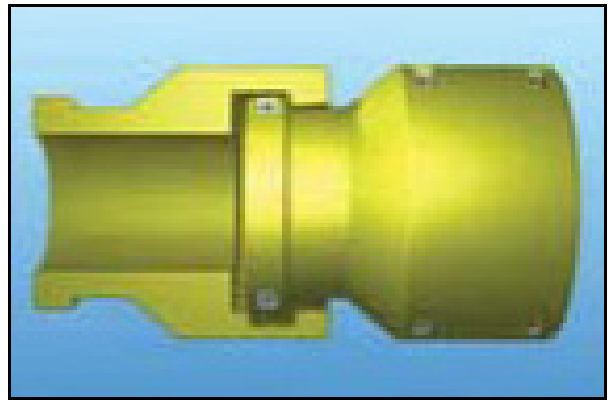

Figure 3-51: Joint Bending Restrictor Cutaway (Marc Jeroense, ABB AB High Voltage Cables)

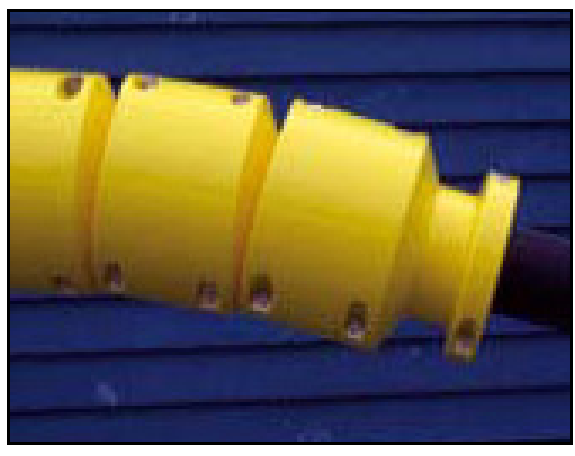

Figure 3-52: Joint Bending Restrictor (Marc Jeroense, ABB AB High Voltage Cables) 


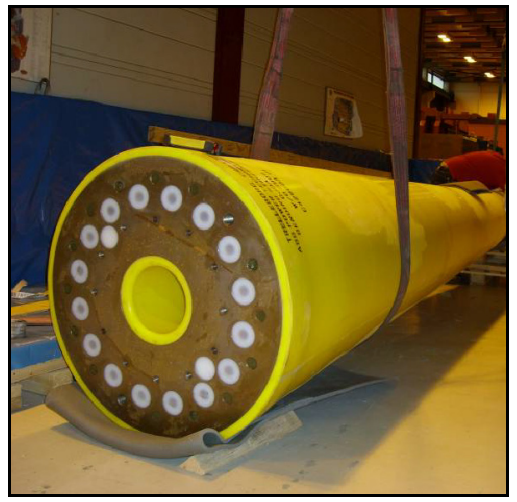

Figure 3-53: Cable Stiffener for Attachment to Off-shore Platform (Marc Jeroense, ABB AB High Voltage Cables)

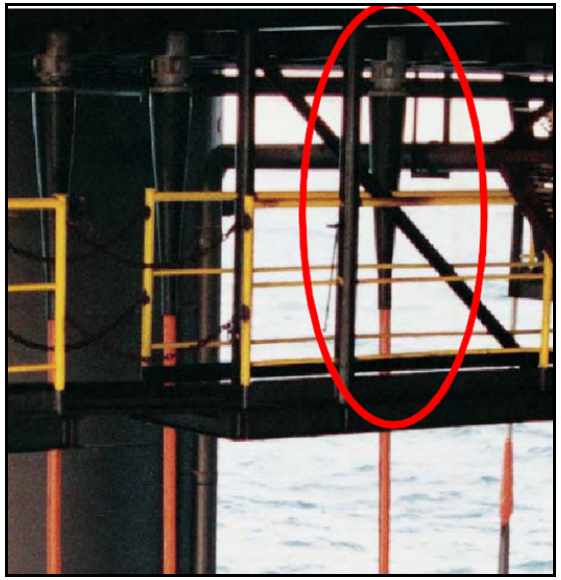

Figure 3-54: Cable Stiffener for Attachment to Off-shore Platform In Situ (Marc Jeroense, ABB AB High Voltage Cables)
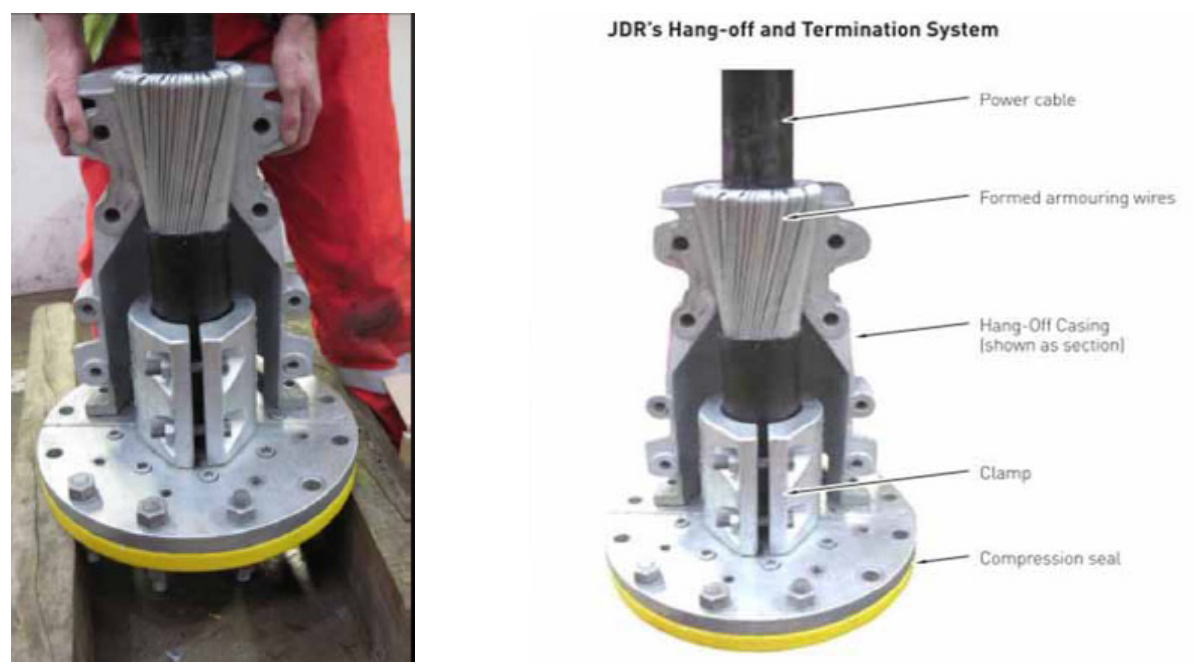

Figure 3-55: Off-shore Cable Termination for Connection to WEC (JDR Cables) 


\subsection{Mooring and Anchoring Systems}

Working in conjunction with PG\&E, WECoMs would have installed WEC mooring systems before deploying their devices. The mooring systems would have had anchors, anchor lines, and buoys. Mooring components were to be prepared at a host facility, loaded on a deployment vessel, and installed at HWC. The vessel may have made a number of trips to and from the host facility to install the mooring system, depending on the size of the mooring components and the capabilities of the vessel. Most mooring systems use drag anchors or gravity anchors. Each of these can use a combination of different mooring line materials.

Mooring and anchor systems are made up of multiple components, which vary based on the types of device or the overall configuration. Details of these systems are found in several of the SAIC reports (Appendix SAIC T, SAIC U, and SAIC V) in addition to the Oregon Wave Energy Trust (OWET)-funded study ${ }^{49}$ and the Harris et al. OREG ${ }^{50}$ document. Additionally, API has developed extensive standards for these systems, which will not be repeated here. Interested parties should review all these documents, as they are all critical to understanding the mooring and anchoring of WECs.

\subsubsection{Return Time of Storms and Survivability}

On January 8, 2004, a severe storm hit Denmark with peak wind speeds exceeding $33 \mathrm{~m} / \mathrm{s}$ over 10-minute averages. The resultant loads caused the main mooring connection for the WEC known as the Wave Dragon to break. The break was caused by a broken load cell, which connected the main mooring lines and the anchor block. The load cell broke at a load lower than the guarantied break load. In this particular case, the WaveDragon platform drifted toward the shore where it stranded close to the beach, with minimal damage.

On May 15, 2010, the one-third-scale Oceanlinx test generator broke free of its mooring in rough seas larger than those it was designed for, and sank after being battered against a local breakwater. It had been moored less than 150 m off-shore. Port Kempla Corporation required Oceanlinx to remove the debris from the ocean floor after the incident.

Both incidents reflect broadly on one of PG\&E's greatest concerns: the survivability of WEC devices in a large storm. The discussion of design strengths and storm return time is critical to the larger aspect of risk. As an introduction, PG\&E reviewed multiple documents on the issue, with one developed by scientists at $\mathrm{OSU}^{51}$ as an example of the complexity of the issue. Figure 3-56 shows multiple NDBC buoy locations along the West Coast of the United States.

\footnotetext{
${ }^{49}$ OWET, 2009. Advanced Anchoring and Mooring Study. Sound and Sea Technology, November 30, 2009.

${ }^{50}$ R.E. Harris, L. Johanning, and J. Wolfram. Mooring systems for wave energy converters: A review of design issues and choices. Ocean Renewable Energy Group. Undated.

${ }^{51}$ June, 2000. Paul D. Komar and Jonathan C. Allan. Analyses of Extreme Waves and Water Levels on the Pacific Northwest Coast. Report to the Oregon Department of Land Conservation and Development - Salem, Oregon. College of Oceanic \& Atmospheric Sciences, Oregon State University, Corvallis, Oregon.
} 


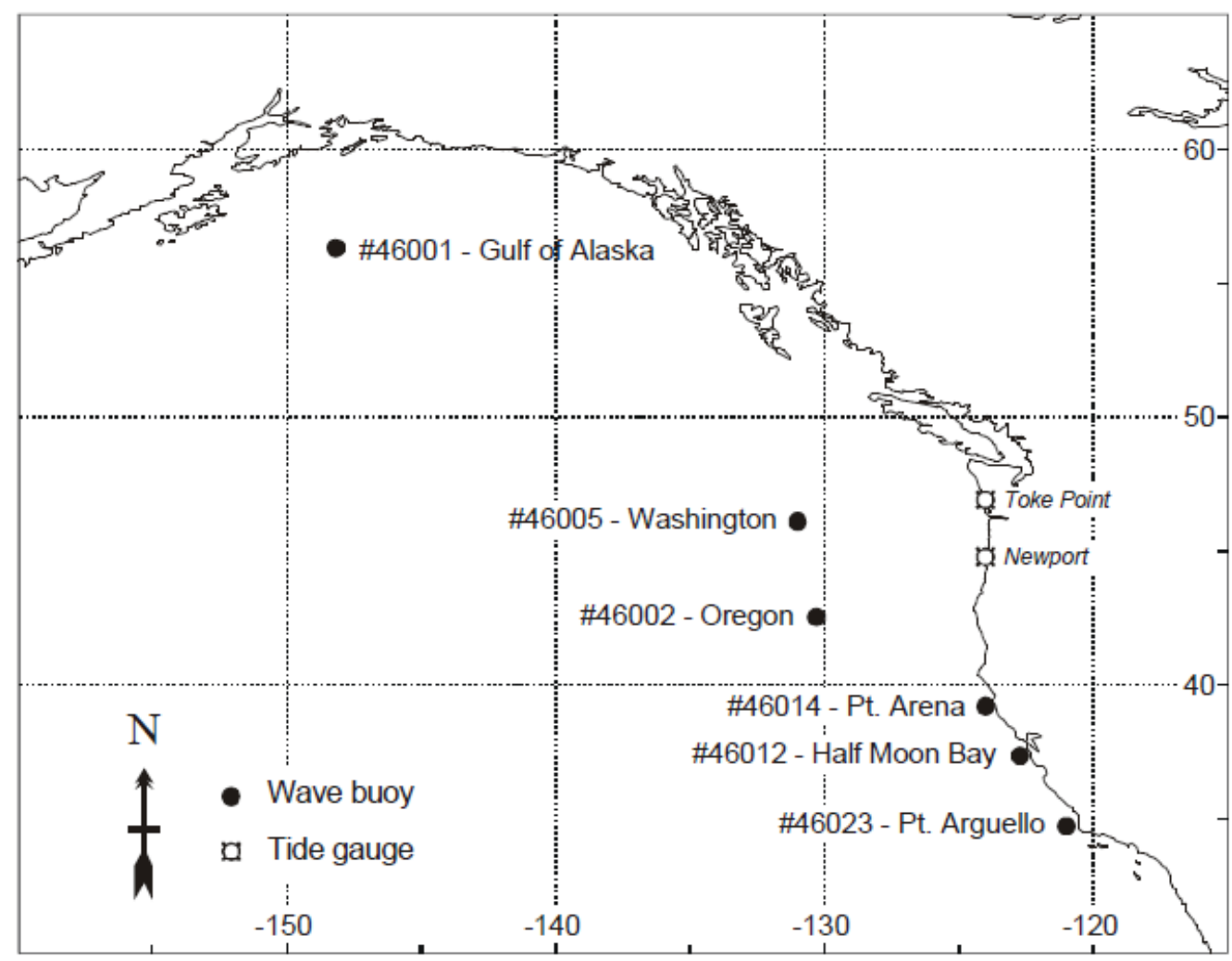

Figure 3-56: NCBC Buoy Locations along the U.S. West Coast (Komar and Allan, 2000)

Figure 3-57 shows the average wave height based on buoy location. The buoys that are representative of California have significantly lower maximum and average wave heights than those in Oregon, Washington, and the Alaskan Gulf. Figure 3-58 shows the spectral chart for the Washington buoy. Of extreme significance is Figure 3-59, which shows that the estimated 95\% confidence level for a 100-year return time is a wave of almost $19 \mathrm{~m}$. Such a wave has significant energy associated with it, but there is no discussion of what return-time wave height is used in OPT's FERC document ${ }^{52}$.

${ }^{52}$ OPT refers to its definition of a 100 -year return time as one in which a wave has a $50 \%$ probability of occurring. According to standard practices, a 50\% probability of a wave occurring would actually be a return time of 114 years. PG\&E is concerned that basic definitions and standards must be applied, so as to facilitate conversations. These are questions that the regulatory community must face. 

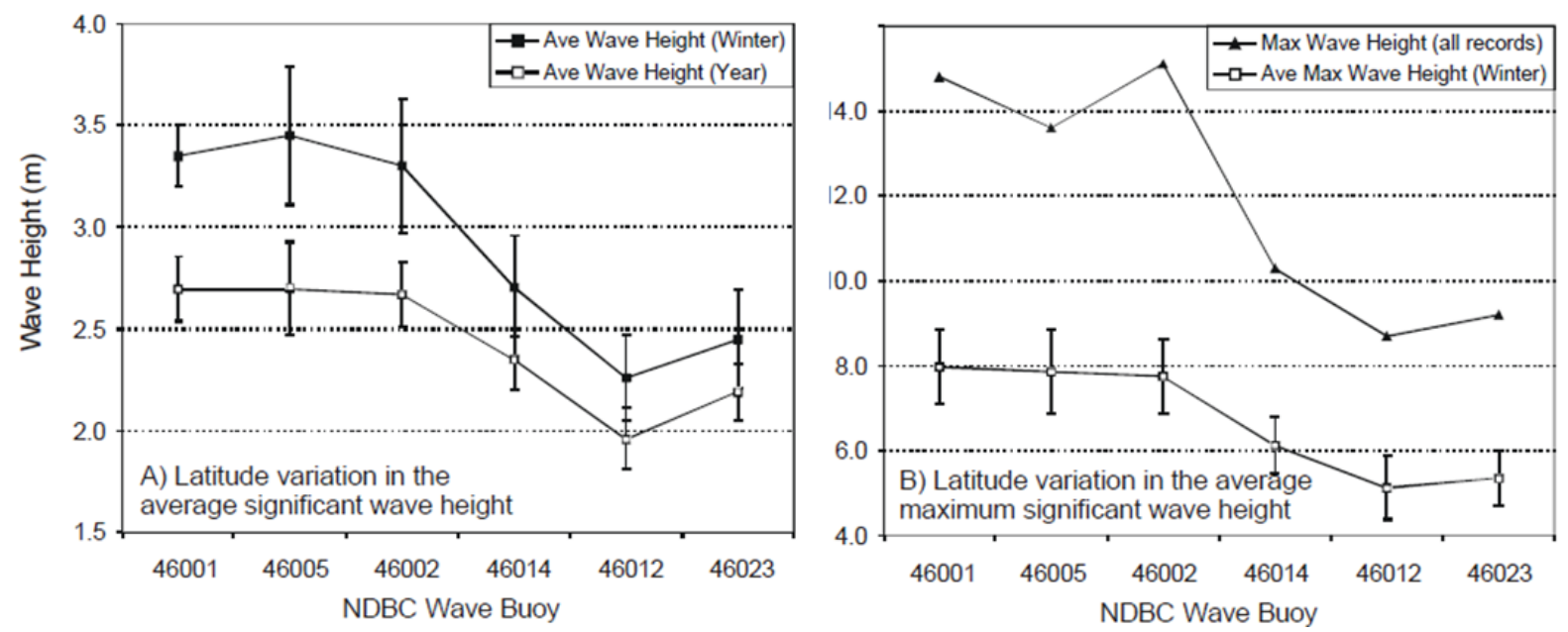

Figure 3-57: Average Wave Height at NDBC Buoys (Komar and Allan, 2000)

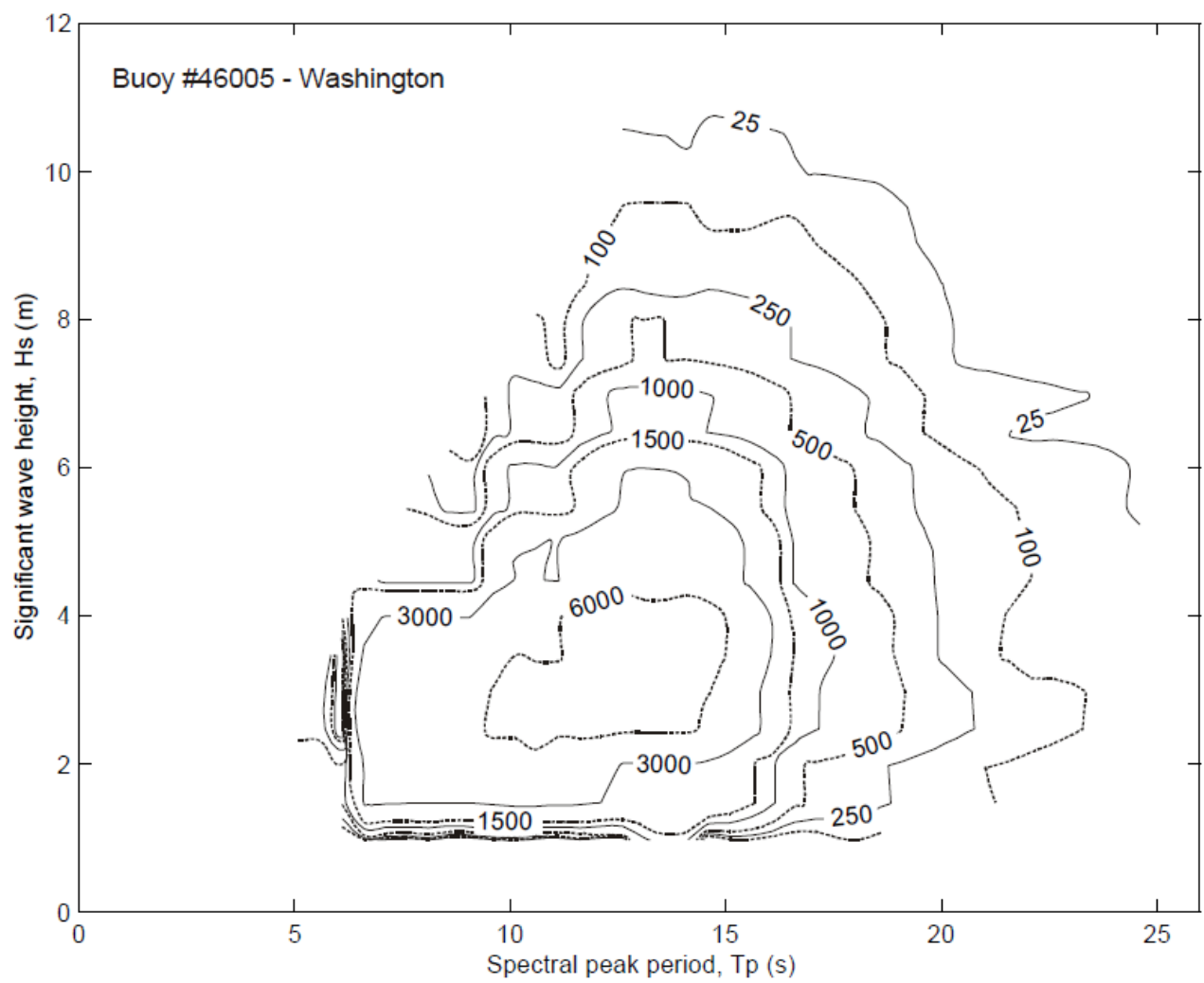

Figure 3-58: Spectral Chart for NDBC Buoy Off-shore of Washington State (Komar and Allan, 2000) 

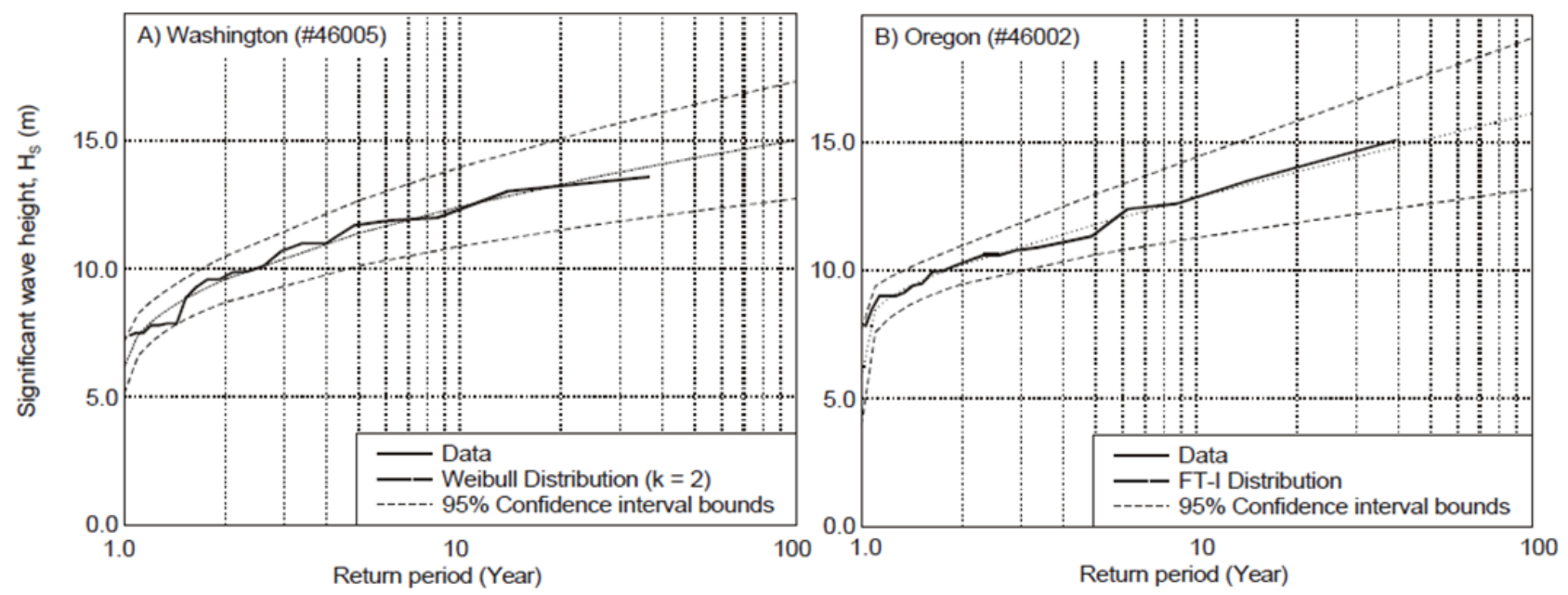

Figure 3-59: 95\% Confidence Intervals for Washington and Oregon Buoys (Komar and Allan, 2000)

If a WEC breaks loose in a major storm, it is not just a potential threat to itself. Once released, it may impact another WEC, which itself may be experiencing extreme storms. Such a collision could result in a catastrophic chain reaction as multiple WECs impact against each other, damaging and perhaps sinking them as well. Such a threat is one that PG\&E considers to be of serious enough consequence to recommend discussions of the risk and how that risk analysis is performed. This has other serious implications, such as the fact that increasing the strength of structural moorings also increases overall cost. At PG\&E's request, SAIC performed some perfunctory analysis of the mooring stresses on a small example WEC (Appendix SAIC V) that evaluated the mooring stresses and reactions due to a 50-year storm. PG\&E feels that this type of effort must be open and transparent to ensure that the proper cost-benefit of the risk is evaluated.

\subsubsection{Mooring Costs}

A major consideration for WECs is the cost of their mooring systems. As discussed above, the risk associated with a mooring line break must be balanced against the actual cost, which is not inexpensive. Figure 3-60 shows the breaking strength for various size mooring line materials, and Figure 3-61 shows the cost for the same materials by size. Mooring anchors - typically steelreinforced concrete blocks - can be quite large, weighing hundreds of tons per anchor, equating to costs in the hundreds of thousands of dollars. For the waters near Humboldt, each WEC device might require more than $300 \mathrm{~m}$ of mooring line. These costs do not take into account the possible need for floats.

PG\&E used these data to assess several WECs that were evaluated as part of the RFI, and found a wide range for mooring costs, from $\$ 0.2$ to $\$ 1.5$ per installed watt. This is a significant cost, which may decline over time only if rope costs fall due to technological development. Steel costs for anchor chain and wire cable are estimated to be at least five times the current cost of raw steel and are not expected to drop significantly even if purchased in bulk. 


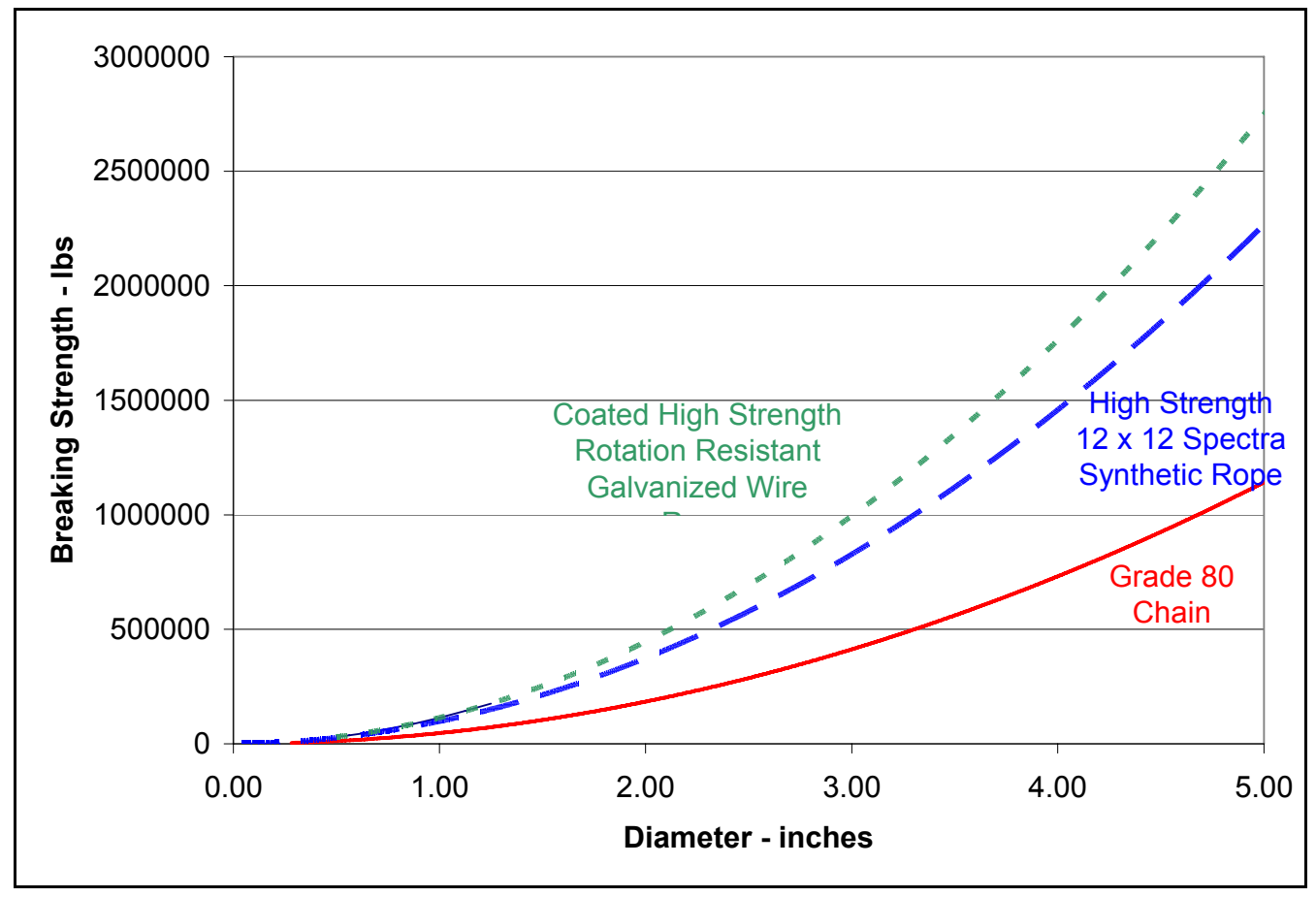

Figure 3-60: Diameter vs. Breaking Strength for Three Major Mooring Line Materials

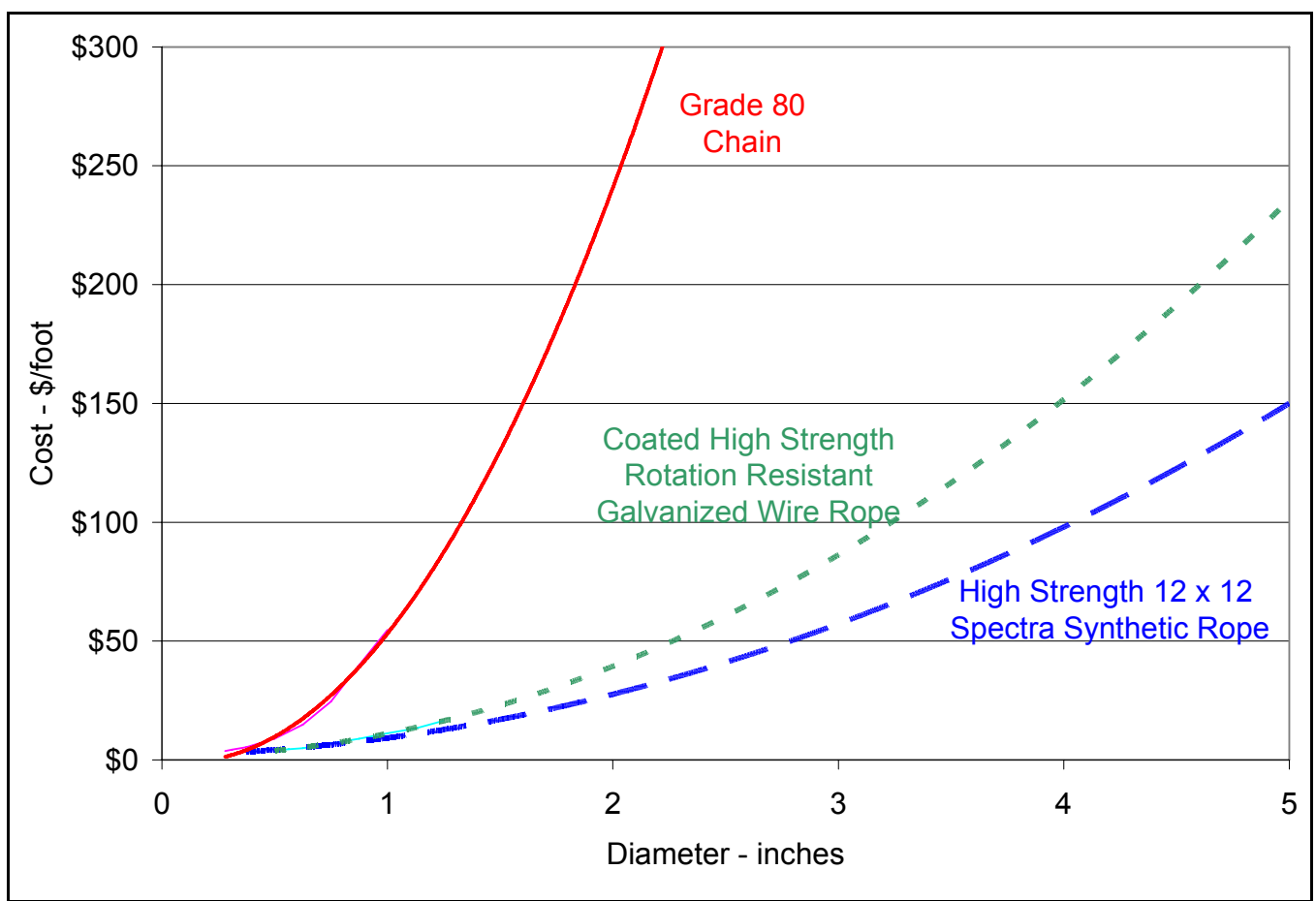

Figure 3-61: Diameter vs. Cost per Foot for Three Major Mooring Line Materials 
PG\&E used available costs for poly line, chain, and galvanized wire cable to estimate costs. These are rough estimates, and may not reflect bulk costs, but are used to obtain order-ofmagnitude estimates. PG\&E found that ploy line (such as Spectra synthetic rope) had the lowest cost per unit strength (Figure 3-62). Wire rope was approximately 30\% more expensive, with Grade 80 anchor chain costing significantly more. However, poly line has a significantly larger factor of safety than steel, and so the costs may offset. PG\&E understands that many device manufacturers use a combination of these three, while others might only use poly rope and concrete anchors. PG\&E feels the merits and drawbacks of these approaches is worth a discussion that incorporates the factors of cost and risk. DOE should evaluate the various anchor systems and simulate the reactions of various WEC devices to different configurations to assist industry decision makers. PG\&E also believes that the WEC manufacturers would be well served to share their data in a consortium to reduce this significant cost for all.

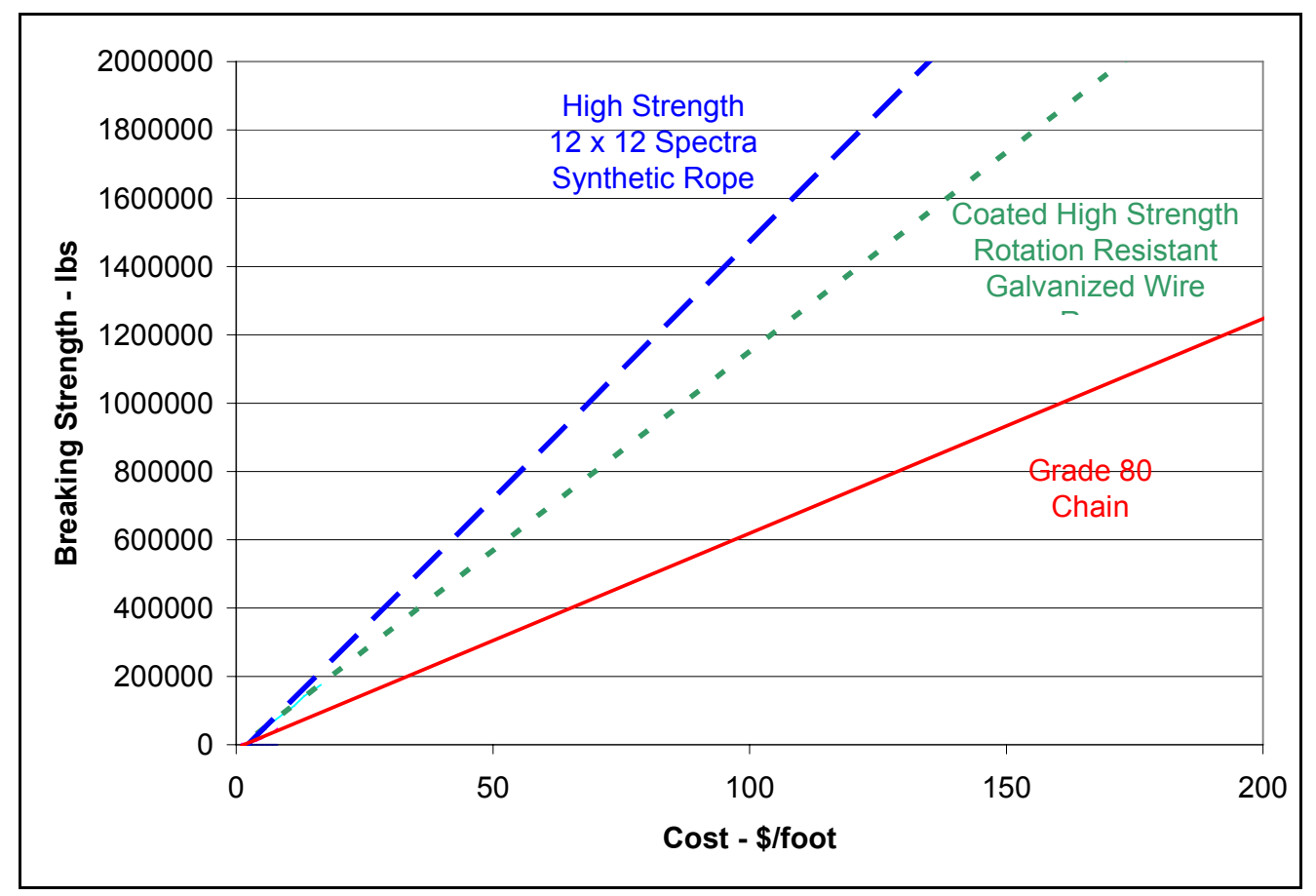

Figure 3-62: Cost per Foot vs. Breaking Strength for Three Major Mooring Line Materials

\subsection{Capacity Factor and Availability}

To support decisions regarding wave energy conversion systems, the factors affecting cost performance have to be quantified. Although the capital costs for WECs are many times greater than lifetime O\&M costs, these costs offer significantly greater uncertainty. PG\&E feels that it is necessary to explore O\&M costs in order to determine likely ranges of cost elements and identify those components that have the greatest contribution to the overall uncertainty.

The power of a WEC system can be described by: 
Power $=f_{m} f_{e} A \times \sum t_{T H} C_{i}$

$f_{m}$ - power factor due to mechanical losses

$f_{e}-$ power factor due to electrical losses

$A$ - power factor due to downtime due to failures in the system from mechanical or electrical (or availability)

$t_{T H}$ - total hours of grouped wave period and height (over a year)

$C_{i}$ - power conversion factor for a given hour of wave period and height

The power factors $f_{m}, f_{e}$, and $A$ are averages over the project lifetime. The product of the sum of $\mathrm{C}_{i}$ and $t_{T H}$ gives the overall power output for a given device. That factor, divided by the device's maximum production over a one-year period, is the capacity factor (see Section 3.4.2). PG\&E estimated that the capacity factor for the Humboldt WaveConnect project would be approximately $31.5 \%$.

The capacity factor for electrical losses, $f_{e}$, comes from both line resistance and the capacitance effect (although there are other electrical capacitance losses associated with the production of renewables). Like wind turbines, WECs often use induction generators due to their rugged nature, lack of maintenance, and low cost. These systems do require reactive power to operate and capacitive compensation is often engineered into the system, although interactions between the WEC, the power network, and the capacitor compensation must be dealt with through interactions between the utility and the manufacturer. Resistive losses would become significant at highest production. Since resistive losses follow the $\mathrm{I}^{2} \mathrm{R}$ law, and assuming a $300 \mathrm{~mm}$ copper power cable, maximum losses would be less than $0.5 \%$. Including capacitive effects, the total losses are approximately $1 \%$ for a $6 \mathrm{~km}$ cable. Although these losses would increase substantially for systems far off shore or for higher voltage systems, most wave facilities should be no more than $15 \mathrm{~km}$ off the coast and initial developments are likely to be in the $34.5-\mathrm{kV}$ range. Overall transformer losses are also $0.5 \%$ on both sides, for a total loss of $1 \%$. Therefore, $f_{e}$ is around $98 \%$.

The mechanical capacity factor, $f_{m}$, is highly dependent upon the technology type. As an example, an oscillating water column device will have the efficiency issues associated with a Wells turbine, as well as compressibility losses of the air in the chamber as the wave forces air through the turbine. Point absorbers exhibit major frictional losses through the hydraulic systems. This factor is separate from the power conversion factor, which is considered to be the conversion factor from a wave energy spectra $\left(t_{T H}\right)$ for the particular device. Separating it allows improvements in technology, such as a move from hydraulics to direct-drive systems, to be considered. Although PG\&E did discuss this factor with several manufacturers, details are not provided in this report due to confidentiality considerations. However, the mechanical capacity factor can be significant, and explains why there is a desire to move to direct-drive technologies.

The availability factor of a power plant, $A$, is the amount of time that it is able to produce electricity over a certain period divided by the total period. Of these factors, $A$, is most closely 
related to the issue of O\&M, which is in turn related to the issue of wave variation throughout the year. If the WEC system fails during large storm events, it may be difficult to access or retrieve the WEC. Though the availability factor is dependent upon how the performance of mechanical and electrical components will tend to degrade over time, the failure rate (which would account for downtimes) is unknown. OPT feels that its availability is around 90\% (as discussed below), and PG\&E has used this figure for its cost calculation efforts although the value cannot be confirmed due to lack of historical data with these devices.

PG\&E found that WECoMs fell into two general groups: those that believed their WEC devices would likely have to be towed to a shipyard for repairs, at least for their initial years; and those that believed their devices could be maintained via small tug boats or helicopters. Among the device manufacturers that felt in-situ repair was adequate, there were also those that provided redundancy so that if a power producing component failed, there was still power produced overall. Thus, the issue of availability is complicated by many variables, not the least of which is the device type.

OPT in its FERC application ${ }^{53}$ estimated that its WEC device had an overall capacity factor of $35 \%$ and an estimated availability of $90 \%$. The various factors in Table 3-8 shows the O\&M activities that OPT expected could occur during the lifetime of the project. Details are found in the FERC document.

Table 3-8: Anticipated O\&M Activities for OPT Reedsport Project (OPT 2010)

\begin{tabular}{||c|l|l||}
\hline Item & \multicolumn{1}{|c|}{ Description } & \multicolumn{1}{c||}{ Frequency } \\
\hline 1 & Continuous on-shore monitoring and operation & Throughout the duration of the FERC license. \\
\hline 3 & Preventative maintenance/site inspection & Monthly. \\
\hline 4 & $\begin{array}{l}\text { Planned maintenance - retrieval, refurbishment, } \\
\text { redeployment }\end{array}$ & $\begin{array}{l}\text { Annually unless otherwise specified in the } \\
\text { Settlement Agreement Study Plans. }\end{array}$ \\
\hline 5 & $\begin{array}{l}\text { The first PowerBuoy may initially be retrieved } \\
\text { after two years. A five-year major service period } \\
\text { is anticipated for the other PowerBuoys deployed } \\
\text { at the site. }\end{array}$ \\
\hline 6 & Supporting documentation & $\begin{array}{l}\text { As required, weather and other safety conditions } \\
\text { being considered. }\end{array}$ \\
\hline 7 & Management and storage of spare parts & $\begin{array}{l}\text { Reports produced after monthly inspection, } \\
\text { equipment inspections, and maintenance records }\end{array}$ \\
\hline \hline
\end{tabular}

O\&M costs are impacted by component reliability, environmental factors, WEC device configuration, and other factors. The lifetime of the device will significantly affect O\&M costs, as older equipment will require more attention (and fail more often), but also because O\&M costs incurred in the years furthest will be most impacted by the discount rate assumptions. Although it may be valid to assume that off-shore platforms offer a good estimate of WEC lifetime, this is also not yet proven. Estimates of operational lifetime of WEC devices will not be available until more experience is gained with full-scale devices.

${ }^{53}$ OPT 2010, Reedsport OPT Wave Park, FERC Project No. 12713. Environmental Assessment Vol II of IV 
Of critical concern is the issue of when a system is maintained. PG\&E and other utilities value the production of energy in summer months highly, and so create contracts with power providers that penalize non-production during that period. However, this is the safest time of the year for maintenance of devices. It will be a difficult balance for the wave energy conversion manufacturers to schedule springtime or fall major maintenance in order to avoid production penalties.

\subsection{Cable Cost and Installation Estimates}

This section examines various cable configuration cost scenarios for placing the pilot wave energy system off the coast of Humboldt. The pilot project concept originally focused on four cables of $2.5 \mathrm{MW}$ each, rated at $12 \mathrm{kV}$. It was assumed that the WEC devices would not be able to produce acceptable $12-\mathrm{kV}$ voltage, and that further power conditioning would be required at the on-shore tie-in facility. Therefore, four cables would be needed for testing up to four different WEC devices.

What was unknown at the time of PG\&E's RFI was whether the devices would be able to meet grid-ready connected quality voltage at the WEC device. Since the time of the initial pilot conceptual scenario and the RFI, PG\&E has discussed with multiple WEC manufacturers their devices' capabilities and abilities to deliver power system quality. Although technical details still need to be discussed, the majority of WEC manufacturers verbally said they could meet this criterion, and some explicitly stated so in their responses to PG\&E's RFI.

As a result, and through internal discussions among PG\&E engineers, a new consensus emerged that the optimal future build-out at this site would use $34.5-\mathrm{kV}$ cables rated at no more than $30 \mathrm{MW}$. This is approximately the largest diameter cable that can be installed without mobilizing a large-scale cable installation ship. Another reason for employing $34.5-\mathrm{kV}$ voltage cable was to create some standardization within the industry, since wind power is already standardized at 34.5 $\mathrm{kV}$, and to create a de minimus cost for cable that allows the maximum return on investment. It is less costly to install larger cables, but the 30-MW scope appeared to yield the best return given the constraints for this site.

This section summarizes the methodology and results of SAIC's July 2010 Pilot Infra Lifecycle Cost Analysis (LCA) (Appendix SAIC X) with a focus on the up-front capital costs. The basic assumptions behind the LCA related to construction of the electrical infrastructure to support up to four different arrays of WECs of various types installed within the boundaries of the site, as well as up to four power cables plus site preparation. The additional analysis described focuses on different permutations of cable cost and associated installation. It is assumed that for the first five years of the initial effort there would be substantial monitoring of the entire system to meet regulatory concerns. As the regulatory community becomes more familiar with wave power technology, PG\&E expects the yearly O\&M costs associated with the general infrastructure to decrease. O\&M costs associated with the WECs are not addressed here.

In order to examine this, PG\&E developed a cable cost estimator. The estimator bases its calculations on various quotes given to SAIC by industry providers. Since most of these quotes 
were developed in 2009-2010 time frame, PG\&E recommends that any new estimates be adjusted to account for changes in copper and oil prices since 2010. Oil price is an acceptable stand-in for both energy and hydrocarbon-based material cost.

\subsubsection{The SAIC LCA}

The SAIC LCA estimated annual costs for the Humboldt WaveConnect pilot project assuming initial detailed engineering and long lead-time procurement in Year Zero, defined as beginning when FERC granted the license. Year One site construction assumes installation of the shore pad, submarine power cables, site-marker buoys, and initial installation of mooring devices, with WEC installation occurring in Year Two. Years Three through Seven would be the operational years, during which the WECs produce power that is sent to shore. The site would then be decommissioned in Year Eight.

SAIC's scope involved engineering services only, and did not incorporate any other services or PG\&E efforts. The important assumptions are shown below, with some other minor ones detailed in the SAIC LCA:

- The costs assume a five-year operational period - that is, five years of WEC operations, preceded by installation and succeeded by decommissioning.

- The costs presented are very rough order of magnitude (VROM) engineering estimates and are not an estimate of bid for services by either SAIC or any other vendor.

- Preliminary design activities are assumed to be complete.

- All WEC-associated costs (installation, operating, maintaining, and decommissioning) are assumed to be the full responsibility of the WEC vendor.

- All unknown (i.e., emergency) contingencies have been removed from this estimate. Minimal contingency funding remains within the costs presented.

- This estimate assumes no long-term monitoring is required at the site after removal. After decommissioning it is assumed that the site is remediated and PG\&E bears no further responsibilities.

- No time-value of money (e.g. inflation or cost growth factors) have been applied. Costs are presented in 2010 dollars.

As stated above, the original assumption behind the four-cable design was that WEC manufacturers would not be able to perform conditioning at the WEC device, and that matching PG\&E's frequency and power quality would require on-shore equipment. All other assumptions in this document call for the individual WEC to produce system power quality at the device, without the requirement for intermediary power conditioning on shore. This allows the use of a single cable rather than four, and is a major change from the SAIC LCA. 


\subsubsection{Cable Route Conceptual Scenarios}

Two conceptual scenarios are evaluated. The two scenarios are themselves split into subscenarios. Scenario 1 envisions a facility placed entirely within the current pilot area, which is considered to be just within the OCS. This scenario assumes that there will be no future facility at the location and that the devices will be removed at the end of the project.

Figure 3-63 shows the placement of the cable for Scenario 1. In this scenario, the capacity of all the cable installations equal $10 \mathrm{MW}$, allowing four devices of a maximum nameplate production capacity of $2.5 \mathrm{MW}$. All cables have a maximum extent of $8.2 \mathrm{~km}$ and are just short of the OCS, allowing the pilot to operate in waters of $45 \mathrm{~m}$ in depth or less.

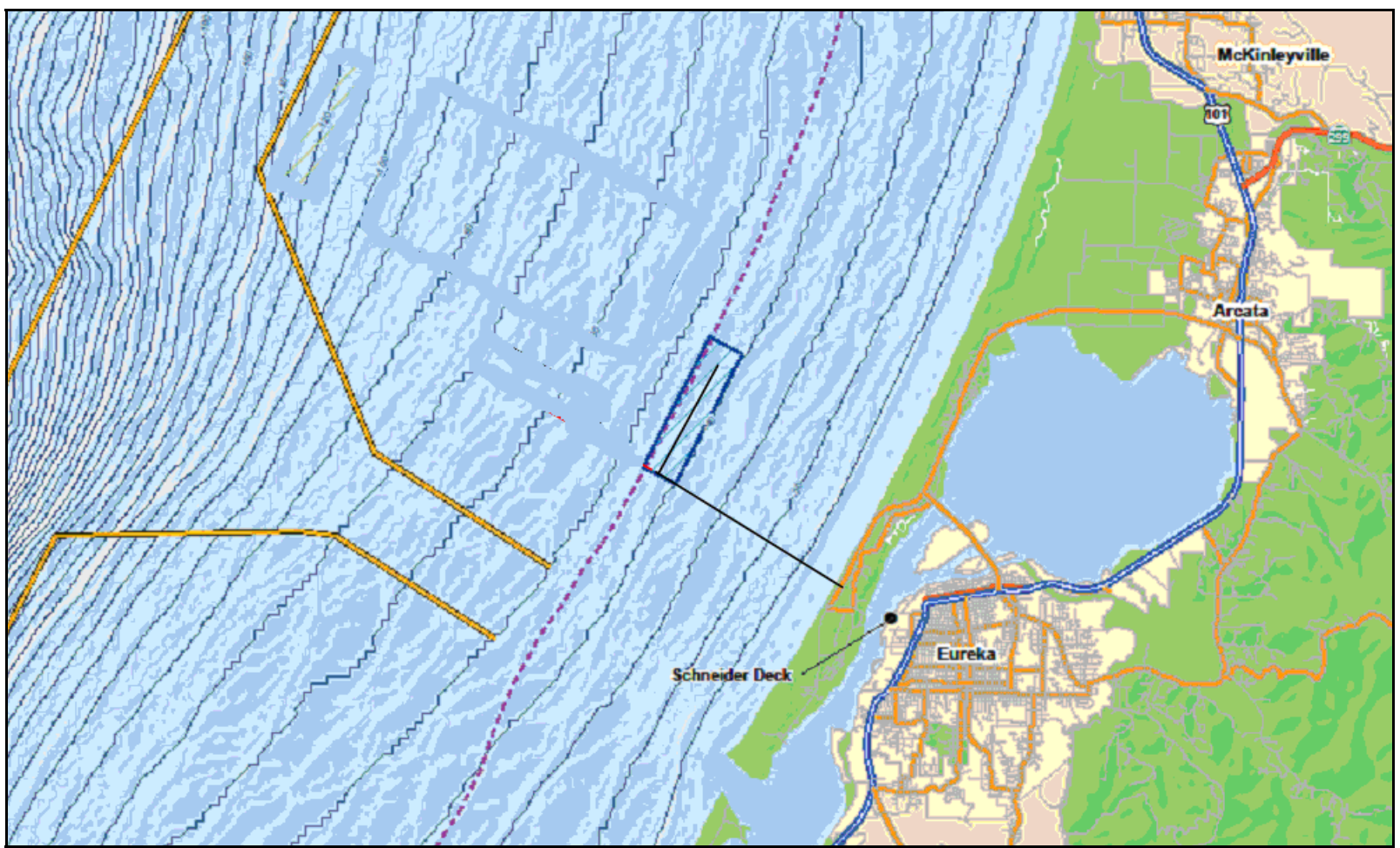

Figure 3-63: Scenario 1-Project Site within the Pilot Area 


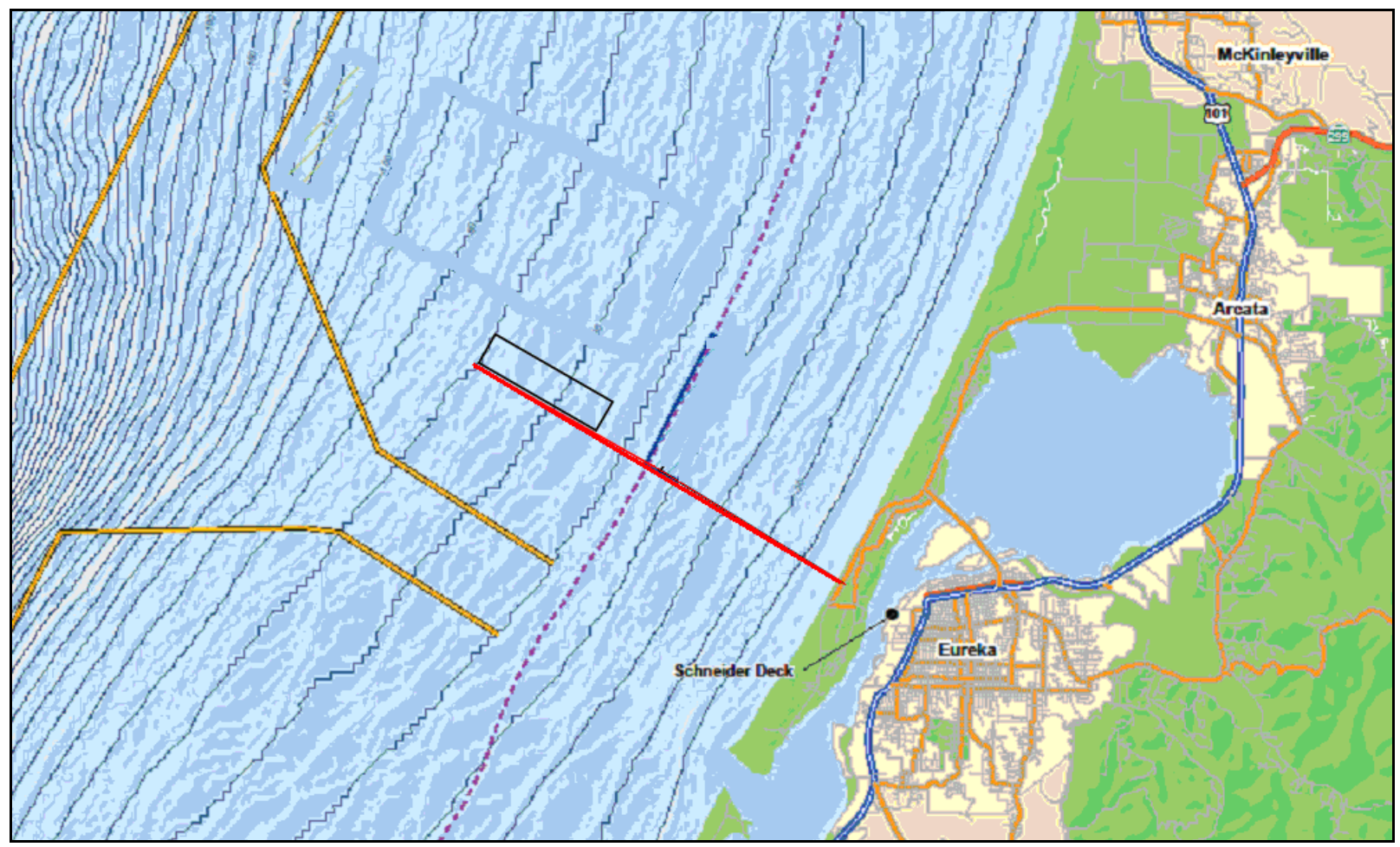

Figure 3-64: Scenario 2-Project Site on Outer Continental Shelf

Scenario 2 assumes that one or two $34.5-\mathrm{kV}$ cables are laid on BOEMRE-controlled lands on the OCS (Figure 3-64). The pilot project is to be built entirely within the OCS, making it a precursor to a larger facility at the end of the pilot. The cable extends to $10 \mathrm{~km}$, which is at approximately $70 \mathrm{~m}$ in depth, giving a depth range for this scenario of between $45 \mathrm{~m}$ and $70 \mathrm{~m}$. This scenario assumes that BOEMRE and FERC allow a move to the OCS, with BOEMRE accepting FERC's NEPA for the duration of the pilot. It is also assumed that BOEMRE, FERC and the State Lands Commission (SLC) would cooperate on a cost-effective Environmental Assessment process, with the agencies assuming joint lead roles. For a full-scale project, PG\&E would apply for an update of the NEPA document with BOEMRE and a full-scale license from FERC.

\subsubsection{Cable Install Calculator and Installation Costs}

Based on information collected by SAIC, PG\&E created an Excel spreadsheet-based Cable Install Calculator to look at various levels of cable install costs. The current calculator likely produces a conservative estimate of the cost of cable per meter. As more information becomes available in the future, the estimator can be improved. Improvements that could be added now would allow for variation in the price of copper and the use of the actual copper weight.

Before developing the calculator, PG\&E examined the costs associated with options ranging from a small $12-\mathrm{kV}$ cable to a large $115-\mathrm{kV}$ cable. This outreach included discussions with various high-level electrical infrastructure engineering firms, as well as detailed discussions with SAIC and various cable companies. PG\&E found that the reasonable upper limit for a cable 
capacity that did not include extremely large costs for cable ship mobilization and shipment was a $34.5-\mathrm{kV}$ cable rated at $30 \mathrm{MW}$. This is reasonable, in that WEC devices along the West Coast are substantially closer to shore than many of the wind-based facilities in the European Market, where the distance involved requires either a $115-\mathrm{kV}$ (or European voltage equivalent) or a DC cable.

To help foster some standards in the industry, all estimates concerning a pilot facility on the OCS (Scenario 2) assumed that each WEC device outputs power at $34.5 \mathrm{kV}$. It was estimated that $\$ 10$ million (Section 3.5.1) would be required to upgrade the on-shore facilities, which would include a $34.5-\mathrm{kV}$ to $60-\mathrm{kV}$ step-up transformer.

The calculator included the above assumptions and incorporated the costs described in the SAIC report, as well as detailed discussions that took place with SAIC. It attempts to take a unitized approach to the cable installation cost. In general, there are three major dependencies: the number of cables, the distance of the cable run, and the type of cable.

For a single cable run, horizontal directional drilling cost represents approximately $10 \%$ to $20 \%$ of the entire capital install effort. The installation cost (approximately $60 \%$ of the total) is about twice the cable cost (approximately 30\% of the total), and has additional significant contingencies built in due to the uncertainties involved in any ocean-going effort. Multiple cable runs change this ratio, but for this cost-estimating purpose the single cable alone is generally assessed.

Figure 3-65 shows the cable cost (per mile) for the various scenarios. The figure below uses traditional miles (as opposed to nautical miles), and so the pilot facility would require approximately a 5.1 mile $(8.2 \mathrm{~km})$ cable based on an initial assessment of separation for the devices. For Scenario 2, the total cable distance for a cable run to $70 \mathrm{~m}$ in depth is approximately 6.3 miles $(10 \mathrm{~km})$. The assumed costs include cable, ship mobilization and demobilization, and some engineering and environmental support. 


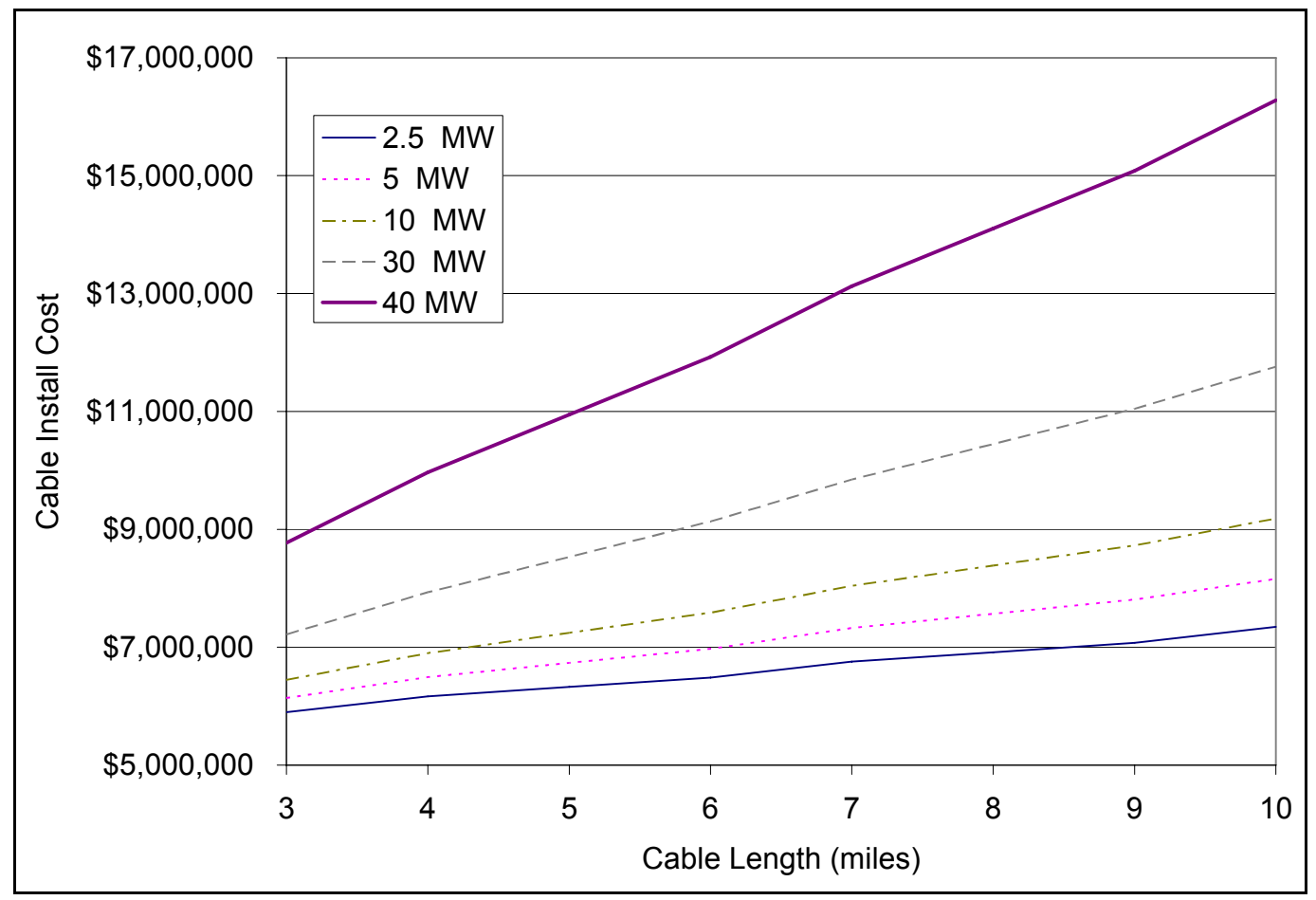

Figure 3-65: Cable and Installation Costs for Various Cable Runs (40-MW scenario comprises two 20-MW cables)

\subsubsection{Subsea Cable Installation Scenarios}

The following analyses examine the two major conceptual scenarios described above. Each of these scenarios have sub-scenarios, such as a single 2.5-MW cable (Scenario 1a) or a single 10MW cable (Scenario 1d), each of which is discussed below. It is assumed that the WEC is capable of supplying system quality power at appropriate voltage level at the device, without requiring any on-shore conditioning. Each device would also need appropriate breaker controls on board. These scenarios place a greater emphasis on WEC scope and maturity, as the need to deliver system-level power quality is certain to be a requirement in a larger commercial buildout. They are all conservative, and PG\&E does not expect that many of the associated costs would be required for longer build-outs, although some such as sentry buoys would still be required. The scenarios are outlined in ascending order of greater flexibility and effectiveness to PG\&E:

Scenario 1a: In this conceptual scenario, a single 2.5-MW cable is installed, allowing installation of either one 2.5-MW device or a few smaller kilowatt-scale devices. After a fiveyear test the cable is removed, along with the rest of the infrastructure. A major issue is that only one large device could be installed - or, if smaller WECs were used, larger ones would not be available. This scenario eliminates several different technologies, and closes multiple options. It is the least attractive of the three scenarios, although it is (slightly) less expensive than others. 
Scenario 1b: In this conceptual scenario, a single 5-MW cable is installed, connecting to either two or three WECs. The configuration could comprise two 2.5-MW devices or a combination of a $2.5-\mathrm{MW}$ device, a $1.25-\mathrm{MW}$ device, and a $300-\mathrm{kW}$ device. After a five-year test the cable is removed, along with the rest of the infrastructure. This option gives more flexibility than Scenario 1a, but limits the pilot to a maximum of $5 \mathrm{MW}$. This scenario is much more attractive than Scenario 1a, and the cost difference is minimal.

Scenario 1c: In this conceptual scenario, a single 7.5-MW cable is installed, connecting to either two or three WECs. Configurations could include three 2.5-MW devices or a combination of two 2.5-MW devices, a 1.25-MW device, and a $300-\mathrm{kW}$ device. After a five-year test the cable is removed, along with the rest of the infrastructure. This option gives more flexibility than Scenario $1 \mathrm{a}$ or $1 \mathrm{~b}$, but limits the pilot to a maximum of $7.5 \mathrm{MW}$. This scenario is much more attractive than scenario $1 \mathrm{a}$ or $1 \mathrm{~b}$, and the cost difference is minimal.

Scenario 1d: In this conceptual scenario, a single 10-MW cable is installed, connecting to two, three or four WECs. This configuration allows multiple configurations of devices and maximizes the possibilities for assessment. It ensures that any devices installed could operate at full installed capacity without restrictions. After a five-year test the cable is removed, along with the rest of the infrastructure. This option gives the most flexibility. This scenario is much more attractive than the other scenarios, and the cost difference is minimal.

Scenario 1e: In this conceptual scenario, four 2.5-MW cables create the capacity for $10 \mathrm{MW}$, giving each WEC its own cable. This configuration was the SAIC fall-back position, which PG\&E, after discussions with WEC manufacturers, concluded was unnecessary. It does permit multiple configurations of devices and maximizes the possibilities for assessment. It also ensures that any devices installed could operate at full installed capacity without restrictions. After a five-year test the cables are removed, along with the rest of the infrastructure. This option gives the most flexibility. This scenario is less attractive than the other scenarios due to its cost.

Scenario 2: Using a cable rated at $34.5 \mathrm{kV}$, either a single $30-\mathrm{MW}$ or two $20-\mathrm{MW}$ cables are installed, extending into BOEMRE waters. A $34.5-\mathrm{kV}$ to $60-\mathrm{kV}$ substation is built on shore at a cost of $\$ 10$ million. WEC devices are rated at $34.5 \mathrm{kV}$ and are system-to-grid ready at the device. This scenario allows for installation for two to four WECs, and allows maximum device-type flexibility so that the output is not restricted to $5 \mathrm{MW}$ as a maximum. This scenario also allows for two different end scenarios, described below.

Scenario 2a: A single 30-MW cable is installed to BOEMRE lands on the OCS. In this scenario, no effort is extended toward a larger build-out. After a five-year test the cable is removed, along with the rest of the infrastructure.

Scenario 2b: A single 30-MW cable is installed to BOEMRE lands on the OCS. After several years of data collection and operation, PG\&E applies for a full BOEMRE lease and 25-year FERC permit. 
Scenario 2c: Dual 20-MW cables are installed to BOEMRE lands on the OCS. In this scenario no effort is extended toward a larger build-out. After a five-year test the cables are removed, along with the rest of the infrastructure.

Scenario 2d: Dual 20-MW cables are installed to BOEMRE lands on the OCS. After several years of data collection and operation, PG\&E applies for a full BOEMRE lease and 25-year FERC permit.

\subsubsection{Summary of Costs}

Table 3-9 and 3-10 show the fixed cost for initial engineering and initial capital cost, respectively. The cost is split equally between Years One and Two. Table 3-11 shows the annual O\&M cost, whose low range values are applied to Years Three through Seven. Table 3-12 is the decommissioning cost, which appears in Year Eight. Note that Scenarios $2 \mathrm{~b}$ and $2 \mathrm{~d}$ assume the project is extending beyond the initial five years. The cost in Year Eight for Scenario $2 b$ and $2 d$ is the annual O\&M cost. Engineering costs on subsequent projects should fall dramatically, building on lessons learned from this effort. PG\&E expects the costs found in Table 3-9 and 3-12 especially to drop, with the costs in Table 3-12 expected to eventually become de minimus for larger builds.

Tables 3-13 through 3-17 summarize the costs for the various sub-scenarios under Scenario 1. Tables 3-18 and 3-19 are the costs for the various sub-scenarios under Scenario 2 using the medium-range costs. Capital and up-front costs are split evenly across Years One and Two. Finally, the yearly summary of the costs is provided in Table 3-20.

PG\&E concluded that for an initial effort it may be reasonable to assume yearly O\&M costs (which are substantial) for the cable infrastructure, but not for any large-scale build-out. PG\&E subscribes to the philosophy advocated by many of the large, off-shore power engineering firms who advised that, for an ocean-going effort, the system should be engineered to have an exceptionally low probability of failure, installed correctly, and left alone. It is therefore recommended that the yearly O\&M costs provided below should not be applied to any largescale build-out or a larger adaptive monitoring effort. 
Table 3-9: Summary of Estimated Initial Engineering Costs

\begin{tabular}{|l|c|c|c|}
\hline \multirow{2}{*}{ Initial Engineering Costs } & \multicolumn{3}{|c|}{ Cost (\$K) } \\
\cline { 2 - 4 } & Low & Medium & High \\
\hline Detailed Design & $\$ 692.80$ & $\$ 769.80$ & $\$ 846.80$ \\
\hline Engineering Staffing - Cables & $\$ 151.50$ & $\$ 256$ & $\$ 360.50$ \\
\hline Engineering Staffing - Buoy Installation & $\$ 86$ & $\$ 130$ & $\$ 163.50$ \\
\hline Engineering Staffing (Total Installation) & $\$ 550$ & $\$ 825$ & $\$ 1,100$ \\
\hline PG\&E Engineering Staffing and Oversight & $\$ 810$ & $\$ 1,620$ & $\$ 2,430$ \\
\hline Total & $\mathbf{\$ 2 , 2 9 0}$ & $\mathbf{\$ 3 , 6 0 1}$ & $\mathbf{\$ 4 , 9 0 1}$ \\
\hline
\end{tabular}

Table 3-10: Summary of Initial Capital Costs (Fixed)

\begin{tabular}{|l|c|c|c|}
\hline \multirow{2}{*}{ Initial Capital Costs (Fixed) } & \multicolumn{3}{|c|}{ Cost (\$K) } \\
\cline { 2 - 4 } & Low & Medium & High \\
\hline Cable Termination & $\$ 1,250$ & $\$ 1,250$ & $\$ 1,250$ \\
\hline Marker Buoys & $\$ 220$ & $\$ 330$ & $\$ 440$ \\
\hline Wave Measurement Buoys & $\$ 249.10$ & $\$ 397$ & $\$ 469$ \\
\hline Buoy/Sensor Installation & $\$ 73.50$ & $\$ 92.30$ & $\$ 111$ \\
\hline Data Acquisition and Telemetry & $\$ 1,081$ & $\$ 1,201$ & $\$ 1,321$ \\
\hline PG\&E Network Operations Center Upgrades & $\$ 71.10$ & $\$ 79$ & $\$ 87$ \\
\hline Total & $\mathbf{\$ 2 , 9 4 5}$ & $\mathbf{\$ 3 , 3 4 9}$ & $\mathbf{\$ 3 , 6 7 8}$ \\
\hline
\end{tabular}

Table 3-11: Summary of Yearly O\&M Costs

\begin{tabular}{|l|c|c|c|}
\hline \multirow{2}{*}{ Yearly O\&M } & \multicolumn{3}{|c|}{ Cost (\$K) } \\
\cline { 2 - 4 } & Low & Medium & High \\
\hline Staffing - Engineering & $\$ 135$ & $\$ 270$ & $\$ 405$ \\
\hline PG\&E Engineering & $\$ 135$ & $\$ 270$ & $\$ 405$ \\
\hline Site Inspections & $\$ 500$ & $\$ 725$ & $\$ 1,000$ \\
\hline Charter Vessels & $\$ 90$ & $\$ 135$ & $\$ 180$ \\
\hline Contingency Response Plan & $\$ 200$ & $\$ 250$ & $\$ 300$ \\
\hline Miscellaneous & $\$ 8$ & $\$ 20$ & $\$ 32$ \\
\hline Travel & $\$ 20.40$ & $\$ 40.80$ & $\$ 61.20$ \\
\hline Total & $\mathbf{\$ 1 , 0 8 8}$ & $\mathbf{\$ 1 , 7 1 1}$ & $\mathbf{\$ 2 , 3 8 3}$ \\
\hline
\end{tabular}

Table 3-12: Summary of Decommissioning Estimated Costs

\begin{tabular}{|l|c|c|c|}
\hline \multirow{2}{*}{ Decommissioning Estimated Costs } & \multicolumn{3}{|c|}{ Cost (\$K) } \\
\cline { 2 - 4 } & Low & Medium & High \\
\hline Submarine Cable Infrastructure & $\$ 2,910$ & $\$ 3,235$ & $\$ 3,560$ \\
\hline Sea Based Infrastructure & $\$ 55.4$ & $\$ 73.8$ & $\$ 92.3$ \\
\hline Data Acquisition and Telemetry Infrastructure & $\$ 21.6$ & $\$ 24$ & $\$ 26.4$ \\
\hline Shore Station & $\$ 50.4$ & $\$ 56$ & $\$ 61.6$ \\
\hline Site Remediation & $\$ 22.5$ & $\$ 25$ & $\$ 27.5$ \\
\hline Staffing - Engineering & $\$ 145$ & $\$ 285$ & $\$ 425$ \\
\hline Engineering - PG\&E & $\$ 145$ & $\$ 285$ & $\$ 425$ \\
\hline Total & $\mathbf{\$ 3 , 3 5 0}$ & $\mathbf{\$ 3 , 9 8 4}$ & $\mathbf{\$ 4 , 6 1 8}$ \\
\hline
\end{tabular}


Table 3-13: Summary of Cable and Electrical Infrastructure Installation Costs $2.5 \mathrm{MW}$ (Scenario 1a)

\begin{tabular}{|l|c|c|c|}
\hline \multirow{2}{*}{ Initial Engineering Costs } & \multicolumn{3}{|c|}{ Cost (\$K) } \\
\cline { 2 - 4 } & Low & Medium & High \\
\hline Submarine Power Cable & $\$ 1,393$ & $\$ 1,466$ & $\$ 1,539$ \\
\hline Horizontal Directional Drill & $\$ 481$ & $\$ 506$ & $\$ 532$ \\
\hline Submarine Power Cable Installation & $\$ 4,152$ & $\$ 4,370$ & $\$ 4,589$ \\
\hline Shore Substation/Fairhaven Interconnection & $\$ 5,700$ & $\$ 6,000$ & $\$ 6,300$ \\
\hline Total & $\mathbf{\$ 1 1 , 7 2 5}$ & $\mathbf{\$ 1 2 , 3 4 2}$ & $\mathbf{\$ 1 2 , 9 6 0}$ \\
\hline
\end{tabular}

Table 3-14: Summary of Cable and Electrical Infrastructure Installation Costs $5 \mathrm{MW}$ (Scenario 1b)

\begin{tabular}{|l|c|c|c|}
\hline \multirow{2}{*}{ Initial Engineering Costs } & \multicolumn{3}{|c|}{ Cost (\$K) } \\
\cline { 2 - 4 } & Low & Medium & High \\
\hline Submarine Power Cable & $\$ 1,787$ & $\$ 1,881$ & $\$ 1,975$ \\
\hline Horizontal Directional Drill & $\$ 481$ & $\$ 506$ & $\$ 532$ \\
\hline Submarine Power Cable Installation & $\$ 4,152$ & $\$ 4,370$ & $\$ 4,589$ \\
\hline Shore Substation/Fairhaven Interconnection & $\$ 5,700$ & $\$ 6,000$ & $\$ 6,300$ \\
\hline Total & $\mathbf{\$ 1 2 , 1 2 0}$ & $\mathbf{\$ 1 2 , 7 5 8}$ & $\mathbf{\$ 1 3 , 3 9 6}$ \\
\hline
\end{tabular}

Table 3-15: Summary of Cable and Electrical Infrastructure Installation Costs 7.5 MW (Scenario 1c)

\begin{tabular}{|l|c|c|c|}
\hline \multirow{2}{*}{ Initial Engineering Costs } & \multicolumn{3}{|c|}{ Cost (\$K) } \\
\cline { 2 - 4 } & Low & Medium & High \\
\hline Submarine Power Cable & $\$ 2,055$ & $\$ 2,164$ & $\$ 2,272$ \\
\hline Horizontal Directional Drill & $\$ 481$ & $\$ 506$ & $\$ 532$ \\
\hline Submarine Power Cable Installation & $\$ 4,152$ & $\$ 4,370$ & $\$ 4,589$ \\
\hline Shore Substation/Fairhaven Interconnection & $\$ 5,700$ & $\$ 6,000$ & $\$ 6,300$ \\
\hline Total & $\mathbf{\$ 1 2 , 3 8 8}$ & $\mathbf{\$ 1 3 , 0 4 0}$ & $\mathbf{\$ 1 3 , 6 9 2}$ \\
\hline
\end{tabular}

Table 3-16: Summary of Cable and Electrical Infrastructure Installation Costs 10 MW (Scenario 1d)

\begin{tabular}{|l|c|c|c|}
\hline \multirow{2}{*}{ Initial Engineering Costs } & \multicolumn{3}{|c|}{ Cost (\$K) } \\
\cline { 2 - 4 } & Low & Medium & High \\
\hline Submarine Power Cable & $\$ 2,282$ & $\$ 2,402$ & $\$ 2,523$ \\
\hline Horizontal Directional Drill & $\$ 481$ & $\$ 506$ & $\$ 532$ \\
\hline Submarine Power Cable Installation & $\$ 4,152$ & $\$ 4,370$ & $\$ 4,589$ \\
\hline Shore Substation/Fairhaven Interconnection & $\$ 5,700$ & $\$ 6,000$ & $\$ 6,300$ \\
\hline Total & $\mathbf{\$ 1 2 , 6 1 5}$ & $\mathbf{\$ 1 3 , 2 7 9}$ & $\mathbf{\$ 1 3 , 9 4 3}$ \\
\hline
\end{tabular}


Table 3-17: Summary of Cable and Electrical Infrastructure Installation Costs 10 MW, Four 2.5-MW Cables (Scenario 1e)

\begin{tabular}{|l|c|c|c|}
\hline \multirow{2}{*}{ Initial Engineering Costs } & \multicolumn{3}{|c|}{ Cost (\$K) } \\
\cline { 2 - 4 } & Low & Medium & High \\
\hline Submarine Power Cable & $\$ 3,718$ & $\$ 3,914$ & $\$ 4,110$ \\
\hline Horizontal Directional Drill & $\$ 890$ & $\$ 937$ & $\$ 984$ \\
\hline Submarine Power Cable Installation & $\$ 5,662$ & $\$ 5,960$ & $\$ 6,258$ \\
\hline Shore Substation/Fairhaven Interconnection & $\$ 5,700$ & $\$ 6,000$ & $\$ 6,300$ \\
\hline Total & $\mathbf{\$ 1 5 , 9 7 0}$ & $\mathbf{\$ 1 6 , 8 1 1}$ & $\mathbf{\$ 1 7 , 6 5 1}$ \\
\hline
\end{tabular}

Table 3-18: Summary of Cable and Electrical Infrastructure Installation Costs 30 MW 35-kV (Scenario 2)

\begin{tabular}{|l|c|c|c|}
\hline \multirow{2}{*}{ Initial Engineering Costs } & \multicolumn{3}{|c|}{ Cost (\$K) } \\
\cline { 2 - 4 } & Low & Medium & High \\
\hline Submarine Power Cable & $\$ 4,216$ & $\$ 4,438$ & $\$ 4,659$ \\
\hline Horizontal Directional Drill & $\$ 481$ & $\$ 506$ & $\$ 532$ \\
\hline Submarine Power Cable Installation & $\$ 4,256$ & $\$ 4,480$ & $\$ 4,704$ \\
\hline Shore Substation/Fairhaven Interconnection & $\$ 9,500$ & $\$ 10,000$ & $\$ 10,500$ \\
\hline Total & $\mathbf{\$ 1 8 , 4 5 3}$ & $\mathbf{\$ 1 9 , 4 2 4}$ & $\mathbf{\$ 2 0 , 3 9 5}$ \\
\hline
\end{tabular}

Table 3-19: Summary of Cable and Electrical Infrastructure Installation Costs 40 MW 35 kV (Scenario 2)

\begin{tabular}{|l|c|c|c|}
\hline \multirow{2}{*}{ Initial Engineering Costs } & \multicolumn{3}{|c|}{ Cost (\$K) } \\
\cline { 2 - 4 } & Low & Medium & High \\
\hline Submarine Power Cable & $\$ 6,471$ & $\$ 6,812$ & $\$ 7,153$ \\
\hline Horizontal Directional Drill & $\$ 481$ & $\$ 506$ & $\$ 532$ \\
\hline Submarine Power Cable Installation & $\$ 4,864$ & $\$ 5,120$ & $\$ 5,376$ \\
\hline Shore Substation/Fairhaven Interconnection & $\$ 9,500$ & $\$ 10,000$ & $\$ 10,500$ \\
\hline Total & $\mathbf{\$ 2 1 , 3 1 7}$ & $\mathbf{\$ 2 2 , 4 3 8}$ & $\mathbf{\$ 2 3 , 5 6 0}$ \\
\hline
\end{tabular}


Table 3-20: Yearly Summary of WaveConnect Estimated Costs (Based on Medium Cost Estimate, with no change due to NPV)

\begin{tabular}{|c|c|c|c|c|c|c|c|c|c|}
\hline \multirow{3}{*}{ Year } & \multicolumn{9}{|c|}{ Cost (\$K) } \\
\hline & $2.5 \mathrm{MW}$ & $5 \mathrm{MW}$ & $7.5 \mathrm{MW}$ & $10 \mathrm{MW}$ & $10 \mathrm{MW}^{*}$ & $30 \mathrm{MW}$ & $30 \mathrm{MW}$ & $40 \mathrm{MW}$ & $40 \mathrm{MW}$ \\
\hline & $1 \mathrm{a}$ & $1 b$ & $1 \mathrm{c}$ & 1d & $1 e$ & $2 a$ & $2 b$ & $2 c$ & $2 d$ \\
\hline 1 & $\$ 9,646$ & $\$ 9,854$ & $\$ 9,995$ & $\$ 10,114$ & $\$ 11,880$ & $\$ 13,187$ & $\$ 13,187$ & $\$ 14,694$ & $\$ 14,694$ \\
\hline 2 & $\$ 9,646$ & $\$ 9,854$ & $\$ 9,995$ & $\$ 10,114$ & $\$ 11,880$ & $\$ 13,187$ & $\$ 13,187$ & $\$ 14,694$ & $\$ 14,694$ \\
\hline 3 & $\$ 1,088$ & $\$ 1,088$ & $\$ 1,088$ & $\$ 1,088$ & $\$ 1,088$ & $\$ 1,088$ & $\$ 1,088$ & $\$ 1,088$ & $\$ 1,088$ \\
\hline 4 & $\$ 1,088$ & $\$ 1,088$ & $\$ 1,088$ & $\$ 1,088$ & $\$ 1,088$ & $\$ 1,088$ & $\$ 1,088$ & $\$ 1,088$ & $\$ 1,088$ \\
\hline 5 & $\$ 1,088$ & $\$ 1,088$ & $\$ 1,088$ & $\$ 1,088$ & $\$ 1,088$ & $\$ 1,088$ & $\$ 1,088$ & $\$ 1,088$ & $\$ 1,088$ \\
\hline 6 & $\$ 1,088$ & $\$ 1,088$ & $\$ 1,088$ & $\$ 1,088$ & $\$ 1,088$ & $\$ 1,088$ & $\$ 1,088$ & $\$ 1,088$ & $\$ 1,088$ \\
\hline 7 & $\$ 1,088$ & $\$ 1,088$ & $\$ 1,088$ & $\$ 1,088$ & $\$ 1,088$ & $\$ 1,088$ & $\$ 1,088$ & $\$ 1,088$ & $\$ 1,088$ \\
\hline 8 & $\$ 3,984$ & $\$ 3,984$ & $\$ 3,984$ & $\$ 3,984$ & $\$ 3,984$ & $\$ 3,984$ & $\$ 1,088$ & $\$ 3,984$ & $\$ 1,088$ \\
\hline Total & $\$ 28,716$ & $\$ 29,132$ & $\$ 29,414$ & $\$ 29,653$ & $\$ 33,185$ & $\$ 35,798$ & $\$ 32,902$ & $\$ 38,812$ & $\$ 35,917$ \\
\hline $\begin{array}{c}\text { NPV } \\
(11 \%)\end{array}$ & $\$ 23,878$ & $\$ 24,273$ & $\$ 24,541$ & $\$ 24,767$ & $\$ 28,124$ & $\$ 30,609$ & $\$ 29,214$ & $\$ 33,473$ & $\$ 32,079$ \\
\hline Total/W & $\$ 11.49$ & $\$ 5.83$ & $\$ 3.92$ & $\$ 2.97$ & $\$ 3.32$ & $\$ 1.19$ & $\$ 1.10$ & $\$ 0.97$ & $\$ 0.90$ \\
\hline NPV/W & $\$ 9.55$ & $\$ 4.85$ & $\$ 3.27$ & $\$ 2.48$ & $\$ 2.81$ & $\$ 1.02$ & $\$ 0.97$ & $\$ 0.84$ & $\$ 0.80$ \\
\hline
\end{tabular}

\subsection{Range of Overall Costs}

PG\&E evaluated a large amount of cost information in attempting to assess the economics of a large-scale wave project. Although some of the information was incomplete, PG\&E developed a good understanding of the types of questions that would be asked in any future similar effort, including a determination of what were termed "major costs."

\subsubsection{Cost Inputs for the Economic Model}

In most power development projects, the developer attempts to find the major installed costs on a dollar-per-installed-watt basis, as detailed in Chapter 7. The inputs used in the economic models described in Chapter 7 are based on the initial engineering, initial capital, annual O\&M, and decommissioning cost estimates summarized in Tables 3-9 through 3-12 in Section 3.12.5.

As discussed previously, PG\&E also attempted to evaluate the cost of various off-shore cable arrangements. For the purposes of this effort, PG\&E split the evaluation into multiple levels (as was done for the scoping estimates in Section 3.12). Using a cable cost calculator tool, PG\&E developed ranges of input costs for the final economic model. Tables 3-21 through 3-26 below present the costs as used in Chapter 7 for various cable, installation, and substation upgrade costs at both the Humboldt and Central Coast WaveConnect sites. For WEC and O\&M costs, PG\&E applied data as supplied by multiple WECoMs and attempted to use an average as input. 
Table 3-21: Summary of Cable and Electrical Infrastructure Installation Costs, 5 MW (Scenario 1b)

\begin{tabular}{|l|c|c|c|}
\hline \multirow{2}{*}{ Initial Engineering Costs } & \multicolumn{3}{|c|}{ Cost (\$K) } \\
\cline { 2 - 4 } & Low & Medium & High \\
\hline Submarine Power Cable & $\$ 1,787$ & $\$ 1,881$ & $\$ 1,975$ \\
\hline Horizontal Directional Drill & $\$ 481$ & $\$ 506$ & $\$ 532$ \\
\hline Submarine Power Cable Installation & $\$ 4,152$ & $\$ 4,370$ & $\$ 4,589$ \\
\hline Shore Substation/Fairhaven Interconnection & $\$ 5,700$ & $\$ 6,000$ & $\$ 6,300$ \\
\hline Total & $\mathbf{\$ 1 2 , 1 2 0}$ & $\mathbf{\$ 1 2 , 7 5 8}$ & $\mathbf{\$ 1 3 , 3 9 6}$ \\
\hline
\end{tabular}

Table 3-22: Humboldt, Pilot-Capital Cost (Electrical Infrastructure), 10 MW

\begin{tabular}{|l|c|c|c|}
\hline \multirow{2}{*}{} & \multicolumn{3}{|c|}{ Cost (\$K) } \\
\cline { 2 - 4 } & Low & Medium & High \\
\hline Submarine Power Cable & $\$ 2,282$ & $\$ 2,402$ & $\$ 2,523$ \\
\hline Horizontal Directional Drill & $\$ 481$ & $\$ 506$ & $\$ 532$ \\
\hline Submarine Power Cable Installation & $\$ 4,152$ & $\$ 4,370$ & $\$ 4,589$ \\
\hline Shore Substation/Fairhaven Interconnection & $\$ 5,700$ & $\$ 6,000$ & $\$ 6,300$ \\
\hline Total & $\$ 12,615$ & $\$ 13,279$ & $\$ 13,943$ \\
\hline
\end{tabular}

Table 3-23: Humboldt, OCS-Capital Cost (Electrical Infrastructure), 30 MW

\begin{tabular}{|l|c|c|c|}
\hline \multirow{2}{*}{} & \multicolumn{3}{|c|}{ Cost (\$K) } \\
\cline { 2 - 4 } & Low & Medium & High \\
\hline Submarine Power Cable & $\$ 4,216$ & $\$ 4,438$ & $\$ 4,659$ \\
\hline Horizontal Directional Drill & $\$ 481$ & $\$ 506$ & $\$ 532$ \\
\hline Submarine Power Cable Installation & $\$ 4,256$ & $\$ 4,480$ & $\$ 4,704$ \\
\hline Shore Substation/Fairhaven Interconnection & $\$ 9,500$ & $\$ 10,000$ & $\$ 10,500$ \\
\hline Total & $\$ 18,453$ & $\$ 19,424$ & $\$ 20,395$ \\
\hline
\end{tabular}

Table 3-24: Central Coast-Capital Cost (Electrical Infrastructure), 40 MW

\begin{tabular}{|l|c|c|c|}
\hline \multirow{2}{*}{} & \multicolumn{3}{|c|}{ Cost (\$K) } \\
\cline { 2 - 4 } & Low & Medium & High \\
\hline Submarine Power Cable & $\$ 5,356$ & $\$ 5,638$ & $\$ 5,920$ \\
\hline Horizontal Directional Drill & $\$ 481$ & $\$ 506$ & $\$ 532$ \\
\hline Submarine Power Cable Installation & $\$ 4,655$ & $\$ 4,900$ & $\$ 5,145$ \\
\hline Shore Substation/Fairhaven Interconnection & $\$ 20,900$ & $\$ 22,000$ & $\$ 23,100$ \\
\hline Total & $\$ 31,392$ & $\$ 33,045$ & $\$ 34,697$ \\
\hline
\end{tabular}


Table 3-25: Central Coast-Capital Cost (Electrical Infrastructure), 90 MW

\begin{tabular}{|l|c|c|c|}
\hline \multirow{2}{*}{} & \multicolumn{3}{|c|}{ Cost $(\$ K)$} \\
\cline { 2 - 4 } & Low & Medium & High \\
\hline Submarine Power Cable & $\$ 9,356$ & $\$ 9,848$ & $\$ 10,341$ \\
\hline Horizontal Directional Drill & $\$ 686$ & $\$ 722$ & $\$ 758$ \\
\hline Submarine Power Cable Installation & $\$ 5,159$ & $\$ 5,430$ & $\$ 5,702$ \\
\hline Shore Substation/Fairhaven Interconnection & $\$ 21,850$ & $\$ 23,000$ & $\$ 24,150$ \\
\hline Total & $\$ 37,050$ & $\$ 39,000$ & $\$ 40,950$ \\
\hline
\end{tabular}

Table 3-26: Central Coast-Capital Cost (Electrical Infrastructure), $180 \mathrm{MW}$

\begin{tabular}{|l|c|c|c|}
\hline \multirow{2}{*}{} & \multicolumn{3}{|c|}{ Cost (\$K) } \\
\cline { 2 - 4 } & Low & Medium & High \\
\hline Submarine Power Cable & $\$ 18,094$ & $\$ 19,047$ & $\$ 19,999$ \\
\hline Horizontal Directional Drill & $\$ 1,299$ & $\$ 1,367$ & $\$ 1,436$ \\
\hline Submarine Power Cable Installation & $\$ 6,669$ & $\$ 7,020$ & $\$ 7,371$ \\
\hline Shore Substation/Fairhaven Interconnection & $\$ 38,000$ & $\$ 40,000$ & $\$ 42,000$ \\
\hline Total & $\$ 64,062$ & $\$ 67,434$ & $\$ 70,806$ \\
\hline
\end{tabular}

\subsubsection{Major Costs}

Based on the information gathered, PG\&E identified four main areas of cost: the main off-shore power cable, mooring lines and anchors, the WECs themselves, and the installation effort. It is assumed that any future on-shore substation facility would only require minor modification (details of the potential upgrade costs for the various coastal substations are found in Section 3.5.

In talks with a large, off-shore electrical engineering firm experienced with off-shore wind installations, PG\&E also examined the cost for a $115-\mathrm{kV}, 100-\mathrm{MW}$ system with an off-shore substation (in the context of the Central Coast WaveConnect project). The engineering firm gave a preliminary cost estimate of approximately $\$ 50$ million, including the off-shore $115-\mathrm{kV}$ substation but excluding a platform for the substation. Later talks with several WECoMs led PG\&E to conclude that the larger WEC devices could conceivably act as platforms for a substation, with some modifications. PG\&E estimated a $\$ 5$ million cost to adapt and launch the modified WEC and associated substation, yielding a total cost for a 100-MW cable to an offshore facility of $\$ 55$ million. PG\&E feels that the use of 30-MW, 34.5-kV lines may still be the most economical option due to the potential dispersed nature of an off-shore facility.

PG\&E assessed the general costs of a small array (5-MW), a midsize array (30-MW, 4.5-kV), and a large array (180 MW using multiple 34.5-kV cables), including design, support, and installation. PG\&E determined that the installed cost of the small array was $\$ 3,820 / \mathrm{kW}$. For the 
medium 30-MW array, the cost for the cable and install alone was $\$ 790 / \mathrm{kW}$. The installed cost of the $180-\mathrm{MW}$ was calculated to be $\$ 400 / \mathrm{kW}$ (Table 3-27).

As an example of the difficulty involved in reducing costs, consider that WEC capital costs are typically highly dependent on the price of steel used for WEC structures (and for some mooring cables), which is substantial and dictated by the global market. For example, one WEC device designed to generate up to $7 \mathrm{MW}$ would require an estimated 20,000 tons of steel. At a low-end estimated cost for steel of $\$ 2,500 /$ tonne, the constructed cost of such a structure is approximately $\$ 7,140 / \mathrm{kW}$. Adding at least $\$ 1,000 / \mathrm{kW}$ for the installed cost of turbines and the mid-range estimate of $\$ 900 / \mathrm{kW}$ for mooring yields a baseline pre-installation capital cost of about $\$ 904 / \mathrm{kW}$ for such a WEC system.

Table 3-27: Range of Major Costs ${ }^{54}$

\begin{tabular}{|l|c|c|c|}
\hline & Low & Medium & High \\
\hline Cable Costs & $\begin{array}{c}\$ 400 / \mathrm{kW} \text { (for a 180-MW } \\
\text { cable array) }\end{array}$ & $\begin{array}{c}\$ 790 / \mathrm{kW} \\
\text { (for a 30-MW cable) }\end{array}$ & $\begin{array}{c}\$ 3,820 / \mathrm{kW} \\
\text { (for a 5-MW cable array) }\end{array}$ \\
\hline $\begin{array}{l}\text { Mooring Lines and } \\
\text { Anchors }\end{array}$ & $\$ 210 / \mathrm{kW}$ & $\$ 900 / \mathrm{kW}$ & $\$ 1,500 / \mathrm{kW}$ \\
\hline WECs & $\$ 2 ., 500 / \mathrm{kW}$ & $\$ 8,240 / \mathrm{kW}$ & $\$ 16,670 / \mathrm{kW}$ \\
\hline Installation & $\$ 320 / \mathrm{kW}$ & $\$ 750 / \mathrm{kW}$ & $\$ 1.200 / \mathrm{kW}$ \\
\hline
\end{tabular}

The cost of most WEC devices is also dependent on the cost of concrete, which is used for moorings and base structures. As was discussed in Section 3.10, PG\&E found that mooring costs ranged from $\$ 200 / \mathrm{kW}$ to nearly $\$ 1,500 / \mathrm{kW}$. There is great uncertainty in this estimate, as the exact material type, safety factor, and assumed maximum storm are unknown for almost all wave power devices whose developers responded to the RFI.

Opportunities to reduce the overall mooring costs are expected to be small, as mooring technology is relatively mature and competitive due to the shipping and oil-and-gas industries. The same is true for the rest of the system, as the costs of steel, concrete, and synthetic rope are not expected to drop significantly for smaller projects. However, design optimization and volume production may help reduce these material costs over time.

PG\&E based its WEC costs estimates on self-reported data from WECoMs, informed by discussions with some manufacturers of power take-off (PTO) technologies. Much of the cost of many WEC devices is attributable to the high cost of manufactured steel and complicated PTO systems. The issue of how WEC capital costs and LCOE might decline as experience, production volume and installed capacity increase over time, as well as the validity of comparisons with the wind and solar industries, is addressed in Chapter 7.

Finally, the most uncertain of the costs associated with wave power technology is its installation cost. PG\&E heard widely disparate estimates of the cost of on-site installation. A key issue

\footnotetext{
${ }^{54}$ It is assumed that larger installations would experience reduced installation costs per installed watt.
} 
associated with this cost is shipping infrastructure, which at this time must be borrowed from other industries. A wave power project could profitably take advantage of existing infrastructure already established for the oil and gas or off-shore wind industries. However, the West Coast of the United States has very little oil and gas and no off-shore wind infrastructure, and therefore the ships available may be either in high demand or not properly designed for the effort required.

Applying the mid-range cost estimates in Table 3-26, PG\&E concludes that the overall cost of installing a representative WEC is approximately $\$ 11 / \mathrm{W}$. Although PG\&E does not believe this estimate is realistic for the most promising wave power technologies, it is likely a realistic cost estimate for WEC development in the near term. The analysis summarized in Chapter 7 attempts to place these estimates on a firmer predictive footing.

\subsection{HWC Engineering Effort}

As part of the preparation for the facility, PG\&E contracted with multiple parties. Primary among these was Science Applications International Corporation (SAIC), whose role was to develop a highly detailed set of engineering plans for the facility. SAIC's effort was an evolutionary one, which began with a high-level engineering design view and narrowed down by subsystem. SAIC also supported the CH2M Hill permit effort. SAIC in turn subcontracted to ReVision - which had assisted with the original EPRI reports on wave energy - for two specific projects, and with Oregon State University (OSU), which worked on the beginnings of PG\&E's Electric and Magnetic Field (EMF) interaction effort. SAIC also had various local subcontractors who assisted in local harbor evaluations. The resulting reports are summarized in Table 3-28 and provided in the indicated Appendices.

A separate contract was issued to Humboldt State University after PG\&E issued a Request for Proposals to the university community there. This was part of PG\&E's partnering effort as proposed to DOE. Among the non-biological proposals (that are not discussed here) were an effort to create an automated wave assessment model that would use Bayesian approaches to incorporate the model with real-time radar observations. Another was to assess the sediment transport that was occurring near Humboldt. The last was a socio-economic evaluation of the commercial activities of the local fishermen and boating communities, so that PG\&E could assess possible impacts as a result of the project.

To ensure some continuity to future wave research, PG\&E has contacted Sandia National Laboratories (SNL) Hydrokinetic Group and arranged to pass off the results of various computer modeling and research (Appendix PG\&E PC1). PG\&E will hand over all data to SNL at the completion of the project, as well as contacts so that SNL can continue to work with groups whose research they find relevant to its long-term efforts. 
Table 3-28: Engineering and Economic Consulting Reports

\begin{tabular}{|c|c|c|}
\hline Report Name & Report Number & Appendix \\
\hline Support Public Outreach.doc & SAIC Trip Report & SAIC A \\
\hline WaveConnect Top Level Systems Requirements Statement & SAIC 0901-01-001 & SAIC B \\
\hline Site Surveys $4-8$ to $4-10-09$ & SAIC 0901-01-002A & SAIC C \\
\hline Functional Block Diagram Document & SAIC 0901-10-002 & SAIC D \\
\hline WC Infrastructure Top-Level Block Diagram & SAIC 0901-10-003 & SAIC E \\
\hline SBI SEGMENT BLOCK DIAGRAM & SAIC 0901-20-002 & SAIC F \\
\hline SCI SEGMENT BLOCK DIAGRAM & SAIC 0901-30-002 & SAIC G \\
\hline PII SEGMENT BLOCK DIAGRAM & SAIC 0901-40-002 & SAIC H \\
\hline DATI SEGMENT BLOCK DIAGRAM & SAIC 0901-50-002 & SAIC I \\
\hline Visio-Electrical One Line Diagram & SAIC 0901-40-003 & SAIC J \\
\hline Top Level System Interface List & SAIC 0901-10-004 & SAIC K \\
\hline System Requirements CONOPS Presentation & SAIC 0901-01-006 & SAIC L \\
\hline Concept of Operations Document & SAIC 0901-10-005 & SAIC M \\
\hline Functional Requirements Document & SAIC 0901-10-006 & SAIC N \\
\hline System Requirements Specification & SAIC 0901-10-007 & SAIC O \\
\hline SAIC Trip Report - UK Wave Energy Review 7-25 to 8-2-09 & SAIC 0901-01-010 & SAIC P \\
\hline WaveConnect Fast Facts Sheet & SAIC 0901-01-011 & SAIC Q \\
\hline Central Coast Wave Resource Assessment & SAIC 0901-01-017 & SAIC R \\
\hline WEC Cost Assessment & SAIC 0901-01-018 & SAIC S \\
\hline OrcaFlex Mooring System Modeling & SAIC 0901-20-003 & SAIC T \\
\hline Anchor System Analysis Methods & SAIC 0901-20-004 & SAIC U \\
\hline Revised Mooring Analysis & SAIC 0901-20-005 & SAIC V \\
\hline Humboldt Harbor Capabilities Assessment & SAIC 0901-01-019 & SAIC W \\
\hline Pilot Infra Lifecycle Cost Analysis & SAIC 0901-01-020 & SAIC X \\
\hline Conceptual Design Compendium & SAIC 0901-01-022 & SAIC Y \\
\hline WaveConnect Summary Findings & SAIC 0901-01-023 & SAIC Z \\
\hline EMF Modeling Summary Report and Results Guide & SAIC 0901-01-021 & OSU A \\
\hline Wave Modeling Study & HSU - Dr. Charles Chamberlin & HSU A \\
\hline Socioeconomic Baseline Study & HSU - Dr. Steven Hackett & HSU B \\
\hline Sediment Transport Study & HSU - Dr. Jeffry Borgeld & HSU C \\
\hline
\end{tabular}




\section{SAIC Support of Public Outreach: Appendix SAIC A}

SAIC was deeply involved in all public outreach, and developed and presented multiple technical overviews for the public. A discussion of the public outreach is included in Chapter 5, while the technical presentations contributed to or created by SAIC are available from the PG\&E WaveConnect website.

\section{SAIC WaveConnect Top Level Systems Requirements Statement: Appendix SAIC B}

The Top Level System Requirements (TLR) Statement describes the essential requirements for the development of the PG\&E WaveConnect pilot project. The primary TLR goal was to establish the overall project and system size, scope and schedule, and provide guidance to the technical design team for the system design activities.

\section{SAIC Site Surveys 4-8 to 4-10-09: Appendix SAIC C}

This report was an overview of the preliminary harbor assessment, as well as an assessment of potential landing sites. A useful tool for examining landing sites along the California coast is the California Coastal Records Project website (http://www.californiacoastline.org), which has historical and recent aerial photos of the entire California coastline. This information, in conjunction with NOAA charts, is an excellent resource.

The site survey group came to a conclusion that the harbor at Fort Bragg was unusable as a major point of repair or for towing in wave energy devices. Although Fort Bragg has the capacity to have up to $50 \mathrm{MW}$ of generation (excluding local usage, which would allow for a larger buildout) it was felt that no devices could be towed into the harbor. This is actually not as great a consideration as was felt at the time, as several of the devices are maintained by small boat or helicopter, and would only receive dockside support at a major port such as San Francisco.

\section{SAIC Functional Block Diagram Document: Appendix SAIC D}

The primary goal of the Functional Block Diagram (FBD) document was to establish the overall frame of reference for the technical baseline, and to define a common language for system and sub-system elements. Furthermore, both internal interfaces (within the WaveConnect infrastructure) and external interfaces (to elements outside the WaveConnect infrastructure) were identified. Specific interface details are not described, but are yet to be developed as part of the preliminary design process.

Contents of the document are derived from the Top Level Requirements (TLR) document, Appendix SAIC B. Included in the FBD document are the following:

- WC Infrastructure Top-Level Block Diagram, 0901-10-003 (Appendix SAIC E)

- SBI Segment Block Diagram, 0901-20-002 (Appendix SAIC F) 
- SCI Segment Block Diagram, 0901-30-002 (Appendix SAIC G)

- PII Segment Block Diagram, 0901-40-002 (Appendix SAIC H)

- DATI Segment Block Diagram, 0901-50-002 (Appendix SAIC I)

- Visio-Electrical One Line Diagram, 0901-40-003 (Appendix SAIC J)

The functional description and block diagrams were designed to conform to an organizational hierarchy, described in Table 3-29. The arrangement follows a logical system engineering approach and provides a convenient breakdown of system labels to enable development of interface boundaries and design work activities.

Table 3-29: WaveConnect System Element Hierarchy

\begin{tabular}{|l|l|}
\hline System Level & Element Level \\
\hline Top level & System \\
\hline 2nd level & Segment \\
\hline 3rd level & Sub-system \\
\hline 4th level & Assembly \\
\hline 5th level & Sub-assembly (optional for complex assemblies) \\
\hline 6th level & Component or part \\
\hline
\end{tabular}

The system infrastructure excludes the WEC devices and the grid interconnect functions. For each system infrastructure element, functional blocks are numbered to identify the appropriate relationship to segment, sub-system, and assembly. This aids in interface definition and identification, provides straightforward assimilation of logical groupings, and sets the technical work breakdown structure (WBS) organization to the design activity (Table 3-30). 
Table 3-30: WaveConnect System Infrastructure Top-Level Functional WBS

\begin{tabular}{|c|c|}
\hline System WBS & Element \\
\hline 10 & WaveConnect System Infrastructure \\
\hline 20 & Sea-Based Infrastructure (SBI) Segment \\
\hline 201 & Navigation and Site Boundary Sub-system \\
\hline 202 & Site Monitoring Sub-System \\
\hline 203 & SBI Anchoring and Mooring Sub-System \\
\hline 30 & Submarine Cabled Infrastructure (SCI) Segment \\
\hline 301 & Submarine Transmission Cable Sub-System \\
\hline 302 & Wet-End Cable Termination Sub-System \\
\hline 40 & Power Interconnect Infrastructure (PII) Segment \\
\hline 401 & Command and Control Sub-System \\
\hline 402 & Electrical Power Conversion Sub-System \\
\hline 403 & Electrical Power Distribution Sub-System \\
\hline 404 & Power Protection Sub-System \\
\hline 50 & Data Acquisition and Telemetry Infrastructure (DATI) Segment \\
\hline 501 & Data Telemetry Sub-System \\
\hline 502 & Data Storage Sub-System \\
\hline 503 & Data Security and Communications Sub-System \\
\hline 60 & Logistics and Facility Support Segment \\
\hline 601 & Logistics \\
\hline 602 & Transportation \\
\hline 603 & Contingency Response \\
\hline 70 & Physical Security and Safety Segment \\
\hline 701 & Physical Security Sub-System \\
\hline 702 & Safety Sub-System \\
\hline
\end{tabular}

\section{SAIC Top Level System Interface List: Appendix SAIC K}

The primary goal of the Top Level System Interface document was to provide a list of system interfaces important to the management development of the WaveConnect technical baseline, using the common language for system and sub-system elements as defined in SAIC 0901-10002 (Appendix SAIC D) and that documents' related drawings. Furthermore, both internal interfaces (within the WaveConnect infrastructure) and external interfaces (to elements outside the WaveConnect infrastructure) are outlined. 
SAIC System Requirements Concept of Operations (CONOPS) Presentation: Appendix SAIC L and SAIC CONOPS Document: Appendix SAIC M

This Concept of Operations (CONOPS) Presentation (0901-01-006) and Document (0901-01005) describe the planned operational scenario of the entire WaveConnect system from cradle-tograve, through the construction, operational test and evaluation, and decommissioning phases. This includes the sea and land based infrastructure, maintenance (both routine and unexpected), response activities, logistics coordination, and staffing requirements. The CONOPS document is envisioned as an "evergreen" document that should evolve over time and incorporate lessons learned. The CONOPS approach is one that is used throughout the industry. Although it is currently one document, PG\&E foresees that it could be expanded based on the systems approach outlined earlier.

Starting with the CONOPS, SAIC was to follow up with a preliminary functional analysis, outlining systems requirements specifications, and generating a preliminary requirements analysis, including traceability matrix. SAIC was to use these analyses to develop operational, life-cycle management, and maintenance parameters for each sub-system and illustrate the interworking of sub-system, segment, and system in installation and operations scenarios.

\section{SAIC Functional Requirements Document: Appendix SAIC N}

This Functional Requirements Document (FRD) contains flow-down requirements from the WaveConnect Top Level Requirements Statement (Appendix SAIC B). The functional requirements are subservient to the top level requirements, with the intent that they agree in principle. In cases where there is disagreement between them, the PG\&E technical team shall arbitrate specific functional requirements, and if necessary, amend program requirements to achieve WaveConnect goals (in keeping with the evergreen philosophy of the CONOPs and other documents).

This document describes the overall requirements for the participants in the WaveConnect project. In this context, there are two user groups: the PG\&E team, including the monitoring technicians and the data analysis team, and the WEC developers. The PG\&E maintenance teams maintain the safety and integrity of the WaveConnect on-shore facilities and provide oversight to off-shore devices, while the PG\&E data analysis team compile and analyze data obtained during the life of the system. The WEC developers were to be responsible for delivery, installation, maintaining and operating their WECs at WaveConnect.

WaveConnect is divided into four major physical infrastructure segments:

1. Sea-Based Infrastructure (SBI), which includes marine elements for wet-plant navigation and site boundary elements, mechanical mooring elements, and wave measurement buoys for the SBI;

2. Submarine Cabled Infrastructure (SCI), which includes submarine power transmission cables, wet-end power cable terminations, and marine cable protection elements; 
3. Power Interconnect Infrastructure (PII), which includes electrical power conversion, conditioning, distribution, and protection elements of the System, and command and control elements of the electrical sub-system;

4. Data Acquisition and Telemetry Infrastructure (DATI), which includes data collection, transport, and local storage elements, data topology and encryption, and network interface to external elements.

Two additional segments are used in the full description of the WaveConnect site: (1) Logistics and Facility Support and (2) Physical Security and Safety (PSS). Logistics and Facility Support is notionally a logistical element and captures support functions to conduct installation, operations, maintenance, and recovery of the installed infrastructure. PSS addresses security and safety of the site, including monitoring and notification for the off-shore elements and wave energy conversion devices.

\section{SAIC System Requirements Specification: Appendix SAIC O}

The System Requirements Specification document describes the specifications that are required for construction of WaveConnect, and were to be used as a foundation for the conceptual design phase. This document identifies the specifications for the functional requirements identified in the Functional Requirements Document, (Appendix SAIC N). The document was to serve as the design basis for the remainder to the project, with changes to the document requiring specific customer approval through a formal process.

\section{SAIC Trip Report - UK Wave Energy Review 7-25 to 8-2-09: Appendix SAIC P}

PG\&E and SAIC personnel went to Great Britain and Ireland to conduct technical meetings with UK and Irish-based wave energy device developers and test facility operators; visit test facilities in Scotland, England, and Ireland; and to meet with representatives from UK and Irish wave energy development agencies. The trip review goes into a summary of the meetings as well as plans for collaborative action in the future, including the development of MOUs.

\section{SAIC WaveConnect Fast Facts Sheet: Appendix SAIC Q}

The Fast Facts Sheet (FFS) was developed in response to questions that were being put forward by the regulatory agencies. The FFS gave a synopsis of answers that were then used as inputs to the DPLA.

The FFS was only a part of a wider engineering support to CH2M Hill, PG\&E's consultant responsible for required permitting and environmental aspects of the WaveConnect on-shore and off-shore sites. SAIC's primary efforts as part of the support to CH2M Hill was to support and create the technical information required to develop the Project Description section of the Humboldt Site WaveConnect draft FERC license application. SAI first developed the "Fast Facts" list for the technical topical areas of anchoring and mooring, submarine cabling, shore 
facility, logistics and facilities, and WECs. This enabled the CH2M Hill staff to use a common set of core technical information on which to base permit application development. SAIC then develop a draft Project Description section detailing the technical content for the above areas. This was used by CH2M Hill to write the technical information section of the DPLA.

As part of this, SAIC developed initial draft civil engineering site drawings for both the Humboldt sites. Drawings included a typical WEC device, based on data collected through the RFI and other miscellaneous information, as well as on-shore cable interconnects.

\section{SAIC Central Coast Wave Resource Assessment: Appendix SAIC R}

As the wave energy resource is one of the key economic drivers of any wave energy project, a solid understanding of that resource is critical to estimate energy production from wave energy conversion devices. As part of its Central Coast Wave Connect Permit Application, PG\&E wished to know the impact of Point Arquella on wave energy, in order to begin a possible siting of a facility (to assess cable length, best possible location, etc.). This was made more difficult by the existence of the Vandenberg Marine Reserve, which limited the cable route. A SWAN model was developed of the area, using the most relevant NOAA wave measurement stations as well as the known bathymetry near the deployment site, and taking into account the likelihood of wave blockage effects in the southern portions of the deployment area.

The objectives of the study were:

1. Develop annual average values of Significant Wave Height (Hs) and Energy Period (Te) over the deployment site area. In deep water, these two variables can be used to compute the power density, which is an indicator of wave energy device performance level. As such, an understanding of the spatial distribution of power density values allows the array placement to be refined within the existing deployment site boundaries;

2. Develop scatter diagrams showing Hs versus Te for a single likely deployment location, which can be used by device manufacturers to estimate device performance;

3. Develop directional spectrum for a single likely deployment location for a full year. These directional spectra can be used for further statistical analysis and will aid device developers to fully understand the directionality and frequency distribution of the wave energy at the deployment site.

Figure 3-66 indicates the energy available in the area based on these preliminary studies. Table 3-31 shows the Output Point Statistics. Raw data is also available. 


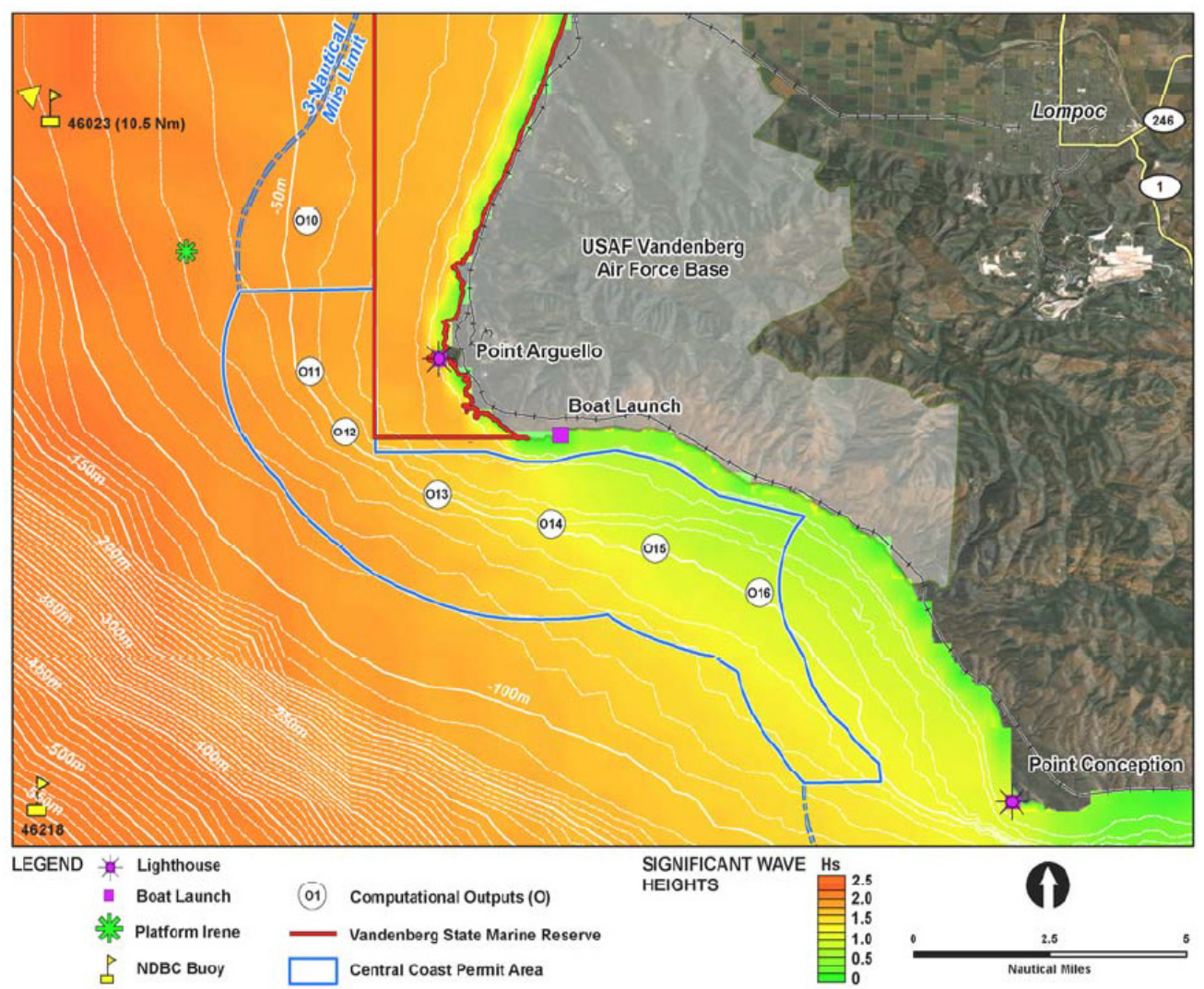

Figure 3-66: Average Off-shore Power Density near the Central Coast WaveConnect Site

Table 3-31: Output Point Statistics for the Central Coast WaveConnect Area

\begin{tabular}{|l|c|c|}
\hline Output Point & Average Hs (meters) & Average P (kW/m) \\
\hline O10 & 2.29 & 33.2 \\
\hline O11 & 2.29 & 32.69 \\
\hline O12 & 2.21 & 30.89 \\
\hline O13 & 2.18 & 29.12 \\
\hline O14 & 1.99 & 22.99 \\
\hline O15 & 1.61 & 13.77 \\
\hline O16 & 1.31 & 9.87 \\
\hline
\end{tabular}

\section{SAIC WEC Cost Assessment: Appendix SAIC S}

PG\&E requested SAIC to subcontract with Re-Vision, which had assisted EPRI in developing many of the cost estimates associated with its reports. The assessment involved comprehensively addressing cost and economic issues using a parametric modeling framework that Re-Vision developed over the past seven years as a result of its technical lead role in over 30 marine energy studies for organizations. 
In order to assess the device lifecycle cost, two parallel approaches were pursued. The first used Re-Vision proprietary design and cost data to identify lifecycle cost. Because the underlying cost data was confidential, only high-level cost data that cannot be directly related to a specific device was developed. Only deep-water WEC devices were considered. While this approach provides the highest level of confidence, it lacks transparency for commercial sensitivity reasons. The second approach consisted of reviewing existing European policies and incentives to gain an understanding of how other countries support this emerging industry and provide an independent comparison to data developed under the first approach.

It is important to understand that without knowledge of which devices will be deployed at the sites of interest, the cost and performance estimates will have inherently large uncertainty ranges. As such, the presented cost data should be viewed as indicative, as actual projections may significantly deviate from the projected figures, depending on the technologies chosen.

PG\&E did use much of the cost assessment in its estimations, but based on discussions with multiple technology experts, as well as with the various WEC manufacturers, found that this assessment under predicted several components of the system, including the cost of cable installation and how costs might fall over time. Many of the estimates were similar to those found in the EPRI reports. PG\&E discusses its cost estimations in this and later chapters.

\section{SAIC OrcaFlex Mooring System Modeling: Appendix SAIC T}

PG\&E viewed mooring systems as the crucial component in the safety of a WEC device or larger array. Inadequate design of the mooring system can contribute to the costly failure of a device and possibly other devices that an unmoored WEC could entangle or damage. Overdesign of a mooring system can quickly escalate installation and removal costs. Proper mooring system design requires consideration of the specific environmental characteristics of the installation site, design loads, design life, and operation and maintenance requirements. In order to assess the mooring system of a WEC devices applying to come to WaveConnect, a means of validating the suitability of a mooring design for the project site was explored.

This document describes the initial methodology for evaluating a mooring design for a three point moored WEC device, and demonstrates the application of the methodology using a finite element analysis software program (ORCAFlex). The results can be used as an input into the planning process prior to the installation of any moorings or equipment at the site. A later effort looked at an example wave energy device in a fifty year storm.

\section{SAIC Anchor System Analysis Methods: Appendix SAIC U}

This document evaluates existing designs of pile, deadweight, direct-embedment, and drag embedment anchors. Guidelines for the design of anchors for oil and gas platforms, vessels, and wind turbine structures created by different off-shore industry entities are compiled to provide a streamlined process that guides the user through the assessment of an existing anchor analysis. 
The general approach to anchor design requires consideration of the type of mooring, the loads expected at the anchor, and the marine geology at the installation site. Anchors can be designed for temporary or permanent use, with the design of permanent moorings requiring additional levels of redundancy to prevent failure. The thoroughness and extent of investigation into the project site geology is greater for permanent moorings, and additional factors of safety are included when calculating the capacity of the anchor. The loads experienced by the anchor are a function of the mooring configuration, the physical environment, and the object that is being moored. Ocean currents act on the mooring and object, wind forces act on surface objects, and waves exert repetitive forces on all objects within the water column. The ability of the anchor to resist these loads is dependent on the type and size of the anchor, and the soils in which it is located. The capacity of the soil to hold an anchor in place depends on the soil type and its index properties. A detailed understanding of the loads applied to the anchor and the geology of the installation site are the starting point in designing an anchor.

Other major industry documents exist. These are discussed later in the section on moorings.

\section{SAIC Revised Mooring Analysis: Appendix SAIC V}

A generic WEC device was used to evaluate the basic shape and mooring design. A solid model, complete with a calculated mass and buoyancy, was developed by PG\&E based on responses to the PG\&E RFI. This model will be referred to as the "notional oscillating water column WEC" or simply "notional O-WEC" throughout the SAIC document. Using this model, SAIC calculated both the hydrostatics and various dynamic parameters. The calculated hydrostatics and dynamics, together with a notional mooring design, was input into OrcaFlex $9.4 \mathrm{~b}$ for analysis. Finally, the OrcaFlex data was post processed in MathCAD to smooth the time series data, calculate the scouring area, and plot the information. The data is included herein. PG\&E feels that mooring designs and their interactions with the environment should be shared to increase confidence in the mooring systems. This is especially critical, as one device breaking loose could cause multiple devices to follow suit.

Eight different simulations of the WEC mooring response were completed varying parameters ranging from wave height to anchor chain size. Table 3-32 provides a summary of each case.

Table 3-32: Summary of Simulation Cases

\begin{tabular}{|c|l|l|}
\hline Case & \multicolumn{1}{|c|}{ Description } & \multicolumn{1}{c|}{ Notes } \\
\hline 01 & 50 -year Storm & Section 6.2.1, Discussion included \\
\hline 02 & $20 \%$ Reduction of 50-year Storm & Section 6.2.2, Environmental data only \\
\hline 03 & $20 \%$ Increase of 50-year Storm & Section 6.2.3, Environmental data only \\
\hline 04 & Winter's Day & Section 6.2.4, Discussion included \\
\hline 05 & Increased Wave Period & Section 6.2.5, Environmental data only \\
\hline 06 & Replaced 100 m of Chain with Nylon & Section 6.2.6, Environmental data only \\
\hline 07 & Replaced 100 m of Chain with Nylon & Section 6.2.7, Discussion included \\
\hline $01 \_45$ & Moved Wave Direction to $45^{\circ}$ & Section 6.2.9, Environmental data only \\
\hline
\end{tabular}


Of importance is the modeling of chain movement on the seafloor. This report gives feedback to the regulatory agencies concerning the impact of drag anchors on benthic environs. As was seen in the preliminary mooring using a three-point anchor system, the impact from that type of system is restricted to the footprint of the concrete anchors themselves.

\section{SAIC Humboldt Harbor Capabilities Assessment: Appendix SAIC W}

SAIC and local subcontractors conducted a harbor capabilities assessment for Humboldt Bay to identify the key factors and infrastructure that would be necessary for supporting WaveConnect wave energy site activities, ranging from performing studies to launching WEC devices, ongoing maintenance, and ultimate retrieval of the devices. Capabilities that were assessed included:

- Harbor Capabilities

- Waterfront Facility Alternatives

- Waterfront Industrial Capabilities

- Heavy Lift Infrastructure Capabilities

- Hydrographic Survey Capabilities

- Electrical Infrastructure (North Spit)

- Transportation Infrastructure.

The study made use of local experience and site knowledge provided by local subcontractors, including Winzler \& Kelly, Pacific Affiliates Consulting Engineers, and Fred Devine Diving and Salvage Company, as well as information collected by the consultant during prior site survey visits. Assessment findings were documented in a report that includes sources, contact information, and associated web links where available.

\section{SAIC Pilot Infra Lifecycle Cost Analysis: Appendix SAIC X}

The Pilot Infra Lifecycle Cost Analysis summarizes estimated annual costs for the WaveConnect pilot project off Humboldt, California. It is based on an assumption that the pilot project would begin detailed engineering and long-lead-time procurements in Year One once the FERC permit is awarded. Year Two consists of the construction of the site including installation of the shore pad, submarine power cables, site marker buoys, WEC installation, and the start of environmental monitoring. Years Three through Seven were operational years, during which the WECs produce power and send it to shore. The final year, Year Eight, was to consist of decommissioning of the overall site. This estimate is based on the concept of a five-year pilot license and removal, but much of the costs are applicable to longer projects.

Within each of these project phases (design and planning, construction, operation, and decommissioning) sub-tasking for major categories were identified, for which a range of costs were attributed. A basic three-point estimation approach was taken within each task area to identify expected minimum, maximum, and mid-point costs. For those cost elements for which a 
reasonable certainty exists for successful project execution, only a single, mid-point value is provided.

Engineering judgment was applied to determine the reasonableness of the cost data, given the technical assumptions of the project as stated within the WaveConnect Top Level Requirements, Functional Requirements, and Concept of Operations. Assumptions contained within these references have been modified since the original issue. The overall WaveConnect pilot project has been scaled back to reduce costs; specific cost savings areas include contingency response, contingency funding, PG\&E staffing, and a spare submarine power cable. Assumptions used to formulate the cost analysis, specifically where the cost analysis deviates from any of the referenced documents, are listed. Detailed cost data and calculations are provided in the cost spreadsheet.

\section{SAIC Conceptual Design Compendium: Appendix SAIC Y}

The Conceptual Design Compendium document represents reflects the design elements of key systems and infrastructure segments. These design artifacts were developed during the WaveConnect Conceptual Design activities conducted in 2009 and 2010. In May 2010, PG\&E stopped design activity to reassess the financial viability of the Humboldt County WaveConnect site, as cost information became available through the engineering design and the permit application process. Because the conceptual design process was in a data collection and analysis phase at this time, a conceptual design document was never generated for WaveConnect. However, this process itself generated many interim internal work products that, although incomplete, still offer valuable design insight and have therefore been assembled in this compendium.

During this time frame, while the system requirements specifications were being developed as input to conceptual design, most of the conceptual design work focused on infrastructure design elements supporting the preliminary pilot permit application process for the Humboldt site. As such, many work products centered on infrastructure elements most relevant to at-sea environmental aspects as well as large cost and lead time items such as submarine power cabling. Attention was also focused on the overarching system infrastructure, seeking out best practices at other similar wave energy test sites around the globe for comparison and incorporation.

\section{SAIC WaveConnect Summary Findings: Appendix SAIC Z}

PG\&E requested SAIC to provide a Summary Findings Report and lessons learned, based on their experience with the technical planning and engineering activities performed for the WaveConnect program. Each section contains a high-level discussion of the key lessons learned during the planning for and conceptual design of the system infrastructure at the proposed WaveConnect site in Humboldt County. The lessons learned relate specifically to the SAIC scope of work, and may not represent PG\&E's opinion. PG\&E wished SAIC to give their unbiased opinion of the effort. It should be recognized that the SAIC effort essentially ended 
after the submittal of the FERC DPLA and public response meeting, and so does not incorporate discussions that PG\&E had internally or with the WEC manufacturers.

\section{SAIC/OSU EMF Modeling Summary Report and Results Guide: Appendix OSU A}

SAIC used its existing knowledge in the area of sub-sea electric and magnetic field (EMF) modeling, instrumentation, and ambient field strengths in the sub-sea marine environment to assist PG\&E in its understanding of the impact of the proposed cables. It is known that EM field strength is also highly dependent on local geologic, bathymetric, and hydrographic conditions.

To support environmental planning, SAIC worked with Oregon State University (OSU) to develop a set of computational models to simulate geologic, oceanic, and atmospheric properties of the physical environment using static boundary conditions. The computer model consisted of $\mathrm{GNU}^{55}$ based Fortran90 reference codes for calculating electric and magnetic fields using frequency domain, FDM (finite difference method) methods for up to three dimensions. SAIC established a computing infrastructure to achieve the analysis objectives. As part of the initial investigation, SAIC generated an initial set of 1D/3D reference models and EMF calculations. These can serve as benchmark calculations, which can then be later compared against simulations calculated from commercial finite element analysis software suites.

SAIC has provided a set of reference codes compatible with Fortran90 programming standards, including a driver routine in Fortran90 for the user interface as well as 3D finite difference code (ASCII text format) that calculates EM fields for 3D air/ocean/earth models and depicts primary source fields generated by dipole sources and secondary fields induced by those primary fields. PG\&E will collaborate with Sandia National Laboratory as part of the technology transfer on this.

\section{HSU Wave Modeling Effort: Appendix HSU A}

PG\&E contracted with Humboldt State University (HSU) to produce a localized wave forecasting tool that would automatically connect to NOAA's WW3 data. This effort would then be a baseline for yet another scope: using radar to generate additional data regarding the local wave regime, in order to supplement data that would be collected with WaveRider buoys. The overall scope of the effort was to:

- Perform a detailed resource assessment for wave power production in the WaveConnect Study Area through a hindcast study of sea state conditions.

- Establish infrastructure and expertise to support long-term, real-time radar monitoring of the WaveConnect pilot project site.

- Integrate "hard" (direct observation) and "soft" (SWAN model output) data in support of the goals above.

\footnotetext{
${ }^{55} \mathrm{http}: / /$ en.wikipedia.org/wiki/GNU_General_Public_License
} 
- Measure wave attenuation patterns induced by wave energy converters (WECs) in order to produce conservative estimates of potential surf zone impacts from the WaveConnect pilot project.

Regretfully, only a portion of Part 1 was completed before efforts were cancelled. The resulting scripts that were produced will be handed off to Sandia National Laboratory.

\section{HSU Socioeconomic Baseline Study: Appendix HSU B}

To generate information on baseline physical, biological, and socio-economic conditions, PG\&E contracted with a consortium of HSU researchers to conduct research on the test site and adjacent areas of the ocean. This incomplete draft report describes baseline usage of the test site and adjacent areas by whale watching tour operators, commercial and recreational fishermen, and pleasure boaters. The report also describes overall commercial fishing activity in the affected region. The overall goal of this report is to describe current uses of the marine environment in the study area and adjacent waters, with the idea being to better understand potential spatial use conflicts and trade-offs involving the development of a wave farm in coastal Humboldt County waters.

Eureka and Trinidad are the primary locations of potentially impacted marine activity. Therefore these two cities and the surrounding minor ports (i.e. Fields Landing, King Salmon, Arcata, and McKinleyville) will be referred to throughout the report in discussions of baseline marine activity in the area.

Although the fishing area looks extensive in comparison to the crabbing grounds (Figures 3-67 and 3-68), the economics of the two areas tell a different story. The small crabbing ground area is responsible for approximately $60 \%$ of almost $\$ 14$ million in local fisheries income. The remaining $40 \%$ comes from a much more disperse area. Although there is some disagreement as to whether fishing could take place among the WECs, it is certain that the crabbing industry would feel a much larger impact than the more dispersed fishing industry, especially if a facility were placed on the OCS beyond $11 \mathrm{~km}$. 


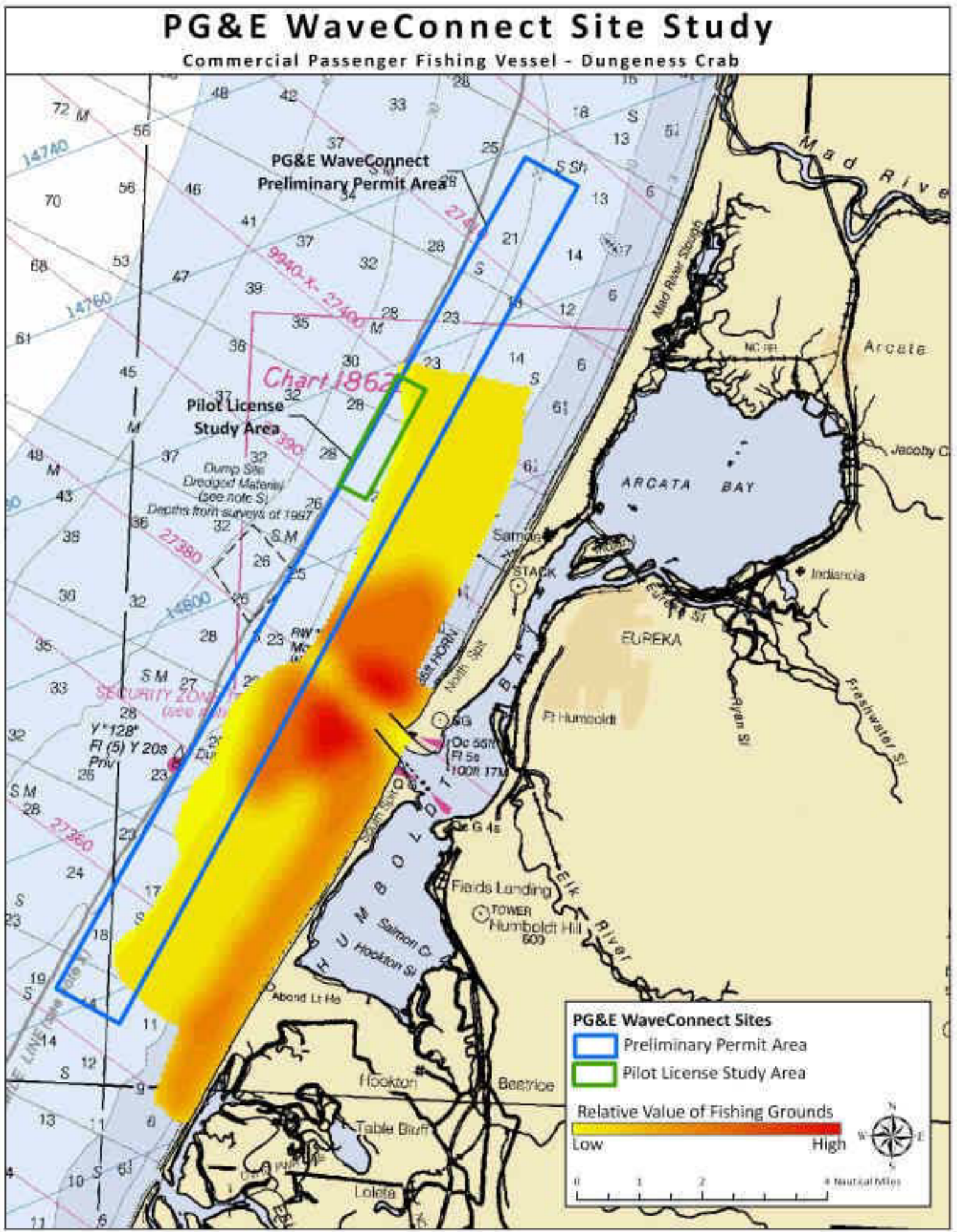

Figure 3-67: Dungeness Crab Fishing Activity in the Vicinity of WaveConnect Site 


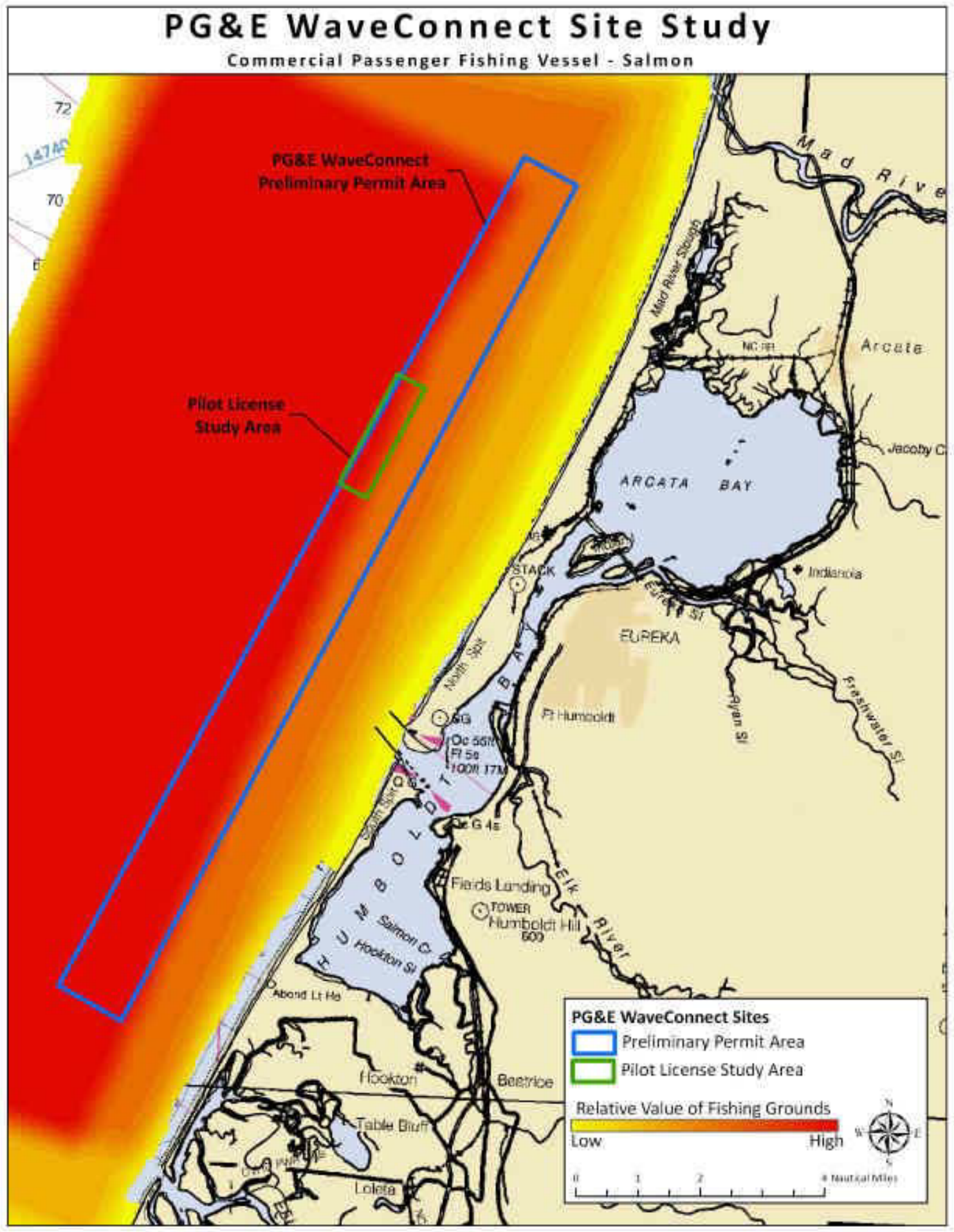

Figure 3-68: Commercial Passenger Fishing Activity in the Vicinity of WaveConnect Site 


\section{HSU Sediment Transport Study: Appendix HSU C}

As part of an effort to assess the movement of sediment due to wave action, HSU performed a series of cross-beach profiles surveys. The surveyed beaches ranged from Centerville Beach at the south end of the littoral cell to Moonstone Beach at the northern end of the cell. The sampling period covered the transition from the 2009-10 La Nina event to the 2010-11 El Nino event. During the study period, the beaches in the HBLC experienced the greatest changes in profile and in sediment character in May and again in September, October, and November of 2010. The amount of change was greatest on the southern portion of the littoral cell. At the very south end of the cell, at Centerville Beach, the beach profile was observed to transition from a summer-type profile (a.k.a. swell-wave profile) to a wintertime profile (a.k.a. storm-wave profile) in response to significant changes in the height and period of the incoming waves. Major shifts were observed in May and from September to November. The sand level on the beaches changed by as much as 2 meters between surveys at Centerville Beach. The amount of elevation change was less farther north in the cell; at the north end of the cell, less than $50 \mathrm{~cm}$ of elevation change was observed. Further details and actual observations and locations are found in Appendix HSU C. 


\section{Environmental Assessment}

\subsection{Permitting Process}

Environmental permitting for the Humboldt WaveConnect faced significant challenges that many other kinds of projects do not. Those challenges stemmed largely from:

- Permitting an unknown and untested technology with which project owners, the general public, and regulatory agencies had little or no familiarity, and;

- The demonstration project concept of the WaveConnect program, which led to a more programmatic approach toward evaluating project environmental effects.

Many kinds of facilities that are similar to hydrokinetic power facilities have been permitted in the ocean. Project owners and agencies have considered the environmental effects of facilities that involve construction on the seafloor, such as subsea electrical and communication cables; cable moorings, such as buoys; and structures floating on or near the ocean surface, such as offshore oil platforms. However, WECs present a unique combination of these different marine engineering elements, leading to uncertainty regarding the real effects of these technologies.

One of the principal challenges in permitting WaveConnect, therefore, had to do with uncertainty regarding the expected extent of its environmental effects. This uncertainty was partly due to the lack of specific information concerning the WEC technologies, but also due to a relative lack of understanding about the complex marine environment. Critical baseline information in the project area was sparse and it was fundamentally difficult to gather sufficient supplemental information as a basis against which to assess project effects for permitting. The magnitude of environmental effects was largely unmeasured and the effectiveness of specific mitigation measures untested.

Compounding the uncertainty was the fact that WaveConnect involved a general program to permit a demonstration facility for several different types of WECs. In addition, the process of selecting specific WEC manufacturers to participate in the program could not take place until site selection and preliminary designs were complete to form the basis of a Request for Proposals for manufacturers. Consequently, to meet the FERC preliminary permit time restrictions, environmental permitting discussions had to begin before it would have been possible to describe the designs and mooring systems of particular WECs that would participate.

\subsubsection{Lead Permitting Agency}

At the time PG\&E began developing WaveConnect, FERC and the Minerals Management Service (MMS) - later known as the Bureau of Ocean Energy Management, Regulation, and 
Enforcement (BOEMRE) — disputed jurisdiction over licensing renewable energy facilities on the outer continental shelf (OCS). FERC claimed jurisdiction over licensing hydrokinetic facilities under the Federal Power Act, which granted FERC authority to license water power facilities but which FERC had to that point only exercised on land-based projects. However, the Federal Power Act of 2005 appeared to grant BOEMRE jurisdiction over all energy facilities on the OCS.

Partly due to this unresolved dispute, the Humboldt project was sited in territorial waters (less than $5 \mathrm{~km}$ from shore) for the following principal reasons:

- Such waters would clearly be under the undisputed jurisdiction of FERC.

- FERC maintained an established process for licensing hydroelectric power plants sited on terrestrial rivers, whereas BOEMRE/MMS had not yet promulgated rules and regulations for permitting marine renewable energy facilities beyond interim policies that were expected to change.

- For an early-stage technology, siting closer to the operations and maintenance support harbor would be preferable to a location farther off-shore.

\subsubsection{FERC Pilot License Procedures}

In August 2007, FERC published a white paper, updated in April 2008, proposing procedures for expedited permitting of hydrokinetic pilot projects that could meet certain criteria. Projects qualifying for a pilot license would:

- Be approximately $5 \mathrm{MW}$ in generating capacity

- Not be located in an "environmentally sensitive area" (such as a marine reserve)

- Operate under the pilot license for five years, after which they could file a separate application for a standard 30-year license.

In an effort to hedge against uncertainties of permitting a new technology, the pilot license would include a provision that, in the event of an unforeseen and catastrophic impact or potential impact, the license would be suspended and the project facilities removed immediately.

FERC also envisioned that a pilot license would be granted under a NEPA Environmental Assessment (EA) and Finding of No Significant Impact (FONSI), rather than an Environmental Impact Statement (EIS) and Record of Decision (ROD). In fact, if a project could not meet the requirements for a FONSI by demonstrating that it would cause no significant adverse impacts with mitigation, then it could not qualify for a pilot license and would require a license under FERC's standard Integrated Licensing Process (ILP). FERC envisioned that its EA under the pilot licensing procedures could be completed in approximately six months, from the time that an application is ready for environmental review to the time when it is ready for Commission approval. For these procedures, FERC envisioned that it could license projects on a relatively small scale that would have foreseeable and relatively minor environmental effects. 
FERC's pilot license procedures therefore offered the prospect that hydrokinetic project developers and regulatory agencies could work together to permit shorter-term and smaller-scale projects that could be used to develop a better understanding of both the technologies and their environmental effects. The procedures would allow developers of hydrokinetic projects to evaluate their devices and begin to gather information from direct experience about the actual environmental effects of marine hydrokinetic energy development without a longer-term commitment to a particular site or mode of operation. The requirement that a project owner remove the project if there was an unforeseen and immitigable adverse impact was designed to reduce uncertainty regarding the environmental effects of new hydrokinetic technologies and the lack of information about their environmental effects.

PG\&E chose the FERC pilot license process for the Humboldt Project. The reasons for choosing this process included:

- FERC's pilot process fit the WaveConnect concept of a small- to medium-scale WEC array demonstration facility that could potentially be expanded at some point to a full-scale commercial operation.

- It was thought that the pilot license process would allow for a smaller initial investment and expedited schedule to begin project operations and return data that would help evaluate the feasibility of hydrokinetic technologies in their current form, and to inform the expansion of the project under a full 30-year license at a larger scale if feasible.

- Given the new technology and uncertainties surrounding the potential environmental effects of marine hydrokinetic energy, the pilot process potentially offered regulatory agencies and concerned stakeholders assurances of (a) short-duration operation under a single license, and (b) the requirement for project removal in case of an unforeseen environmental catastrophe. In other words, the pilot license procedures were designed with built-in environmental riskreduction measures.

- The pilot license procedures include provisions for developing monitoring and adaptive management plans that would be approved in advance of construction and could help control and correct any unforeseen environmental impacts as well. This is another measure that could reduce the environmental uncertainty associated with a new technology for the project owner, regulatory agency staff, and concerned stakeholders.

\subsubsection{Permitting Processes and Phases}

A summary of the steps involved in the FERC Pilot Licensing Procedure is shown in Table 4-1. To complete permitting, a number of permitting analyses and documents were required, most important of which was the FERC Final Pilot License Application (FPLA). Information developed to satisfy the FERC licensing process is also required for the ancillary or parallel permitting processes. With the FPLA (and its precursor the DPLA) as the master document, this same information would be reformatted and revised as necessary to prepare the other key permitting documents. Paralleling these planning and permitting efforts were engineering design, public involvement and stakeholder participation efforts, which are described below. 
Table 4-1: FERC Pilot License Procedures

\begin{tabular}{|c|c|c|}
\hline Activity & Participants & Duration \\
\hline \multicolumn{3}{|l|}{ I. Pre-Filing } \\
\hline \multicolumn{3}{|c|}{$\begin{array}{l}\text { Applicant files: } \\
\text { - Draft Pilot License Application } \\
\text { - Monitoring and Adaptive Management Plans } \\
\text { - Notice of Intent to file Application } \\
\text { - Request for Waivers } \\
\text { - Request for Non-Federal Representative for Section } 106 \text { NHPA and Section } 7 \text { ESA }\end{array}$} \\
\hline $\begin{array}{l}\text { FERC issues: } \\
\text { - Notice of Pre-filing process } \\
\text { - Designation of Non-Federal Representative for } \\
\text { Section } 106 \text { and Section } 7\end{array}$ & FERC & 15 days \\
\hline $\begin{array}{l}\text { Parties file comments on the DPLA and Monitoring } \\
\text { and Adaptive Management Plans }\end{array}$ & $\begin{array}{l}\text { FERC } \\
\text { Regulatory Agencies } \\
\text { Stakeholders } \\
\end{array}$ & 60 days \\
\hline $\begin{array}{l}\text { Technical conference to discuss DPLA and } \\
\text { Monitoring and Adaptive Management Plans }\end{array}$ & \begin{tabular}{|l|} 
Applicant \\
FERC \\
Regulatory Agencies \\
Stakeholders \\
\end{tabular} & $\begin{array}{l}\text { 15-day FERC notice } \\
\text { before meeting }\end{array}$ \\
\hline $\begin{array}{l}\text { Pre-filing process concludes: } \\
\text { - FERC Notices Conclusion of Pre-filing } \\
\text { - FERC issues Determination on Request for } \\
\text { Waiver }\end{array}$ & FERC & $\begin{array}{l}15 \text { days after } \\
\text { Technical Conference }\end{array}$ \\
\hline \multicolumn{3}{|l|}{ II. Filing and Post-Filing } \\
\hline \multicolumn{3}{|c|}{$\begin{array}{l}\text { Applicant files: } \\
\text { - Pilot License Application } \\
\text { - Revised Monitoring and Adaptive Management Plans } \\
\text { - Draft Biological Assessment } \\
\text { - CZMA Consistency Determination Application (Coastal Development Permit Application) } \\
\text { - CWA Section } 401 \text { Water Quality Certification Application } \\
\end{array}$} \\
\hline $\begin{array}{l}\text { FERC issues: } \\
\text { - } \text { Acceptance of Application Notice } \\
\text { - Ready for Environmental Analysis Notice } \\
\text { - Request for Interventions } \\
\text { - } \text { Biological Assessment } \\
\end{array}$ & FERC & $\begin{array}{l}15 \text { days after } \\
\text { Application filed }\end{array}$ \\
\hline $\begin{array}{l}\text { Agencies and others file comments on the } \\
\text { Application, proposed conditions }\end{array}$ & \begin{tabular}{|l|} 
Regulatory agencies \\
Stakeholders \\
\end{tabular} & 30 days from Notices \\
\hline FERC issues Environmental Assessment (if FONSI) & FERC & $\begin{array}{l}60 \text { days from } \\
\text { Recommendations }\end{array}$ \\
\hline $\begin{array}{l}\text { Comments on the Environmental Assessment } \\
\text { 10J Resolution }\end{array}$ & $\begin{array}{l}\text { Regulatory Agencies } \\
\text { Stakeholders } \\
\text { Applicant } \\
\end{array}$ & $\begin{array}{l}30 \text { days from } E A \\
\text { issuance }\end{array}$ \\
\hline
\end{tabular}

A partial list of other significant federal and state regulatory processes beyond the FERC process is found in Table 4-2. The permitting program for WaveConnect was suspended before 
completion of the Pilot Licensing Procedure. The activities completed prior to suspension consisted of the following major phases:

- Critical Issues Analysis

- Preparation of environmental baseline information

- Conceptual design of the WaveConnect site and development of a generalized project description

- Identification of generic WEC devices available for deployment

- Analysis of potential environmental effects

- Preparation and submittal of draft FERC Pilot License Application (official start of the prefiling process)

- Preparation of Monitoring and Adaptive Management Plans (MAMPs).

Table 4-2: Significant Federal and State Regulatory Permits and Authorization (partial list) ${ }^{56}$

\begin{tabular}{|c|c|c|}
\hline Agency & Law, Regulation, Ordinance & Application Document/Permit \\
\hline $\begin{array}{l}\text { California State Lands } \\
\text { Commission }\end{array}$ & $\begin{array}{l}\text { California Environmental Quality Act } \\
\text { compliance for lease of submerged } \\
\text { lands }\end{array}$ & $\begin{array}{l}\text { Environmental Impact Report } \\
\text { prepared by third party }\end{array}$ \\
\hline US Fish and Wildlife Service & Endangered Species Act & $\begin{array}{l}\text { Incidental Take Authorization/ } \\
\text { Biological Opinion }\end{array}$ \\
\hline $\begin{array}{l}\text { National Marine Fisheries } \\
\text { Service }\end{array}$ & $\begin{array}{l}\text { Endangered Species Act } \\
\text { Marine Mammal Protection Act }\end{array}$ & $\begin{array}{l}\text { Incidental Take Authorization/ } \\
\text { Biological Opinion } \\
\text { Letter of Authorization }\end{array}$ \\
\hline US Army Corps of Engineers & $\begin{array}{l}\text { Rivers and Harbors Act } \\
\text { Clean Water Act }\end{array}$ & $\begin{array}{l}\text { Section } 10 \text { permit } \\
\text { Section } 404 \text { permit to dredge or } \\
\text { fill }\end{array}$ \\
\hline $\begin{array}{l}\text { California Department of Fish } \\
\text { and Game (CDFG) }\end{array}$ & California Endangered Species Act & $\begin{array}{l}2081 \text { Incidental Take } \\
\text { Authorization }\end{array}$ \\
\hline $\begin{array}{l}\text { California Office of Historic } \\
\text { Preservation }\end{array}$ & National Historic Preservation Act & $\begin{array}{l}\text { Section } 106 \text { compliance and } \\
\text { consultation (if historic properties } \\
\text { present) }\end{array}$ \\
\hline California Coastal Commission & California Coastal Act & Coastal Development Permit \\
\hline $\begin{array}{l}\text { State Water Resources Control } \\
\text { Board }\end{array}$ & $\begin{array}{l}\text { Federal Clean Water Act (delegated } \\
\text { to state agency implementation) }\end{array}$ & $\begin{array}{l}\text { Section } 401 \text { Water Quality } \\
\text { Certification }\end{array}$ \\
\hline
\end{tabular}

\footnotetext{
${ }^{56}$ Other permitting processes might or might not apply, depending on the final siting and design of on-shore and offshore permitting facilities. This list does not include County and other local agency authorizations.
} 
In actuality, all of these phases except the Critical Issues Analyses led directly to the preparation of the DPLA for the Humboldt Project. The Environmental Baseline information and effects analyses form the core of the DPLA's Exhibit E. The Critical Issues Analyses also contributed to the DPLA because preliminary data collected for these analyses provided initial information for environmental baseline data collection. The MAMPs were submitted as appendices to the DPLA per FERC regulations.

\subsubsection{Critical Issues Analyses}

Environmental permitting work began on WaveConnect with Critical Issues Analyses for both the Mendocino and Humboldt sites. These were conducted during the summer of 2007, after PG\&E filed the FERC Preliminary Permit Applications. These reviews focused on four topical areas:

- Vessel Traffic and Use of the Sea Space

- Biological Resources and Sensitive Species

- Geomorphology/Coastal Processes

- Federal, State, and Local Permitting.

Their purpose was to identify environmental permitting or public policy factors that could significantly affect the cost and time it would take to permit the WaveConnect project at these sites or that would influence project siting or design. A secondary purpose was to provide information that would help in the final siting of the facilities.

\section{Vessel Traffic}

The Critical Issues Analysis examined vessel traffic routes, sea lanes, and restrictions to vessel traffic to and from the two project areas. For each of the prospective projects, the review listed the main and subsidiary ports that would be the sources of vessel traffic, including the ports at Fort Bragg's Noyo Harbor, which would serve the Mendocino Project, and Eureka, which would serve the Humboldt Project, as well as smaller ports including Albion and Shelter Cove in Mendocino County and Trinidad in Humboldt County. The report included discussions, based on readily available information, of the main categories of vessel traffic (off-shore long-distance shipping, commercial fishing, other commercial activities, recreational fishing, other recreational activities), numbers of vessels, and seasonality of the vessel traffic.

This analysis included a detailed discussion of the local fisheries and fishery habitats, such as their quantities and economic value. For example, the report described the ranges in terms of water depth and general habitat (rocky or sandy substrate) of various species of commercial value. The analysis also included brief discussions of recreational and commercial diving and surfing activities in the two project areas that could lead to use conflicts with ocean energy. 


\section{Biological Resources}

The biological resources Critical Issues Analysis began with lists of species that occur in the general project area, such as marine vegetation/algae, invertebrates, fish, mammals, birds, and reptiles. Similarly, for the on-shore environment the lists considered terrestrial wildlife and plants that could be affected by project activities and construction. Rare, threatened, and endangered species that are listed under the Federal Endangered Species Act (ESA) or California Endangered Species Act (CESA) were also identified. This part of the analysis included a table with a description of survey requirements for each of the species that could be present. The review also listed marine life protected areas, such as the California Marine Conservation Area and Point Cabrillo and McKerricher State Marine Conservation Areas (SMCAs), as well as Habitat Areas of Particular Concern (HAPCs) and a discussion of restrictions that would apply within these areas to project development. In addition, this part of the analysis included a table summarizing key biological resources permitting issues for the projects.

\section{Coastal Process}

The coastal process section of the Critical Issues Analysis addressed questions relating to onshore and off-shore effects of removing energy from wave trains as they reach the California Coast. Would this change shoreline erosion, affect sediment transport along the coast, or diminish the height and power of waves at locations preferred by recreational surfers? These issues were addressed using a modeling analysis of a hypothetical wave farm using the Pelamis Wave Power WEC device. Because Pelamis Wave Power had published the wave power matrix chart for this device, it was possible to model the effects of removing power from waves under differing sea states. The power matrix chart shows the expected power generation under different conditions of wave period and significant wave height (the WECs do not operate with the same efficiency in all sea states). Using project area wave height and period data from buoys operating near the project sites, this matrix was converted to wave energy reduction and wave height reduction matrices reflecting conditions immediately behind (downwave) of a hypothetical wave energy farm consisting of $40750-\mathrm{kW}$ Pelamis devices. The analysis then examined the effects of wave refraction and diffraction downwave of the hypothetical wave farm in recovering (filling in) wave energy between the farm and shore, and calculated estimated wave height reductions at varying distances from the wave farm. This analysis showed that a wave farm of this size $6.5 \mathrm{~km}$ from shore would have little or no effect on wave height and energy. It was therefore concluded that it would similarly have little to no effect on coastal erosion processes.

\section{Federal, State, and Local Permitting}

The permitting section of the report provided a permitting "roadmap" that included the FERC licensing process for hydrokinetic power plants, the California Environmental Quality Act with the State Lands Commission as lead agency, and local permitting authorities Humboldt and Mendocino counties under the Coastal Zone Management Act. 


\subsubsection{Environmental Baseline Information}

The first phase of work preparing the Humboldt Project DPLA involved collecting environmental baseline information in each of the key disciplines requiring discussion to prepare the FERC license application. These disciplines, per FERC regulations, are:

- Geology and Soils

- Water Resources

- Marine Fish and Aquatic Resources

- Marine Wildlife

- Terrestrial Resources

- Threatened and Endangered Species

- Recreation and Land Use

- Cultural Resources

- Aesthetics

- Socioeconomics.

As stated above, this work had begun in the preparation of the Critical Issues Analysis for the Humboldt project, which involved preliminary research on vessel traffic patterns, commercial fishing uses and recreational uses of the project area, and threatened and endangered species that might be affected.

As the initial baseline data-gathering took place, discussions were ongoing with the community and the stakeholder group (Humboldt Working Group; see discussion elsewhere in this report of the public involvement and stakeholder participation process) regarding the final siting and configuration of the project. For this reason, the baseline information gathered was regional and sub-regional to provide a more general context for developing project impact analyses.

Initially, the project included a study area $1.85 \mathrm{~km}$ wide and from 3.7 to $5.55 \mathrm{~km}$ from shore, and extending northeast to southwest for a distance of approximately $30 \mathrm{~km}$ on either side of the entrance to Humboldt Bay, which was the area remaining after the portions of the preliminary permit that intersected with the OCS were eliminated from consideration. After some discussions with local fishers, the project study area was reduced to include only the area to the north side of the Humboldt Bay harbor entrance. This area was considered to be relatively less productive as crab fishing grounds than the area south of the harbor entrance. The revised study area was 1.8 $\mathrm{km}$ wide and $18 \mathrm{~km}$ long, stretching from the entrance to Humboldt Bay north and east along the territorial waters boundary.

For the off-shore areas, gathering the environmental baseline data involved searching the available literature for previous studies that had been conducted on sediment transport, water quality, and marine life. It was during the environmental baseline data-gathering phase that the 
off-shore WEC deployment footprint was defined as an area approximately $2 \mathrm{~nm}$ long and 0.5 nm wide.

On-shore facilities would include a cable landing site, an on-shore cable route to electrical conditioning equipment, and a transmission line connecting the conditioning equipment building with the PG\&E's Fairhaven Substation or the substation located at the Freshwater Pulp Mill. Baseline data-gathering for the on-shore site included field surveys for rare plants, wildlife, and cultural (archaeological and historic) resources. Baseline work also involved interviewing members of the surfing community to determine where popular surfing sites might be located along the North Spit of Humboldt Bay on-shore of the WEC deployment area. For the Aesthetics analysis, baseline work involved examining local area plans and field work to assess viewsheds and viewer types and numbers in the area from which the WECs and on-shore facilities might be seen.

A vast array of literature was reviewed to gather baseline data on the large number of marine invertebrate, fish, mammal, reptilian, and bird species that could be present in the project area. Where available, studies of the Humboldt Bay littoral cell itself were accessed. Where these were not available, studies of the habitat, distribution, abundance and behavior in other locations were used.

\section{Research Partner Participation}

Concurrent with PG\&E's development of baseline information for the DPLA, PG\&E began negotiations to fund environmental baseline studies by Humboldt State University (HSU), Redwood Sciences Laboratory (RSL), and Klamath Bird Observatory (KBO) as research partners in various environmental disciplines for which HSU, RSL, and KBO staff had specialized local knowledge (Appendix 5-1 contains the final reports from these partners). These areas included marine mammals and birds, the economics of commercial fishing, benthic invertebrate communities, wave regimes, and marine fish, among others. With one exception, these studies would not have been completed in sufficient time such that their full and final results could be incorporated into the DPLA. However, the results would have been available to help inform later discussions leading to final permitting and implementation of construction and post-construction monitoring plans.

One of the studies provided in advance of the DPLA involved pinnipeds and cetaceans in the Humboldt Bay region conducted by Dr. Dawn Goley, professor of marine biology, and her students. This study involved field surveys of whale migration behavior and movements and tagging studies of harbor seal movements. It included both a compilation of data from previous years of work and new data collected specifically for WaveConnect (Appendix 5-1).

RSL is a research laboratory of the United States Forest Service that had conducted field inventories of marine birds and mammals along the Humboldt Coast for approximately 20 years, but had not analyzed nor published much of the resulting data. RSL had collected the data in consistent transects along the coast according to a specific protocol over this period of time and had also developed algorithms to convert raw observations into population density estimates (by 
correcting for distance-to-observation, for example). The initial purpose of this data collection effort had been to assess population densities and trends for the marbled murrelet, a threatened species (endangered under CESA), but the population counts also included all other marine birds and mammals sighted. Because of its intensive effort and long-term nature, this source of baseline information promised to be more valuable than any study that PG\&E could have conducted on its own in a reasonable period of time. PG\&E funded an effort by RSL and its associate KBO to analyze and report on the bird and marine mammal data from the Humboldt Area, leading to population density estimates (Appendix 5-1).

\subsubsection{Analysis of Environmental Effects}

Analysis of environmental effects began in July 2009, as project facility location and design information were being finalized. For each of the key environmental disciplines, this involved considering the final project design and analyzing potential effects on resources of public interest. As described above, however, at the time the analysis was begun to meet the required deadlines for filing the FERC DPLA, detailed information regarding which specific WECs and mooring systems would participate in WaveConnect was not available. At that point, the procurement process to develop the RFP and pre-select possible participating WEC manufacturers had begun but no WEC participants had yet been selected.

Lack of specific information presented a challenge to the analysis of environmental effects, in that it was necessary to describe the project in terms of a more general permitting "envelope" encompassing a general description of project design types rather than specific designs. Specific project designs would fit within this general envelope of effects or could be assumed to have environmental effects that would be the same as or less than those described by the envelope. As the participant WECs were selected, the license application and analyses would be updated to be more specific, under the general assumption that more specific project description information would result in a reduction of estimated impacts with better information. However, by the time the DPLA was prepared and submitted, the PG\&E procurement process was not complete. For example, the number of WEC devices that would be deployed was not known for certain at the time of DPLA filing.

Table 4-3 is a brief summary of the most important non-biological environmental issues that were considered in this analysis, by discipline. Please note that this is not a comprehensive list of effects analyzed, but a partial list, including the most important or controversial issues.

Table 4-4 summarizes the likely effects of the HWCP project on marine mammals, while Table 4-5 summarizes its effects on invertebrates, fish and essential fish habitats. Note that the degrees of potential effects are classified as negligible, minor adverse, adverse, or unknown. All items listed are addressed in greater detail in the sections of the DLPA provided under "DPLA Reference." The DPLA is provided in its entirety in the Appendix. 
Table 4-3: Key Environmental Issues Analyzed

\begin{tabular}{|c|c|}
\hline Discipline & Potential Effects Considered \\
\hline Geology and Soils & $\begin{array}{l}\text { Tsunami hazard } \\
\text { Subsea cable "thrumming" if not buried } \\
\text { On-shore erosion resulting from on-shore facility construction } \\
\text { Potential of wave energy harvesting to alter sediment transport and } \\
\text { erosion along the shore }\end{array}$ \\
\hline $\begin{array}{l}\text { Marine Fish and Aquatic } \\
\text { Resources }\end{array}$ & $\begin{array}{l}\text { Electric and magnetic field interference with green sturgeon migration } \\
\text { Creation of artificial reef } \\
\text { Disruption of benthic habitats during construction and operation }\end{array}$ \\
\hline Terrestrial Resources & $\begin{array}{l}\text { Disruption of rare plants Beach layia (Layia carnosa) and Humboldt Bay } \\
\text { wallflower (Erysimum menziesii ssp. eurekense) on shore }\end{array}$ \\
\hline Recreation and Land Use & $\begin{array}{l}\text { Harvesting of wave energy could reduce wave height, affecting } \\
\text { recreational surfing on shore }\end{array}$ \\
\hline Aesthetics & $\begin{array}{l}\text { Lighted WECs could be seen at night from shore } \\
\text { WECs could be seen from recreational areas during the day }\end{array}$ \\
\hline Water Resources & $\begin{array}{l}\text { WECs might leak hazardous materials or oil-based products, affecting } \\
\text { water quality }\end{array}$ \\
\hline Marine Wildlife & $\begin{array}{l}\text { Migrating gray whales and other cetaceans could collide with cables or } \\
\text { become entangled in fishing gear caught on WEC mooring cables. } \\
\text { WEC devices could act as haul locations for pinnipeds } \\
\text { Diving birds could become entangled in fishing gear caught on mooring } \\
\text { cables } \\
\text { Sea birds could collide with WEC superstructures at night. } \\
\text { WEC operational noise could disrupt cetaceans communication }\end{array}$ \\
\hline $\begin{array}{l}\text { Threatened and } \\
\text { Endangered Species }\end{array}$ & $\begin{array}{l}\text { Potential destruction of rare plant habitat on shore (see above) } \\
\text { Potential disruption of green sturgeon migration due to EMF (see above) } \\
\text { WEC moorings could cause artificial reef, causing differential predation } \\
\text { on juvenile salmon }\end{array}$ \\
\hline Cultural Resources & On-shore facilities could damage archaeological sites \\
\hline Socioeconomics & WEC deployment removes crab fishing and other fishing ground. \\
\hline
\end{tabular}


Table 4-4: Effects Summary on Marine Mammals Likely to Occur in the HWCP Area

\begin{tabular}{|c|c|c|c|}
\hline Effect on Species & $\begin{array}{l}\text { Degree of Effect } \\
\text { (Negligible, Minor } \\
\text { Adverse, Adverse, } \\
\text { or Unknown) }\end{array}$ & $\begin{array}{l}\text { Possible Mitigation } \\
\text { and Monitoring } \\
\text { ("Proposed } \\
\text { Environmental } \\
\text { Measures") }\end{array}$ & $\begin{array}{l}\text { DPLA Reference } \\
\text { (see Appendix 5-2) }\end{array}$ \\
\hline \multicolumn{4}{|c|}{ Harbor Seal, Steller Sea Lion, California Sea Lion } \\
\hline $\begin{array}{l}\text { Vessel traffic. Injury } \\
\text { due to vessel collision } \\
\text { and propeller strike }\end{array}$ & Adverse & $\begin{array}{l}\text { Limit vessel speeds, } \\
\text { minimize number of } \\
\text { vessels and trips, } \\
\text { minimize number of } \\
\text { night time trips }\end{array}$ & $\begin{array}{l}\text { DPLA Section 5.3.4 Marine Wildlife } \\
\text { 5.3.4.2.1 Potential Effects on Pinnipeds and } \\
\text { Cetaceans Likely to Occur in the HWCP Area } \\
\text { Page 5.3.4-27 } \\
\text { DPLA Section 5.3.4 Marine Wildlife } \\
\text { 5.3.4.5 Unavoidable Adverse Impacts } \\
\text { Page 5.3.4-45 } \\
\text { DPLA Section 5.3.6 Threatened and } \\
\text { Endangered Species } \\
\text { 5.3.6.2.3 Marine Species } \\
\text { Potential Effects of the Project on Threatened } \\
\text { and Endangered Marine Mammals Likely to } \\
\text { Occur in the HWCP Area } \\
\text { Page 5.3.6-80 }\end{array}$ \\
\hline $\begin{array}{l}\text { Noise. Acclimation, } \\
\text { avoidance, disruption } \\
\text { of foraging, due to } \\
\text { noise from vessels, } \\
\text { construction, } \\
\text { decommissioning, } \\
\text { devices }\end{array}$ & $\begin{array}{l}\text { Minor adverse from } \\
\text { vessel noise, } \\
\text { construction and } \\
\text { decommissioning } \\
\text { noise; unknown } \\
\text { noise and effects } \\
\text { from devices }\end{array}$ & $\begin{array}{l}\text { See vessel } \\
\text { mitigations above. } \\
\text { Noise from devices } \\
\text { should be monitored } \\
\text { relative to ambient } \\
\text { noise }\end{array}$ & $\begin{array}{l}\text { DPLA 5.3.4 Marine Wildlife } \\
\text { 5.3.4.2.1 Potential Effects on Pinnipeds and } \\
\text { Cetaceans Likely to Occur in the HWCP Area } \\
\text { Page 5.3.4-35 } \\
\text { DPLA 5.3.4 Marine Wildlife } \\
\text { 5.3.4.5 Unavoidable Adverse Impacts } \\
\text { Page 5.3.4-45 } \\
\text { DPLA 5.3.6 Threatened and Endangered } \\
\text { Species } \\
\text { 5.3.6.2.3 Marine Species } \\
\text { Potential Effects of the Project on Threatened } \\
\text { and Endangered Marine Mammals Likely to } \\
\text { Occur in the HWCP Area } \\
\text { Page 5.3.6-80 }\end{array}$ \\
\hline $\begin{array}{l}\text { Contaminants. } \\
\text { Bioaccumulation of } \\
\text { toxic compounds due } \\
\text { to chemical releases, } \\
\text { breathing exhaust, fur } \\
\text { fouling }\end{array}$ & Minor adverse & $\begin{array}{l}\text { Handle and use all } \\
\text { lubricants, fuels, } \\
\text { solvents, etc. } \\
\text { following standard } \\
\text { and required safety } \\
\text { procedures }\end{array}$ & $\begin{array}{l}\text { DPLA 5.3.4 Marine Wildlife } \\
\text { 5.3.4.2.1 Potential Effects on Pinnipeds and } \\
\text { Cetaceans Likely to Occur in the HWCP Area } \\
\text { Page 5.3.4-38 } \\
\text { DPLA 5.3.6 Threatened and Endangered } \\
\text { Species } \\
\text { 5.3.6.2.3 Marine Species } \\
\text { Potential Effects of the Project on Threatened } \\
\text { and Endangered Marine Mammals Likely to } \\
\text { Occur in the HWCP Area } \\
\text { Page 5.3.6-81 }\end{array}$ \\
\hline
\end{tabular}




\begin{tabular}{|c|c|c|c|}
\hline Effect on Species & $\begin{array}{l}\text { Degree of Effect } \\
\text { (Negligible, Minor } \\
\text { Adverse, Adverse, } \\
\text { or Unknown) }\end{array}$ & $\begin{array}{l}\text { Possible Mitigation } \\
\text { and Monitoring } \\
\text { (“Proposed } \\
\text { Environmental } \\
\text { Measures") }\end{array}$ & $\begin{array}{l}\text { DPLA Reference } \\
\text { (see Appendix 5-2) }\end{array}$ \\
\hline $\begin{array}{l}\text { Artificial lighting. } \\
\text { Attraction to prey } \\
\text { aggregated at bright } \\
\text { deck lights, } \\
\text { construction and } \\
\text { decommissioning lights }\end{array}$ & $\begin{array}{l}\text { Minor adverse; } \\
\text { Negligible effects } \\
\text { due to navigation } \\
\text { lights }\end{array}$ & $\begin{array}{l}\text { Minimize and shield } \\
\text { lights, limit } \\
\text { construction and } \\
\text { decommissioning to } \\
\text { daylight hours }\end{array}$ & $\begin{array}{l}\text { DPLA 5.3.4 Marine Wildlife } \\
\text { 5.3.4.2.1 Potential Effects on Pinnipeds and } \\
\text { Cetaceans Likely to Occur in the HWCP Area } \\
\text { Page 5.3.4-38-39 } \\
\text { DPLA 5.3.6 Threatened and Endangered } \\
\text { Species } \\
\text { 5.3.6.2.3 Marine Species } \\
\text { Potential Effects of the Project on Threatened } \\
\text { and Endangered Marine Mammals Likely to } \\
\text { Occur in the HWCP Area } \\
\text { Page 5.3.6-81 }\end{array}$ \\
\hline $\begin{array}{l}\text { Structures. Attraction } \\
\text { to fish aggregations } \\
\text { (FAD) and artificial reef } \\
\text { effects }\end{array}$ & $\begin{array}{l}\text { Minor and possibly } \\
\text { beneficial effects }\end{array}$ & $\begin{array}{l}\text { No mitigation } \\
\text { needed. }\end{array}$ & $\begin{array}{l}\text { DPLA 5.3.4 Marine Wildlife } \\
\text { 5.3.4.2.1 Potential Effects on Pinnipeds and } \\
\text { Cetaceans Likely to Occur in the HWCP Area } \\
\text { Page 5.3.4-39 } \\
\text { DPLA 5.3.6 Threatened and Endangered } \\
\text { Species } \\
\text { 5.3.6.2.3 Marine Species } \\
\text { Potential Effects of the Project on Threatened } \\
\text { and Endangered Marine Mammals Likely to } \\
\text { Occur in the HWCP Area } \\
\text { Page 5.3.6-81 }\end{array}$ \\
\hline $\begin{array}{l}\text { Electric and magnetic } \\
\text { fields from cables and } \\
\text { devices. Possible } \\
\text { impacts on behavior, } \\
\text { orientation and } \\
\text { navigation }\end{array}$ & $\begin{array}{l}\text { Minor and possibly } \\
\text { negligible }\end{array}$ & $\begin{array}{l}\text { Shielding and burial } \\
\text { of cables, "Faraday } \\
\text { cages" around } \\
\text { devices }\end{array}$ & $\begin{array}{l}\text { DPLA 5.3.4 Marine Wildlife } \\
\text { 5.3.4.2.1 Potential Effects on Pinnipeds and } \\
\text { Cetaceans Likely to Occur in the HWCP Area } \\
\text { Page 5.3.4-41 } \\
\text { DPLA 5.3.6 Threatened and Endangered } \\
\text { Species } \\
\text { 5.3.6.2.3 Marine Species } \\
\text { Potential Effects of the Project on Threatened } \\
\text { and Endangered Marine Mammals Likely to } \\
\text { Occur in the HWCP Area } \\
\text { Page 5.3.6-82 }\end{array}$ \\
\hline \multicolumn{4}{|c|}{ Gray Whale, Minke Whale, Humpback Whale, Blue Whale } \\
\hline $\begin{array}{l}\text { Vessel traffic. Injury } \\
\text { due to vessel collision } \\
\text { and propeller strike }\end{array}$ & Adverse & $\begin{array}{l}\text { Limit vessel speeds, } \\
\text { minimize number of } \\
\text { vessels and trips, } \\
\text { night time trips, limit } \\
\text { construction and } \\
\text { decommissioning to } \\
\text { outside winter } \\
\text { migration }\end{array}$ & $\begin{array}{l}\text { DPLA 5.3.4 Marine Wildlife } \\
\text { 5.3.4.2.1 Potential Effects on Pinnipeds and } \\
\text { Cetaceans Likely to Occur in the HWCP Area } \\
\text { Page 5.3.4-27 } \\
\text { DPLA 5.3.4 Marine Wildlife } \\
\text { 5.3.4.5 Unavoidable Adverse Impacts } \\
\text { Page 5.3.4-45 } \\
\text { DPLA 5.3.6 Threatened and Endangered } \\
\text { Species } \\
\text { 5.3.6.2.3 Marine Species } \\
\text { Potential Effects of the Project on Threatened } \\
\text { and Endangered Marine Mammals Likely to } \\
\text { Occur in the HWCP Area } \\
\text { Page 5.3.6-82-84 }\end{array}$ \\
\hline
\end{tabular}




\begin{tabular}{|c|c|c|c|}
\hline Effect on Species & $\begin{array}{l}\text { Degree of Effect } \\
\text { (Negligible, Minor } \\
\text { Adverse, Adverse, } \\
\text { or Unknown) }\end{array}$ & $\begin{array}{l}\text { Possible Mitigation } \\
\text { and Monitoring } \\
\text { ("Proposed } \\
\text { Environmental } \\
\text { Measures") }\end{array}$ & $\begin{array}{l}\text { DPLA Reference } \\
\text { (see Appendix 5-2) }\end{array}$ \\
\hline $\begin{array}{l}\text { Noise. Difficulty in prey } \\
\text { detection, } \\
\text { communication, } \\
\text { navigation, orientation; } \\
\text { avoidance of area due } \\
\text { to noise from vessels, } \\
\text { construction, } \\
\text { decommissioning, } \\
\text { devices }\end{array}$ & $\begin{array}{l}\text { Adverse effects } \\
\text { from vessel noise, } \\
\text { construction and } \\
\text { decommissioning } \\
\text { noise; unknown } \\
\text { noise and effects } \\
\text { from devices }\end{array}$ & $\begin{array}{l}\text { See vessel } \\
\text { mitigations above. } \\
\text { Noise from devices } \\
\text { should be monitored } \\
\text { relative to ambient } \\
\text { noise conditions }\end{array}$ & $\begin{array}{l}\text { DPLA 5.3.4 Marine Wildlife } \\
\text { 5.3.4.2.1 Potential Effects on Pinnipeds and } \\
\text { Cetaceans Likely to Occur in the HWCP Area } \\
\text { Page 5.3.4-35 } \\
\text { DPLA 5.3.4 Marine Wildlife } \\
\text { 5.3.4.5 Unavoidable Adverse Impacts } \\
\text { Page 5.3.4-45 } \\
\text { DPLA 5.3.6 Threatened and Endangered } \\
\text { Species } \\
\text { 5.3.6.2.3 Marine Species } \\
\text { Potential Effects of the Project on Threatened } \\
\text { and Endangered Marine Mammals Likely to } \\
\text { Occur in the HWCP Area } \\
\text { Page 5.3.6-82-84 }\end{array}$ \\
\hline $\begin{array}{l}\text { Contaminants. } \\
\text { Bioaccumulation of } \\
\text { toxic compounds due } \\
\text { to chemical releases }\end{array}$ & Minor adverse & $\begin{array}{l}\text { Handle and use all } \\
\text { lubricants, fuels, } \\
\text { solvents, etc. } \\
\text { following standard } \\
\text { and required safety } \\
\text { procedures }\end{array}$ & $\begin{array}{l}\text { DPLA 5.3.4 Marine Wildlife 5.3.4.2.1 Potential } \\
\text { Effects on Pinnipeds and Cetaceans Likely to } \\
\text { Occur in the HWCP Area } \\
\text { Page 5.3.4-38 } \\
\text { DPLA 5.3.6 Threatened and Endangered } \\
\text { Species } \\
\text { 5.3.6.2.3 Marine Species } \\
\text { Potential Effects of the Project on Threatened } \\
\text { and Endangered Marine Mammals Likely to } \\
\text { Occur in the HWCP Area } \\
\text { Page 5.3.6-83-84 }\end{array}$ \\
\hline $\begin{array}{l}\text { Artificial lighting. } \\
\text { Attraction to prey } \\
\text { aggregated at bright } \\
\text { deck lights, } \\
\text { construction and } \\
\text { decommissioning lights }\end{array}$ & $\begin{array}{l}\text { Negligible, effects } \\
\text { in small area } \\
\text { relative to species' } \\
\text { range }\end{array}$ & None Proposed & $\begin{array}{l}\text { DPLA 5.3.4 Marine Wildlife } \\
\text { 5.3.4.2.1 Potential Effects on Pinnipeds and } \\
\text { Cetaceans Likely to Occur in the HWCP Area } \\
\text { Page 5.3.4-38-39 } \\
\text { DPLA 5.3.6 Threatened and Endangered } \\
\text { Species } \\
\text { 5.3.6.2.3 Marine Species } \\
\text { Potential Effects of the Project on Threatened } \\
\text { and Endangered Marine Mammals Likely to } \\
\text { Occur in the HWCP Area } \\
\text { Page 5.3.6-83-84 }\end{array}$ \\
\hline $\begin{array}{l}\text { Structures. } \\
\text { Entanglement with } \\
\text { cables or fishing gear } \\
\text { and debris caught on } \\
\text { devices or cables; } \\
\text { attraction to fish } \\
\text { aggregation (FAD } \\
\text { effect) }\end{array}$ & $\begin{array}{l}\text { Adverse for } \\
\text { entanglement; } \\
\text { unknown for FAD } \\
\text { effect but likely } \\
\text { negligible }\end{array}$ & $\begin{array}{l}\text { Frequent monitoring } \\
\text { and removal of lost } \\
\text { fishing gear or debris; } \\
\text { installation of } \\
\text { "pingers" to alert } \\
\text { whales } \\
\text { Unknown for FAD } \\
\text { effects }\end{array}$ & $\begin{array}{l}\text { DPLA 5.3.4 Marine Wildlife } \\
\text { 5.3.4.2.1 Potential Effects on Pinnipeds and } \\
\text { Cetaceans Likely to Occur in the HWCP Area } \\
\text { Page 5.3.4-39 } \\
\text { DPLA 5.3.6 Threatened and Endangered } \\
\text { Species } \\
\text { 5.3.6.2.3 Marine Species } \\
\text { Potential Effects of the Project on Threatened } \\
\text { and Endangered Marine Mammals Likely to } \\
\text { Occur in the HWCP Area } \\
\text { Page 5.3.6-83-84 }\end{array}$ \\
\hline
\end{tabular}




\begin{tabular}{|c|c|c|c|}
\hline Effect on Species & $\begin{array}{l}\text { Degree of Effect } \\
\text { (Negligible, Minor } \\
\text { Adverse, Adverse, } \\
\text { or Unknown) }\end{array}$ & $\begin{array}{l}\text { Possible Mitigation } \\
\text { and Monitoring } \\
\text { ("Proposed } \\
\text { Environmental } \\
\text { Measures") }\end{array}$ & $\begin{array}{l}\text { DPLA Reference } \\
\text { (see Appendix 5-2) }\end{array}$ \\
\hline \multirow{2}{*}{$\begin{array}{l}\text { Electric and magnetic } \\
\text { fields from cables and } \\
\text { devices. Possible } \\
\text { impacts on behavior, } \\
\text { orientation and } \\
\text { navigation }\end{array}$} & \multirow[t]{2}{*}{$\begin{array}{l}\text { Minor and possibly } \\
\text { negligible }\end{array}$} & \multirow[t]{2}{*}{$\begin{array}{l}\text { Shielding and burial } \\
\text { of cables, "Faraday } \\
\text { cages" around } \\
\text { devices }\end{array}$} & $\begin{array}{l}\text { DPLA 5.3.4 Marine Wildlife 5.3.4.2.1 Potential } \\
\text { Effects on Pinnipeds and Cetaceans Likely to } \\
\text { Occur in the HWCP Area } \\
\text { Page 5.3.4-41 }\end{array}$ \\
\hline & & & $\begin{array}{l}\text { DPLA 5.3.6 Threatened and Endangered } \\
\text { Species } \\
\text { 5.3.6.2.3 Marine Species } \\
\text { Potential Effects of the Project on Threatened } \\
\text { and Endangered Marine Mammals Likely to } \\
\text { Occur in the HWCP Area } \\
\text { Page 5.3.6-83-84 }\end{array}$ \\
\hline \multicolumn{4}{|c|}{$\begin{array}{l}\text { Harbor Porpoise, Small Odontocetes (Dall's Porpoise, Pacific White-sided Dolphin, and Risso's Dolphin) and } \\
\text { Transient Killer Whale }\end{array}$} \\
\hline \multirow[t]{2}{*}{$\begin{array}{l}\text { Vessel traffic. Injury } \\
\text { due to vessel collision } \\
\text { and propeller strike }\end{array}$} & \multirow[t]{2}{*}{ Minor adverse } & \multirow[t]{2}{*}{$\begin{array}{l}\text { Limit vessel speeds, } \\
\text { minimize number of } \\
\text { vessels and trips, } \\
\text { minimize number of } \\
\text { night time trips }\end{array}$} & $\begin{array}{l}\text { DPLA 5.3.4 Marine Wildlife } \\
\text { 5.3.4.2.1 Potential Effects on Pinnipeds and } \\
\text { Cetaceans Likely to Occur in the HWCP Area } \\
\text { Page 5.3.4-27 }\end{array}$ \\
\hline & & & $\begin{array}{l}\text { DPLA 5.3.4 Marine Wildlife } \\
\text { 5.3.4.5 Unavoidable Adverse Impacts } \\
\text { Page 5.3.4-45 }\end{array}$ \\
\hline \multirow{3}{*}{$\begin{array}{l}\text { Noise. Acclimation of } \\
\text { noise, avoidance of } \\
\text { area, due to increased } \\
\text { noise from vessels, } \\
\text { construction, } \\
\text { decommissioning, } \\
\text { devices }\end{array}$} & \multirow{3}{*}{$\begin{array}{l}\text { Minor adverse from } \\
\text { vessels, } \\
\text { construction and } \\
\text { decommissioning } \\
\text { noise; unknown } \\
\text { noise and effects } \\
\text { from devices }\end{array}$} & \multirow{3}{*}{$\begin{array}{l}\text { See vessel } \\
\text { mitigations above. } \\
\text { Noise from devices } \\
\text { should be monitored } \\
\text { relative to ambient } \\
\text { noise conditions }\end{array}$} & $\begin{array}{l}\text { DPLA 5.3.4 Marine Wildlife } \\
\text { 5.3.4.2.1 Potential Effects on Pinnipeds and }\end{array}$ \\
\hline & & & $\begin{array}{l}\text { Cetaceans Likely to Occur in the HWCP Area } \\
\text { Page 5.3.4-35 }\end{array}$ \\
\hline & & & $\begin{array}{l}\text { DPLA 5.3.4 Marine Wildlife } \\
\text { 5.3.4.5 Unavoidable Adverse Impacts } \\
\text { Page 5.3.4-45 }\end{array}$ \\
\hline $\begin{array}{l}\text { Contaminants. } \\
\text { Bioaccumulation of } \\
\text { toxic compounds due } \\
\text { to chemical releases. }\end{array}$ & Minor adverse & $\begin{array}{l}\text { Handle and use all } \\
\text { lubricants, fuels, } \\
\text { solvents, etc. } \\
\text { following standard } \\
\text { and required safety } \\
\text { procedures }\end{array}$ & $\begin{array}{l}\text { DPLA 5.3.4 Marine Wildlife } \\
\text { 5.3.4.2.1 Potential Effects on Pinnipeds and } \\
\text { Cetaceans Likely to Occur in the HWCP Area } \\
\text { Page 5.3.4-38 }\end{array}$ \\
\hline $\begin{array}{l}\text { Artificial lighting. May } \\
\text { attract prey and } \\
\text { porpoise, increasing } \\
\text { potential for other } \\
\text { impacts }\end{array}$ & Minor adverse & $\begin{array}{l}\text { Minimize and shield } \\
\text { lights, limit } \\
\text { construction and } \\
\text { decommissioning to } \\
\text { daylight hours }\end{array}$ & $\begin{array}{l}\text { DPLA 5.3.4 Marine Wildlife } \\
\text { 5.3.4.2.1 Potential Effects on Pinnipeds and } \\
\text { Cetaceans Likely to Occur in the HWCP Area } \\
\text { Page 5.3.4-38-39 }\end{array}$ \\
\hline $\begin{array}{l}\text { Structures. } \\
\text { Entanglement with lost } \\
\text { gear caught on cables } \\
\text { or devices; artificial } \\
\text { reef effects could } \\
\text { attract fish and } \\
\text { increase foraging }\end{array}$ & $\begin{array}{l}\text { Adverse for } \\
\text { entanglement; } \\
\text { Unknown for FAD } \\
\text { effect but likely } \\
\text { negligible }\end{array}$ & $\begin{array}{l}\text { Frequent monitoring } \\
\text { and removal of lost } \\
\text { fishing gear or debris; } \\
\text { installation of } \\
\text { "pingers" to alert } \\
\text { porpoises }\end{array}$ & $\begin{array}{l}\text { DPLA 5.3.4 Marine Wildlife } \\
\text { 5.3.4.2.1 Potential Effects on Pinnipeds and } \\
\text { Cetaceans Likely to Occur in the HWCP Area } \\
\text { Page 5.3.4-39 }\end{array}$ \\
\hline
\end{tabular}




\begin{tabular}{|l|l|l|l|}
\hline Effect on Species & $\begin{array}{c}\text { Degree of Effect } \\
\text { (Negligible, Minor } \\
\text { Adverse, Adverse, } \\
\text { or Unknown) }\end{array}$ & $\begin{array}{c}\text { Possible Mitigation } \\
\text { and Monitoring } \\
\text { ("Proposed } \\
\text { Environmental } \\
\text { Measures") }\end{array}$ & \multicolumn{1}{|c|}{$\begin{array}{c}\text { DPLA Reference } \\
\text { (see Appendix 5-2) }\end{array}$} \\
\hline $\begin{array}{l}\text { Electric and magnetic } \\
\text { fields from cables and } \\
\text { devices. Possible } \\
\text { impacts on behavior, } \\
\text { orientation and } \\
\text { navigation }\end{array}$ & $\begin{array}{l}\text { Minor and possibly } \\
\text { negligible }\end{array}$ & $\begin{array}{l}\text { Shielding and burial } \\
\text { of cables, "Faraday } \\
\text { cages" around } \\
\text { devices }\end{array}$ & $\begin{array}{l}\text { DPLA 5.3.4 Marine Wildlife } \\
\text { 5.3.4.2.1 Potential Effects on Pinnipeds and } \\
\text { Cetaceans Likely to Occur in the HWCP Area } \\
\text { Page 5.3.4-41 }\end{array}$ \\
\hline
\end{tabular}

Table 4-5: Effects Summary of the HWCP Project on Invertebrates, Fish and Essential Fish Habitat

\begin{tabular}{|c|c|c|c|}
\hline Effect on Species & $\begin{array}{l}\text { Degree of Effect } \\
\text { (Negligible, Minor } \\
\text { Adverse, Adverse, } \\
\text { or Unknown) }\end{array}$ & $\begin{array}{l}\text { Possible Mitigation } \\
\text { and Monitoring } \\
\text { ("Proposed } \\
\text { Environmental } \\
\text { Measures") }\end{array}$ & DPLA Reference \\
\hline \multicolumn{4}{|c|}{ Benthic Infaunal Invertebrates } \\
\hline $\begin{array}{l}\text { Contaminants. } \\
\text { Chemical compounds } \\
\text { can be ingested and } \\
\text { become toxic }\end{array}$ & $\begin{array}{l}\text { Minor adverse } \\
\text { because volumes } \\
\text { released very low }\end{array}$ & $\begin{array}{l}\text { Handle and use all } \\
\text { lubricants, fuels, } \\
\text { solvents, etc. } \\
\text { following standard } \\
\text { and required safety } \\
\text { procedures }\end{array}$ & $\begin{array}{l}\text { DPLA 5.3.3 Marine Resources } \\
\text { Section: 5.3.3.21 Contaminants, } \\
\text { Page 5.3.3-36 }\end{array}$ \\
\hline $\begin{array}{l}\text { Structure. Disturbance } \\
\text { associated with } \\
\text { construction and } \\
\text { decommissioning }\end{array}$ & $\begin{array}{l}\text { Minor adverse and } \\
\text { localized }\end{array}$ & None proposed & $\begin{array}{l}\text { DPLA 5.3.3 Marine Resources } \\
\text { Section 5.3.3.2.5 Structure, } \\
\text { Page 5.3.3-39 }\end{array}$ \\
\hline \multicolumn{4}{|l|}{ Biofouling Invertebrates } \\
\hline $\begin{array}{l}\text { Structure. Biofouling is } \\
\text { associated with } \\
\text { structure in the water } \\
\text { column and on bottom }\end{array}$ & $\begin{array}{l}\text { Minor adverse and } \\
\text { localized }\end{array}$ & $\begin{array}{l}\text { Use anti-fouling } \\
\text { paints, perform } \\
\text { maintenance to } \\
\text { remove biofouling } \\
\text { organisms }\end{array}$ & $\begin{array}{l}\text { DPLA 5.3.3 Marine Resources } \\
\text { Section 5.3.3.2.5 Structure, } \\
\text { Page 5.3.3-39 }\end{array}$ \\
\hline \multicolumn{4}{|c|}{ Planktonic Invertebrates (Copepods, Euphausiids, Dungeness Crab Megalopae, Zooplankton, Squid) } \\
\hline $\begin{array}{l}\text { Contaminants. } \\
\text { Chemical compounds } \\
\text { may be toxic }\end{array}$ & $\begin{array}{l}\text { Negligible, volumes } \\
\text { released very low, } \\
\text { and species } \\
\text { distributions are } \\
\text { ephemeral and } \\
\text { patchy }\end{array}$ & None proposed & $\begin{array}{l}\text { DPLA 5.3.3 Marine Resources } \\
\text { 5.3.3.2.1 Contaminants, } \\
\text { Page 5.3.3-36 }\end{array}$ \\
\hline
\end{tabular}




\begin{tabular}{|c|c|c|c|}
\hline Effect on Species & $\begin{array}{l}\text { Degree of Effect } \\
\text { (Negligible, Minor } \\
\text { Adverse, Adverse, } \\
\text { or Unknown) }\end{array}$ & $\begin{array}{l}\text { Possible Mitigation } \\
\text { and Monitoring } \\
\text { ("Proposed } \\
\text { Environmental } \\
\text { Measures") }\end{array}$ & DPLA Reference \\
\hline $\begin{array}{l}\text { Artificial lighting. } \\
\text { Aggregation at bright } \\
\text { deck lights, } \\
\text { construction and } \\
\text { decommissioning } \\
\text { lights, navigation and } \\
\text { safety lights could } \\
\text { expose species to } \\
\text { predation }\end{array}$ & Minor adverse & $\begin{array}{l}\text { Minimize lights or limit } \\
\text { construction and } \\
\text { decommissioning to } \\
\text { daylight hours; none } \\
\text { proposed for } \\
\text { navigation and safety } \\
\text { lights }\end{array}$ & $\begin{array}{l}\text { DPLA 5.3.3 Marine Resources } \\
\text { 5.3.3.2.2 Artificial Lighting, } \\
\text { Page 5.3.3-36-37 }\end{array}$ \\
\hline $\begin{array}{l}\text { Entrainment. } \\
\text { Withdrawn with } \\
\text { seawater into WECs }\end{array}$ & $\begin{array}{l}\text { No effect, proposed } \\
\text { WECs not likely to } \\
\text { entrain }\end{array}$ & None proposed & $\begin{array}{l}\text { DPLA 5.3.3 Marine Resources } \\
\text { 5.3.3.2.3 Entrainment, } \\
\text { Page 5.3.3-37 }\end{array}$ \\
\hline $\begin{array}{l}\text { Structures. Species } \\
\text { may be attracted to } \\
\text { structures and their } \\
\text { lights }\end{array}$ & $\begin{array}{l}\text { Negligible, attraction } \\
\text { probably due to } \\
\text { artificial lighting }\end{array}$ & None proposed & $\begin{array}{l}\text { DPLA 5.3.3 Marine Resources } \\
\text { 5.3.3.2.5 Structure } \\
\text { Page 5.3.3-39 } \\
\text { DPLA 5.3.3 Marine Resources } \\
\text { 5.3.3.2.2 Artificial Lighting, } \\
\text { Page 5.3.3-36-37 }\end{array}$ \\
\hline \multicolumn{4}{|c|}{ Epibenthic Invertebrates and Dungeness Crab } \\
\hline $\begin{array}{l}\text { Contaminants. } \\
\text { Chemical compounds } \\
\text { may be toxic }\end{array}$ & $\begin{array}{l}\text { Negligible, volumes } \\
\text { released very low, } \\
\text { and species can } \\
\text { move away from } \\
\text { releases }\end{array}$ & None proposed & $\begin{array}{l}\text { DPLA 5.3.3 Marine Resources } \\
\text { 5.3.3.2.1 Contaminants, } \\
\text { Page 5.3.3-36 }\end{array}$ \\
\hline $\begin{array}{l}\text { Habitat disturbance } \\
\text { associated with } \\
\text { construction, structure }\end{array}$ & $\begin{array}{l}\text { Minor adverse and } \\
\text { localized }\end{array}$ & None proposed & $\begin{array}{l}\text { DPLA 5.3.3 Marine Resources } \\
\text { 5.3.3.2.5 Structure } \\
\text { Page 5.3.3-39 }\end{array}$ \\
\hline $\begin{array}{l}\text { Artificial lighting. } \\
\text { Aggregation at bright } \\
\text { deck lights, } \\
\text { construction and } \\
\text { decommissioning } \\
\text { lights, navigation and } \\
\text { safety lights could } \\
\text { expose species to } \\
\text { predation }\end{array}$ & Minor adverse & $\begin{array}{l}\text { Minimize lights or limit } \\
\text { construction and } \\
\text { decommissioning to } \\
\text { daylight hours; none } \\
\text { proposed for } \\
\text { navigation and safety } \\
\text { lights }\end{array}$ & $\begin{array}{l}\text { DPLA 5.3.3 Marine Resources } \\
\text { 5.3.3.2.2 Artificial Lighting, } \\
\text { Page 5.3.3-36-37 }\end{array}$ \\
\hline $\begin{array}{l}\text { Structures. Species } \\
\text { may be attracted to } \\
\text { bottom structures }\end{array}$ & $\begin{array}{l}\text { Negligible, not } \\
\text { known to be } \\
\text { attracted to } \\
\text { structures }\end{array}$ & None proposed & $\begin{array}{l}\text { DPLA 5.3.3 Marine Resources } \\
\text { 5.3.3.2.5 Structure } \\
\text { Page 5.3.3-39 }\end{array}$ \\
\hline
\end{tabular}




\begin{tabular}{|c|c|c|c|}
\hline Effect on Species & $\begin{array}{l}\text { Degree of Effect } \\
\text { (Negligible, Minor } \\
\text { Adverse, Adverse, } \\
\text { or Unknown) }\end{array}$ & $\begin{array}{l}\text { Possible Mitigation } \\
\text { and Monitoring } \\
\text { ("Proposed } \\
\text { Environmental } \\
\text { Measures") }\end{array}$ & DPLA Reference \\
\hline $\begin{array}{l}\text { Electric and Magnetic } \\
\text { Fields. Possible } \\
\text { disorientation and } \\
\text { behavioral changes }\end{array}$ & $\begin{array}{l}\text { Unknown electric } \\
\text { and magnetic field } \\
\text { exposures from } \\
\text { power cables or } \\
\text { WECs, and } \\
\text { unknown responses }\end{array}$ & $\begin{array}{l}\text { Shielding and burial } \\
\text { of cables, "Faraday } \\
\text { cages" around } \\
\text { devices }\end{array}$ & $\begin{array}{l}\text { DPLA 5.3.3 Marine Resources } \\
\text { 5.3.3.2.6 Electric and Magnetic Fields, } \\
\text { Page 5.3.3-41 }\end{array}$ \\
\hline \multicolumn{4}{|l|}{ Flatfish } \\
\hline $\begin{array}{l}\text { Contaminants. } \\
\text { Chemical compounds } \\
\text { may be toxic }\end{array}$ & $\begin{array}{l}\text { Negligible, volumes } \\
\text { released very low, } \\
\text { and species can } \\
\text { move away from } \\
\text { releases }\end{array}$ & None proposed & $\begin{array}{l}\text { DPLA 5.3.3 Marine Resources } \\
\text { 5.3.3.2.1 Contaminants, } \\
\text { Page 5.3.3-36 }\end{array}$ \\
\hline $\begin{array}{l}\text { Noise. Short-term } \\
\text { disturbance from } \\
\text { vessel construction, } \\
\text { decommissioning noise }\end{array}$ & $\begin{array}{l}\text { Negligible; flatfishes } \\
\text { not known to be } \\
\text { very sensitive to } \\
\text { noise }\end{array}$ & None proposed & $\begin{array}{l}\text { DPLA 5.3.3 Marine Resources } \\
\text { 5.3.3.2.4 Noise } \\
\text { Page 5.3.3-37 }\end{array}$ \\
\hline $\begin{array}{l}\text { Artificial lighting. } \\
\text { Species not known to } \\
\text { aggregate around } \\
\text { lights and are bottom } \\
\text { oriented }\end{array}$ & Negligible & None proposed & $\begin{array}{l}\text { DPLA 5.3.3 Marine Resources } \\
\text { 5.3.3.2.2 Artificial Lighting, } \\
\text { Page 5.3.3-36-37 }\end{array}$ \\
\hline $\begin{array}{l}\text { Structures. Species not } \\
\text { known to be attracted } \\
\text { to structures }\end{array}$ & $\begin{array}{l}\text { Negligible, not } \\
\text { known to be } \\
\text { attracted to } \\
\text { structures }\end{array}$ & None proposed & $\begin{array}{l}\text { DPLA 5.3.3 Marine Resources } \\
\text { 5.3.3.2.5 Structure } \\
\text { Page 5.3.3-39 }\end{array}$ \\
\hline $\begin{array}{l}\text { Electric and Magnetic } \\
\text { Fields. Effects unlikely, } \\
\text { species not known to } \\
\text { have sensitive } \\
\text { electroreceptors }\end{array}$ & Negligible & None proposed & $\begin{array}{l}\text { DPLA 5.3.3 Marine Resources } \\
\text { 5.3.3.2.6 Electric and Magnetic Fields, } \\
\text { Page 5.3.3-41 }\end{array}$ \\
\hline \multicolumn{4}{|l|}{ Pelagic Schooling Fish } \\
\hline $\begin{array}{l}\text { Contaminants. } \\
\text { Chemical compounds } \\
\text { may be toxic }\end{array}$ & $\begin{array}{l}\text { Negligible, volumes } \\
\text { released very low, } \\
\text { and species } \\
\text { distributions } \\
\text { ephemeral and } \\
\text { patchy }\end{array}$ & None proposed & $\begin{array}{l}\text { DPLA 5.3.3 Marine Resources } \\
\text { 5.3.3.2.1 Contaminants, } \\
\text { Page 5.3.3-36 }\end{array}$ \\
\hline $\begin{array}{l}\text { Artificial lighting. } \\
\text { Aggregation at bright } \\
\text { deck lights, } \\
\text { construction and } \\
\text { decommissioning } \\
\text { lights, navigation and } \\
\text { safety lights could } \\
\text { expose species to } \\
\text { predation }\end{array}$ & Minor adverse & $\begin{array}{l}\text { Minimize lights or limit } \\
\text { construction and } \\
\text { decommissioning to } \\
\text { daylight hours; none } \\
\text { proposed for } \\
\text { navigation and safety } \\
\text { lights }\end{array}$ & $\begin{array}{l}\text { DPLA 5.3.3 Marine Resources } \\
\text { 5.3.3.2.2 Artificial Lighting, } \\
\text { Page 5.3.3-36-37 }\end{array}$ \\
\hline $\begin{array}{l}\text { Entrainment. } \\
\text { Withdrawn with } \\
\text { seawater into WECs }\end{array}$ & $\begin{array}{l}\text { No effect, proposed } \\
\text { WECs not likely to } \\
\text { entrain }\end{array}$ & None proposed & $\begin{array}{l}\text { DPLA 5.3.3 Marine Resources } \\
\text { 5.3.3.2.3 Entrainment, } \\
\text { Page 5.3.3-37 }\end{array}$ \\
\hline
\end{tabular}




\begin{tabular}{|c|c|c|c|}
\hline Effect on Species & $\begin{array}{l}\text { Degree of Effect } \\
\text { (Negligible, Minor } \\
\text { Adverse, Adverse, } \\
\text { or Unknown) }\end{array}$ & $\begin{array}{l}\text { Possible Mitigation } \\
\text { and Monitoring } \\
\text { (“Proposed } \\
\text { Environmental } \\
\text { Measures") }\end{array}$ & DPLA Reference \\
\hline $\begin{array}{l}\text { Noise. Short-term } \\
\text { disturbance from } \\
\text { construction and } \\
\text { decommissioning } \\
\text { noise, and vessel } \\
\text { noise; unknown effects } \\
\text { from device noise }\end{array}$ & $\begin{array}{l}\text { Minor adverse. } \\
\text { Clupeid fishes } \\
\text { sensitive to noise, } \\
\text { although they may } \\
\text { acclimate; unknown } \\
\text { noise and effects } \\
\text { from devices }\end{array}$ & $\begin{array}{l}\text { Limit vessel speeds, } \\
\text { minimize number of } \\
\text { vessels and trips } \\
\text { Noise from device } \\
\text { operations should be } \\
\text { monitored relative to } \\
\text { ambient site } \\
\text { conditions }\end{array}$ & $\begin{array}{l}\text { DPLA 5.3.3 Marine Resources } \\
\text { 5.3.3.2.4 Noise } \\
\text { Page 5.3.3-37 }\end{array}$ \\
\hline $\begin{array}{l}\text { Structures. Species } \\
\text { may be attracted to } \\
\text { structures and lights }\end{array}$ & $\begin{array}{l}\text { Negligible, attraction } \\
\text { probably due to } \\
\text { artificial lighting }\end{array}$ & None proposed & $\begin{array}{l}\text { DPLA 5.3.3 Marine Resources } \\
\text { 5.3.3.2.5 Structure } \\
\text { Page 5.3.3-39 }\end{array}$ \\
\hline $\begin{array}{l}\text { Electric and Magnetic } \\
\text { Fields. Effects unlikely, } \\
\text { species not known to } \\
\text { have sensitive } \\
\text { electroreceptors }\end{array}$ & Negligible & None proposed & $\begin{array}{l}\text { DPLA 5.3.3 Marine Resources } \\
\text { 5.3.3.2.6 Electric and Magnetic Fields, } \\
\text { Page 5.3.3-41 }\end{array}$ \\
\hline \multicolumn{4}{|l|}{ Elasmobranchs } \\
\hline $\begin{array}{l}\text { Noise. Short-term } \\
\text { disturbance from } \\
\text { vessel, construction, } \\
\text { decommissioning noise }\end{array}$ & $\begin{array}{l}\text { Negligible due to } \\
\text { species' motility and } \\
\text { short duration }\end{array}$ & None proposed & $\begin{array}{l}\text { DPLA 5.3.3 Marine Resources } \\
\text { 5.3.3.2.4 Noise } \\
\text { Page 5.3.3-37 }\end{array}$ \\
\hline $\begin{array}{l}\text { Contaminants. } \\
\text { Chemical compounds } \\
\text { may be toxic. }\end{array}$ & $\begin{array}{l}\text { Negligible, volumes } \\
\text { released very low, } \\
\text { and species can } \\
\text { move away from } \\
\text { releases }\end{array}$ & None proposed & $\begin{array}{l}\text { DPLA 5.3.3 Marine Resources } \\
\text { 5.3.3.2.1 Contaminants, } \\
\text { Page 5.3.3-36 }\end{array}$ \\
\hline $\begin{array}{l}\text { Artificial lighting. } \\
\text { Species not known to } \\
\text { aggregate around } \\
\text { lights }\end{array}$ & Negligible & None proposed & $\begin{array}{l}\text { DPLA 5.3.3 Marine Resources } \\
\text { 5.3.3.2.2 Artificial Lighting, } \\
\text { Page 5.3.3-36-37 }\end{array}$ \\
\hline $\begin{array}{l}\text { Structures. Species not } \\
\text { known to be attracted } \\
\text { to structures }\end{array}$ & $\begin{array}{l}\text { Negligible, not } \\
\text { known to be } \\
\text { attracted to } \\
\text { structures }\end{array}$ & None proposed & $\begin{array}{l}\text { DPLA 5.3.3 Marine Resources } \\
\text { 5.3.3.2.5 Structure } \\
\text { Page 5.3.3-39 }\end{array}$ \\
\hline $\begin{array}{l}\text { Electric and Magnetic } \\
\text { Fields. Possible } \\
\text { disorientation and } \\
\text { behavioral changes }\end{array}$ & $\begin{array}{l}\text { Unknown electric } \\
\text { and magnetic field } \\
\text { exposures from } \\
\text { power cables or } \\
\text { WECs, unknown } \\
\text { responses }\end{array}$ & $\begin{array}{l}\text { Shielding and burial } \\
\text { of cables, "Faraday } \\
\text { cages" around } \\
\text { devices }\end{array}$ & $\begin{array}{l}\text { DPLA 5.3.3 Marine Resources } \\
\text { 5.3.3.2.6 Electric and Magnetic Fields, } \\
\text { Page 5.3.3-41 }\end{array}$ \\
\hline \multicolumn{4}{|c|}{ Rockfish, Lingcod, Greenling, Cabezon } \\
\hline $\begin{array}{l}\text { Contaminants. Species } \\
\text { may occur in project } \\
\text { area due to artificial } \\
\text { reef effect, toxicity } \\
\text { effects }\end{array}$ & $\begin{array}{l}\text { Minor adverse } \\
\text { because volumes } \\
\text { released very low }\end{array}$ & $\begin{array}{l}\text { Handle and use all } \\
\text { lubricants, fuels, } \\
\text { solvents, etc. } \\
\text { following standard } \\
\text { and required safety } \\
\text { procedures }\end{array}$ & $\begin{array}{l}\text { DPLA 5.3.3 Marine Resources } \\
\text { 5.3.3.2.1 Contaminants, } \\
\text { Page 5.3.3-36 }\end{array}$ \\
\hline
\end{tabular}




\begin{tabular}{|c|c|c|c|}
\hline Effect on Species & $\begin{array}{l}\text { Degree of Effect } \\
\text { (Negligible, Minor } \\
\text { Adverse, Adverse, } \\
\text { or Unknown) }\end{array}$ & $\begin{array}{l}\text { Possible Mitigation } \\
\text { and Monitoring } \\
\text { ("Proposed } \\
\text { Environmental } \\
\text { Measures") }\end{array}$ & DPLA Reference \\
\hline $\begin{array}{l}\text { Noise. Short-term } \\
\text { disturbance from } \\
\text { vessel, construction, } \\
\text { decommissioning noise }\end{array}$ & $\begin{array}{l}\text { Negligible. } \\
\text { Rockfishes not } \\
\text { known to be very } \\
\text { sensitive to noise }\end{array}$ & None proposed & $\begin{array}{l}\text { DPLA 5.3.3 Marine Resources } \\
\text { 5.3.3.2.4 Noise } \\
\text { Page 5.3.3-37 }\end{array}$ \\
\hline $\begin{array}{l}\text { Artificial lighting. } \\
\text { Species not known to } \\
\text { aggregate around } \\
\text { lights, are bottom } \\
\text { oriented }\end{array}$ & Negligible & None proposed & $\begin{array}{l}\text { DPLA 5.3.3 Marine Resources } \\
\text { 5.3.3.2.2 Artificial Lighting, } \\
\text { Page 5.3.3-36-37 }\end{array}$ \\
\hline $\begin{array}{l}\text { Structures. Species } \\
\text { attracted to structures, } \\
\text { artificial reef effect }\end{array}$ & $\begin{array}{l}\text { Negligible, } \\
\text { potentially beneficial }\end{array}$ & None proposed & $\begin{array}{l}\text { DPLA 5.3.3 Marine Resources } \\
\text { 5.3.3.2.5 Structure } \\
\text { Page 5.3.3-39 }\end{array}$ \\
\hline $\begin{array}{l}\text { Electric and Magnetic } \\
\text { Fields. Effects unlikely, } \\
\text { species not known to } \\
\text { have sensitive } \\
\text { electroreceptors }\end{array}$ & Negligible & None proposed & $\begin{array}{l}\text { DPLA 5.3.3 Marine Resources } \\
\text { 5.3.3.2.6 Electric and Magnetic Fields, } \\
\text { Page 5.3.3-41 }\end{array}$ \\
\hline \multicolumn{4}{|l|}{ Salmonids } \\
\hline $\begin{array}{l}\text { Noise. Short-term } \\
\text { disturbance from } \\
\text { vessel, construction, } \\
\text { decommissioning noise }\end{array}$ & $\begin{array}{l}\text { Negligible due to } \\
\text { species' motility and } \\
\text { short duration }\end{array}$ & None proposed & $\begin{array}{l}\text { DPLA 5.3.3 Marine Resources } \\
\text { 5.3.3.2.4 Noise } \\
\text { Page 5.3.3-37 } \\
\text { DPLA 5.3.6 Threatened and Endangered } \\
\text { Species } \\
\text { 5.3.6.2 Environmental Impacts and } \\
\text { Recommendations } \\
\text { Page 5.3.6-76 }\end{array}$ \\
\hline $\begin{array}{l}\text { Contaminants. } \\
\text { Chemical compounds } \\
\text { may be toxic. }\end{array}$ & $\begin{array}{l}\text { Negligible, volumes } \\
\text { released very low, } \\
\text { and species can } \\
\text { move away from } \\
\text { releases }\end{array}$ & None proposed & $\begin{array}{l}\text { DPLA 5.3.3 Marine Resources } \\
\text { 5.3.3.2.1 Contaminants, } \\
\text { Page 5.3.3-36 } \\
\text { DPLA 5.3.6 Threatened and Endangered } \\
\text { Species } \\
\text { 5.3.6.2 Environmental Impacts and } \\
\text { Recommendations } \\
\text { Page 5.3.6-77 }\end{array}$ \\
\hline $\begin{array}{l}\text { Artificial lighting. } \\
\text { Aggregation at bright } \\
\text { deck lights, } \\
\text { construction and } \\
\text { decommissioning } \\
\text { lights, navigation and } \\
\text { safety lights could } \\
\text { expose species to } \\
\text { predation }\end{array}$ & Minor adverse & $\begin{array}{l}\text { Minimize lights or limit } \\
\text { construction and } \\
\text { decommissioning to } \\
\text { daylight hours; none } \\
\text { proposed for } \\
\text { navigation and safety } \\
\text { lights }\end{array}$ & $\begin{array}{l}\text { DPLA 5.3.3 Marine Resources } \\
\text { 5.3.3.2.2 Artificial Lighting, } \\
\text { Page 5.3.3-36-37 } \\
\text { DPLA 5.3.6 Threatened and Endangered } \\
\text { Species } \\
\text { 5.3.6.2 Environmental Impacts and } \\
\text { Recommendations } \\
\text { Page 5.3.6-77 }\end{array}$ \\
\hline
\end{tabular}




\begin{tabular}{|c|c|c|c|}
\hline Effect on Species & $\begin{array}{l}\text { Degree of Effect } \\
\text { (Negligible, Minor } \\
\text { Adverse, Adverse, } \\
\text { or Unknown) }\end{array}$ & $\begin{array}{l}\text { Possible Mitigation } \\
\text { and Monitoring } \\
\text { ("Proposed } \\
\text { Environmental } \\
\text { Measures") }\end{array}$ & DPLA Reference \\
\hline $\begin{array}{l}\text { Structures. Species not } \\
\text { known to be attracted } \\
\text { to structures }\end{array}$ & $\begin{array}{l}\text { Negligible, not } \\
\text { known to be } \\
\text { attracted to } \\
\text { structures }\end{array}$ & None proposed & $\begin{array}{l}\text { DPLA 5.3.3 Marine Resources } \\
\text { 5.3.3.2.5 Structure } \\
\text { Page 5.3.3-39 } \\
\text { DPLA 5.3.6 Threatened and Endangered } \\
\text { Species } \\
\text { 5.3.6.2 Environmental Impacts and } \\
\text { Recommendations } \\
\text { Page 5.3.6-78 }\end{array}$ \\
\hline $\begin{array}{l}\text { Electric and Magnetic } \\
\text { Fields. Effects unlikely, } \\
\text { species not known to } \\
\text { be sensitive }\end{array}$ & Negligible & None proposed & $\begin{array}{l}\text { DPLA 5.3.3 Marine Resources } \\
\text { 5.3.3.2.6 Electric and Magnetic Fields, } \\
\text { Page 5.3.3-41 } \\
\text { DPLA 5.3.6 Threatened and Endangered } \\
\text { Species } \\
\text { 5.3.6.2 Environmental Impacts and } \\
\text { Recommendations } \\
\text { Page 5.3.6-78 }\end{array}$ \\
\hline \multicolumn{4}{|l|}{ Green Sturgeon } \\
\hline $\begin{array}{l}\text { Noise. Short-term } \\
\text { disturbance from } \\
\text { vessel, construction, } \\
\text { decommissioning noise }\end{array}$ & $\begin{array}{l}\text { Negligible due to } \\
\text { species' motility and } \\
\text { short duration }\end{array}$ & None proposed & $\begin{array}{l}\text { DPLA 5.3.3 Marine Resources } \\
\text { 5.3.3.2.4 Noise } \\
\text { Page 5.3.3-37 } \\
\text { DPLA 5.3.6 Threatened and Endangered } \\
\text { Species } \\
\text { 5.3.6.2 Environmental Impacts and } \\
\text { Recommendations } \\
\text { Page 5.3.6-76 }\end{array}$ \\
\hline $\begin{array}{l}\text { Contaminants. } \\
\text { Chemical compounds } \\
\text { may be toxic. }\end{array}$ & $\begin{array}{l}\text { Negligible, volumes } \\
\text { released very low, } \\
\text { and species can } \\
\text { move away from } \\
\text { releases }\end{array}$ & None proposed & $\begin{array}{l}\text { DPLA 5.3.3 Marine Resources } \\
\text { 5.3.3.2.1 Contaminants, } \\
\text { Page 5.3.3-36 } \\
\text { DPLA 5.3.6 Threatened and Endangered } \\
\text { Species } \\
\text { 5.3.6.2 Environmental Impacts and } \\
\text { Recommendations } \\
\text { Page 5.3.6-77 }\end{array}$ \\
\hline $\begin{array}{l}\text { Artificial lighting. } \\
\text { Species not known to } \\
\text { aggregate around } \\
\text { lights }\end{array}$ & Negligible & None proposed & $\begin{array}{l}\text { DPLA 5.3.3 Marine Resources } \\
\text { 5.3.3.2.2 Artificial Lighting, } \\
\text { Page 5.3.3-36-37 } \\
\text { DPLA 5.3.6 Threatened and Endangered } \\
\text { Species } \\
\text { 5.3.6.2 Environmental Impacts and } \\
\text { Recommendations } \\
\text { Page 5.3.6-77 }\end{array}$ \\
\hline
\end{tabular}




\begin{tabular}{|c|c|c|c|}
\hline Effect on Species & $\begin{array}{l}\text { Degree of Effect } \\
\text { (Negligible, Minor } \\
\text { Adverse, Adverse, } \\
\text { or Unknown) }\end{array}$ & $\begin{array}{l}\text { Possible Mitigation } \\
\text { and Monitoring } \\
\text { ("Proposed } \\
\text { Environmental } \\
\text { Measures") }\end{array}$ & DPLA Reference \\
\hline $\begin{array}{l}\text { Structures. Species not } \\
\text { known to be attracted } \\
\text { to structures }\end{array}$ & $\begin{array}{l}\text { Negligible, not } \\
\text { known to be } \\
\text { attracted to } \\
\text { structures }\end{array}$ & None proposed & $\begin{array}{l}\text { DPLA 5.3.3 Marine Resources } \\
\text { 5.3.3.2.5 Structure } \\
\text { Page 5.3.3-39 } \\
\text { DPLA 5.3.6 Threatened and Endangered } \\
\text { Species } \\
\text { 5.3.6.2 Environmental Impacts and } \\
\text { Recommendations } \\
\text { Page 5.3.6-78 }\end{array}$ \\
\hline $\begin{array}{l}\text { Electric and Magnetic } \\
\text { Fields. Highly } \\
\text { receptive. Possible } \\
\text { disorientation, } \\
\text { behavioral changes, } \\
\text { interference with } \\
\text { migration }\end{array}$ & $\begin{array}{l}\text { Unknown electric } \\
\text { and magnetic field } \\
\text { exposures from } \\
\text { power cables or } \\
\text { WECs, unknown } \\
\text { responses }\end{array}$ & $\begin{array}{l}\text { Shielding and burial } \\
\text { of cables, "Faraday } \\
\text { cages" around } \\
\text { devices }\end{array}$ & $\begin{array}{l}\text { DPLA 5.3.3 Marine Resources } \\
\text { 5.3.3.2.6 Electric and Magnetic Fields, } \\
\text { Page 5.3.3-41 } \\
\text { DPLA 5.3.6 Threatened and Endangered } \\
\text { Species } \\
\text { 5.3.6.2 Environmental Impacts and } \\
\text { Recommendations } \\
\text { Page 5.3.6-78 }\end{array}$ \\
\hline \multicolumn{4}{|l|}{ Essential Fish Habitat } \\
\hline $\begin{array}{l}\text { Structure. Habitat } \\
\text { conversion or loss for } \\
\text { some species, creates } \\
\text { habitat for others (fish } \\
\text { aggregation device } \\
\text { [FAD] and artificial reef } \\
\text { effects) }\end{array}$ & Minor adverse & $\begin{array}{l}\text { Minimize ability for } \\
\text { pinniped haul-out and } \\
\text { seabird roosting }\end{array}$ & $\begin{array}{l}\text { DPLA 5.3.3 Marine Resources } \\
\text { 5.3.3.3 Potential Effects of the Project on } \\
\text { Essential Fish Habitat, } \\
\text { Page 5.3.3-43 }\end{array}$ \\
\hline $\begin{array}{l}\text { Degradation of water } \\
\text { quality }\end{array}$ & Minor adverse & $\begin{array}{l}\text { Handle and use all } \\
\text { lubricants, fuels, } \\
\text { solvents, etc. } \\
\text { following standard } \\
\text { and required safety } \\
\text { procedures }\end{array}$ & $\begin{array}{l}\text { DPLA 5.3.3 Marine Resources } \\
\text { 5.3.3.3 Potential Effects of the Project on } \\
\text { Essential Fish Habitat, } \\
\text { Page 5.3.3-43 }\end{array}$ \\
\hline $\begin{array}{l}\text { Change of sediment, } \\
\text { bottom substrate }\end{array}$ & Minor adverse & None proposed & $\begin{array}{l}\text { DPLA 5.3.3 Marine Resources } \\
\text { 5.3.3.3 Potential Effects of the Project on } \\
\text { Essential Fish Habitat, } \\
\text { Page 5.3.3-43 }\end{array}$ \\
\hline $\begin{array}{l}\text { Electric and Magnetic } \\
\text { Fields. Possible } \\
\text { disorientation and } \\
\text { behavioral changes }\end{array}$ & Unknown & $\begin{array}{l}\text { Shielding and burial } \\
\text { of cables, "Faraday } \\
\text { cages" around } \\
\text { devices }\end{array}$ & $\begin{array}{l}\text { DPLA 5.3.3 Marine Resources } \\
\text { 5.3.3.2.6 Electric and Magnetic Fields, } \\
\text { Page 5.3.3-41 } \\
\text { DPLA 5.3.3 Marine Resources } \\
\text { 5.3.3.3 Potential Effects of the Project on } \\
\text { Essential Fish Habitat, } \\
\text { Page 5.3.3-43 }\end{array}$ \\
\hline
\end{tabular}




\subsubsection{Monitoring and Adaptive Management Plans}

The FERC pilot license procedures require the submittal of MAMPs that specify measures the project owner will take to monitor the project area before and after construction to determine whether there are unforeseen environmental impacts. If such impacts occur, then the MAMPs specify adaptive management measures that could be taken to reduce or eliminate them, or a process by which such measures could be devised and discussed with regulatory agencies. While in most instances the environmental permitting process is designed to foresee environmental impacts, disclose them, and develop measures to avoid or mitigate them, adaptive management recognizes that there may be unforeseen impacts. This is particularly the case with untested technologies such as hydrokinetic power generation.

The fundamental strategy behind the MAMPs was to monitor key resources (e.g., species listed under the federal and California Endangered Species Acts), with decision points to continue monitoring where issues were observed, suspend monitoring after a reasonable effort where no issues were detected, and re-initiate monitoring if an issue of concern were to resurface.

PG\&E developed MAMPs in consultation with the appropriate regulatory agencies and included them as appendices to the DPLA. These included MAMPs for the following:

\section{Marine Mammals}

The MAMP for marine mammals addressed several questions, including (1) would whales become entangled in derelict fishing gear, leading to injury or death; (2) would WEC noise cause injury or behavioral disturbance to whales; (3) would pinnipeds be attracted to WECs for haulout, leading to injury and over-predation on salmon in the WEC vicinity?

\section{Marine Fish and Invertebrates}

The MAMP for fish and invertebrates addressed the following: (1) would the WECs act as fish attraction devices, concentrating prey and leading to increased predation on listed species such as salmon; (2) would WEC mooring anchors create an artificial reef, resulting in fish aggregation and possible increased predation on listed species; (3) would electric and magnetic fields generated by the subsea transmission cable interfere with the migration behavior of the endangered green sturgeon or (4) the behavior and movement patterns of Dungeness crab?

\section{Seabirds}

The MAMP for seabirds addressed the following: (1) would the WECs' lights attract seabirds and increase the risk of collision, injury, and death; (2) would diving seabirds become entangled in derelict fishing gear, leading to injury or death; (3) would seabirds be exposed to hazardous chemicals; (4) would seabirds be attracted to the WECs for roosting, nesting, and foraging and, as a result, be exposed to injury or death due to collision, entanglement, and exposure? 
Discussions regarding the MAMPs continued after submittal of the DPLA and up to the time at which PG\&E suspended work on the Humboldt Project. PG\&E met with the resources agencies to discuss the MAMPs and monitoring approaches, and the MAMPs were being revised at the time of project suspension. The permitting agencies had not formally approved the MAMPs at that time, however. The potential cost of implementing agency recommendations regarding monitoring and adaptive management for a project on this scale was one factor in PG\&E's determination that implementing Humboldt WaveConnect could become economically infeasible. The revised draft MAMPs existing at the time of project suspension are provided in Appendix 5-3.

\subsection{Public and Agency Comment}

The DPLA was filed on March 1, 2010. FERC announced a Notice of Intent to file license application, filing of draft application, and request for waivers of integrated licensing process regulations necessary for expedited processing of a hydrokinetic pilot project license application, and requested comments from stakeholders and interested parties within 60 days (by April 30, 2010). In addition to comments from FERC, comments received during this time included those from the following 10 parties:

- California Coastal Commission

- California Department of Fish and Game

- California State Lands Commission

- California State Water Resources Control Board

- Federal Energy Regulatory Commission

- Fishermen Interested in Safe Hydrokinetics Committee

- Humboldt Fishermen's Marketing Association

- Margaret Herbelin, member of the public

- National Oceanic and Atmospheric Administration, National Marine Fisheries Service (NOAA Fisheries)

- United States Fish and Wildlife Service.

On May 5, 2010, FERC in conjunction with the California State Lands Commission (CSLC) hosted two public meetings, the purpose of which was to invite participation from the public; to discuss the proposed project, and information and monitoring needs for a pilot project license; and to obtain agency and public views on the scope and content of the environmental information and analysis to be included in the draft Environmental Impact Report. The meetings were held on June 9, at 12:00 p.m. and at 6:30 p.m., pursuant to 18 Code of Federal Regulations (CFR) 5.3 of the Commission's regulations and Section 15083, Title 14, California Code of Regulations (CCR). 
Two public speakers commented in support of the HWCP. Written public and agency comments were received between May 26 and June 25, 2010, and were submitted either electronically to FERC or by hard copy to CSLC.

Altogether, more than 300 responses on specific issues were received from state and federal agencies that submitted written comments on the DPLA. The comments ranged from observations on the FERC licensing procedures to requests for clarification or additional analysis. The comments pertained to all sections of the DPLA including the license application, Exhibit E, F, and G. With respect to Exhibit E, the comments touched on all environmental resource areas; however, the majority of the comments focused on potential impacts to marine and coastal wildlife due to loss or change in habitat, gear entanglement, underwater noise, and MAMPs. Appendix 5-4 contains a copy of all agency and stakeholder comments.

\subsubsection{Comment Classification}

Table 4-6 summarizes the types of agency comments received and categorizes them as either "editorial/procedural," indicating an editorial comment (i.e. text revision) with minimal effort to address; "additional analysis," indicating that the commenter requests additional or revised analysis requiring no additional field work but moderate effort to address; and "data collection," indicating that the commenter requests new or additional data collection and analysis requiring a significant level of effort to address. Table 4-7 (next page) summarizes the most significant comments (i.e. those identified as "additional analysis" or "data collection") that were received, grouped by topic area.

Table 4-6: Frequency of HWCP Agency Comments by Type

\begin{tabular}{|c|c|c|c|c|}
\hline \multirow[b]{2}{*}{ Agency } & \multicolumn{3}{|c|}{ Number of Comments Received } & \multirow[b]{2}{*}{$\begin{array}{c}\text { Total } \\
\text { Comments }\end{array}$} \\
\hline & $\begin{array}{l}\text { Editorial/ } \\
\text { Procedural }\end{array}$ & $\begin{array}{c}\text { Requires } \\
\text { Additional } \\
\text { Analysis but No } \\
\text { Data Collection }\end{array}$ & $\begin{array}{c}\text { Requires } \\
\text { Additional Data } \\
\text { Collection and } \\
\text { Analysis }\end{array}$ & \\
\hline $\begin{array}{l}\text { California Coastal } \\
\text { Commission }\end{array}$ & 1 & - & - & 1 \\
\hline $\begin{array}{l}\text { California Department of } \\
\text { Fish and Game }\end{array}$ & 1 & 11 & 5 & 17 \\
\hline $\begin{array}{l}\text { California State Lands } \\
\text { Commission }\end{array}$ & 26 & 21 & 4 & 51 \\
\hline $\begin{array}{l}\text { California State Water } \\
\text { Resources Control Board }\end{array}$ & 1 & - & - & 1 \\
\hline $\begin{array}{l}\text { National Marine Fisheries } \\
\text { Service }\end{array}$ & 55 & 129 & 17 & 201 \\
\hline $\begin{array}{l}\text { U.S. Fish and Wildlife } \\
\text { Service }\end{array}$ & 10 & 13 & 4 & 27 \\
\hline FERC & 13 & 35 & 1 & 49 \\
\hline Total & 107 & 177 & 22 & 347 \\
\hline
\end{tabular}


Table 4-7: Comment Classification, and Cost and Schedule Implications for Addressing Significant Comments

\begin{tabular}{|c|c|c|c|c|}
\hline Comment & $\begin{array}{c}\text { Agencyl } \\
\text { Agencies } \\
\text { that } \\
\text { Commented }\end{array}$ & $\begin{array}{l}\text { Approx. } \\
\text { Cost to } \\
\text { Address or } \\
\text { Implement }\end{array}$ & $\begin{array}{l}\text { Schedule } \\
\text { to Address }\end{array}$ & Additional Notes \\
\hline \multicolumn{5}{|l|}{ Wave Energy Conversion Devices } \\
\hline $\begin{array}{l}\text { Several of the commenters noted that } \\
\text { PG\&E adopted a conservative project } \\
\text { design "envelope" approach to } \\
\text { environmental analysis in the DPLA, } \\
\text { under which PG\&E assumed that } \\
\text { each of the available WEC design } \\
\text { types appropriate for the HWCP site } \\
\text { would participate in the HWCP. } \\
\text { Several of the commenters indicated } \\
\text { an expectation that WECs would be } \\
\text { described more specifically in the } \\
\text { FPLA. One of the commenters, the } \\
\text { USFWS, stated the following: } \\
\text { In order for the Service to analyze } \\
\text { potential effects of WECs on its trust } \\
\text { resources, detailed descriptions of } \\
\text { any potential WEC device that could } \\
\text { be deployed in the Project must be } \\
\text { included in the FPLA (USFWS } \\
\text { General Comment 5). }\end{array}$ & $\begin{array}{l}\text { USFWS } \\
\text { CDFG } \\
\text { USFWS } \\
\text { NMFS } \\
\text { FERC }\end{array}$ & $\begin{array}{l}\$ 50,000 \text { to } \\
\$ 100,000\end{array}$ & $\begin{array}{l}2 \text { to } 4 \\
\text { months }\end{array}$ & $\begin{array}{l}\text { Comment points to a } \\
\text { fundamental } \\
\text { challenge with } \\
\text { project approach: A } \\
\text { programmatic } \\
\text { approach } \\
\text { (appropriate for a } \\
\text { demonstration } \\
\text { facility or pilot } \\
\text { project) where WEC } \\
\text { devices are only } \\
\text { generally described } \\
\text { vs. detailed design } \\
\text { criteria for specific } \\
\text { "chosen" WEC } \\
\text { devices. Agencies } \\
\text { preferred the latter } \\
\text { in order to } \\
\text { characterize } \\
\text { potential impacts. }\end{array}$ \\
\hline $\begin{array}{l}\text { Provide a simulation of all of the } \\
\text { devices. }\end{array}$ & CSLC & $\begin{array}{l}\$ 100,000 \text { to } \\
\$ 500,000\end{array}$ & $\begin{array}{l}4 \text { weeks to } \\
6 \text { months }\end{array}$ & $\begin{array}{l}\text { This is dependent } \\
\text { on number of } \\
\text { devices and } \\
\text { configuration; see } \\
\text { above comment }\end{array}$ \\
\hline \multicolumn{5}{|c|}{ Additional Baseline or Environmental Data } \\
\hline $\begin{array}{l}\text { Commenters noted that project } \\
\text { effects could not be understood } \\
\text { without adequate baseline information } \\
\text { against which to measure any } \\
\text { changes. As a result, additional } \\
\text { baseline studies are warranted, } \\
\text { including a benthic and pelagic } \\
\text { community study, sedimentation } \\
\text { study, bathymetric study, and } \\
\text { shipwreck study. Agencies stated that } \\
\text { they should be engaged in the } \\
\text { development of baseline studies. } \\
\text { Humboldt State University (HSU) was } \\
\text { awarded several contracts by PG\&E } \\
\text { to perform baseline surveys and } \\
\text { studies for the HWCP. However, as } \\
\text { the agencies commented, the }\end{array}$ & $\begin{array}{l}\text { USFWS } \\
\text { CSLC } \\
\text { CDFG } \\
\text { USFWS } \\
\text { NMFS } \\
\text { FERC }\end{array}$ & $\begin{array}{l}\$ 500,000 \text { to } \\
\$ 3 \text { million }\end{array}$ & $\begin{array}{l}12 \text { months } \\
\text { to } 24 \\
\text { months }\end{array}$ & $\begin{array}{l}\text { The lack of available } \\
\text { baseline data was a } \\
\text { major challenge of } \\
\text { the FERC Pilot } \\
\text { licensing process. } \\
\text { Especially for those } \\
\text { agencies that had } \\
\text { ESA/CESA } \\
\text { protection } \\
\text { responsibilities. The } \\
\text { adequacy of the } \\
\text { HSU studies to fulfill } \\
\text { baseline data needs } \\
\text { was never resolved. }\end{array}$ \\
\hline
\end{tabular}




\begin{tabular}{|c|c|c|c|c|}
\hline Comment & $\begin{array}{l}\text { Agencyl } \\
\text { Agencies } \\
\text { that } \\
\text { Commented }\end{array}$ & $\begin{array}{l}\text { Approx. } \\
\text { Cost to } \\
\text { Address or } \\
\text { Implement }\end{array}$ & $\begin{array}{l}\text { Schedule } \\
\text { to Address }\end{array}$ & Additional Notes \\
\hline \multicolumn{5}{|l|}{$\begin{array}{l}\text { proposals for these studies were not } \\
\text { discussed with or evaluated by the } \\
\text { resource agencies prior to issuance of } \\
\text { the contracts. Therefore, there is } \\
\text { agency concern that it is possible that } \\
\text { the baseline data collected by HSU } \\
\text { will not meet the agency's needs. In } \\
\text { addition, the environmental analyses } \\
\text { in the DPLA lacked the baseline data } \\
\text { to be collected by these studies. }\end{array}$} \\
\hline \multicolumn{5}{|l|}{ Electric and Magnetic Fields (EMF) } \\
\hline $\begin{array}{l}\text { Two agencies commented that } \\
\text { additional information on EMF was } \\
\text { needed. Specifically, an evaluation of } \\
\text { EMF effects on marine species } \\
\text { associated with a matrix of power } \\
\text { cables in the water column and along } \\
\text { the bottom since affects are likely to } \\
\text { be different than one submarine } \\
\text { power cable. This situation needs to } \\
\text { be evaluated for the entire period of } \\
\text { operation. In addition, the potential } \\
\text { effects of shutting down and restarting } \\
\text { WEC operations (e.g., fluctuating } \\
\text { EMFs and noise) should also be } \\
\text { discussed. }\end{array}$ & $\begin{array}{l}\text { CDFG } \\
\text { NMFS }\end{array}$ & $\begin{array}{l}\$ 300,000 \text { to } \\
\$ 500,000\end{array}$ & 5 years & $\begin{array}{l}\text { The MAMPs that } \\
\text { were proposed for } \\
\text { the project } \\
\text { contained decision } \\
\text { points where studies } \\
\text { could be reduced if } \\
\text { no impacts were } \\
\text { detected. Several } \\
\text { agencies felt that } \\
\text { studies should } \\
\text { continue for the } \\
\text { duration of project } \\
\text { operations } \\
\text { regardless of initial } \\
\text { findings, due to the } \\
\text { potential for take of } \\
\text { green sturgeon. }\end{array}$ \\
\hline \multicolumn{5}{|l|}{ Air Quality } \\
\hline $\begin{array}{l}\text { One agency requested a greenhouse } \\
\text { gas }(\mathrm{GHG}) \text { analysis consistent with } \\
\mathrm{AB} 32 \text { and subsequent legislation, } \\
\text { including a quantification of } \mathrm{GHGs} \\
\text { from construction, operation, and } \\
\text { maintenance activities. }\end{array}$ & CSLC & $\begin{array}{l}\$ 5,000 \text { to } \\
\$ 15,000\end{array}$ & 4-6 weeks & \\
\hline \multicolumn{5}{|l|}{ Noise } \\
\hline $\begin{array}{l}\text { The sound intensity and frequency } \\
\text { spectrum of individual WEC units are } \\
\text { most likely not the same as multiple } \\
\text { units (up to a maximum of } 30 \text { ) in } \\
\text { multiple arrays in the four berths. The } \\
\text { effects of noise on aquatic species } \\
\text { from both construction and operation } \\
\text { of WECs, as well as operation of } \\
\text { multiple WECs, will need to be } \\
\text { evaluated in the FPLA and studied } \\
\text { during operations of the HWCP. An }\end{array}$ & NMFS & $\begin{array}{l}\$ 50,000 \text { to } \\
\$ 500,000\end{array}$ & $\begin{array}{l}\text { 1-2 months } \\
\text { (need } \\
\text { seasonal } \\
\text { analysis) }\end{array}$ & $\begin{array}{l}\text { Data regarding } \\
\text { sound intensity and } \\
\text { frequency of specific } \\
\text { WEC devices is } \\
\text { largely unavailable. } \\
\text { This points to the } \\
\text { disparity between } \\
\text { what agencies } \\
\text { needed for impact } \\
\text { evaluation of public } \\
\text { trust resources }\end{array}$ \\
\hline
\end{tabular}




\begin{tabular}{|c|c|c|c|c|}
\hline Comment & $\begin{array}{l}\text { Agencyl } \\
\text { Agencies } \\
\text { that } \\
\text { Commented }\end{array}$ & $\begin{array}{l}\text { Approx. } \\
\text { Cost to } \\
\text { Address or } \\
\text { Implement }\end{array}$ & $\begin{array}{l}\text { Schedule } \\
\text { to Address }\end{array}$ & Additional Notes \\
\hline $\begin{array}{l}\text { approximation of time of exposure } \\
\text { and level of exposure should also be } \\
\text { included. }\end{array}$ & & & & $\begin{array}{l}\text { versus a pilot or } \\
\text { demonstration } \\
\text { facility where such } \\
\text { information would be } \\
\text { collected. }\end{array}$ \\
\hline \multicolumn{5}{|c|}{ Monitoring and Adaptive Management Plans } \\
\hline $\begin{array}{l}\text { All three plans have limited sampling } \\
\text { periods of one to two years with } \\
\text { decision points to end the monitoring. } \\
\text { CDFG believes that the project should } \\
\text { be monitored the entire period of } \\
\text { operation, regardless of number of } \\
\text { years or outcome of sampling to } \\
\text { collect as much data as possible. }\end{array}$ & CDFG & $\begin{array}{l}\$ 6.9 \text { million } \\
\text { (cumulative } \\
\text { costs; } \\
\text { resource- } \\
\text { specific } \\
\text { details } \\
\text { shown } \\
\text { below) }\end{array}$ & $5-6$ years & $\begin{array}{l}\text { The scientific } \\
\text { method cannot } \\
\text { prove that there are } \\
\text { no impacts from a } \\
\text { proposed project. } \\
\text { Since uncertainty } \\
\text { will always exist } \\
\text { perpetual monitoring } \\
\text { is often proposed as } \\
\text { an alternative to } \\
\text { decision making. }\end{array}$ \\
\hline $\begin{array}{l}\text { NMFS recommends pre- and post- } \\
\text { installation surveys for ambient noise. }\end{array}$ & NMFS & $\$ 100,000$ & $\begin{array}{l}2 \text { months + } \\
\text { seasonal } \\
\text { variation }\end{array}$ & $\begin{array}{l}\text { Part of the proposed } \\
\text { approach was to } \\
\text { collect more } \\
\text { baseline data during } \\
\text { the two years prior } \\
\text { to WEC device } \\
\text { installation. }\end{array}$ \\
\hline $\begin{array}{l}\text { Fish and Invertebrates. Fish } \\
\text { populations should be monitored in } \\
\text { the HWCP site and control sites prior } \\
\text { to construction to determine fish } \\
\text { attraction (FAD) effects. Once the } \\
\text { appropriate questions and } \\
\text { hypotheses are developed, sampling } \\
\text { methodology and frequency will likely } \\
\text { need to be modified and should be } \\
\text { developed transparently among } \\
\text { PG\&E and resources agencies and } \\
\text { other interested stakeholders as } \\
\text { appropriate. }\end{array}$ & $\begin{array}{l}\text { NMFS } \\
\text { CDFG }\end{array}$ & $\begin{array}{l}\$ 500,000- \\
\$ 1 \text { million }\end{array}$ & 5 years & $\begin{array}{l}\text { Monitoring for FAD } \\
\text { was included in the } \\
\text { original MAMPs, } \\
\text { although this } \\
\text { comment implies } \\
\text { that monitoring } \\
\text { would be modified } \\
\text { by agencies and } \\
\text { continue indefinitely. }\end{array}$ \\
\hline $\begin{array}{l}\text { Fish and Invertebrates. A thorough } \\
\text { discussion between the Applicant and } \\
\text { NMFS is warranted regarding the } \\
\text { monitoring and adaptive management } \\
\text { plan for green sturgeon. }\end{array}$ & NMFS & \$1million + & 5 years & $\begin{array}{l}\text { Agencies requested } \\
\text { a much more } \\
\text { elaborate and } \\
\text { extensive monitoring } \\
\text { program than } \\
\text { proposed due to the } \\
\text { potential for take of } \\
\text { green sturgeon. }\end{array}$ \\
\hline $\begin{array}{l}\text { Marine Mammals: Infrared cameras } \\
\text { should be used to detect hauled out }\end{array}$ & NMFS & $\begin{array}{l}\$ 500,000- \\
\$ 1 \text { million }\end{array}$ & 5 years & $\begin{array}{l}\text { This method of } \\
\text { monitoring could be }\end{array}$ \\
\hline
\end{tabular}




\begin{tabular}{|c|c|c|c|c|}
\hline Comment & $\begin{array}{l}\text { Agencyl } \\
\text { Agencies } \\
\text { that } \\
\text { Commented }\end{array}$ & $\begin{array}{l}\text { Approx. } \\
\text { Cost to } \\
\text { Address or } \\
\text { Implement }\end{array}$ & $\begin{array}{c}\text { Schedule } \\
\text { to Address }\end{array}$ & Additional Notes \\
\hline $\begin{array}{l}\text { animals or migrating whales (i.e., the } \\
\text { heat from the blow would be picked } \\
\text { up by the sensor). }\end{array}$ & & & & $\begin{array}{l}\text { expensive, } \\
\text { depending on the } \\
\text { number of cameras } \\
\text { that are required, }\end{array}$ \\
\hline $\begin{array}{l}\text { Marine Mammals: Use autonomous } \\
\text { recorders to detect ambient noise and } \\
\text { changes in noise levels pre- and post- } \\
\text { installation, including boat traffic noise } \\
\text { through the area. }\end{array}$ & NMFS & $\begin{array}{l}\$ 500,000- \\
\$ 1 \text { million }\end{array}$ & 5 years & $\begin{array}{l}\text { The use of } \\
\text { autonomous } \\
\text { recorders was } \\
\text { included in the } \\
\text { MAMPs. }\end{array}$ \\
\hline $\begin{array}{l}\text { Marine Mammals: Acoustic } \\
\text { monitoring is limited to detecting } \\
\text { those animals that vocalize. } \\
\text { Therefore, NMFS suggests this } \\
\text { technique should be used in } \\
\text { conjunction with other methods of } \\
\text { observation, as well. }\end{array}$ & NMFS & $\begin{array}{l}\$ 50,000- \\
\$ 500,000\end{array}$ & 5 years & $\begin{array}{l}\text { Adding boat or } \\
\text { shore based } \\
\text { monitoring can } \\
\text { expand a monitoring } \\
\text { program significantly }\end{array}$ \\
\hline $\begin{array}{l}\text { Seabirds: In order to evaluate } \\
\text { deposition rates and locations, beach } \\
\text { carcass surveys should occur along } \\
\text { the entire lengths of the following } \\
\text { beaches: South Spit; beach at the } \\
\text { mouth of the Elk River inside } \\
\text { Humboldt Bay; beach from Ma-l'el } \\
\text { Dunes north to Mad River County } \\
\text { Park; and, beaches from Mad River } \\
\text { County Park north to the mouth of the } \\
\text { Little River. }\end{array}$ & USFWS & \$1million + & 5 years & $\begin{array}{l}\text { The use of beach } \\
\text { carcass surveys as } \\
\text { an effective } \\
\text { measure of bird } \\
\text { strike impacts at } \\
\text { WEC devices } \\
\text { located } 2.5-3 \mathrm{mi} \\
\text { from shore was } \\
\text { controversial due to } \\
\text { the inability to } \\
\text { conclusively } \\
\text { determine that WEC } \\
\text { devices directly } \\
\text { caused morality of } \\
\text { the bird. }\end{array}$ \\
\hline $\begin{array}{l}\text { Seabirds: Resource agency } \\
\text { recommends extending the } \\
\text { monitoring and adaptive management } \\
\text { program as necessary to satisfy } \\
\text { monitoring issues one through four, } \\
\text { regardless of duration as necessary } \\
\text { to evaluate and asses impacts } \\
\text { associated with HWCP. The Seabird } \\
\text { Plan should be robust, statistically } \\
\text { valid, and sampling effort should be } \\
\text { supported by the best available } \\
\text { science. }\end{array}$ & CDFG & $\$ 1$ million + & 5 years & $\begin{array}{l}\text { Limits of scientific } \\
\text { method and } \\
\text { resulting uncertainty } \\
\text { result in request for } \\
\text { extended } \\
\text { monitoring. }\end{array}$ \\
\hline
\end{tabular}


Table 4-8 shows a summary of the costs associated with MAMP activities as described in Table 4-7.

Table 4-8: Monitoring and Adaptive Management (MAMP) Cost for 5-Year Pilot Project Operation

\begin{tabular}{|l|c|c|c|}
\hline & $\begin{array}{c}\text { Cost per Year } \\
\text { (Thousands } \$ \text { ) }\end{array}$ & $\begin{array}{c}\text { Total Effort } \\
\text { Time }\end{array}$ & $\begin{array}{c}\text { Total Cost } \\
\text { (Thousands \$) }\end{array}$ \\
\hline $\begin{array}{l}\text { NMFS recommends pre- and post- installation } \\
\text { surveys for ambient noise. }\end{array}$ & $\$ 600 / \mathrm{yr}$ & 0.167 year & $\$ 100$ \\
\hline $\begin{array}{l}\text { Monitor Fish populations prior to construction to } \\
\text { determine (FAD) effects. }\end{array}$ & $\$ 200 / \mathrm{yr}$ & 5 years & $\$ 1,000$ \\
\hline Marine Mammals: Infrared cameras & $\$ 200 / \mathrm{yr}$ & 5 years & $\$ 1,000$ \\
\hline $\begin{array}{l}\text { Marine Mammals: Use autonomous noise } \\
\text { recorders. }\end{array}$ & $\$ 200 / \mathrm{yr}$ & 6 years & $\$ 1,200$ \\
\hline $\begin{array}{l}\text { Marine Mammals: Acoustic monitoring with } \\
\text { other methods of observations }\end{array}$ & $\$ 200 / \mathrm{yr}$ & 6 years & $\$ 600$ \\
\hline Seabirds: Beach carcass surveys & $\$ 100 / \mathrm{yr}$ & 5 years & $\$ 600$ \\
\hline $\begin{array}{l}\text { Seabirds: Extended MAMP supported by the } \\
\text { best available science }\end{array}$ & $\$ 200 / \mathrm{yr}$ & 5 years & $\$ 1,000$ \\
\hline Total MAMP Cost & & & $\$ 6,900$ \\
\hline
\end{tabular}

\subsection{Additional Efforts Needed to Secure the Pilot License}

Had PG\&E gone forward with the project beyond the point of suspension, the next steps would have been as follows:

- Work with the regulatory agencies to address the concerns and information requested in their comments on the DPLA. Per FERC procedures, one or more Technical Conferences might have been needed to resolve issues, concerns, and information requests. A FERC-noticed Technical Conference was held.

- Resubmit to FERC the revised MAMPs. Upon receipt of the revised MAMPs FERC would allow stakeholders a 30-day comment period. At the end of this comment period, assuming that all concerns had been addressed, FERC would notice the conclusion of the pre-filing process and issue its determination on PG\&E's request for waiver (essentially, permission to use the pilot license procedures).

- After resolution of the questions, comments, and information requests, revise the DPLA to prepare the FPLA, containing the revised MAMPs, and file the document for review and final approval by FERC. This would formally initiate the post-filing activity. 
- Prepare and submit to FERC the Draft Biological Assessments (1) for terrestrial species and marine birds with the U.S. Fish and Wildlife Service and (2) for marine fish and mammals with NOAA Fisheries.

- Prepare and submit the Coastal Zone Management Act Consistency Determination Application. In California, this is an application for a Coastal Development Permit under the California Coastal Act (1) for on-shore facilities, with Humboldt County under the Approved Local Coastal Plan and (2) for off-shore facilities, with the California Coastal Commission and provides copies to FERC.

- Prepare and submit a Clean Water Act Section 401 Application for Water Quality Certification to the State Water Resources Control Board, provide a copy to FERC.

With these documents in hand, FERC would notice their acceptance of the FPLA, notice the FPLA as ready for environmental analysis, and issue a Request for Interventions. FERC would also formally issue the Biological Assessments with requests to U.S. Fish and Wildlife Service and NOAA Fisheries to begin formal consultation under Section 7 of the Endangered Species Act.

FERC would then collect recommendations, conditions, and comments on the FPLA, and issue its Environmental Assessment/FONSI for review and discussion. FERC would accept agency comments on the EA/FONSI, and resolve any issues under Section 10(j) of the Federal Power Act regarding agency conditions on the FERC license. The project would then be ready for FERC Commission Decision.

It is also possible that after conducting the environmental analysis FERC would have determined that there could be significant unmitigated adverse impacts and, therefore, the project would not qualify for a pilot license. Under those circumstances, the project would be required to seek a full FERC license under the standard Integrated Licensing Process. Also under these circumstances, the project would not be bound by a five-year licensing term or 5-MW licensing restrictions. The project could be configured as a larger project with a standard 30-year licensing term and would perhaps not be required to have a condition for emergency removal.

To summarize, assuming that FERC licensing would have been successfully completed, the project would need to obtain several additional authorizations to be ready to start construction. As mentioned, the following processes are integrated with the FERC licensing process as federal agency consultation processes (or federal processes delegated to state-level authority) and so would be part of the FERC licensing process:

- Endangered Species Act Section 7 Consultation-U.S. Fish and Wildlife and NOA Fisheries

- National Historic Preservation Act Section 106-California Office of Historic Preservation

- Clean Water Act Section 401-State Water Resources Control Board

- Clean Water Act Section 404-United States Army Corps of Engineers 
- $\quad$ Rivers and Harbors Act, Section 10 Permit

- Marine Mammals Protection Act Letter of Authorization-NOAA Fisheries

- Navigation and Navigable Waters Act Aids to Navigation Review-United States Coast Guard.

The time and effort that would have been required to complete the FERC license application and, subsequently or concurrently, the other authorizations (see also Section 4.4 below), is unknown. At the time of suspension, however, it was clear that the regulatory agencies could not move forward without additional information. Some of these information needs were outlined in the comments on the DPLA. It remained to be determined precisely what information would be required to complete permitting and also the time frame and phase of the permitting process within which it would be provided.

Table 4-7, above, broadly addresses the tasks that might have been necessary to address the DPLA comments, and the possible costs and schedule for doing so. This table includes both tasks and costs and their schedule for items that would be needed to prepare an FPLA that would be accepted by FERC as ready for environmental review as well as items that would be included in the MAMPs but that would be implemented during construction and operation.

Most importantly, the comments made it clear that an FPLA ready for FERC's environmental analysis would require more detailed information on the WEC devices and their moorings as well as additional baseline information. As stated, the lack of available baseline data was a major challenge of the FERC pilot licensing process, especially for those agencies that had listed species protection responsibilities. What was not entirely clear at the time of project suspension is exactly how much and what kind of baseline data would be sufficient to form the basis of the regulatory agency reviews. The schedule for delivery of this information was also not entirely resolved. The draft MAMPs proposed that a significant amount of baseline information from the final project site chosen would be developed after licensing but before construction began. This information would form the basis for controlled studies of the project's effects. That is, the baseline information proposed to be collected in the MAMPs was designed to form a basis for comparison of pre- and post-project conditions and to detect any unforeseen and adverse effects on the marine environment and sensitive species, but not to evaluate those effects in the first place. This approach assumed that existing information was sufficient for determining that the project would not have adverse effects on sensitive species that could not be mitigated. The question of what level of information would be required before licensing for federal and state regulatory agencies to be able to issue their authorizations remained in discussion at the time of suspension.

FERC pilot licensing procedures call for a technical conference to determine what changes might be needed to MAMPs or the DPLA before formally filing the FPLA. At the meetings of the Permitting Subcommittee of the Humboldt Working Group that were being held after the DPLA was issued, the extent of agency data needs for biological resources permitting was an important topic. In addition, PG\&E at the time was promulgating two initiatives to address this issue: 
- As described in Section 4.1.5, the RSL and KBO were under contract to PG\&E to analyze and prepare reports on population densities of marine birds and marine mammals. The RSL and KBO had collected this information from marine vessels working systematic transects in the project area for 20 years. The information resulting from these studies was not project site-focused, but because of its long-term nature and its ability to address questions of species density, had many advantages over baseline data that could have been gathered specifically for the project in one or two seasons.

- PG\&E had issued a Request for Proposals from HSU staff for PG\&E to fund research projects that would essentially provide environmental baseline information relevant to topics of specific interest to the regulatory agencies. HSU responded with a detailed proposal for several important studies, including studies of benthic invertebrates, a sampling study of marine fisheries, and field surveys for cetaceans and pinnepeds, among others.

At the time of suspension, the RSL and KBO had not completed their work (although the work continued and was completed in early 2011). Some of the HSU studies were implemented before the project was suspended, including baseline fish sampling, whale watching data, industry and tourist fleet statistics, fishing industry economics and statistics, boat population statistics, a benthic organisms study, a diffuser scour study, wave modeling, and sediment transport study. The HSU fisheries baseline study was completed in March 2011. The remaining studies were put on hold when the suspension occurred.

Had the project gone forward and had the project been delayed for sufficient time to allow for completion of the RSL/KBO and HSU studies, it is unclear whether the baseline information provided would have been sufficient for the purposes of FERC and the agencies to allow for completion of a DPL considered ready for environmental analysis. The cost of the RSL/KBO efforts was approximately $\$ 75,000$ and the cost of the HSU studies was approximately $\$ 500,000$. However, HSU indicated that it would take approximately one year to complete the studies. Once the studies were completed, it would have been necessary to discuss further with the regulatory agencies the adequacy of the baseline information for their final regulatory permitting analysis and whether additional surveys would be needed before filing the FPLA and completing the permitting process.

Three main scenarios would have been possible at this point:

- The biological resources agencies might have concluded that baseline information provided to date would be sufficient for them to make findings of potential effect on listed species, as long as a robust monitoring program were put in place to ensure against unforeseen impacts. The project costs moving forward in this case would have involved monthly costs to administer the program and continue the stakeholder process, costs of the California Environmental Quality Act (CEQA) analysis by State Lands Commission (see additional discussion below), and costs to obtain ancillary permits (CWA Section 401 and 404, etc.). Total additional permitting cost to obtaining the pilot license under this scenario would have been approximately $\$ 700,000$ to $\$ 1.2$ million. A significant part of this cost would have been 
payment to the California State Lands Commission for the preparation of its Environmental Impact Report.

- The biological resources agencies might have concluded that additional baseline studies conducted by RSL/KBO and HSU would be sufficient for them to make findings of potential effect on listed species. Submittal of the FPLA would have been delayed for six to 12 months, and FERC's environmental review would have taken an additional six months beyond that time. The cost of completing the licensing under this scenario would have been similar to that of Scenario \#1 except that there would have been approximately $\$ 600,000$ in additional costs for the RSL/KBO and HSU studies, and more if additional studies were deemed essential.

- The biological resources agencies might have concluded that only implementation of one or two years of robust studies of the project area (whales, fish, benthos, etc.) would be sufficient to form a basis for them to make findings of potential effect on listed species. Submittal of the FPLA would have been delayed for one or two years and licensing for two to three years. The potential cost of this scenario is difficult to predict. It might have involved a broad range of studies of various costs that, at the time of suspension, were considered as baseline studies for the MAMPs, to be conducted after licensing and before construction. As indicated in Table 4-7, these costs could have been substantial, ranging from $\$ 1$ million to $\$ 3$ million or more.

State agencies for parallel permitting processes could have requested additional information or studies to complete their authorization processes.

\subsection{Parallel Permitting Processes Required to Construct the Project}

Some of the additional and parallel permitting processes would have been entirely in local- or state-agency jurisdiction and not as closely integrated into the FERC licensing process as those listed above. If FERC were to resolve all of the issues associated with sister-agency permits and authorizations so that FERC was able to issue a license to PG\&E for the Humboldt Project, PG\&E would have to obtain authorization from state and local agencies before constructing the project. Most importantly, these are:

- Submerged Lands Lease-CSLC

- California Environmental Quality Act Notice of Determination-CSLC

- Coastal Development Permit (below mean high tide)-California Coastal Commission

- Coastal Development Permit (terrestrial areas within the coastal zone-Humboldt County as agency with delegated approval authority under the approved Local Coastal Plan

- California Endangered Species Act Incidental Take Authorization-California Department of Fish and Game. 
Because the leasing of submerged lands would involve a discretionary action by a California state agency, the California State Lands Commission, it would also require a thorough environmental permitting review under CEQA that would closely parallel the review done by FERC under NEPA. The CSLC had determined at the time of project suspension that it would prepare a full Environmental Impact Report (EIR) (the CEQA equivalent of a NEPA EIS), rather than an Initial Study (equivalent of a NEPA EA). The CSLC indicated that, in their view, an EIR would be a more robust and defensible document for this project than an Initial Study. The preparation of an EIR normally takes 12 to 18 months and is at least as rigorous as an EIS. However, CSLC had determined at the time of suspension that it would be willing to accelerate preparation of this document. Although it is possible to prepare combined NEPA/CEQA documents if they are parallel process documents (that is, CEQA Initial Study and NEPA EA or a CEQA EIR and NEPA EIS), it is not feasible to do so when the federal document is an EA and the state document is an EIR. Therefore, the EIR would have proceeded on a somewhat independent track.

Furthermore, the CSLC has independent authority under CEQA to conduct environmental consequences analyses and request information it feels would be required to disclose the potential effects of the project and complete the CEQA review. It is therefore possible that CSLC could have requested information for its CEQA analysis that other agencies did not require for their permitting efforts. For example, one of the comments from the CSLC suggested that bathymetric surveys be conducted in advance of licensing to determine the presence or absence of shipwrecks along the submarine cable route that could be significant cultural resources. While this issue may have been resolved (for example, by CSLC agreeing that the recent U.S. Geological Survey bathymetry in the area would suffice), it is an example of the fact that, until these ancillary permitting processes were well underway, it would not have been completely clear what information would have been needed to obtain the permits and authorizations to construct the project.

The California Coastal Commission (CCC) process is not a CEQA or CEQA-like process, but a special permit mandated by the California Coastal Act for projects sited within the coastal zone (generally $300 \mathrm{~m}$ from the mean high water line of the ocean). The California Coastal Act and Coastal Development Permit process pays particular attention to issues that involve coastal access and recreation, visual resources, geological hazards (often involving headlands and bluffs), and effects on biological resources, particularly coastal wetlands. Consequently, the CDP permit process would proceed on a parallel but separate track from the FERC and other federal permitting processes. In addition, the CCC permitting process has different requirements than federal or other state-mandated processes for biological resources analysis. For example, to define jurisdictional wetlands under the Clean Water Act, a candidate site must meet all of three criteria: (1) hydric soils, (2) wetland hydrology (periodic saturation), and (3) wetland vegetation. Under the CCC definition, a candidate site must only meet one of these criteria.

The California Endangered Species Act lists many of the same species as the Federal Endangered Species Act, but also includes a few species not federally listed. If the list of potentially affected species is the same under the federal and state acts, then the California Department of Fish and Game need not require a separate incidental take authorization (2081 
permit) under the California act. Instead, if they agree with the U.S. Fish and Wildlife Service/NOAA Fisheries analysis of the project's effects on listed species, they can instead issue a letter of concurrence. In the case of the Humboldt project, there were two species - the longfin smelt and the eulachon - that would potentially be affected by the project and are Californialisted but not federally listed species. For this reason, a 2081 permit from CDFG would also have been necessary. It is possible that CDFG would have requested additional information about these species.

\subsection{Lessons Learned from Agency Interactions}

Other than the potential for conflicts with commercial fishing, the set of issues with the highest likelihood of causing significant cost escalations and delays concerned biological resources permitting, as described above. In permitting a marine hydrokinetic project under the Federal Endangered Species Act (Incidental Take Authorization) or California Endangered Species Act (2081 Permit), regulatory agency personnel must conduct an analysis based on facts provided by the permit applicant that will lead to a supported conclusion regarding the level of "take" (death, harm, or harassment as defined by the Endangered Species Act) that a project will cause to a particular species. The agency may issue a permit authorizing some level of take incidental to project construction and operation that ensures the continued existence and sustained population of the species. Key biological resources agencies and authorizations are listed in Table 4-9.

Table 4-9: Key Biological Resources Jurisdictions

\begin{tabular}{|l|l|l|}
\hline Law & Agency & Jurisdiction \\
\hline Federal Endangered Species Act & $\begin{array}{l}\text { National Oceanic and } \\
\text { Atmospheric Administration } \\
\text { (NOAA) National Marine } \\
\text { Fisheries Service }\end{array}$ & $\begin{array}{l}\text { For marine mammals, } \\
\text { anadromous fish, marine } \\
\text { invertebrates and plants, and } \\
\text { sea turtles listed under the ESA }\end{array}$ \\
\hline Federal Endangered Species Act & US Fish and Wildlife Service & $\begin{array}{l}\text { Terrestrial species of plants and } \\
\text { animals, marine birds, and sea } \\
\text { otters }\end{array}$ \\
\hline Marine Mammal Protection Act & $\begin{array}{l}\text { NOAA National Marine } \\
\text { Fisheries Service }\end{array}$ & $\begin{array}{l}\text { Marine mammals (other than } \\
\text { those listed under the ESA) } \\
\text { take }\end{array}$ \\
\hline Marine Mammal Protection Act & US Fish and Wildlife Service & $\begin{array}{l}\text { Marine mammals - sea otters } \\
\text { (walrus, polar bear, and } \\
\text { manatee not found in project } \\
\text { area) }\end{array}$ \\
\hline $\begin{array}{l}\text { Magnuson-Stephens Fishery } \\
\text { Act }\end{array}$ & $\begin{array}{l}\text { NOAA National Marine } \\
\text { Fisheries Service }\end{array}$ & Essential Fish Habitat \\
\hline $\begin{array}{l}\text { California Endangered Species } \\
\text { Act }\end{array}$ & $\begin{array}{l}\text { California Department of Fish } \\
\text { and Game }\end{array}$ & $\begin{array}{l}\text { Species listed under the } \\
\text { California ESA }\end{array}$ \\
\hline
\end{tabular}




\subsubsection{Sensitive Species}

Perhaps the largest single obstacle to permitting the Humboldt WaveConnect project had to do with uncertainties over the potential for take that the project would cause and the amounts and kinds of information that would be required to document the level of take. The Humboldt Working Group and its permitting subcommittee grappled with these issues throughout the project.

Uncertainty regarding local populations of listed species and project effects is often a significant permitting obstacle for terrestrial projects, for which project site habitats are readily accessible for field inventories. Permitting in the marine environment provides several additional challenges including:

- Most species of marine life are highly mobile and transitory, making population assessments very difficult for a particular part of the ocean or making multiple, seasonal assessments necessary.

- Conducting population and habitat assessments in the marine environment is very expensive, can be hazardous, and is seasonally restricted by marine conditions.

- Partly for the above reasons, long-term studies of marine life populations and habitats are much less available for marine species than for terrestrial ones.

Successful permitting requires a demonstration to the key regulatory agencies that WaveConnect would cause acceptable levels of take to listed species given the mitigation measures to reduce the levels of identified impacts. Conducting several years of biological field surveys at sea would result in a better understanding of the use of the project area by various species. However, the cost of such a program would be high, the time needed to implement it would be long, and the resulting information would not necessarily resolve all questions about the effects of a wave energy farm on marine biota. The lack of existing data in the marine environment with such devices meant that considerable uncertainty would remain.

The FERC pilot license process included measures that appeared to have potential to reduce some of the agency concerns and uncertainties. Under the pilot license procedures, the wave energy farm would be in operation for a period of only five years (plus installation/testing and decommissioning, for a total of eight years). After this period of time, the project could apply for a full 30-year license under FERC's Integrated Licensing Process. The short-term initial license would be long enough for testing the WECs and determining whether significant unforeseen environmental impacts were occurring. It would provide a short enough duration that any longterm damage to the environment could be forestalled, managed or eliminated.

In addition to the limited license term, the pilot procedures would include a mandatory license condition that if the project caused an unforeseen, significant, immitigable adverse impact to a critical resource (such as an endangered species on the verge of extinction) FERC would require cessation, license cancellation, and facility removal. This kind of condition is not a standard condition in a FERC hydropower license, and would add significant risk and uncertainty to the financing and planning of a wave energy farm. However, this provision could give the regulatory 
agency staff some sense of security that their licensing action would not cause an unforeseen adverse impact.

The FERC license would also require PG\&E to develop the MAMPs as documents that would set standards for determining the significance of project-related effects (also difficult in the marine environment) and investigate (1) the effectiveness of the mitigation measures, and (2) whether unforeseen impacts might be taking place. To determine whether the wave energy farm was causing adverse environmental effects, it would be necessary to establish a more detailed baseline of information about the final project site, its habitats, and the species and conditions present before construction. Therefore, with the provisions for facility removal condition and MAMPs in place, FERC could issue the pilot license on the basis of information available in the existing literature, to be supplemented by the pre-construction baseline information and continued monitoring information.

This is somewhat different than the permitting process for a non-marine infrastructure project. For such a project, the normal process would be to gather baseline information from available literature, conduct field surveys (following a specific protocol for certain species), assess impacts, and obtain an authorization for incidental take that would cover the life of the project (usually 30 to 50 years). The environmental permitting laws and regulations assume that there is sufficient information available in advance of permitting to assess the potential for a project's impacts and to take the impacts into consideration through avoidance and mitigation measures. Once the permit is issued, the project owner is mostly free to operate the project so long as the license conditions are followed.

Some types of projects, such as hydropower projects, do include significant requirements for monitoring and adaptive management in their licensing. However, it is also the case that hydropower projects generally involve clearly defined, closed or clearly bounded riverine environmental systems for which it is a simpler task to design and implement monitoring and adaptive management programs. The ocean, by contrast, is a vast and open system in which monitoring is difficult and expensive, and where assessing effects is more difficult than it is for terrestrial ecosystems.

The biological resources issues of most controversy and concern were:

- Would the WEC mooring cable array interfere with gray whale migration? Gray whales are not listed under the Endangered Species Act, but are protected from take under the Marine Mammal Protection Act. Or, perhaps more likely, would derelict fishing gear become entangled in the mooring cables and become a hazard for whales?

- Would the WEC array in any way cause harm to the threatened marbled murrelet? The marbled murrelet is considered to be in jeopardy of extinction such that any prospect of causing harm or death would be considered very serious under the Endangered Species Act. Principal concerns had to do with diving birds becoming entangled in lost fishing gear fixed to the mooring cables and drowning, or birds being attracted to WEC lighting and colliding with WEC superstructures at night. 
- Would electric and magnetic fields (EMF) from the subsea electrical cable interfere with the migration of the threatened green sturgeon or to sharks and rays (elasmobranchs)? Sturgeon and elasmobranchs are known to be very sensitive to EMF.

- Would the WECs become a fish attraction device (FAD) that would result in differential predation of endangered or threatened juvenile salmon? The addition of structured habitat would be likely to attract fish, including both juvenile salmon and their predators.

Although these were not the only biological permitting issues being considered by the regulatory agencies and PG\&E, they were those surrounded by the most uncertainty. While many other issues were raised and addressed, they were generally seen as resolvable with relatively simple measures. Although these issues needed to be investigated, they did not appear to pose a significant threat that could not be mitigated to less-than-significant levels.

Given the limited term of the license, at the time PG\&E suspended work some progress had been made in resolving the key biological resources environmental permitting issues in discussions between the project team and the regulatory agencies. The concept under discussion was that the monitoring and mitigation measures stipulated in the MAMPs would help control unforeseen impacts and also significantly increase understanding of the potential effects of marine hydrokinetics on fish and wildlife.

However, there were differences of opinion and approach regarding the level of monitoring that would be necessary for regulatory agency approval. The initial draft of the MAMPs, as submitted with the DPLA, provided for baseline monitoring for marine mammals, fish, and invertebrates before construction began, during construction to address construction-specific impacts, and during operation for (in most cases) one year, to confirm that unlikely adverse impacts were not in fact occurring. This two-year monitoring program would cost $\$ 2.5$ million to $\$ 3.5$ million.

However, agency comments on the plans included requests for greatly expanded monitoring, as well as monitoring each year of operation to collect information and, again, ensure that there would be no unforeseen impacts. The overall cost of this seven- to eight-year program might have been $\$ 3$ million to $\$ 7$ million or higher, approaching 15\% of PG\&E's expected $\$ 50$ million investment (for the submarine cable and on-shore facilities only, not including the WEC cost).

In retrospect, the FERC pilot license process offered an opportunity for licensing new and littleunderstood technology by proposing a method to reduce regulatory uncertainty and allow projects to go forward in the face of uncertainty that could only be resolved by direct experience. The short term of the license and reliance on MAMPs were key elements of this program. One unfortunate and unforeseen result of this approach was that discussions required to move permitting forward shifted focus from likely impacts on regulated species and the means of mitigating those impacts, toward general monitoring to detect impacts that were not foreseen. Given this premise, the costs of permitting the project could become unpredictable and uncontrolled. In a typical project, permitting costs are discovered before construction and involve the costs of surveys to assess populations and habitats, analysis to determine impacts, and negotiations over mitigation measures, with some monitoring during construction and operation. Permitting discussions with regulatory agencies are focused on the potential for impacts, which 
is considered mostly knowable in advance. When the impacts are seen as unknowable, the preconstruction cost of addressing questions that could arise also cannot be known.

An alternative to this process for a project like WaveConnect would be to collect baseline data before submitting the DPLA and then focus the permitting efforts on obtaining incidental take authorizations, with less emphasis on monitoring and adaptive management (although MAMPs would be required and would still be an important part of licensing). In this case, there would be project development schedule risk during the permitting and planning stage, because there would be no guarantee that information developed in the first year of collection would suffice for the regulatory agencies and that such agencies would not request additional data at significantly higher cost and extended schedule.

This option was not open to WaveConnect on a scheduling basis alone. In order to meet FERC's scheduling requirements to maintain the FERC Preliminary Permit, it was necessary to move forward with the DPLA concurrent with final siting engineering design. The final project site was not determined until late in 2009, shortly before DPLA submission was required. In addition, had PG\&E begun collecting baseline environmental data as soon as the program began, the focus of collection would have had to have been the entire $30 \mathrm{~km}$-long project siting area rather than the final $3.2 \mathrm{~km}$-long siting location. A comprehensive field investigation on this scale would not have been feasible for a project of this nature.

\subsubsection{Commercial Fishing}

Commercial fishing presented the largest potential conflict with the Humboldt WaveConnect project as a conflict of economic interests and uses at the site chosen, and is likely to be a conflict that arises repeatedly for future wave farm projects. The marine hydrokinetic energy industry will need to find ways to reconcile their interests with those of fishers, both recreational and commercial. This topic is considered a socioeconomic issue rather than a biological one under NEPA, CEQA and the Coastal Development Permitting process under the California Coastal Act.

Marine hydrokinetic energy facilities take up sea space, including space that is used by commercial fishers. The fishers view the use of sea space by a wave farm as potential loss of income that exacerbates other losses of a regulatory nature, including the seasonal and spatial closing of fisheries and designation of marine reserves. Although it is true that the marine reserves and perhaps even wave energy farms will help to protect and stabilize fish populations and lead to a more sustainable fishery in the long run, it is also true that the fishers feel threatened by any encroachment on fishing grounds. While ocean energy developers may feel that territorial and outer continental shelf waters are a public resource and that ocean energy development is just as legitimate a use in these waters as commercial fishing, the fishers clearly feel that they have a precedent right. Project developers in commercial fishing areas need to understand the point of view of the fishers from the start of a project if they wish to be successful in coming to agreement with the fishers and obtaining authorization to build. 
This authorization is needed in California, at least, because any ocean energy project will require a Coastal Development Permit for construction in state waters. The regulatory agency that issues this permit, the California Coastal Commission, has made it clear that some form of accommodation with the commercial fishing community is necessary before they will do so.

The Humboldt WaveConnect program worked closely with the local commercial fishing community and recreational fishers. Commercial fishers attended the initial public meeting and were engaged, and made it clear that they felt ocean energy had the strong potential to severely disrupt their economic interest. The commercial fishing community nominated two representatives, with alternates, to the Humboldt Working Group, and these representatives attended regularly and contributed to the discussions. PG\&E also held several meetings with commercial fishing representatives outside of the working group, and took two tours of the marine project site on commercial fishing boats.

These meetings and discussions were extremely helpful in bringing the fishing representatives and the project development team to a fundamental understanding of the needs of each group that could later form the basis for an agreement going forward. Without meetings and this incremental development of mutual understanding and a growing level of familiarity and trust, collaboration and communication could have disintegrated into confrontation.

Although a formal agreement was not finalized with the fishers at the time of project suspension, the basic principles of a potential agreement had been discussed. These included:

- PG\&E would provide some form of compensation to the fishing community for the loss of fishing grounds. PG\&E's initial proposal was based on (a) the value of the local crab fishery; (b) the gross area of the crab fishing grounds, as determined by the fishers in surveys, and; (c) the area that Humboldt WaveConnect would remove from crab fishing use, including a buffer zone and transit lanes. The compensation would be yearly and would be managed by a third party for the general benefit of the fishing community (as opposed to payouts to individual fishers based on claims of being displaced from common fishing grounds).

- A provision to reimburse crab fishers for fishing gear that was lost because of entanglement in the WEC mooring cables and a mechanism to verify loss due to the project.

- Agreements to hire off-season crab boats as needed for maintenance and other WEC operations.

In addition, PG\&E worked very closely with the fishing community to determine the final siting of the wave farm. This involved siting north of the harbor entrance, and then moving the final site $11 \mathrm{~km}$ north of the entrance, even though this would impose several millions of dollars of additional subsea cable cost. Just prior to submittal of the DPLA in March 2010, strong feedback from the commercial fishing community to the two representatives resulted in a re-evaluation of the final site, and a well-attended meeting of the commercial fishers and the project team resulted in an agreement to relocate the project site further south and closer to the harbor entrance. This final site selection ultimately improved the project economics with respect to cable installation costs while minimizing any potential impacts on fishing activities based on direct input from the affected community. 
Although siting the project at any location within the area under consideration at the time would potentially conflict with some form of commercial fishing, trawling and sport fishing, siting the Humboldt project in state territorial waters raised the additional concern that the project would be located within the range of Dungeness crab fishing, which is the most valuable fishery in the Humboldt Bay-Trinidad area. Siting the project in deeper water further off-shore on the OCS would have avoided the conflict with crab fishing, but not with some other fisheries. These issues might be easier to deal with in deeper waters because the specific fishing grounds are not as circumscribed as is the near-shore crab fishery.

\subsubsection{Permitting Lessons Learned}

Some of the most important lessons learned through the environmental permitting process are summarized below.

\section{FERC Pilot License Procedures}

The FERC pilot license procedures offered what appeared to be an expedited means of "getting iron in the water" so that both the WEC industry and regulatory agencies could learn about this new technology and its actual, as opposed to speculative, environmental effects. After months of project development work and meeting with the Humboldt Working Group and agencies, it became apparent that regulatory agency responsibilities, particularly under the Endangered Species and Marine Mammal Protection Acts, do not easily allow for expedited permitting. Agency staff is required to develop very specific estimates of allowable take and to modify those limits if it appears that they will be exceeded, because take exceedance is a violation of the law. If listed species are at risk, the assessment process is necessarily slow and methodical and must be based on sound scientific evidence. Similarly, CEQA does not provide for expedited permitting under a limited-term license, although the license duration could be taken into consideration during CEQA review.

This observation suggests a second conclusion. The easiest way to expedite permitting or avoid delays under the Endangered Species Act is to have detailed, recent, comprehensive scientific baseline data available to form the basis for any impact assessments and take estimates. Particularly in the marine environment, this type of data collection is expensive and time consuming. Coupled with the likely requirement of agencies for extensive monitoring and adaptive management due to the uncertainties of operating new technology in the ocean environment, the long-term costs of the environmental permitting component of a hydrokinetic project are likely to be relatively high as a percentage of capital cost. For a project at the scale of WaveConnect, the operational time (five years) of the pilot license would not allow the project to generate much revenue from electricity sales to offset these costs in the short time available.

\section{Inner Continental Shelf vs. Outer Continental Shelf}

Humboldt WaveConnect was sited within territorial waters, for reasons explained above. This siting had the advantage of reducing the seafaring distance from shore and length of electrical 
transmission and mooring cable needed, thus reducing cost. However, it became apparent during project development that there would be significant advantages to developing a wave energy farm farther from shore and on the Outer Continental Shelf (OCS). From a permitting perspective, facilities within state waters would only include the subsea transmission cable and would therefore require a less complex and comprehensive CEQA compliance effort if the project were located on the OCS.

Siting the project farther from shore would have helped address two of the most difficult environmental permitting issues as well. A location 9.6 to $13 \mathrm{~km}$ from shore would have largely avoided the twice-yearly gray whale migration and reduced concerns that the WECs would harm the species. Cetaceans would still be encountered on the OCS, but not to the extent they are during the gray whale migration. In addition, a location at this distance would have removed the project from the most productive Dungeness crabbing grounds and done much to reduce or eliminate the potential conflict with crab fishers that were much in evidence during project development.

Now that FERC and BOEMRE have resolved their jurisdictional differences, there is a new, albeit untested, regulatory path forward for permitting marine hydrokinetic energy on the OCS. The new rules call for both a FERC license and BOEMRE lease, with NEPA compliance for both of these steps. Although the project team was encouraged by the real progress made by the two agencies to harmonize and link their respective permitting processes for hydrokinetics facilities located on the OCS, there remains significant uncertainty as to the application of these to an actual project at this time. A guidance document release by FERC and BOEMRE following issuance of a joint Memorandum of Understanding (MOU) in 2009 is helpful but incomplete in resolving some areas of conflict or uncertainty in how the options offered by the two agencies would apply to a project such as that envision for WaveConnect.

\section{State-level Permitting}

CEQA requires the mitigation of adverse affects to less-than-significant levels if feasible. CEQA decision makers can reach a finding of overriding consideration where the benefits of a project are compelling and an impact would be significant after mitigation, but this requires a thorough analysis of project benefits and political will on the part of the decision makers to do so. For new technologies, however, it may be difficult or even impossible to document unequivocally that particular environmental impacts could be reduced to levels below significance, when there is little or no experience implementing and operating such technologies and little understanding of the magnitude of impacts that they may cause or, in some areas, whether they have any effect at all.

\section{Programmatic Permitting}

The "envelope" programmatic approach to permitting could be a viable approach in other circumstances and, indeed, is used in environmental permitting analyses of various types of programs. Very often, however, programmatic permitting involves implementing known specific 
measures (for example, routine vegetation management along a high-voltage transmission system's right-of-way corridors) with exact locations where specific actions will occur unspecified in the permitting document. For example, one could apply this approach and conclude that, with the best management practices and standard operating procedures described in the permitting documents, the program as implemented within the locational envelope will not have significant and adverse impacts.

In the case of WaveConnect, the program was to install WECs of one or more several specified types that would use one or more types of moorings. Given this envelope without specific WEC descriptions, construction methods, operational profiles, etc., it was possible to effectively analyze some environmental effects in terms of the outer envelope or worst case. For example, the WEC considered for inclusion in WaveConnect with the largest out-of-water superstructure (WaveBob) was used for the visual simulations. The impacts of any WEC actually selected for participation in WaveConnect would have visual impacts equal to or less than WaveBob. While this argument makes logical sense, to regulatory agency personnel unfamiliar with WEC technology, this approach does not remove all uncertainty. Being able to describe the project in very specific terms is always preferable and leads to more regulatory confidence.

\section{Project Scale}

Attempts to bridge information gaps and agency concerns by reducing the footprint of the project met with limited success. Again, this was likely due to the uncertainties surrounding deployment of new technology whose impacts are not known, as well as the programmatic approach taken to describe the number and type of WEC devices. Agency concerns may have been reduced if specific WECs had been selected and specific information provided on number, size, spatial configuration, and mooring/anchor systems employed.

However, the above approach led to the concept of reducing the environmental footprint of a project per megawatt of installed capacity. This method would favor fewer devices, each having greater generation capability. Avoiding a "forest" of cables (associated with anchoring, mooring, and grid connections) could significantly reduce the risk of entanglement by marine mammals, which was one of the major agency concerns. This approach would also favor the development of small distributed sites rather than large wave farms.

After the experiences of WaveConnect and other hydrokinetic project efforts, it is widely acknowledged that early wave energy projects in the United States and California will bear a much heavier burden for permitting until more experience is gained through operation of an actual facility in the ocean environment. As specific issues of potential concern prove to be benign in actuality or mitigation solutions are agreed upon, the permitting hurdles and resulting cost implications are expected to decrease significantly, improving the economic viability of this technology for meeting renewable energy goals. 


\section{Stakeholder \& Community Engagement}

\subsection{Stakeholder Engagement Approach}

The approach taken to address the many unique challenges and needs of siting a renewable energy project with an emerging and unfamiliar technology such as wave energy conversion, was to create an open and transparent process where the project could evolve as interests were understood and information was gathered, informing the project.

\subsubsection{Goals for Stakeholder Engagement}

The following goals for stakeholder engagement were identified early on and informed the development of the stakeholder engagement process:

- Use collaboration to develop the WaveConnect projects so that the projects reflect the interests and needs of all stakeholders to the extent feasible.

- Provide a credible venue for the community to become informed, provide input, and collaboratively develop solutions to concerns about the project.

- Pro-actively identify and resolve issues, to the extent possible. This should achieve a timelier project with greater win-wins for all involved.

- Facilitate the development of lasting working relationships among PG\&E and key stakeholders, in order to have a shared base of understanding and trust.

- Seek community and agency support for a pilot license application for Humboldt, and license application for Central Coast, by incorporating stakeholder interests and reflecting them in the license application and other documents.

- Involve agencies in discussing and finding ways to jointly address their regulatory requirements in a timely fashion.

- Collaboratively develop the Monitoring and Adaptive Management Plans so they address environmental and regulatory requirements in a manner that is less costly and less impactful to the wave energy project and the environment.

- Build a broader understanding of wave energy technology for the local community

The following strategies for stakeholder engagement were identified and informed the development of the stakeholder engagement process:

- Provide clear and consistent messaging about the project to ensure that stakeholders understand the project and associated milestones in the near term. 
- Provide varying levels of engagement to allow for engagement by stakeholders with differing levels of time, interest, and capacity to collaborate.

- Use transparency and open communications to address issues that arose as the project developed in specificity.

- Understand stakeholders' interests and concerns, including those of the community and regulatory and resource agencies.

- Demonstrate thorough listening, engagement and actions that local community and agency concerns are heard and addressed.

\subsection{Stakeholder Engagement Process}

Below is a description of the various public engagement and outreach activities that were implemented for the Humboldt and Central Coast projects, respectively, in chronological order. The same public engagement and outreach approach was used for both projects, but modified slightly in implementation to complement the unique geography and stakeholders for each project.

\subsubsection{The Humboldt WaveConnect Pilot Project}

Approximately 25 initial interviews were conducted with a broad cross-section of stakeholders to identify key issues, concerns, and uncover underlying interests about the project. Insights from these interviews informed the development of the stakeholder engagement process. Stakeholders interviewed for the Humboldt project included:

- $\quad$ Tribes

- Commercial fishing

- Recreational fishing

- Environmental

- Economic/business

- Labor

- Community-at-large

- Elected officials

- Academic

- Regulatory and permitting agencies.

On May 19, 2009, approximately one year after FERC granted the Preliminary Permit, PG\&E held a public kickoff meeting to inform the public of its plans to actively move forward with the project. Approximately 100 members of the public attended. The objectives of the meeting were 
to introduce the public to the project, solicit nominations for representatives to the Humboldt Working Group (HWG), and solicit questions and comments from the public.

Information about the project was provided via posters, handouts, factsheets, presentations, visual simulations, and one-on-one discussions in an open town hall format. Informational topics included a project description, maps of the preliminary permit area, wave energy technology and types of devices, engineering considerations, environmental review and the regulatory/permitting process, and the public engagement plan and opportunities to get involved. Following the open format, the project team was introduced and the public was given an opportunity to ask questions.

\subsubsection{Establishing the Humboldt Working Group (HWG)}

The HWG was established as a multi-interest stakeholder group that would engage in a collaborative effort to select the proposed site, prioritize select criteria for the technologies, and assist in the development of the pilot license application to FERC and the associated adaptive management and monitoring plans. The HWG also collaboratively developed and adopted its own operating protocols, which included a charter statement, responsibilities, ground rules, communication protocols, and the decision making process.

Nominations for participation in the HWG were solicited at the Public Kickoff Meeting in May 2009. The selection process for participation in the HWG was conducted by an Ad Hoc Working Group, whose members were selected based on feedback from the stakeholder interviews (described above) and consisted of 12 stakeholders representing a cross-section of interests in the Humboldt County community. The Ad Hoc Working Group met once in person and once via a conference call to review nominations, select HWG members from the nominees, and provide input on HWG Operating Protocols.

A number of tools were used to organize the HWG, which comprised a group of more than 60 individuals, including:

- Creating and continually updating stakeholder contact information in a database.

- Creating an e-mail distribution list and sending regular updates informing the group of upcoming meetings, project updates, information sharing between HWG members.

- Conducting outreach phone calls to all participants prior to each meeting to encourage attendance, hear issues and concerns, and help set expectations for the meeting purpose and outcomes.

Subcommittees of the HWG were formed when specific topics merited further detailed discussion. Subcommittees created include the HWG Site Selection Subcommittee, the HWG Permitting Authority Subcommittee, the HWG Fishing Subcommittee, and the HWG Communications Subcommittee. 


\section{The HWG Site Selection Subcommittee}

The HWG Site Selection subcommittee was convened twice as the topic of site selection became more detailed: once early on in the process and once later in the process. The subcommittee was composed of a cross section of interests on the HWG, with a majority of the participants representing commercial and recreational fishing and surfing interests - those most potentially impacted by the project. To learn more about the deliberations of the HWG Site Selection Subcommittee, visit: http://www.pge.com/about/environment/pge/cleanenergy/waveconnect/projects.shtml.

\section{The HWG Permitting Authority Subcommittee}

The HWG Permitting Authority Subcommittee was the largest and most active subcommittee of the HWG. It was composed of all state and federal permitting and regulatory agencies involved in the project. This subcommittee met on an approximately monthly basis to work on the collaborative development of the FERC pilot license application and associated adaptive management and monitoring plans. The goal of the subcommittee was to create a mutually acceptable FERC license application that met the regulatory requirements and needs of each agency. In order to achieve this, the subcommittee collaboratively developed an integrated agency timeline which combined all agency requirements and deadlines into one interdependent process. This was a particularly critical exercise, as a project of this type had not been permitted to date in the state of California, and many of the regulations had not been applied in this context. This "road map" for permitting was a useful guide in further discussions with the subcommittee and the larger HWG, as well as for the project development team. To learn more about the deliberations of the HWG Permitting Authority Subcommittee, visit: http://www.pge.com/about/environment/pge/cleanenergy/waveconnect/projects.shtml.

\section{The HWG Fishing Subcommittee}

The HWG Fishing Subcommittee was convened later in the process when the topic of the preferred site of the commercial fishing community was re-raised. This subcommittee was comprised of several dozen commercial fishermen, recreational fishermen, and other interested members of the HWG. This subcommittee met once to discuss the various commercial and recreational fishing interests and preferences for the location of the project site.

\section{The HWG Communications Subcommittee}

The HWG Communications Subcommittee was convened to help coordinate the public outreach for the February 2 Public Update Meeting. The subcommittee identified various outreach mechanisms that were best suited to garner the local community's attendance. These included production of a flyer, posting of flyers at key public locations, sending e-mail announcements to key distribution lists, identifying local publications for print ad announcements, among others. 


\subsubsection{Subsequent Meetings and Outreach Activities}

A second public meeting was held on February 2, 2010, several weeks prior to the filing of the Draft Pilot License Application (DPLA) for the project. Twelve members of the HWG, representing a cross section of interests, served on a panel to answer questions from the public. Approximately 150 members of the public attended. The objectives of the meeting were to provide an update on the project's progress, provide an update on the work and deliberations of the HWG, and inform the public of PG\&E's intent to file a Draft Pilot License Application (DLPA) with FERC on March 1, 2010 and opportunities for public input on that draft. Information about the project was provided at the meeting via posters, handouts, factsheets, presentations, visual simulations, panel questions and answers, and one-on-one discussions.

On June 8 and 9, 2010, FERC and the California State Lands Commission conducted a joint Public Scoping Meeting for the DPLA and Lease Application. Although this was not a meeting of PG\&E or the HWG, members of the HWG attended to give formal verbal comment for the record.

Prior to convening the stakeholder engagement process, PG\&E representatives had strong existing relationships with interested stakeholders in the community. These relationships were further developed and maintained throughout the process through direct calls, meetings and other informal communications. Frequent phone calls and e-mail contact was made by the project team with the members of the HWG to make sure that all were prepared to effectively participate in each meeting. Team representatives also conducted additional extensive in-person outreach to hear issues, concerns and recommendations for process improvements, which were then brought before the group as a whole.

In addition, periodic e-mail updates were sent at project milestones to inform the broader list of stakeholders (beyond the HWG) of the project's progress. This list included several hundred individuals and was compiled from the initial stakeholder interviews, public meeting attendee lists, people who signed up for updates on the project website, and others who specifically asked to be included. The public engagement team responded to replies and inquiries about the project.

Several joint field trips to the prospective areas for project siting were taken over the course of the project to draw out potential stakeholder concerns about the project site. Two trips with the commercial crab fishermen and PG\&E's engineering, environmental, and public engagement consultants took place over the course of the project. These trips helped the consultants and PG\&E understand the interests and concerns of the local fishing community about the project. The second trip was conducted soon after the first. PG\&E chartered a university research vessel, the Coral Sea, to give the entire HWG a tour of the project site. This tour was helpful in giving the HWG an understanding of the potential project site and the challenges of managing a project in an ocean environment.

The media was kept consistently informed of upcoming project events and milestones via press releases and one-on-one outreach calls. 
Prior to the February 2010 Public Update Meeting, presentations on the project were given to local elected officials, including the Humboldt County Board of Supervisors, Eureka City Council, Arcata City Council, and Trinidad City Council. The PG\&E team conducted ongoing outreach to congressional representatives, legislative offices, and other local policy leaders.

Informational materials were developed to communicate with various audiences about the project. These included factsheets, frequently asked questions, informational posters, maps, comment forms, PowerPoint presentations, agendas, and meeting summaries.

In addition, PG\&E hosted a WaveConnect program website where the public could access up-todate information on the projects, including project descriptions, project maps, project timelines, licensing and permitting process information, wave energy technology information, recent wave energy research, formal FERC filings, PG\&E project team contact information, and public engagement information. In the public engagement section of the website for the Humboldt project, the public was able to access information on the HWG, how the HWG was established, HWG Operating Protocols, a HWG member list, and an archive of Humboldt project meeting dates, agendas, presentations, meeting summaries, other meeting materials, and ways to contact the HWG.

\subsection{Project Outcomes}

\subsubsection{Positive Outcomes}

Overall, the public engagement process for the Humboldt project was a qualified success. Through the initial stakeholder interviews, the Public Kickoff Meeting, and most importantly, through the deliberations of the HWG and its subcommittees, a substantial amount of support and faith in the process was built in the Humboldt County community, and with regulatory and permitting agencies. Much of this trust was built through the relationships established with stakeholders early on, and continued throughout the process. To encourage a collaborative spirit within the HWG, PG\&E staff and public engagement consultants reached out to all participants to hear their perspectives on the project including potential challenges, potential solutions to the challenges, and potential community benefits. This continuous outreach also gave stakeholders the opportunity to raise misconceptions or rumors about the project and share process and substantive concerns. This continuous listening, adjusting, and addressing needs that arose helped maintain strong relationships and respect for the effort.

Through the stakeholder interviews key issues, concerns, and interests were understood early on and informed the development of a stakeholder engagement process that provided a venue to address and deal with issues as they arose. Throughout the interviews, additional stakeholders were identified, helping to develop a complete and diverse list of stakeholders to engage in the process. These interviews served as initial steps to building confidence in the community for the process. 
The public meetings were well attended, positive in tone, productive, and built momentum for the process. Awareness and attendance were generated by:

- Sending e-mail announcements to the entire stakeholder database

- Making advanced phone calls to key stakeholders

- Posting flyers in key local venues

- Enlisting stakeholder help to disseminate flyers/e-mails to their distribution lists

- Placing ads in key local newspapers

- Announcing meetings on key radio spots

- Distributing press releases to key media outlets.

\section{The Humboldt Working Group}

Many consensus decisions were achieved, including collaborative development and adoption of the HWG operating protocols, project site selection within the FERC preliminary permit boundary, and meeting design and panel participation in the February Public Update Meeting, along with many other decisions. The process for collaborative decision making included joint information gathering and exploration, identification of potential options/solutions to choose between, evaluation of options/solutions, and selection of the preferred option based on mutual interests. The consensus-based facilitation used to achieve these decisions helped to move the process along.

The collaborative process enabled early site selection, and subsequent modification to a new site which would better meet the needs for PG\&E, the commercial fishing community, and the full HWG. The combination of dialogue, information gathering, field trips and trust enabled the early success. This early success made it possible for the HWG to re-evaluate the decision later in the process and adjust it accordingly.

Throughout the process, the HWG maintained strong, active participation, with over 50 participants continually attending. This demonstrates the strength of the process and the commitment and keen interest by all participants. HWG participants also conducted significant outreach to their respective constituents, broadening community and regulatory agencies' awareness of the HWC project and wave energy in general.

PG\&E's willingness to hear and directly address siting needs and other concerns or interests that arose were central to the success of the process. Interests and concerns of the HWG both on the process and the content were reflected by PG\&E in future meetings. This built trust in the process, the facilitators, and the applicant. 
The HWG Permitting Authority Subcommittee

All agency participants demonstrated active and sincere engagement early on and throughout the process. This was demonstrated through consistently well attended in-person meetings (with significant travel by many) and active follow up on action items, as well as through the successes described below.

The agencies collaboratively developed an integrated agency timeline and a shared commitment to execute each of their responsibilities according to the timeline, to the extent possible. This timeline served as a good tool to keep the agencies and PG\&E on track with their commitments. The exercise of creating the integrated agency timeline was also helpful in facilitating the challenging discussion of how to define and coordinate agencies' regulatory requirements for application to a new technology.

Agency participants were forthcoming with the identification of topics needing to be addressed in the Monitoring and Adaptive Management Plans (MAMPs) and supported collaborative development of other plans. There was also much momentum generated towards developing and incorporating "thresholds" or "triggers" in the plans. However, the project ended and the process stopped short of further development of the "triggers" or "thresholds" and the actual negotiation of the Monitoring and Adaptive Management Plans.

Throughout the process, and particularly in the very last meeting, HWG participants expressed very strong support and appreciation for the collaborative effort for this project. Many agency participants expressed appreciation for the early involvement and the collaborative process. Some stakeholders expressed interest in community partnerships to create a robust, green technology industry and infrastructure to support a Humboldt County economy.

\subsubsection{Challenges}

Although the stakeholder engagement process yielded some successes, there were some unresolved issues.

A particularly challenging topic of discussion within the HWG was the development of an agreement to address the displacement of fishing activities, particularly on the important commercial Dungeness crab fishing grounds. An agreement with the fishing community on mitigation for the potential impacts they would face was not fully initiated or negotiated at the time of suspending the project. A key difficulty here was the challenge of devising a fair mitigation for use of a common public resource by multiple users, one whose value fluctuated greatly from year to year.

There was a "chicken-or-egg" challenge in the WEC selection process, which PG\&E attributes to the challenge of proposing a programmatic versus a project-specific approach to the pilot program On the one hand, it was helpful that the HWG was able to be actively involved in learning about and contributing to the WEC selection process, to the extent that environmental and ocean user concerns factored into the relative merits of the devices considered. On the other 
hand, lack of specific detail about the devices multiplied the potential impacts of the project design and infrastructure beyond what would have been ultimately seen in a final project design. These uncertainties, which are not unusual for an early stage technology, led to concerns and some conservative assumptions by HWG community and agency members that led to potential very high costs to address issues of concern.

Two months prior to the filing of the DPLA, PG\&E raised the concern that in light of what appeared to be potentially much higher-than-expected costs for the project, an operational period longer than the five years earlier proposed might be necessary to ameliorate impacts to ratepayers by allowing a greater longer period in which to amortize the cost. The short duration of the pilot license process was intended to address concerns that unforeseen impacts from a project would not be long-lasting, and the longer timeframe discussed raised new issues for the HWG, particularly among permitting agencies concerned that this could require more extensive baseline and monitoring to ensure protected resources would not be significantly impacted. . This is another challenge with new technologies and learning about development costs and challenges "real time" through the process.

Within the HWG Permitting Authority Subcommittee, the main outstanding issues were around negotiating the MAMPs. While the subcommittee was collaborating on the MAMPs, the need to file formal comments on the Draft Pilot License Application (DPLA) within 60 days of the filing caused the agencies to file comprehensive comments identifying all issues and concerns with the project, including some that had been discussed and were progressing towards a workable agreement but had not been resolved. In turn, PG\&E was required under the FERC process to compile and evaluate the large number of comments in order to prepare a comprehensive response.

While PG\&E reassessed the interrelated challenges of the commercial and cost issues, formal comments by permitting agencies, and a limited budget to conduct the feasibility stage of the project, only one meeting was held with the Permitting Authority Subcommittee to address the potentially significant challenges facing continuation of the effort. Effectively, the collaborative process was suspended while the project was reevaluated, and this left the effort, on paper, at an apparently polarized point. However, it is important to note that had other project challenges been resolved and the collaborative subcommittee process resumed, the preceding efforts would have likely contributed to finding mutually viable solutions to the issues raised in the formal filing of comments.

\subsection{Conclusions: Lessons Learned and Process Recommendations}

Overall, the process used (and described above) was a qualified success that increased effective stakeholder participation. .A collaborative stakeholder approach can be a powerful asset when it includes the following activities, whose implementation should be tailored to specific projects:

- Conducting stakeholder interviews and an assessment

- Holding public meetings around important project milestones 
- Convening a community-selected collaborative stakeholder working group

- Creating and convening subcommittees as needed

- Creating a regulatory/permitting agency subcommittee

- Conducting ongoing outreach using a wide range of methods

- Sending periodic e-mail updates to all stakeholders

- Taking field trips with stakeholders

- Holding policy maker briefings

- Producing various materials (handouts) to communicate about the project

- Creating a project website to house all project materials, timelines, etc.

The variety of types of communications and levels of intensity enables stakeholders, agencies, members of the public and others to participate in a way that best addresses their interests and availability to engage. One recommendation for future projects of this type is that they use three levels of outreach and engagement:

- Highly Active: create a community-selected collaborative stakeholder working group that convenes regularly to learn about and provide input on the project;

- Moderately Active: Conduct broad outreach including briefings with local elected officials, conduct public meetings, and other briefings with interested stakeholders;

- Least Active/Information-Only: provide information about the project via a project website, e-mail updates, and other materials.

In order to build a collaborative working group that can effectively communicate on a specific topic, a common base of knowledge must be created among the members. This can be done though sharing existing project information, providing background presentations on wave energy technology, permitting process, environmental review process, as well as an understanding of their shared roles and responsibilities.

Openness by the applicant/developer is the key to creating an open and transparent process. PG\&E was very clear and helped explain the project, their interests, what they could do/not do to accommodate local community, environmental and regulatory needs. The PG\&E project manager and team were personable, recognized as honest, and always available to discuss the project with stakeholders. The team also demonstrated a sincere interest in understanding and respecting other stakeholders' interests.

Early collaborative successes built mutual confidence among stakeholders. As an example, PG\&E and the fishing community (commercial and recreational fishers), the surfing community and others jointly agreed upon the specific project site within the permit area, accommodating potentially impacted fishing and surfing interests by going further north than would be ideal from a purely cost perspective. Based on additional fishing community feedback, the preferred ocean site was subsequently modified. This early demonstration of listening to the HWG enabled 
solutions to be found that met community needs. This and other early successes in finding mutually viable solutions helped build a sense among the participants that their time and energy was appreciated and put to good use by the developer.

Conducting outreach through existing local organizations and established channels of communication was a very successful method to reach the broadest audience possible to ensure that stakeholders with key interest were informed and involved early in the process rather than later when some project decisions might have been more difficult to revisit. Reach stakeholders through existing organizations networks and use community resources where they already exist.

It is best to employ as many methods as reasonable to create transparency. Some techniques that proved successful in the stakeholder engagement included preparing meeting summaries, tracking action items, timely follow through on next steps, and posting all materials on a project website. These small steps helped create transparency and accountability in the process, and confidence that all issues were being fairly addressed by both the developer and the stakeholders.

With a new and evolving technology such as wave energy, it is imperative to be clear with stakeholders that these projects have a lot of unknowns (engineering, environmental permitting, funding, etc) and it is not uncommon, if not likely, for the project description to change substantially throughout the process. For this project, both the licensing/permitting process and the areas of uncertainty were described in as much detail as was available to stakeholders. The challenge in this case was how to effectively convey the importance of recognizing and accepting that the project could change as new information was gained, while having enough project details of substance and established parameters to continue making meaningful progress.

Conducting outreach calls to HWG members prior to each meeting to get input for development of an effective agenda and to encourage attendance is a recommended approach. These outreach calls also provided an opportunity for stakeholders to clear up misunderstandings or rumors about the project as opposed to spending valuable collaborative meeting time to accomplish this. This advance outreach prior to the meetings gave an opportunity to inform stakeholders of latest developments on the project and what they can expect at the next meeting. This helped the stakeholders prepare for the meeting and be ready to engage with constructive and on-target input.

The establishment of a project website allowed active stakeholders and the general public to have frequent and easy access to project information. This level of access to the project was fundamental to building transparency, trust, and factual knowledge of both the project and the process. Furthermore, it is very helpful to have an easy mechanism to actively update and maintain the project website, both for those highly involved in the process and for those only tracking it.

Active offline listening, both by PG\&E and by the facilitators, to then be able to adjust plans accordingly, worked very well. Establishing rapport with stakeholders early in the process and encouraging offline communication helped create opportunities for positive engagement. 
Strong meeting planning and management enabled all participants to be heard while keeping to time commitments, yet allowing the meaty discussions to extend.

Clear identification of the overall process, timeframes and roles is very important. Creating a visual of the overall project timeline, milestones and critical input opportunities by the public and the collaborative working group is very helpful so all are "grounded" on the process. Reviewing and updating the timeline is also important. With this long term view, stakeholders can understand how the project will progress and how their actions now contribute to the nearterm and long-term goals for the project.

Clearly identify for stakeholders when and how they can provide input in the process. At the same time, make it clear what kind of input will help the project team make good decisions based on public input.

Having an impartial facilitation and public engagement team brought expertise in conducting the engagement and outreach process. It assisted with program design, preparing for and facilitating the collaborative process enabling it to be more effective and efficient.

Clear, concise information and visual tools are very helpful.

Continuously listening and adjusting the process to meet changing needs is important. And having stakeholders see that their input is heard and acted upon to improve the process is very important.

Provide all the possible information needed for stakeholders to easily engage in the process, including: location and directions, times, dates, contact info, topics for discussion, agenda, and other advanced materials. Provide these updates in a timely manner so that people have enough time plan accordingly and key stakeholders can be available. Two weeks in advance of the meeting is preferred, with a reminder e-mail a few days before the meeting date.

If possible, evaluate and choose which WECs are best suited early on in the process. It is best to collaboratively identify with the stakeholders selection criteria and attributes of the various WECs that are best suited to the chosen location and other needs. Stakeholder engagement in WEC selection creates a lot of buy in and ownership by the community for the project.

The commercial and recreational fishing communities are a diverse and dispersed group of stakeholders with a wide range of interests. Use multiple means to reach out to these stakeholders, including: public meetings, one-on-one outreach, convene larger fishing specific outreach/update/input meetings, boat rides to learn about their operations, take tours of the project site on fishing vessels, and go to the places where they work and hang out and talk to them about their interests. These recommendations also apply to all stakeholders. 


\section{Central Coast WaveConnect}

\subsection{Site History}

In October 2009, PG\&E signed a Memorandum of Understanding (MOU) ${ }^{57}$ with Vandenberg Air Force Base (VAFB), a facility of the Department of Defense (DOD). DOD's goal is to produce $25 \%$ of its energy via renewable sources by 2025 , and the department receives doublecredit if renewable energy is generated on federal land (such as on BOEMRE lands) and consumed at a federal facility ${ }^{58}$. The MOU was in preparation for an application to FERC ${ }^{59}$ for a preliminary permit in the ocean area that surrounds the boat ramp built for Space Shuttle solid rocket booster recovery. The site possessed multiple advantages, including:

- The wave energy at $5 \mathrm{~km}$ off-shore is approximately equal to that of PG\&E's Humboldt WaveConnect site, without some of its more extreme storms;

- Available deep water (85 m) within $5 \mathrm{~km}$;

- The local VAFB community sees the facility as a long-term advantage;

- Transmission line capacities out of the area are substantial;

- Due to extensive oil and gas (O\&G) exploration efforts, a significantly greater baseline of environmental data is available in the Southern California area than at the Humboldt WaveConnect site, especially in the area surrounding the prospective VAFB site; and

- Significant shipping resources are available via the network that currently supports the O\&G industry in the same region, as well as the resources of the world's third largest port of Los Angeles/Long Beach.

On December 11, 2009, PG\&E applied to FERC for a Preliminary Permit for a site off the coast of Santa Barbara County in California, between Point Arguello and Point Conception near VAFB. The purpose of the Preliminary Permit was to provide the applicant with three years of exclusive rights to the site without the threat of a competing permit or license application being filed on the site and to obtain priority over other applicants in a subsequent license application proceeding.

PG\&E’s Preliminary Permit Application proposed a project consisting of:

\footnotetext{
${ }^{57}$ The PG\&E and VAFB MOU is included in Appendix X.

${ }^{58}$ Energy Policy Act of 2005 (EPACT), and the Energy Independence and Security Act of 2007.

${ }^{59}$ PG\&E has since learned that no FERC permit is required for an electrical system that connects to a military base's electrical distribution system and supplies only the base, since VAFB is exempt from the Federal Power Act. This fact would allow the Central Coast site to reach a goal of a 20-MW "pseudo pilot" within three years.
} 
- Multiple arrays of WECs;

- Installations of WECs in depths ranging from 10 to $100 \mathrm{~m}$ of water;

- $5.6-$ to $8-\mathrm{km} 12-\mathrm{kV}$ transmission line to shore;

- Anchoring devices; and

- Appurtenant facilities.

On May 14, 2010, FERC issued PG\&E a Preliminary Permit for the Central Coast WaveConnect (CCWC) project. The Preliminary Permit gave PG\&E the exclusive right to prepare an Application for a License and file it with FERC within three years of the May 1, 2010 effective date of the issuance of the Preliminary Permit. On April 29, 2011, PG\&E simultaneously filed its second Six-Month Progress Report and a Petition to Surrender the Preliminary Permit for the site.

\subsection{Site Selection Considerations}

As with the Humboldt WaveConnect Preliminary Permit, PG\&E selected a wide CCWC area to investigate for a possible future site. A large permit area would allow PG\&E to eliminate from consideration any area found inappropriate due to incompatibility with environmental characteristics or existing uses, without eliminating all potential sites within the permit area. The experience gained during the Humboldt WaveConnect activities, including agency and local stakeholder input, helped refine the initial project area requested for the preliminary permit for the CCWC to avoid any identified likely conflicts at the outset.

The proposed location for the CCWC had several potential advantages. The wave resource, while not quite as robust as in northern California waters, is still substantial enough to support a wave energy facility. The resource does decline in intensity in the waters south of Point Conception, due to the interference from the Channel Islands and the general angle of California's southerly coastline; however, the CCWC permit area was located north of any significant reductions in wave energy potential. Additionally, the greater range depths in closer proximity to shore than the Humboldt site offered preferable options for deployment of a range of prospective WEC devices.

The nearby presence of VAFB also presented an opportunity to utilize the long history of base operations in the area, which have yielded valuable information on the environmental characteristics and user activities for the permit area. The relative distance from a harbor reduced the likelihood of conflict with fishing activities due to the distance required to travel to and from the permit area; however, accessible harbor facilities would still be required to support the proposed CCWC. To this end, underutilized on-shore support facilities located on the base were identified as potential components for the project, and the MOU that was executed between PG\&E and VAFB allowed the parties to explore ways to collaborate on the CCWC. Potential areas of collaboration included interconnection of the project output directly to the VAFB electric infrastructure. 


\subsection{Environmental Permitting}

At the time of suspension, environmental permitting studies had not begun for the CCWC beyond obtaining a general understanding of the key environmental permitting issues. This initial examination showed that there would be certain similarities in permitting the two sites and certain significant differences.

In terms of biological resources, there are a number of marine species whose ranges would normally include both the Humboldt and Central Coast sites. Among marine mammals were the gray whale, a species not listed under the federal Endangered Species Act (ESA) whose large annual migration takes place in near-shore waters, and two ESA-listed (threatened or endangered) whales, the blue whale and humpback whale. ESA-listed fishes include the steelhead and tidewater goby.

A number of ESA-listed marine species are present in the Humboldt site area, but not at Central Coast. These include federally listed Chinook and Coho salmon, green sturgeon, eulachon, marbled murrelet and the California listed longfin smelt. Federally listed marine species that are likely to occur in the Central Coast project area but not in the Humboldt area include the leatherback turtle and the southern sea otter. There are also a number of terrestrial plant and wildlife species that could be affected by on-shore facilities at the project sites, but these would not be known for Central Coast until on-shore facility locations were finalized.

A significant permitting topic had to do with the project's potential socioeconomics effects, particularly the potential for conflicts with commercial fishing. For the Humboldt site, the possible conflict with commercial crab fishing, in particular, was a significant issue because the project site was within the commercial crab fishing grounds and could have involved displacing crab fishing from some of this area. Although commercial fishing also takes place at the Central Coast site, it is relatively distant from the nearest fishing ports of Santa Barbara, Port San Luis, and Morro Bay. Meetings with representatives of the commercial fishing community at both Santa Barbara and Morro Bay indicated that the project area is regularly fished; however, commercial fishing records indicate that the catch for most of the commercially important fisheries is significantly lower in the area between Point Conception and Point Arguello than further north and east. Additionally, discussions with the Surfrider Foundation indicated that there is only one publicly accessible surfing place near the Central Coast site, Jalama State Beach. To allay potential concerns from the surfing community, the preliminary permit area was designed to exclude a 3.2-km buffer from Jalama Beach. A similar exclusion area from an important surfing location at the entrance to Humboldt Bay was implemented for the Humboldt site during the pre-filing activities.

In terms of potential conflict with recreational viewers or sensitive visual receptors, it was determined that there are few residential or recreational uses along the shoreline adjacent to the Central Coast site, due to the presence of and restricted access to VAFB. Although there are elevated viewpoints on shore near the Central Coast site (in contrast to the Humboldt site), these viewpoints are largely uninhabited and inaccessible. 
The proposed CCWC faced several possible permitting avenues based on the evolving and untried regulatory framework, each with their own opportunities and complications.

\subsection{Stakeholder Engagement Approach}

The approach to identifying and engaging key stakeholders who likely would have an interest in the proposed CCWC closely followed the approach used for the Humboldt WaveConnect project.

Below, in chronological order, is a description of the various public engagement and outreach activities that were implemented for CCWC. The same public engagement and outreach approach was used for both the Humboldt and Central Coast projects, but modified slightly in implementation to complement the unique geography and stakeholders for each project. Please refer to Chapter 6 of this report for more discussion on the approach.

\subsubsection{Outreach Activities before Filing Preliminary Permit Application}

In late 2009, prior to public notification about the project launch, PG\&E staff met with Santa Barbara County supervisors to inform them of the upcoming project and discuss any questions or concerns they had.

In November 2009, after PG\&E and VAFB executed the MOU to jointly develop wind and wave energy at the base and prior to application to FERC for a preliminary permit to study the site, PG\&E conducted a planning meeting with multiple VAFB divisions to provide information about the proposed project and learn about site-specific issues, opportunities and constraints. Additional stakeholders were identified, and coordination with their internal public relations team was established.

\subsubsection{Outreach Activities after Filing Preliminary Permit Application}

Twenty phone interviews and 14 in-person interviews were conducted with stakeholders for this project. Similar to the Humboldt stakeholder interviews, these interviews helped identify key issues and concerns, and uncover underlying interests regarding the project. Understanding these issues, concerns, and interests at an early stage informed the development of key elements of the stakeholder engagement process. This provided a venue to address these topics as they arose. These interviews also helped identify important stakeholders and yielded helpful recommendations for structuring the process.

Two local public meetings were held in Santa Barbara County: one in Santa Barbara and one in Santa Maria. The purpose of the meetings was to inform the public of PG\&E's desire to build a wave energy project off the coast of VAFB and PG\&E's submittal of an application with FERC for a Preliminary Permit to explore the feasibility of a wave energy project in the described offshore site, to share technical information about wave energy technology and engineering considerations, to provide information on the environmental review and permitting process, and 
to provide information on the engagement process and opportunities to get involved. Similar to the Humboldt Public Kickoff Meeting, PG\&E announced its intent to convene a community stakeholder working group. Nominations for participation were solicited at these meetings.

The planning effort, public outreach, and format for these meetings were identical to the Public Kickoff Meeting for the Humboldt WaveConnect Pilot Project, as described in Chapter 5. Materials prepared for these meetings, including the agenda, a fact sheet, maps, informational posters and identical handouts, a nomination form for participation in the working group, and a comment form can be found on the WaveConnect website: www.pge.com/waveconnect.

\subsubsection{Ongoing Communications}

In February 2010, at the public kickoff meetings, nominations for the collaborative working group were solicited. Individuals known to have a keen interest in the project were contacted via email to solicit their nominations. The nomination period was held open through the end of May 2010. Over the course of the nomination period, the public engagement team responded to inquiries from stakeholders about whether/when the collaborative working group would be formed and other project related questions.

Periodic email updates were sent at project milestones to inform a broad list of stakeholders of the project's progress. This list was compiled from the initial stakeholder interviews, public meeting attendee lists, folks who signed up for updates on the project website, and others who specifically asked to be included. The public engagement team responded to replies and inquiries about the project.

In addition, PG\&E hosted a WaveConnect program website where the public could access up-todate information on the projects, including project descriptions, project maps, project timelines, licensing and permitting process information, wave energy technology information, recent wave energy research, formal FERC filings, PG\&E project team contact information, and public engagement information.

\subsection{Evolving Engineering Efforts at the Central Coast WaveConnect Site}

The Central Coast area of California has substantial opportunities for interconnection to the PG\&E grid. Costs for developing on-shore interconnects in that area are substantially less, and the existing infrastructure is substantially greater, than along the North Coast area. Consequently, PG\&E chose Central Coast as an alternative site to the initial Mendocino WaveConnect project. Figure 6-1 shows the proposed overland route as well as the off-shore route, while Figure 6-2 shows a close-up view of the beach access. Figure 6-1 also shows the route extending beyond the $3 \mathrm{~nm}$ limit as part of an examination of a possible alternative site on the OCS. 


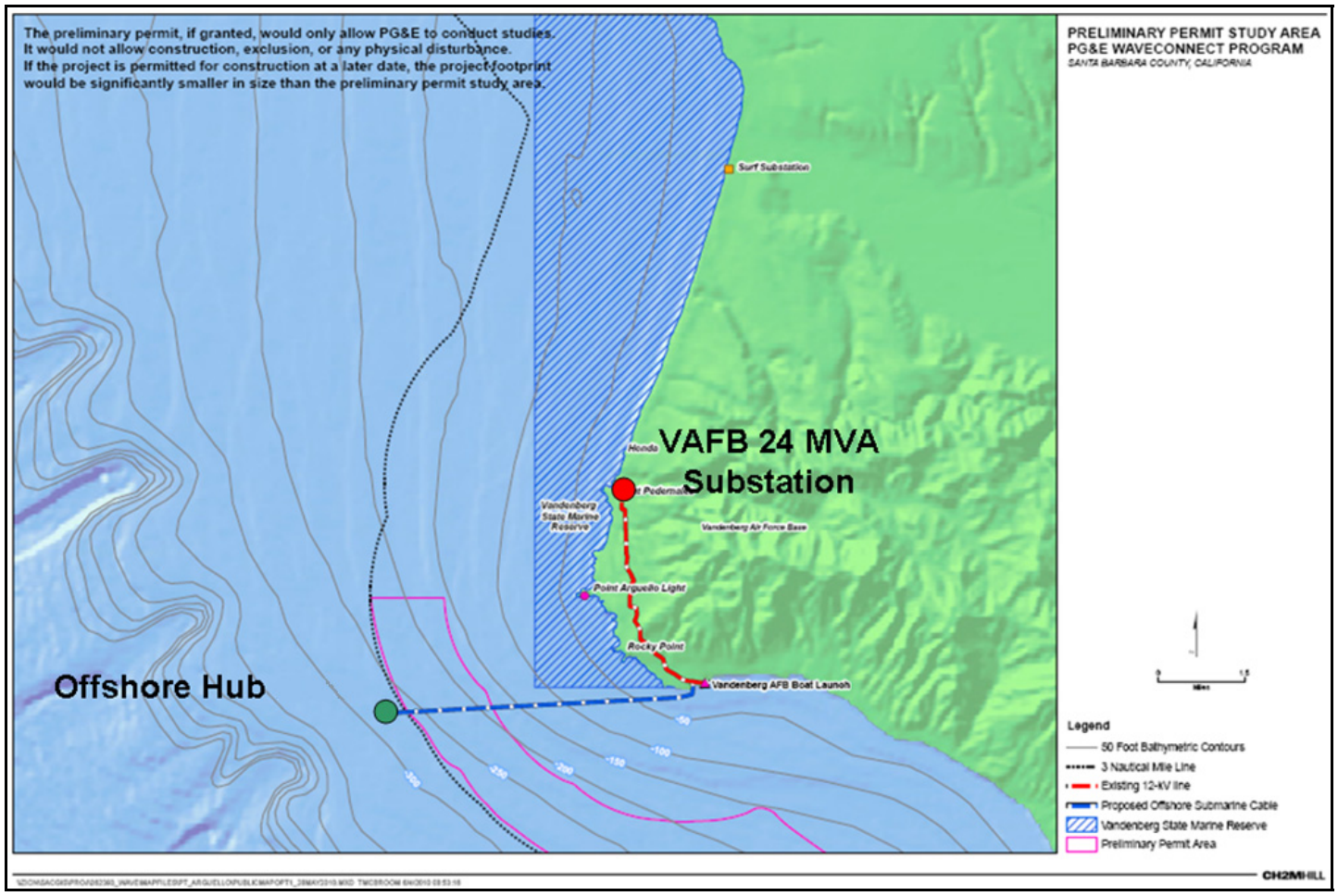

Figure 6-1: Proposed Overland and Off-shore Routes

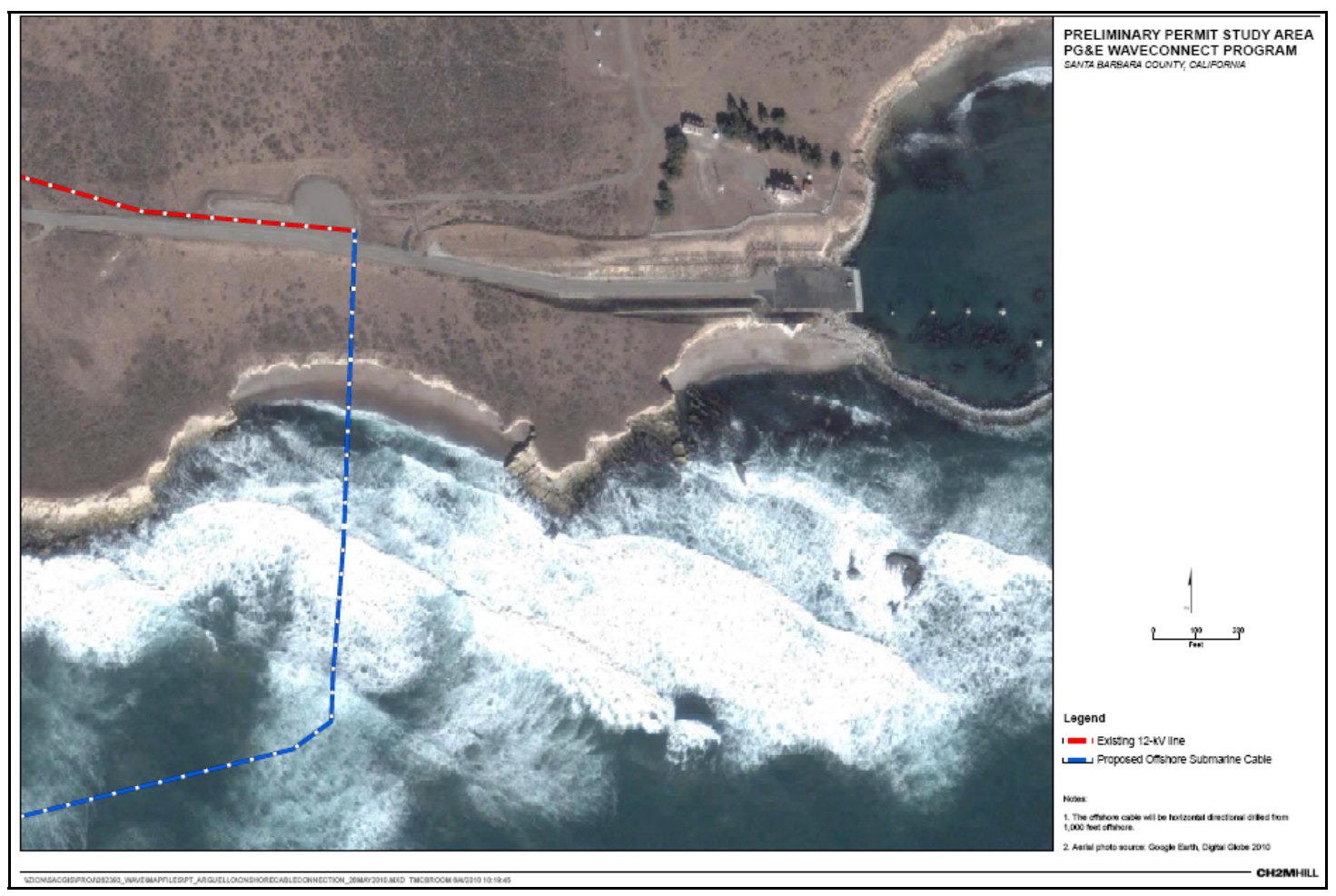

Figure 6-2: Close-up Aerial View of Beach Access 
As PG\&E began its initial engineering evaluations, it was quickly determined that a 12-MW cable, as stated in the FERC permit application, would not be a cost-effective power conduit. This led PG\&E to begin evaluating the costs associated with a larger build-out. Several alternatives evolved, including one involving multiple cables of 30 to $35 \mathrm{MW}(34.5 \mathrm{kV})$ extending to the off-shore site, and another that would employ a single 100-MW, 115-kV highvoltage cable. Estimated costs for the lower-capacity cable were discussed earlier.

For the potential 100-MW build-out, PG\&E approached a firm with extensive off-shore experience whose overall cost estimate for the project, including an off-shore substation, was just under \$100 million. That estimate included engineering, cable cost, cable lay, and HDD efforts. It did not include the expense of a semi-submersible platform, which could conceivably cost an additional \$20 million. In later discussions with the manufacturers of the larger WECs, it was determined that their platforms could conceivably be used as bases for the off-shore substation.

The overall cost for this effort would have been approximately equal to using three 30-MW cables but the project risk would have been substantially less, as this firm had completed similar projects elsewhere and would have handled and warranted all aspects of the effort. However, these plans did not go beyond discussion phases due to PG\&E's internal focus on the Humboldt project. Such an alternative would have been more characteristic of a true test facility, since no large-scale build-out would use multiple "home run" cables. Off-shore wind projects originally started with separate, low-voltage home run cables and then graduated to off-shore substations with sets of cable "spokes" leading out to the various devices. Additionally, PG\&E could have built a facility that somewhat resembled its final form, even if it is an evolutionary state.

\subsection{Licensing Issues}

FERC noted that PG\&E's permit application described a phased construction approach, with the installation of $10 \mathrm{MW}$ during the first phase and an eventual build-out to $100 \mathrm{MW}$. In order to evaluate the phased construction approach, FERC requested that PG\&E's application include:

- A detailed construction schedule for each phase of construction, including type of technology, location, and incremental nameplate capacity for each phase of construction and for each generating unit to be installed;

- The proposed environmental measures associated with each phase of construction; and

- Justification for the phased construction approach.

FERC felt that it could support a phased approach, due to the inability of WEC manufacturers to deliver up to $100 \mathrm{MW}$ of devices and install them within a short time period, and so made a substantial effort to accommodate PG\&E's strategy.

PG\&E also explored other regulatory paths for the Central Coast site. These included substantial discussions with BOEMRE and VAFB, which yielded an alternative concept in which PG\&E, in 
cooperation with VAFB, would allow the Air Force rather than FERC to become the lead agency for licensing a smaller effort. More details would have been required to assess the feasibility of this approach, but the concept would have been that Air Force/DOD would act as the lead agency, with BOEMRE performing the NEPA Assessment. VAFB would then accept the BOEMRE NEPA as its guiding document and authorize project initiation.

PG\&E understood that as long as power generated by the CCWC had de minimus impact on the national grid then, per the precedent of Verdant Power's Roosevelt Island Tidal Energy Project, FERC could waive certain licensing requirements for the project (a circumstance commonly known as the "Verdant Exception"). In that event, DOD rather than FERC could act as lead regulatory agency. This would give PG\&E the opportunity to develop a hybrid pilot project, in collaboration with DOE and the DOD, which would begin with a small 10-MW facility in the first year and increase to a maximum of $30 \mathrm{MW}$ by year two. An adaptive management process would monitor its impacts. This path would allow a project with a larger size and a longer duration than the FERC pilot license process. After a few years, if no major environmental impacts were detected, PG\&E could apply to FERC for a full license and continue up to a 100MW facility.

\subsection{Project Outcomes}

Coincident with the first year of the Preliminary Permit process for the Central Coast WaveConnect project, the challenges posed by the Humboldt WaveConnect project were better understood by PG\&E and the other project participants. Most of the difficulties faced by the HWC appeared likely to confront the proposed CCWC as well, even if FERC's more traditional licensing options such as the Integrated Licensing Process (ILP) were to be used. Consequently, for the same reasons as detailed in the HWC sections of this report, including development budgetary constraints, PG\&E submitted a Petition to Surrender the Preliminary Permit for CCWC in May 2011.

Since the CCWC development activities focused mainly on stakeholder engagement, specific outcomes - both positive and negative - are summarized below.

\subsubsection{Positive Outcomes}

The initial stakeholder interviews resulted in clear advice on who to engage and how to engage stakeholders. Key stakeholders identified included local communities (Santa Barbara, north of the site), tribal interests, fishing interests, environmental interests, among others. These interviews served as initial steps to building confidence in the community for the process.

The public meetings were well attended, positive in tone, productive, and built momentum for the process. Awareness and attendance were generated using the following methods:

- Sent email announcements to the entire stakeholder database;

- Made advanced phone calls to key stakeholders; 
- Posted flyers in key local venues;

- Enlisted stakeholder help to disseminate flyers/emails to their distribution lists;

- Placed ads in key local newspapers;

- Announced meetings on key radio spots; and

- Distributed press releases to key media outlets.

\subsubsection{Challenges}

The initial efforts to solicit nominations and convene a working group were suspended while project viability was reassessed.

Establishing a stakeholder engagement process in the Santa Barbara area proved to be challenging due to stakeholders being spread over a large geographic area. This made it difficult to identify a single location where a collaborative group could convene on a regular basis without requiring large amounts of travel time.

Prior and recent fishing community experience on the Marine Life Protection Act (MLPA) stakeholder process has implications for their willingness and enthusiasm to engage in this process. The Central Coast project was initially viewed by the fishing community as yet another threat to their accustomed access to fishing grounds.

There are very strong environmental protection interests in the Santa Barbara community, while there are also strong environmental interests in developing renewable, green technologies. Going forward, the full spectrum of environmental interests would need to be addressed and the right approach would need to be found. 



\section{Economic \& Commercial Issues}

\subsection{Introduction}

This chapter explores the economics and commercial readiness of wave power technology. As part of the effort to understand the economic viability of the technology, PG\&E calculated the levelized cost of energy (LCOE) for a complete wave power system, both at the pilot stage and for more mature commercial projects of various capacities.

This economic assessment process is of critical importance, as PG\&E is obligated to meet a 33\% legislatively mandated Renewable Portfolio Standard (RPS) by 2020 and must therefore select the most cost-effective renewable power options to satisfy the law. To that end, PG\&E periodically issues Requests for Proposals (RFPs) to solicit projects from developers that then supply renewable power to PG\&E under long-term contracts. For wave power to eventually succeed, it will have to compete favorably against other renewable sources in such solicitations.

The proposed commercial arrangement for the WaveConnect pilot project was very different than that of a typical power project, so economic comparisons between the two are not entirely meaningful. Under the proposed arrangement for the pilot project, WECoMs would provide, operate and maintain their devices at no cost for the term of the pilot testing, but would receive a payment for the actual energy delivered: a hybrid of utility ownership and a power purchase agreement (PPA). In a typical utility-owned project, PG\&E would own the entire system, while under a typical PPA, PG\&E would own nothing and simply pay for the actual power delivered. As PG\&E would not be purchasing WECs for the pilot project, PG\&E's economic analysis relied on cost estimates provided by the WECoMs and therefore could not be independently verified. In estimating the LCOE for current and future wave power projects, PG\&E focused its efforts on the cost of balance-of-plant systems (e.g., interconnection) and simply used a range of values for WEC costs as suggested by the WECoMs. Others (such as EPRI $2005^{60}$ ) have evaluated estimated system costs.

In general, a pilot project is more expensive than a commercial project, and LCOE has a different meaning in a pilot project than it would in a commercial project. These distinctions are important to consider throughout the economic discussion that follows.

Wave power is at a distinct disadvantage in that the technology is at a similar level of development today as wind or solar were 20 to 30 years ago. Wave power faces the additional hurdles of uncertain environmental impacts, limited funding for development assistance, and

\footnotetext{
${ }^{60}$ EPRI 2005. Bedard, R, Hagerman, G. Previsic, M, Siddiqui, O, Thresher, R, and Ram, B. Final Summary Report, Project Definition Study-Offshore Wave Power Feasibility Demonstration Project. E2I EPRI Global WP 009 - US Rev 2, September 22, 2005. http://oceanenergy.epri.com/attachments/wave/reports/009_Final_Report_RB_ Rev_2_092205.pdf
} 
more difficult and costly interconnections with the power grid. In particular, wave power interconnection is a challenge in California (and likely elsewhere) as the state's coastline does not offer many suitable interconnection points. California coastal substations tend to have moderate to large capacities but are very widely spaced, limiting the number of wave power projects that can be accommodated without requiring substantial, difficult, and very expensive improvements to on-shore transmission infrastructure.

In addition to the difficulty and expense of working at sea, the fundamental physical characteristics of ocean wave energy help put wave power at a cost disadvantage compared to on-shore wind and solar power. Because a WEC depletes a significant fraction of a wave's energy (in the same way that the Channel Islands reduce the wave energy reaching the coast of southern California, as described in Chapter 1), it is less efficient to place multiple devices behind one another, as the forward devices reduce the energy contained in the oncoming wave front. As a result, a wave power array will generally be laid out in a long and narrow strip running parallel to the shore line, which increases the cost of the distribution network serving the devices. For example, assuming a WEC array "strip" is $0.2 \mathrm{~km}$ wide, a large wave power project (on the order of $250 \mathrm{MW}$ ) might be distributed along almost 42 linear kilometers of off-shore seascape $^{61}$, for a total area of $8.4 \mathrm{~km}^{2}$. Although a $250-\mathrm{MW}$ solar photovoltaic or wind plant would occupy about the same area (approximately 8 acres or $0.032 \mathrm{~km}^{2}$ per MW), solar and wind arrays are typically arranged in a more compact shape that requires much less infrastructure. Additionally, solar and wind arrays use relatively less expensive electrical cabling than the armored sub-sea cables used in an off-shore system.

\subsection{WEC Commercial Assessment}

As described in Chapter 3, PG\&E issued a Request for Information (RFI) on September 16, 2009 soliciting detailed technical and general cost information from various WECoMs that met PG\&E's technology readiness criteria. This RFI process yielded a short list of WECs, from among which PG\&E interviewed the most promising candidate WECoMs to assess their technical and commercial capabilities. Because most of those discussions were covered under non-disclosure agreements, the following summary is presented on a generic basis.

\subsubsection{WECoM Perspective on Humboldt Wave Connect Pilot Approach}

The HWC pilot project was structured as a demonstration facility, similar to the Wave Hub facility in the U.K., in which manufacturers would provide and install their WECs and auxiliary electric cables and moorings, while PG\&E would provide a sub-sea power cable and interconnection to the power grid. Most WECoMs were receptive to this approach; three or four potential candidates were identified as strong candidates to proceed with the pilot demonstration. However, both common and individual concerns were identified, and at least one WECoM indicated it would not be interested in participating. Among the concerns expressed were:

\footnotetext{
${ }^{61}$ This assumes an average wave energy flux of $30 \mathrm{MW} / \mathrm{km}$, where $20 \%$ of the incoming wave energy is converted into power. The "depth" of the array depends on the conversion efficiency of the WEC device, and is complicated. The array could be close to shore (less than $1 \mathrm{~km}$ ), or far from shore (more than $5 \mathrm{~km}$ ).
} 
- WECoMs whose commercialization process was relatively advanced were concerned that the HWC approach was not consistent with their current business models. Some would have preferred larger-scale or more commercially structured projects in which PG\&E paid for WECs up-front to demonstrate the long-term viability of their technologies in the U.S. marketplace. All participants recognized that revenues from a nominal PPA for the output of a small number of one-off devices in a pilot project could not repay their investment in that project. As a result, one WECoM declined to participate because it felt revenues would not have adequately offset project costs, and at least one other WECoM was undecided for the same reason.

- WECoMs were concerned by significant uncertainties over the project timing, structure, size, and other details regarding the pilot project's transition to commercial scale.

- The water depth at the HWC pilot site was not optimal for some WECs, necessitating a somewhat custom design for some devices and leading other WECoMs to lose interest in the Humboldt site. Others expressed stronger interest in the Central Coast WaveConnect site, whose deeper waters better suited their devices (see Chapter 6).

- Almost all WECoMs expressed concern over the cost recovery uncertainty. European-based WECoMs were used to high feed-in tariffs (e.g., \$500+/MWh) and/or up-front investment credits ( $20 \%$ to $40 \%$ ) offered by other (non-U.S.) marine energy demonstration programs. HWC was not designed to allow WECoMs to recover $100 \%$ of their costs.

- Most of the WECoMs did not have an established presence in California or other parts of the United States. Participation in HWC would have required a significant investment of time and money to support project development, installation and operations, with no assurance of future business opportunities in the United States.

Potential advantages related to the HWC cited by a number of the WECoMs included:

- The opportunity to take advantage of a "plug and play" test facility supported by PG\&E consistent with their technology development plans, with some offsetting of costs.

- The strategic benefits of early positioning in the high-profile and potentially profitable California market.

- Support for a transition to commercial-scale project or projects.

- Project timing consistent with their testing and development programs.

In light of these challenges and advantages, three or four potential WECoM candidates were amenable to the pilot arrangement.

\subsubsection{WEC Commercialization}

Interviews were conducted with the WECoMs to better understand their business plans, stage of technical and commercial development, cost projections, and other characteristics and concerns. Cost and performance information was then used for economic modeling. 
Virtually all of the WECoMs interviewed were still in the early stages of funding. The ability of some WECoMs to deliver WECs to the project was dependent on their ability to obtain development funds. Only one interested WECoM that PG\&E was aware of had sufficient funding to fully participate in HWC without seeking additional support.

Funding uncertainty made planning the WaveConnect project difficult, as did a tendency among the WECoMs to keep basic information confidential, including mooring arrangements, line strength, and the characteristics of their anchors. Although most WECoMs shortlisted in the RFI process had produced scale-model prototypes and conducted some in-water testing, most were also in the process of redesigning their WECs, including some that were considering significant technology changes. Such lack of fundamental information and firm designs was problematic in the permitting process and indicative of the gap between technology development and commercial readiness.

\section{WEC Commercial Viability}

From a project owner's perspective, it is important to accurately define key inputs to the project economic model to determine the economic and commercial viability of a given technology. In the HWC project, very little reliable information was available with respect to the expected costs of a WEC plant, its support equipment and its operation and maintenance (O\&M), particularly in the harsh marine environment in which these plants would operate. Less uncertain, but also significant, were device and plant performance over the expected broad range of wave and climatic conditions.

These factors are the primary drivers of economic viability and LCOE. Commercial viability also depends on a WECoM's financial strength and its ability to back performance guarantees. Earlystage technology developers do not typically possess this level of commercial viability.

\section{Production Capacity}

None of the three or four WECoMs considered for the pilot project had commercial-scale fabrication facilities. All were in the process of evaluating domestic fabrication and marine facilities.

\section{U.S. Market Entry}

Most WECoMs did not have a U.S. presence and none had a presence in California. All WECoMs recognized the need to establish some local presence to support local sourcing, fabrication, installation, start-up and O\&M. The resources and costs to support the WaveConnect project were viewed as significant, particularly for non-U.S. companies. 


\section{Other Commercialization Issues}

Other issues hindering WEC commercialization included uncertainties around financial incentives, environmental permitting and related issues. Wave power projects, especially early ones, will incur substantial development and permitting costs, as discussed in previous chapters.

\subsubsection{Pilot Project Commercial Concept}

For the HWC project, PG\&E and the WECoMs discussed a pilot project commercial concept in which PG\&E would serve as project owner and selected WECoMs would provide WECs for testing. PG\&E's responsibilities would include owning and operating infrastructure and licenses, obtaining site control, leading the process for selecting WEC devices, and conducting licensing studies for the entire facility. PG\&E would also be responsible for developing, owning and operating the basic electric infrastructure to evaluate, test, and deploy various WEC devices, including an interconnection point at or near the wave energy array.

WECoM responsibilities in the pilot project would include providing engineering, procurement and installation of their respective WEC devices and mooring/anchoring systems, operating and maintaining the WECs over the life of the project, and removing all WECoM-provided equipment after the pilot term was complete.

To offset some of their costs, WECoMs requested a power purchase agreement (PPA) or feed-in tariff for the duration of the project, an approach similar to that of other wave power demonstrations in Europe such as the European Marine Energy Centre (EMEC) or the Pentland Orkney Wave Energy Resource (POWER) Ltd. PG\&E agreed to consider this request, which would have required approval by the CPUC. PG\&E informed the WECoMs that approval would be more likely if the rate were close to current market prices for power. No approval was requested nor rate determined before the WaveConnect program was suspended.

As a result of the early-stage nature of the project and the constraints described, neither PG\&E nor the WECoMs expected the pilot project by itself to yield positive financial returns. However, future phases aimed to transition the project to a commercial scale within the given siting, environmental and permitting circumstances.

\subsection{Economic Analysis}

There are very few independent evaluations of the economics of WEC applications. The uncertainties underlying this analysis are very large.

Several WECoMs are currently demonstrating near- or full-scale WEC prototypes. The capital and O\&M costs for these demonstration projects are much greater than the projected costs for commercial-scale projects presented in this chapter. In addition, the conversion efficiency, availability, reliability and other key performance metrics for the WEC prototypes could be significantly below the commercial-scale targets. 
Because there are no commercial-scale WEC installations, PG\&E's economic feasibility analysis relies on cost estimates for WEC plant installation and O\&M provided by the WECoMs themselves. Their estimates are presumably based on learning-curve improvements in design, fabrication and production resulting from higher-volume sourcing and production.

PG\&E engaged SAIC/Re-Vision to provide current estimates of cost and performance for various types of WECs. PG\&E also gained information on costs and performance directly from interviews with the more advanced WECoMs. Based on the information provided, PG\&E prepared economic models and evaluated both a pilot hybrid and commercial-scale projects in larger sizes. The key metric used to measure project economics was LCOE. Two cases were evaluated:

- Pilot project/utility ownership, hybrid cost-share model

- Mature commercial project/utility ownership and utility cost model.

Electric output characteristics were based on technical data provided in Chapter 3. Non-WEC capital cost estimates for plant and equipment were based on scope-of-work descriptions and costs, also outlined in Chapter 3. A range of forecasted WEC costs was derived from interviews with WECoMs and other industry data. Costs related to permitting and Monitoring and Adaptive Management Plan (MAMP) development were based on conclusions reached in Chapter 4. Specific model drivers and assumptions are discussed below.

Note that PG\&E applied its own utility revenue requirements model to estimate the LCOE for various facility configurations. To help confirm the validity of PG\&E's assumptions and conclusions, a separate analysis also applied a COE cost calculator developed by EPRI (EPRI 2004a and 2004b), which assumes different accounting methods and is generally less detailed than PG\&E's cost calculator. Based on HWC site-specific inputs, EPRI's results matched PG\&E's quite closely for a 180-MW wave power facility and diverged more for smaller plant sizes. In general, PG\&E's evaluation resulted in near-term LCOE values similar to those calculated by EPRI's model when using the same inputs.

\subsubsection{Assumptions and Key Model Drivers}

The expected capacity, generation conversion efficiency, capital expenditure, O\&M and other model inputs are different for each WEC technology and site. Various WECs performed differently under high- or low-wave-energy scenarios at different depths and conditions. However, during the WECoM interview process, the variation of projected metrics was found to be within the expected uncertainty range of the estimates. Thus, PG\&E has assumed a single blended technology representing the average cost and performance characteristics of the leading WECs.

For modeling purposes, a Net Capacity Factor (NCF) approach was used to convert the gross WEC rating into annual average net energy delivered to the grid. As outlined in Chapter 3, the NCF conversion factor includes the WEC efficiency over the expected wave energy spectrum, electric resistive losses between the WEC and the interconnection point, and an annual 
availability factor to account for forced and unforced outages. Due to differences in how individual WECoMs rated their devices, the modeling effort attempted to be consistent in using the same WEC rating for performance as was used in the $\$ / \mathrm{kW}$ capital cost projections. It has been assumed that sufficient load will be available to accommodate full output of the facility.

It was also assumed that costs for the MAMPs, baseline studies and other permitting costs would fall within the ranges identified for the pilot project and transition to the first commercial-scale project. Thereafter, the commercial-scale cost-reduction factors were applied, assuming that less MAMP and baseline effort would be required as the various agencies developed greater familiarity with the new technology.

Two pricing scenarios apply: one for the pilot and another for a commercial-scale project that the utility would own. A third scenario exists for an IPP, but was not evaluated in this study.

- Pilot: LCOE was evaluated from the perspective of utility ownership of the pilot project. Given the division of commercial responsibility for the pilot project described above, PG\&E's economic modeling assumed that WECoMs would receive a price of $\$ 50 / \mathrm{MWh}$ for power generated. This price is representative of current spot/day-ahead market energy pricing. Participating WECoMs would provide, install and maintain their devices at no additional cost to the utility, which would pay remaining program costs such as site development and interconnection. Thus, the LCOE in this scenario is the sum of $\$ 50 / \mathrm{MWh}$ plus the calculated LCOE of the PG\&E project costs.

- Commercial: As outlined above, PG\&E's models are based on an approach that determines annual revenue requirements necessary to recover the project's capital investment and cost of operations over the project life.

For the base-case analysis, the current Investment Tax Credit (ITC) was assumed to continue at current levels for both the pilot- and commercial-scale projects, although the impacts for the pilot project are minimal due to the WEC cost burden being borne by the WECoMs. In addition, scenarios in which no incentives were available, or the Production Tax Credit (PTC) was taken in lieu of the ITC, were also evaluated. A separate monetization on Renewable Energy Certificate (REC) values or other environmental attributes outside of the revenue requirement approach was not considered.

It is crucial to note that the LCOEs calculated for the HWC pilot project do not necessarily represent the complete costs of developing a pilot-scale wave project today. Informal discussions with some WECoMs suggested an extremely wide range of current device costs. For a commercial project in which the WEC devices are purchased, this would significantly affect LCOE. In addition, an early-stage demonstration device is expected to have significantly greater cost and lower performance than a more mature device. The discussion, data and conclusions that follow reflect those gaps and uncertainties.

\section{O\&M, Capital, Development and Environmental Costs}

WECoMs advised PG\&E that WEC O\&M costs are dominated by fixed costs, similar to their renewable energy competitors, with very little impact resulting from variable operation. In partial 
contrast to the approach used in the SAIC report (Appendix S), PG\&E's model assumed O\&M cost projections provided by the WECoMs expressed on a simple $\$ / \mathrm{kW} / \mathrm{month}$ basis. However, in actuality, as the capital cost of WEC devices declines over time, the fixed annual percentage of WEC capital costs attributable to spare parts and technology improvements would decline as well. O\&M for the non-WEC infrastructure was assumed to be small and accounted for by the margin included in the WEC figures. Estimated WEC O\&M costs for commercial projects decreased from $\$ 15$ to $\$ 8 / \mathrm{kW} / \mathrm{month}$ as project scale increased from 40 to $180 \mathrm{MW}$.

Given the hybrid cost-share structure for the pilot and the prototype status of the WECs, little effort was made to estimate WEC capital costs for the pilot project. Looking ahead to the commercial stage of WEC development, PG\&E used a range of values for WEC device costs as forecast by the WECoMs - for example, $\$ 10,000 / \mathrm{kW}$ for the near-term down to $\$ 2500 / \mathrm{kW}$ for the future when cumulative volume production has led to a mature product price, which some WECoMs believe is a mid-term goal that could be achieved within five to 10 years. As explained above, there is great uncertainty as to both current and future costs of WEC devices and PG\&E did not conduct independent studies to verify the WECoM capital cost forecasts.

In general, WEC capital costs included WEC infrastructure, power conditioning, mooring, anchoring, and installation Other infrastructure capital cost included subsea cables, marshalling, horizontal direct drilling (HDD) to an on-shore riser, power line routing to the substation and grid interconnection, as more fully detailed in Chapter 3.

Costs for the pilot project, permitting and licensing process are outlined in detail in Chapters 3 and 4. Project engineering costs are found in Chapter 3.12.5, with the costs used in the pilot cost estimation summarized in Table 7-1. As noted, although there was a possibility PG\&E could have completed the HWC FPLA within its existing budget, a likely gap of \$2 million to $\$ 5$ million remained to obtain the FPL and corresponding agency approvals.

Costs for the PPA agreement with the participating WECs are based on \$50/MWh for power delivered to PG\&E. California State Land Commission (CSLC) leases are based on BOEMRE's lease rates ${ }^{62}$, assuming California regional wholesale electricity prices of \$100/MWh. Both assume $30 \%$ capacity factor, $5 \%$ electric resistive losses, and $90 \%$ availability.

The cost of the pilot project depends on whether the project is expensed or capitalized, which is a regulatory decision. If capitalized, the pilot project cost would also need to include Allowance for Funds Used During Construction (AFUDC) and Administrative and General Expenses (G\&A). If expensed, the total cost would be $\$ 47.3$ million. If capitalized, the overall cost would be $\$ 50.9$ million. If the WECs were purchased as opposed to making payments to the WECoMs via a PPA, the overall project cost would be on the order of $\$ 90$ million plus WEC device O\&M costs.

The assumptions and data used in PG\&E's modeling effort for future, larger, commercial-scale projects are tabulated in Table 7-2 and discussed in further detail below.

\footnotetext{
${ }^{62}$ Page 29. http://www.boemre.gov/offshore/renewableenergy/PDFs/REnGuidebook_03August2009_3_pdf
} 
Table 7-1: 5-MW Pilot Project Cost for Five Years of Operation

\begin{tabular}{|c|c|c|}
\hline & $\begin{array}{c}\text { Cost } \\
\text { (\$ thousands) }\end{array}$ & Source/Notes \\
\hline $\begin{array}{l}\text { WECs (Includes cable, mooring, O\&M, } \\
\text { installation) }\end{array}$ & 0 & Provided by WECoMs at no cost \\
\hline \multicolumn{3}{|l|}{ Subsea Cable Interconnects } \\
\hline Off-shore Cable Costs and Installation & 6,758 & Table 3-14 \\
\hline Other Off-shore Infrastructure ${ }^{a}$ & 3,349 & Table 3-10 \\
\hline \multicolumn{3}{|l|}{ Development/Permitting Costs } \\
\hline Document Preparation (Consultants) & 2,000 & Includes fees to CSLC and final efforts \\
\hline Baseline Biological Studies & 4,615 & Table 4-7 \\
\hline Initial Project Engineering & 3,601 & Table 3-9 \\
\hline $\begin{array}{l}\text { On-shore Interconnection } \\
\text { (Fairhaven Substation and Gen-Tie) }\end{array}$ & 6,000 & Table 3-14 \\
\hline \multicolumn{3}{|l|}{ O\&M and MAMPs (Five-Year Cost) } \\
\hline PPA & 2,809 & See Text \\
\hline Leases to CSLC & 157 & See Text \\
\hline O\&M & 5,442 & Table 3-11 \\
\hline MAMP & 6,900 & Table 4-7 \\
\hline Initial Lease and Misc. Land Fees & 176 & \\
\hline Decommissioning & 3,984 & Table 3-12 \\
\hline Escalation & 1,585 & Assumes four-year period from 2010 \\
\hline Pilot Project Subtotal & 47,376 & \\
\hline AFUDC & 3,178 & \\
\hline General and Administrative Overhead & 339 & \\
\hline Pilot Project Total (with AFUDC, G\&A) & 50,893 & \\
\hline
\end{tabular}

a. Other Off-shore Infrastructure includes warning buoys, sensors, radar, weather stations, etc. 
Table 7-2: Economic Model Assumptions and Key Inputs for Commercial Projects

\begin{tabular}{|c|c|c|c|}
\hline \multirow{2}{*}{$\begin{array}{l}\text { Plant Basis \& Operation } \\
\text { Size (MW) }\end{array}$} & \multicolumn{3}{|c|}{ Commercial } \\
\hline & 40 & 90 & 180 \\
\hline Commercial Operation Date & 2020 & 2020 & 2020 \\
\hline Project Life (years) ${ }^{a}$ & 25 & 25 & 25 \\
\hline Development/Permitting Duration & 6 & 6 & 6 \\
\hline Engineering/Procurement/Construction & 2 & 2 & 2 \\
\hline Availability Factor & $90 \%$ & $90 \%$ & $90 \%$ \\
\hline Parasitic Losses & $5 \%$ & $5 \%$ & $5 \%$ \\
\hline Net Capacity Factor ${ }^{\mathrm{b}}$ & $30 \%$ & $30 \%$ & $30 \%$ \\
\hline Environmental Compliance and O\&M & 15 & 12 & 9 \\
\hline \multicolumn{4}{|l|}{ Financing and Tax Credits } \\
\hline Annual Escalation $^{c}$ & $1 \%$ & $1 \%$ & $1 \%$ \\
\hline AFUDC Rate ${ }^{d}$ & $8.8 \%$ & $8.8 \%$ & $8.8 \%$ \\
\hline ITC Incentive ${ }^{e}$ & $30 \%$ & $30 \%$ & $30 \%$ \\
\hline \multicolumn{4}{|l|}{ Capital Cost } \\
\hline WEC Interconnects and Gen-Tie (\$ millions) & 14.4 & 19.3 & 30.8 \\
\hline Substation and Network Upgrades (\$ millions) & 22.0 & 23.0 & 40.0 \\
\hline Permitting, Project Engineering, Land (\$ millions) & 19.4 & 19.4 & 19.4 \\
\hline Decommissioning (\$ millions) & 5.0 & 5.0 & 5.0 \\
\hline Subtotal (excluding WECs) (\$ millions) & 60.8 & 66.7 & 95.2 \\
\hline WECs (inc. cables, mooring, installation) ( $\$$ millions) ${ }^{f}$ & $100-400$ & $225-900$ & $450-1,800$ \\
\hline Escalation (\$ millions) & $14.1-42.5$ & $14.2-49.2$ & $27.2-97.2$ \\
\hline Subtotal (\$ millions) & $175-503$ & $305.9-1,016$ & $572-1,992$ \\
\hline AFUDC, G\&A Overhead (\$ millions) & $22.5-52.8$ & $34.8-100$ & $65.2-210$ \\
\hline Total Cost (\$ millions) & $197-556$ & $340.7-1,116$ & $637.6-2,203$ \\
\hline
\end{tabular}

a. From commercial operation date (COD).

b. Includes availability factor (AF) and parasitic losses.

c. Based on CPI-Labor applied from a 2010 baseline to the projected time of expense.

d. AFUDC is the cost of construction-period financing; rate is based on weighted average cost of capital. AFUDC is applied to respective pre-COD costs over the periods defined above.

e. Applicable to qualifying capital cost. ITC is assumed to extend beyond 2013. ITC/PTC is zero for pilot because WEC suppliers would have taken the credit if eligible.

f. WEC cost ranges shown correspond to $\$ 2,500 / \mathrm{kW}$ to $10,000 / \mathrm{kW}$, representing mid-term and nearterm goals of the WECoMs, respectively. 


\subsection{Results}

The results of economic modeling for the pilot project incorporating the hybrid ownership assumptions (WECs provided at no cost, WECoMs receive \$50/MWh payment for energy delivered) and other inputs outlined in section 7.3.1 and Table 7-1 above yielded an LCOE of approximately $\$ 1000 / \mathrm{MWh}$.

A summary of the modeling results for commercial-scale projects (under similar installation and operating conditions as HWC) is presented in Figure 7-1 below. As indicated, wave energy has the potential to achieve an LCOE project cost in the range of \$175-\$270/MWh if and when the WECoMs are able to reduce WEC installed costs to around $\$ 2500 / \mathrm{kW}$. As outlined in Section 7.3 , these results are based on site-specific scope drivers and certain cost assumptions that have yet to be verified. In addition to the WEC capital cost, the most significant cost drivers are WEC O\&M and subsea cable costs, both of which decline as a proportion of overall cost as project scale increases, as shown in Figure 7-1. However, even at $\$ 2,500 / \mathrm{kW}$ for the WECs, and applying the mid-level estimates for the balance of plant, the LCOE for a large wave power project is over $\$ 175 / \mathrm{MWh}$, which is not competitive in today's renewable energy market.

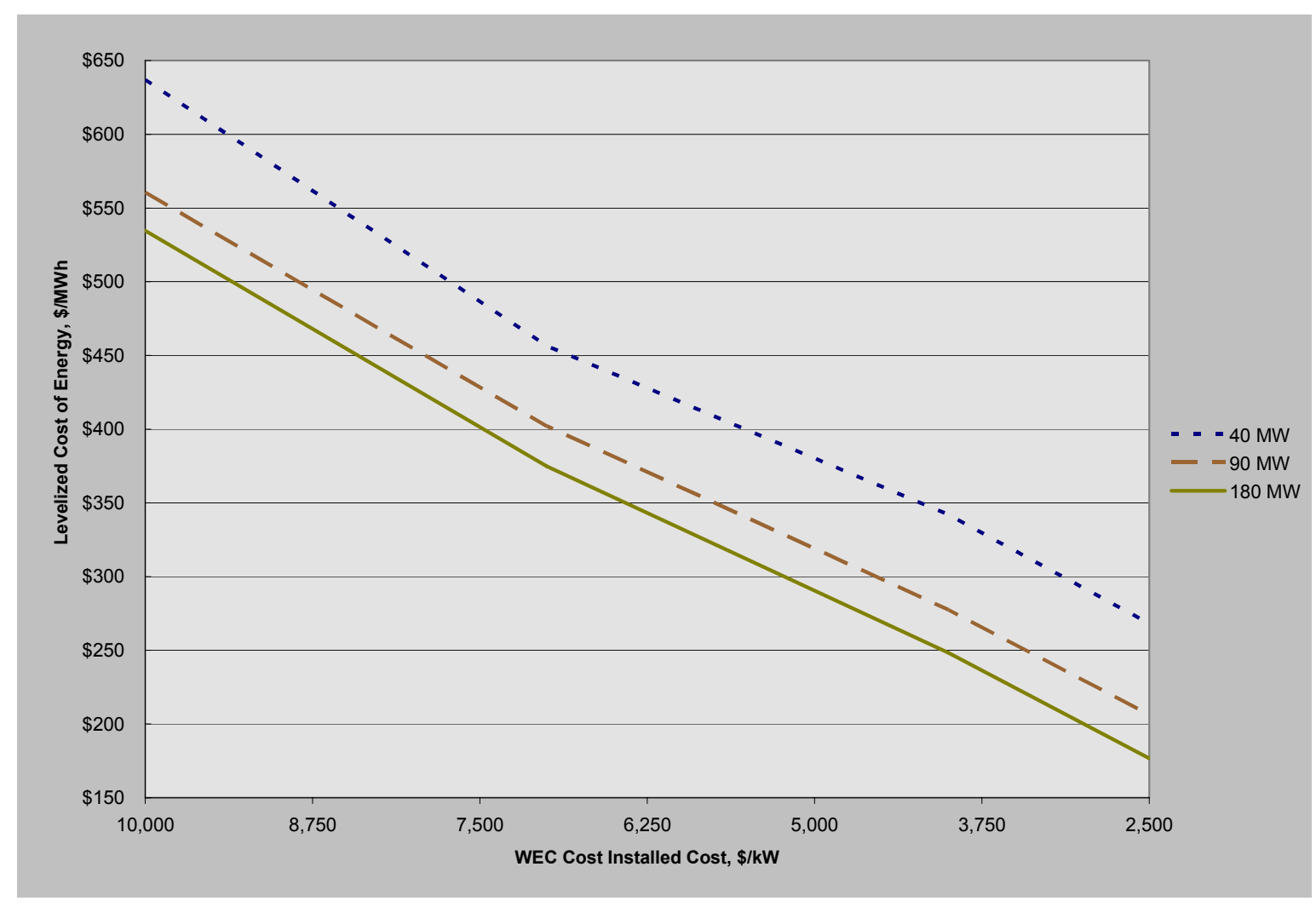

Figure 7-1: Wave Energy Project LCOE for 40-MW, 90-MW and 180-MW Capacities, and Varying Installed Cost of WEC Devices 
If the PTC were available and used instead of the ITC, LCOE would increase by $3 \%$ to $10 \%$ as the WEC cost varies from $\$ 2,500 / \mathrm{kW}$ to $\$ 10,000 / \mathrm{kW}$, respectively. If neither the ITC nor PTC were available, LCOE would increase by $9 \%-13 \%$. Based on the assumptions and analysis presented, wave power is currently not economically feasible even under the favorable hybrid ownership structure outlined in Section 7.2.3 and reflected in Table 7-1 above.

\subsubsection{Discussion}

EPRI has suggested that WEC LCOE will decline as installed capacity increases in a manner comparable to that observed for wind turbines, as indicated in Figure 7-2. This figure indicates that when installed capacity reaches $100 \mathrm{MW}$, the LCOE of wave power will range between approximately $\$ 90-\$ 160 / \mathrm{MWh}(9-16$ cents/kWh), and that when capacity reaches $40,000 \mathrm{MW}$ the LCOE could go as low as $\$ 30-\$ 40 / \mathrm{MWh}$. The left end of the chart corresponds to a total plant cost of around $\$ 2200 / \mathrm{kW}$, which is well below PG\&E estimates for mid-term costs. It is not clear what kind of advances could occur to reach the values presented on the right end to the chart, where the LCOE is $\$ 30-\$ 40 / \mathrm{MWh}$. To reduce LCOE by a factor of three or four, the total project capital costs would have to be reduced by a similar factor, i.e., from $\$ 2200 / \mathrm{kW}$ to $\$ 550$ $\$ 730 / \mathrm{kW}$.

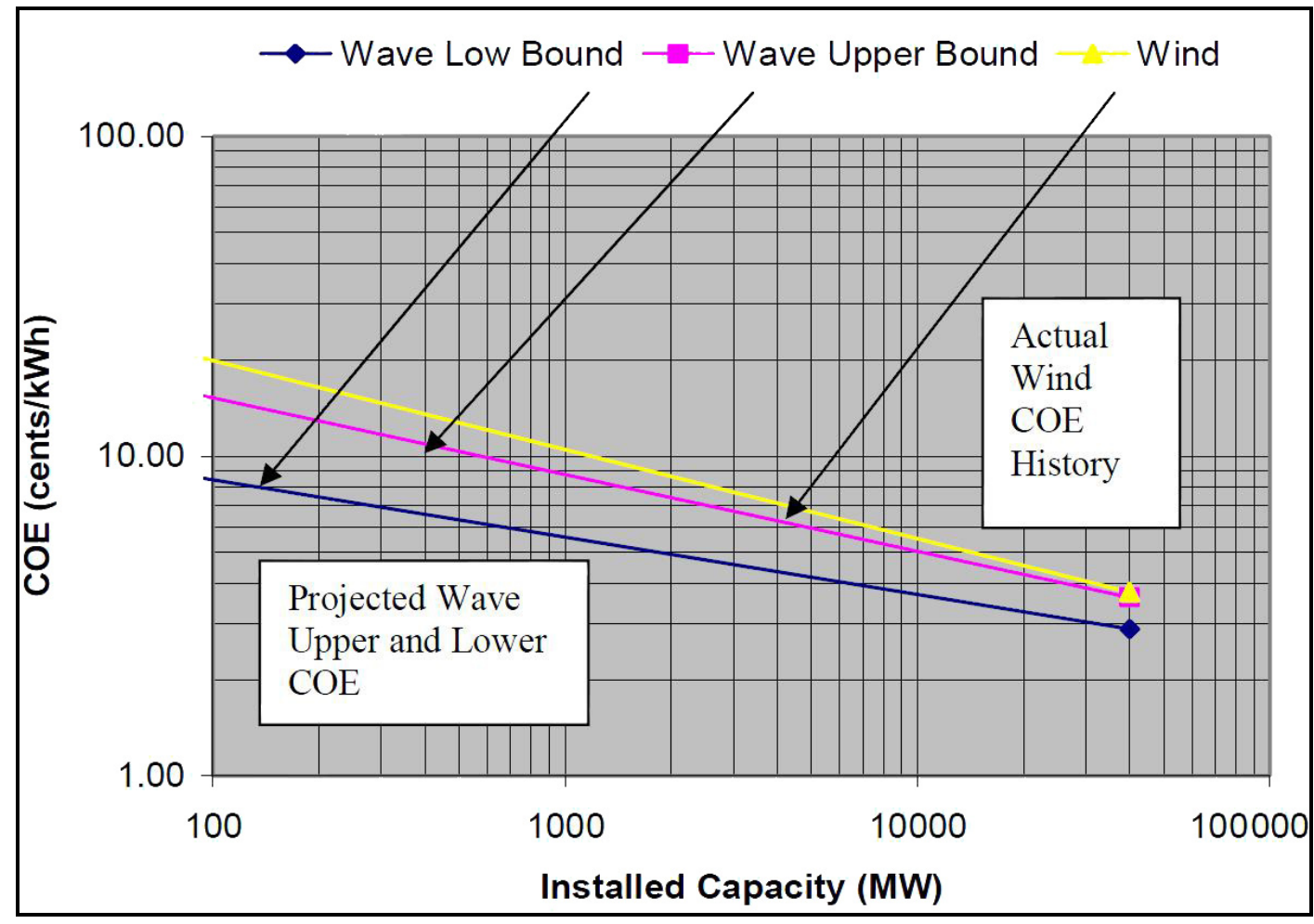

Figure 7-2: COE vs. Installed Capacity (EPRI 2005)

As described above, PG\&E's analysis of mid-term WEC economics resulted in an LCOE of $\$ 175-\$ 270 / \mathrm{MWh}$ when using a WEC cost of $\$ 2500 / \mathrm{kW}$ and balance-of-plant cost estimates as 
described in Chapter 3. The WEC cost was based on WECoMs cost goals, which manufacturers believe they can achieve through economies of scale and technology improvements. The WECoMs did not indicate the cumulative capacity they would need to install to reach their goal, but did indicate they could reach their goal within 5 to 10 years. WECoMs did not provide cost projections for the high installed capacity scenarios represented on the right side of Figure 7-2. WEC demonstration projects are currently very expensive, driven by the high cost of early-stage WEC devices (if purchased), licensing, permitting, environmental compliance, and off-shore electric and other infrastructure.

PG\&E does not expect the LCOE for wave power to decline to the $\$ 30-\$ 40 / \mathrm{MWh}$ indicated in the right portion of the figure in any future scenario, noting that no renewable technologies and very few conventional generation technologies of any type have achieved that target.

\section{Cost Outlook}

Wind and solar technologies flourished to the extent they have because the various incentives available (e.g., investment and production tax credits, feed-in tariff and RFP standards) were sufficient to support large-scale commercial enterprises. Matching the cost-versus-installedcapacity performance of wind and solar power will require significant investment and will be difficult, since wave power is at a low-volume pilot stage compared to wind and solar technologies' more mature, high-volume stages. At such an early state of development, the timing of future wave power capacity growth and cost reduction is difficult to estimate. Potential cost reductions will depend greatly on the specific design details of each device.

As an example of the difficulty in reducing costs, consider that WEC capital costs are typically highly dependent on the price of steel used for WEC structures (and for some mooring cables), which is dictated by the global market. The cost of most WECs is also dependent on the cost of concrete, which is used for moorings and base structures. Opportunities to reduce the overall mooring costs are expected to be minimal, as mooring technology is relatively mature and already competitive due to the shipping and oil and gas industries, and the costs of steel, concrete, and synthetic rope are not expected to drop significantly for smaller projects. However, design optimization and volume production may help reduce material costs over time.

Using high-voltage cables would require large cable-laying ships that are very expensive for dayto-day operations. The key conclusion is that laying cable underwater, where the transition from medium-voltage to high-voltage cable involves a large step up in cost and complexity, demands very different considerations than laying it on land, where economies of scale are different. A project that could be economically served by a single high-voltage cable on land may be much better served by multiple medium-voltage cables at sea. However, a large ocean-power project covering a significant area could indeed prove more economical using high-voltage cable. This issue must be carefully evaluated on a case-by-case basis and requires further study. 


\subsection{Conclusions}

PG\&E's experience and modeling effort identified the following potential benefits offered by wave energy:

- Wave energy can be a baseload resource with a net capacity factor comparable to that of wind energy.

- Wave energy is a predictable resource.

- Assuming marine biological impacts are found to be negligible or readily manageable, WEC devices may offer a very environmentally benign form of power generation.

- As environmental impacts are better understood and verified, cost impacts for the permitting processes will likely drop considerably.

- Agencies indicated support for continuing the existing pilot process and looking for solutions to the permitting challenges that were identified.

- There are significant permitting and technical advantages in locating wave energy sites on the OCS, including deeper water resulting in greater net capacity factors for most WECs.

- Due to high infrastructure costs, commercial-scale economics improve significantly with project scale.

- Improvements in renewable incentives (PTC, ITC, other) would improve wave energy economics. However, until such time, PG\&E's current model reflects the more conservative existing rates.

Disadvantages and key risk areas of wave power projects include:

- Large facility footprint. PG\&E evaluated the overall size of each of the WECs, and found that although most devices have relatively small footprints, their effective footprint spreads over a much larger area. Larger footprints can cause greater impacts to groups such as the fishing industry.

- Technology maturity: WECoM's forecasted cost reductions have not yet been demonstrated.

- A key agency issue is the lack of complete descriptions of WEC devices and their impacts due to their early-stage status and evolving technology. A possible solution to this challenge was introduced during a problem-solving exercise with agencies in which the programmatic approach was promulgated.

- Site selection is complex and involves many variables; optimal sites are rare. After careful analysis, PG\&E concluded that while the Humboldt site might have been adequate for a small pilot project, size limitations related to interconnection capacity and the project's impact on the fishing community made the Humboldt location less attractive for a potential commercial project than other locations along the California coast or on the OCS. A Humboldt project on the OCS would have had less impact on the local fishing community, but would still have been limited in commercial scope to probably no more than $40 \mathrm{MW}$ without significant transmission network upgrades. 
WECs are early-stage devices with evolving designs and little real-world operating experience. These characteristics made environmental impacts difficult to assess and permitting issues more challenging than originally anticipated. Stage One project funding of $\$ 6$ million proved insufficient to complete the necessary development and permitting work, which PG\&E determined would cost at least $\$ 2$ million to $\$ 5$ million more than originally budgeted.

PG\&E found that the cost of developing a five-year, 5-MW WaveConnect pilot project at Humboldt Bay is much greater than the \$15 million to \$20 million originally estimated. Even assuming that vendors provide WEC devices at no cost to the utility, which was the proposed strategy with WaveConnect, PG\&E concluded that non-WEC capital costs would total approximately $\$ 28.1$ million. If escalation, financing, and non-WEC MAMP and O\&M costs are included, estimated project costs increase to \$50.9 million. Without AFUDC and G\&A, the project cost was estimated at $\$ 47.4$ million. ${ }^{63}$ If the WEC devices were purchased, as opposed to paying WECoMs under a PPA, the overall project cost would be on the order of $\$ 90$ million.

It is unclear when or if wave power will become competitive with renewable energy alternatives. Significant additional investment in engineering, testing and demonstration will be needed to improve designs and reduce costs. Using a vendor-provided installed cost goal of $\$ 2500 / \mathrm{kW}$ for mature WEC devices in five to 10 years, PG\&E concluded that their LCOE would be in the range of $\$ 175-\$ 250 / \mathrm{MWh}$, which is not competitive with current or near-term renewable alternatives such as wind or solar photovoltaics.

Although PG\&E discontinued the WaveConnect project and no WEC devices were deployed, WaveConnect advanced PG\&E's understanding of the technological, engineering, permitting, environmental, economic, stakeholder, and related issues involved in undertaking any wave power project now or in the future. As WEC technologies mature, and regulatory and permitting agencies grow more familiar with their environmental impacts, PG\&E believes that wave power will merit further evaluation, demonstration and deployment.

${ }^{63}$ Non-WEC costs include development, undersea distribution cables, substation and network upgrades. Pilot project costs are detailed in Table 7-1. 



\section{A Appendices: Table of Contents}

The following supporting documents are provided as separate appendices.

Appendix A: PG\&E Ocean Energy Technology, Report 007.6-91.4, September 30, 1991

Appendix B: Humboldt WaveConnect Marine Hydrokinetic Pilot Project Draft Pilot License Application (DPLA)

DPLA Introduction

- Cover Letter to FERC - NOI To File Pilot Project License Application

- Notice of Intent

- Contents DPLA

- Initial Statement and Application

- Exhibit "A"

Exhibit "E" - Main Text of the DPLA

Contents

Acronyms

Executive Summary

- 1.0 Application

- 2.0 Purpose-Need

- 3.0 Project Description

- 4.0 Consult-Compliance

- 5.0 Env Analysis

- 5.3.1 Geology and Soils

- 5.3.2 Water Resources 
- 5.3.3 Marine Resources

- 5.3.4 Marine Wildlife

- 5.3.5 Terrestrial Resources

- 5.3.6 Threatened and Endangered Species

- 5.3.7 Recreation and Land Use

- 5.3.8 Cultural Resources

- 5.3.9 Aesthetics

- 5.3.10 Socioeconomics

- 6.0 Development Analysis

- $\quad 7.0$ Comp Dev Analysis

- 8.0 Recs of F\&W Agencies

- 9.0 Consistency with Comp Plans

- $\quad$ 10.0 List of Preparers

\section{Exhibit "F"}

- Figure G-1: Cover Sheet

- Figure C-1: Site Plan 1

- $\quad$ Figure C-2: Site Plan 2

- Figure C-3: Sections

- Figure P-1: Overall Development Boundary

- Figure P-2: Offshore Deployment Area Development Boundary

- Figure P-3: Cable Corridor Development Boundary

- Figure P-4: Onshore Development Boundary

- Figure P-5: Offshore Deployment Area and Equipment

- Figure P-6: Offshore Deployment Area with WEC Deployment

- Figure P-7: Indicative Horizontal Directional Drill Long Section

Exhibit "G"

- Exhibit G Project Boundary

- GIS Files.zip 
Public Consultation Materials

- Attachment A General Humboldt Stakeholder Emails 2009-10

- Attachment B HWG Committee Members

- Attachment C Stakeholder Outreach Tracking Table

- Attachment D SubCommittee Members

- Attachment E Meeting Summaries

- Public Consultation

DPLA Appendices

- App A-1 Safeguard Plan

- App IS-1 DPLA Distribution List

- Appendix E-5.3.2 Wave Modeling

- Appendix E-5.3.3 Fish and Invert Mon and Adpt Mgt Plan

- Appendix E-5.3.4 Marine Mammal Mon and Adpt Mgmt Plan

- Appendix E-5.3.5A Veg Photos

- Appendix E-5.3.5B Seabirds Mon and Adpt Mgmt Plan

- Appendix E-5.3.6A Special-status Plant Species

- Appendix E-5.3.6B Plant Species

- Appendix E-5.3.6C Special-status Animal Species

- Appendix E-5.3.8A Confidential Lit Search

- Appendix E-5.3.8B Historical Societies Consultation

- Appendix E-5.3.8C CRS Resume

- Appendix E-5.3.8D CA-HUM-726 Update

- Appendix E-5.3.8E Native American Consultation

Appendix C: Draft Monitoring and Adaptive Management Plans (MAMPs)

\section{Appendix D: Agency Comments on PG\&E's DPLA and MAMPS}

- HWC DPLA Comments Zip File

- Comments of the California Coastal Commission 
- Comments of the California Dept of Fish \& Game

- Comments of the California State Lands Commission

- Comments of the California State Water Resources Control Board

- Comments of FERC

- Comments of the FISH Committee

- Comments of the Humboldt Fishermen's Marketing Association

- Comments of the National Marine Fisheries Service (NMFS/NOAA)

- Comments of the US Fish \& Wildlife Service

Appendix PG\&E RFI: Request for Information (RFI)

\section{Appendix HSU A: HSU Wave Modeling Effort}

\section{Appendix HSU B: HSU Socioeconomic Baseline Study}

\section{Appendix HSU C: HSU Sediment Transport Study}

- Abstract July11 Humboldt Bay Littoral Cell

- August '10 surveys.xlsx

- December '10.xlsx

- HBLC May_Dec 2010 BeachSurveyNotes.xls

- July '10 surveys.xlsx

- June '10 surveys.xlsx

- Map_HBLC Sample Sites

- May '10 surveys.xlsx

- November '10.xlsx

- October '10 surveys.xlsx

- Sediment Size Humboldt Bay Littoral Cell May_Dec2010

- September '10 surveys.xlsx

Appendix HSU D: Baseline Fisheries Studies

Appendix HSU E: Retrospective Analysis of Marine Mammal Ecological Data and Baseline Marine Mammal Monitoring in Northern California 
Appendix RSL: USDA Forest Service, Redwood Sciences Laboratory: 21 Years of Northern California Marine Surveys

- Seabird and Mammal Observation Summaries Part 1a

- Seabird and Mammal Observation Summaries Part 2a

- Seabird Observation Counts and Densities

- Marine Mammal Observations Summary

Appendix OSU A: SAIC/OSU EMF Modeling Summary Report and Results Guide

- 0901-01-021 EMF Modeling Summary Report and Results Guide 09-27-10

- SAIC-October2009-Milestone-2-completion

- PGE.zip

- fdm3d_v1.2.1.OSU.zip

Appendix PG\&E RFI: Request for Information (RFI)

Appendix SAIC A: SAIC Support of Public Outreach

Appendix SAIC B: SAIC WaveConnect Top Level Systems Requirements Statement

Appendix SAIC C: SAIC Site Surveys 4-8 to 4-10-09

Appendix SAIC D: SAIC Functional Block Diagram Document

Appendix SAIC E: WaveConnect Infrastructure Top-Level Block Diagram (090110-003)

Appendix SAIC F: SBI Segment Block Diagram (0901-20-002)

Appendix SAIC G: SCI Segment Block Diagram (0901-30-002)

Appendix SAIC H: PII Segment Block Diagram (0901-40-002)

Appendix SAIC I: DATI Segment Block Diagram (0901-50-002) 
Appendix SAIC J: Electrical One Line Diagram (0901-40-003)

Appendix SAIC K: SAIC Top Level System Interface List

Appendix SAIC L: SAIC System Requirements Concept of Operations (CONOPS) Presentation (0901-01-006)

Appendix SAIC M: SAIC CONOPS Document (0901-01-005)

Appendix SAIC N: SAIC Functional Requirements Document

Appendix SAIC O: SAIC System Requirements Specification

Appendix SAIC P: SAIC Trip Report: UK Wave Energy Review 7-25 to 8-2-09

Appendix SAIC Q: SAIC WaveConnect Fast Facts Sheet

Appendix SAIC R: SAIC Central Coast Wave Resource Assessment

- 1D-Spectras-2008.zip

- 2D-Spectras-2008.zip

- SWAN Outputs Central Coast.msg

- SWAN Outputs.msg

- SWAN Simulation Output File Notes MP 6-8-10.doc

- Unstructured_Mesh_geoNAD83new.kmz

- Wave Parameters-2008 Matlab.zip

- Wave Parameters-2008.mat

Appendix SAIC S: SAIC WEC Cost Assessment

Appendix SAIC T: SAIC OrcaFlex Mooring System Modeling

- 0901-20-003 Appendix C and D.zip

- 0901-20-003 Baseline Model Properties.xlsx

- 0901-20-003 WaveConnect Point_Abs.sim 
Appendix SAIC U: SAIC Anchor System Analysis Methods

- 0901-20-004 Mathcad worksheets.zip

Appendix SAIC V: SAIC Revised Mooring Analysis

- MathCAD PDF Files.zip

- Native MathCAD Files.zip

- OrcaFlexDemo.zip

- Simulation Files.zip

Appendix SAIC W: SAIC Humboldt Harbor Capabilities Assessment

- Appendix D Hydrographic Survey

- Appendix E Schneider Dock Analysis

- Appendix F Conceptual Railway

- Appendix G Survey Equipment

Appendix SAIC X: SAIC Pilot Infra Lifecycle Cost Analysis

- Quarterly Financial Cashflow Pro-Forma_Rev6.xlsx

Appendix SAIC Y: SAIC Conceptual Design Compendium

Appendix SAIC Z: SAIC WaveConnect Summary Findings

\section{Appendix X: Humboldt Working Group Meetings}

October 28, 2010 - Humboldt Working Group Conference Call

- HWG Conference Call Summary October 28, 2010

August 4, 2010 - Permitting Authority Subcommittee Meeting

- HWG Permitting Authority Subcommittee Meeting Summary August 4, 2010

- HWG Permitting Authority Subcommittee August Meeting Presentation 
April 29, 2010 - HWG Siting Subcommittee Conference Call

- HWG Siting Subcommittee Conference Call Summary April 29, 2010

April 7, 2010 - Permitting Authority Subcommittee Meeting (daytime)

- HWG Permitting Authority Subcommittee April Meeting Summary

- HWG Permitting Authority Subcommittee April Meeting Agenda

April 7, 2010 - HWG Meeting (evening)

- HWG April Meeting Summary

- HWG April Meeting Agenda

March 18, 2010 - HWG Permitting Authority Subcommittee Meeting

- HWG Permitting Authority Subcommittee March Meeting Agenda

- HWG Permitting Authority Subcommittee Meeting Summary March 18, 2010

March 4, 2010 - HWG Conference Call

- HWG Conference Call Summary March 4, 2010

February 17, 2010 - HWG Permitting Authority Subcommittee Conference Call

- HWG Permitting Authority Subcommittee Conference Call Summary February 17, 2010

February 2, 2010 - Humboldt WaveConnect Public Meeting

- Humboldt WaveConnect Public Meeting Summary

- Humboldt WaveConnect Public Meeting Agenda

- Humboldt WaveConnect Public Meeting Presentation

- Humboldt WaveConnect Public Meeting Informational Posters (ZIP, 8 MB)

- Humboldt Pilot Project Overview

- HWG Map

- HWG Project Timeline (PDF, $1 \mathrm{MB})$

- HWG Overview

- HWG Members

- How to Get Involved 
- WEC Selection Schedule

- Wave Energy Converters (WECs) 1

- Wave Energy Converters (WECs) 2

- Wave Energy Converters (WECs) 3

- Wave Energy Converters (WECs) 4

- Wave Energy Converters (WECs) 5

- Wave Energy Converters (WECs) 6

- Resource Topics Addressed in FERC D/FPLA

- Monitoring and Adaptive Management

- Permitting and Regulatory Agency Roles

- Integrated Agency Timeline

- Humboldt WaveConnect Public Meeting Fact Sheet

- Pictures from the Humboldt WaveConnect Public Meeting

- "Waves of Power" Eureka Times-Standard

February 2, 2010 - HWG Permitting Authority Subcommittee Meeting

- HWG Permitting Authority Subcommittee Meeting Summary February 2, 2010

- HWG Permitting Authority Subcommittee February Meeting Presentation

- HWG Permitting Authority Subcommittee February Meeting Agenda

February 1, 2010 - HWG Meeting

- HWG Meeting Summary February 1, 2010

- HWG February Meeting Presentation (PDF, 2 MB)

- HWG February Meeting Agenda

January 7, 2010 - HWG Permitting Authority Subcommittee Meeting

- HWG Permitting Authority Subcommittee Meeting Summary January 7, 2010

- HWG Permitting Authority Subcommittee January Meeting Presentation

- Monitoring and Adaptive Management Handout

- HWG Permitting Authority Subcommittee Action Items

- HWG Permitting Authority Subcommittee January Meeting Agenda 
January 6, 2010 - HWG Meeting

- HWG Meeting Summary January 6, 2010

- HWG January Meeting Presentation

- Monitoring and Adaptive Management Handout

- HWG Action Items

- HWG January Meeting Agenda

December 2, 2009 - HWG Meeting and HWG Permitting Authority Subcommittee Conference Call

- HWG Permitting Authority Subcommittee Conference Call Summary December 2, 2009

- HWG Meeting Summary December 2, 2009

- HWG December Meeting Presentation

- HWG December Meeting Agenda

November 9, 2009 - HWG Biological Resources Agencies Subcommittee Meeting

- HWG Biological Resources Agencies Subcommittee Meeting Summary November 9, 2009

- HWG Biological Resources Agencies Subcommittee Meeting Agenda

November 2, 2009 - HWG Meeting

- HWG Meeting Summary November 2, 2009

- HWG November Meeting Presentation

- HWG November Meeting Agenda

October 5, 2009 - HWG Meeting

- HWG Meeting Summary October 5, 2009

- HWG October Meeting Presentation

- HWG October Meeting Agenda

October 5, 2009 - HWG Permitting Authority Subcommittee Meeting

- HWG Permitting Authority Subcommittee Meeting Summary October 5, 2009

- HWG Permitting Authority Subcommittee Meeting Agenda 
August 26, 2009 - HWG Meeting

- HWG Meeting Summary August 26, 2009

- HWG August Meeting Presentation

- HWG August Meeting Agenda

August 10, 2009 - HWG Site Selection Subcommittee Meeting

- HWG Site Selection Subcommittee Meeting Summary August 10, 2009

- Siting Alternatives Presentation

- HWG Site Selection Subcommittee Meeting Agenda

July 20, 2009 - HWG Kickoff Meeting

- HWG Meeting Summary July 20, 2009

- HWG Kickoff Meeting Agenda

- Humboldt WaveConnect Public Kickoff Meeting

- Agenda (PDF, $1 \mathrm{MB})$

- Public Involvement

- Schedule

- FERC Hydrokinetic Process (PDF, 1 MB)

- FERC Hydrokinetic Resource Topics

- Licensing Permitting Roles

- Example Wave Energy Technologies 1

- Example Wave Energy Technologies 2

- Example Wave Energy Technologies 3

- Device Selection Process (PDF, 1 MB)

- Resource Potential

- Map

- Comment Form

- Nomination Form 